\title{
Modelling ventilated potato bulk storage facilities
}

Nik L.M. Grubben 


\section{Thesis committee}

\section{Promotor}

Prof. Dr Karel J. Keesman

Personal chair at Biobased Chemistry and Technology

Wageningen University \& Research

\section{Other members}

Prof. Dr Remko M. Boom, Wageningen University \& Research

Dr Leo J.S. Lukasse, Wageningen University \& Research

Dr Pieter Verboven, KU Leuven, Belgium

Prof. Dr Hans J. Zwart, University of Twente, Enschede

This research was conducted under the auspices of the Graduate School VLAG (Advanced studies in Food Technology, Agrobiotechnology, Nutrition and Health Sciences). 


\title{
Modelling ventilated potato bulk storage facilities
}

\author{
Nik L.M. Grubben
}

Thesis

submitted in fulfilment of the requirements for the degree of doctor at Wageningen University by the authority of the Rector Magnificus, Prof. Dr A.P.J. Mol, in the presence of the Thesis Committee appointed by the Academic Board to be defended in public on 19 December 2018 at 11 a.m. in the Aula. 
Nik L.M. Grubben

Modelling ventilated potato bulk storage facilities 187 pages.

PhD thesis, Wageningen University, Wageningen, the Netherlands (2018) With references, with summary in English and Dutch

ISBN 978-94-6343-527-7

DOI: https://doi.org/10.18174/462471 


\section{SUMMARY}

The potential of improving the conventional potato bulk storage process is accelerated through this thesis by defining, calibrating and validating a spatially distributed storage model that includes multiple quality aspects. The calibration and validation was performed using large-scale experimental data.

Potatoes are one of the world's staple foods. While their crops are seasonal, the demand for them is continuous, resulting in the need to store them and keep them well. As the climate conditions surrounding stored potatoes influence potato quality and vice versa, climate control is an efficient way to influence product quality. Potato storage facilities therefore widely use climate control to limit losses during storage. However, good climate conditions do not automatically guarantee a high-quality end product. At present, climate control in conventional storage facilities is based on rules of thumb, gathered by trial and error and through experiments that mainly can only be evaluated once a year. Because of that, and also as a result of the increased range of potato varieties, each with its own properties, as well as of changes in growth, climate and storage conditions, finding the optimal storage climate conditions is an art and science that advances very slowly. The use of product quality control in addition to climate control was already proposed in the early 2000s, but is still not yet widely applied in commercial storage facilities due to a gap in insights into particularly the spatial distribution of how multiple quality aspects develop during storage. The aim of this research was to fill a vital gap in the knowledge on how climate and the product quality development of potatoes interact during bulk storage, by developing a spatially distributed mathematical storage model, analysing the simulation results, and evaluating these with respect to experimental data from industrial bulk storage facilities.

In this thesis in particular the temperature, moisture content and reducing sugar content interaction and development in a conventional bulk storage, with a cellar and perforated floor and ventilation capacities of 100-150 cube air per cube product per hour, is evaluated and theoretically improved. A 2-D and 1-D climate-product quality model for the evaluation of the complete bulk storage process are presented in this thesis. This study particularly concerns conventional bulk storage facilities for frying potatoes, but the research is also of value for different types of storage facilities and different agro-materials. 


\section{Summary}

The optimisation of the storage process can be seen as an iterative process. Quite some research is done on the modelling of potato storage facilities (Chapter 2). To obtain storage knowledge, most models are defined on base of physical insight. Analysis of the model outcomes leads to new knowledge and new models. A dynamic spatially distributed model with multiple product quality indicators that was calibrated and validated on base of large-scale storage facility experiments was found to be lacking.

A dynamic 2-D storage model, including actuators (fan and hatch) was described and analysed using computational fluid dynamics (CFD) (Chapter 3). The model describes the dynamics of the product and air temperature and moisture concentration and carbon dioxide concentration in air, and air flow. The air flow was described by a Reynoldsaveraged Navier-Stokes (RANS) model with Comsol's algebraic yPlus turbulence model. The hatch was dynamically modelled using a moving mesh, which results in the repeated creation of new meshes during the dynamic simulations. The model was successfully calibrated and validated on large-scale experimental data for the potato variety Ramos. Conventional climate control includes the use of overpressure, which results in mainly vertical gradients. In simulations, it was possible to reduce the heterogeneity by alternating overpressure and underpressure in combination with an extra air channel near the roof.

To be able to obtain the product quality development during a complete storage season, the 2-D model was reduced to a 1-D climate-product quality model, in which the reducing sugar content was included (Chapter 4). The model was used to gain more knowledge concerning the intensive cooling that occurs between wound-healing and the long-term storage temperature. A decrease in the duration of the cooling resulted in a decrease in weight loss, but an increase (within an acceptable range for processing industry) in reducing sugar formation. In the simulation, the storage strategy could even be improved further by humidification of the air that entered the bulk, resulting in a further reduction of weight losses.

In addition to the climate-product quality model for frying potatoes, a protein content model was developed (Chapter 5). The model was calibrated on data obtained in a largescale storage facility for two different potato varieties (Miss Malina and Agria). The calibration resulted in two different sets of parameters as both varieties showed different dynamical behaviours during the storage process.

The CFD simulations also provided insights into the influence of the actuators on the bulk temperature and moisture content. These simulations produced the first results on the spatial distribution of the controllability of the states. This analysis was extended with more formal classical systems theory concepts of controllability and observability (Chapter 6). These concepts yield only limited info, however. For example controllability only indicates whether a state can be manipulated from an initial state to another state in a finite amount of time. A singular value decomposition of the controllability and 
observability Gramians gave more insight, but the results were found to be inaccurate due to matrix multiplication for small discretisation steps. Therefore, sensitivity fields were included to obtain more practical controllability and observability results with regard to the spatial distribution in the bulk over time. These sensitivity fields indicate that inputto-state and initial-state-to-output provide sufficient information about the controllability and observability of large coupled spatially distributed systems, using finite-dimensional state space representations with small discretisation steps.

In conclusion, this thesis presents a spatially distributed climate-product quality model, evaluated with respect to experimental data from an industrial bulk storage facility. A combination of fast cooling periods, alternating underpressure and overpressure and configuration changes will limit weight loss, save ventilation energy and keeps sugar levels within acceptable ranges. 



\section{SAMENVATTING}

De potentie om de conventionele bulk-aardappelbewaarplaatsen te verbeteren wordt versneld door het in dit proefschrift voorgestelde, gekalibreerde en gevalideerde ruimtelijk verdeeld bewaarmodel, dat meerdere kwaliteitsaspecten bevat. De kalibratie en validatie evaluatie werd uitgevoerd op experimentele data verkregen uit commerciële bewaarplaatsen.

In aardappelbewaarplaatsen wordt wereldwijd klimaatregeling toegepast met als doel bewaarverliezen te minimaliseren. Dit is efficiënt, aangezien de klimaatcondities om de aardappel heen invloed hebben op de kwaliteit van de aardappel. Dit betekent echter niet dat goede klimaatcondities automatisch een goede kwaliteit van het eindproduct garanderen. In de traditionele aardappelbewaarloods zijn de toegepaste klimaatcondities gebaseerd op vuistregels, die zijn verkregen door 'trial and error' en door experimenten die voornamelijk slechts eenmaal per jaar kunnen worden geëvalueerd. Doordat ook voortdurend andere aardappelrassen op de markt verschijnen, die elk hun eigen karakteristieken hebben, en groei-, klimaat- en bewaarcondities niet constant zijn, verloopt de zoektocht naar optimale klimaatcondities traag. Al kort na de recente eeuwwisseling is voorgesteld om naast klimaatregeling ook kwaliteitsbeheersing toe te passen, op basis van wiskundige modellen. Kwaliteitsbeheersing is echter nog niet breed aangeslagen bij commerciële bewaarplaatsen doordat er een gebrek is aan inzicht in de ruimtelijke verdeling van het kwaliteitsverloop tijdens een bewaarperiode. Het doel van dit onderzoek was het verschaffen van de missende cruciale kennis omtrent het verloop van klimaat en productkwaliteit, en hoe deze elkaar gedurende een bewaarperiode beïnvloeden. Dit werd concreet gerealiseerd door het ontwikkelen van een ruimtelijk verdeeld model en het analyseren van de simulatieresultaten op basis van experimentele gegevens uit commerciële bewaarplaatsen.

In dit proefschrift wordt voornamelijk de temperatuur, vochtgehalte en reducerende suikergehalte interactie en ontwikkeling in bestaande bulk-bewaarplaatsen, uitgerust met een kelder, roostervloer en ventilatiecapaciteit van 100-150 kuub lucht per kuub product per uur, geëvalueerd en theoretisch verbeterd. In dit proefschrift worden zowel 2-D als 1-D klimaat-productkwaliteit model voor de evaluatie van een complete bulk-bewaarplaats gepresenteerd. Overigens heeft dit onderzoek in eerste instantie betrekking op standaard bewaarplaatsen voor de bulkopslag van frietaardappelen, maar kan het ook worden 
toegepast voor andere soorten opslagplaatsen en voor andere agromaterialen.

Het verbeteren van het bewaarproces kan gezien worden als een iteratief proces. Er is al veel onderzoek gedaan naar het modelleren van aardappelbewaarplaatsen (Hoofdstuk 2). Om bewaarkennis op te doen worden de meeste modellen gebaseerd op fysische inzichten. Analyses van de modeluitkomsten leiden tot nieuwe kennis en nieuwe modellen. Echter, een dynamisch ruimtelijk verdeeld model met meerdere productkwaliteitsindicatoren, dat gekalibreerd en gevalideerd is op basis van experimenten in commerciële bewaarplaatsen ontbreekt.

Een dynamisch 2-D model, inclusief de actuatoren (ventilator en luiken), is opgesteld en geanalyseerd (Hoofdstuk 3), daarbij gebruikmakend van numerieke stromingsleer (computational fluid dynamics oftewel CFD). Het model bevat de temperatuur van het product en de lucht, en vochtconcentraties en de koolstofdioxideconcentratie in de lucht en een Reynolds-averaged Navier-Stokes (RANS) model met Comsol's Algebraic yPlus turbulentiemodel dat de luchtstroming beschrijft. Het dynamische gedrag van de luiken is geïmplementeerd, met gebruik van een 'mesh' die in de tijd meebeweegt. Door de tijd heen worden herhaaldelijk nieuwe 'meshes' aangemaakt. Het model is met succes gekalibreerd en gevalideerd op data verkregen uit commerciële bewaarloodsen. Door de traditionele toepassing van overdruk ontstaan er voornamelijk gradiënten in de verticale richting. In simulaties bleek het mogelijk om de heterogeniteit terug te brengen door het toepassen van een afwisseling van over- en onderdruk in combinatie met een extra luchtkanaal aan de dakzijde.

Om naast inzicht in korte termijneffecten ook inzicht te verschaffen over het kwaliteitsverloop tijdens een volledig bewaarseizoen is het 2-D model teruggebracht tot een 1-D klimaat-productkwaliteit model, waarbij de reducerende suikers ook aan het model zijn toegevoegd (Hoodstuk 4). Het model is gebruikt om meer inzicht te verkrijgen in het intensieve koeltraject dat plaatsvindt tussen de wondheling en het bereiken van de langetermijn bewaartemperatuur. Hieruit bleek dat het verkorten van het koeltraject in een vermindering van het gewichtsverlies en ventilatie uren resulteert, maar een verhoging van de reducerende suikers oplevert. Een hogere luchtvochtigheid van de lucht leidde tot een verdere verbetering (minder vochtverlies) van de aardappelkwaliteit in de simulatie.

Behalve het klimaat-productkwaliteit model voor frietaardappelen is ook een model voor het eiwitgehalte van de aardappelen tijdens lange- termijn opslag ontwikkeld (Hoofdstuk 5). Het model is gekalibreerd op data verkregen uit een commerciële bewaarplaats met twee verschillende aardappelrassen (Miss Malina en Agria). De kalibratie resultaten resulteerden in twee verschillende sets met parameters voor de twee rassen, omdat beide rassen tijdens de bewaarperiode verschillend dynamisch gedrag vertoonden.

De CFD-simulaties geven inzicht in de invloed die de actuatoren hebben op de aardappelhoop. Deze simulaties geven echter alleen een eerste indruk over de mate van invloed die een actuator kan uitoefenen op iedere toestandsvariabele in ruimtelijke zin. 
Deze CFD-analyse werd vervolgens uitgebreid met de formele begrippen uit de klassieke systeemtheorie van regelbaarheid en waarneembaarheid (Hoofdstuk 6). Deze leverden echter slechts beperkt inzicht voor een ruimtelijke verdeeld model. Regelbaarheid geeft bijvoorbeeld inzicht of een bepaalde begintoestand kan worden beïnvloed om over te gaan naar een willekeurige andere toestand binnen een bepaald tijdsbestek. Ter aanvulling is een singuliere waardeanalyse op de regelbaarheids- en waarneembaarheids 'Gramians' uitgevoerd, wat meer inzicht gaf, maar de resultaten worden onnauwkeuriger door matrixvermenigvuldigingen bij kleinere discretisatiestappen. Daarom zijn gevoeligheidsvelden gebruikt om een meer praktisch begrip van regelbaarheid en waarneembaarheid voor een ruimtelijk verdeelde aardappelhoop te verkrijgen. De gevoeligheidsvelden gaven aan dat, in praktische zin, input-naar-toestand en begin-toestand-naar-output voldoende informatie opleveren betreffende de regelbaarheid en waarneembaarheid van een groot gekoppeld en ruimtelijk verdeeld systeem, ook voor kleine discretisatiestappen.

Samenvattend, verschaft dit proefschrift een ruimtelijk verdeeld klimaat-product kwaliteitsmodel, geëvalueerd aan de hand van experimenteel verkregen data van commerciële bulk-bewaarplaatsen. Een combinatie van snelle inkoelperiodes, wisselende onderdruk en overdruk en aanpassingen van de configuratie aanpassingen zorgt voor het terugdringen van gewichtsverlies, vermindering van ventilatie uren en een toename van suikergehaltes die wel binnen geaccepteerde waardes blijft. 



\section{TABLE OF CONTENTS}

Page

Summary $\quad$ v

Samenvatting $\quad$ ix

1 Introduction 1

2 Modelling ventilated bulk storage of agromaterials: A review $\quad 17$

3 A spatially distributed physical model for dynamic simulation $\begin{array}{ll}\text { of ventilated agro-material in bulk storage facilities } & 47\end{array}$

4 Postharvest frying potato quality development in a large-scale bulk storage facility

5 Modelling potato protein content for large-scale bulk storage facilities

6 Controllability and observability of $2 \mathrm{D}$ thermal flow in bulk storage facilities using sensitivity fields

7 General discussion and conclusions

Acknowledgements

Curriculum Vitae

Overview of completed training activities

Funding 

Chapter 1

\section{INTRODUCTION}




\section{Chapter 1}

\subsection{Aim of the research}

This research was carried out to gain new detailed insights into the development of and interaction between the quality of frying potatoes and climate in bulk storage facilities, and the spatially distribution in those facilities. In general, these storage facilities are climate-controlled and the storage facilities as well as their climate control abilities have improved slowly in recent decades. Climate control settings depend on the season and on the potato variety, but have until now been based on rules of thumb obtained mostly by trial and error. Modern control techniques like optimal or model predictive control (MPC) have made increased potential to optimize climate control, and the development of product quality control. However, these techniques are not yet massively applied in practice because there is still a vital gap in the knowledge on climate and product quality development, the heterogeneous spatial distribution, how to manipulate constraints of the controller, and the lack of a spatially distributed product model containing multiple quality indicators.

To address the missing knowledge, a dynamic spatially distributed model containing relevant climate and product quality indicators is needed. Such a model should serve in the first place for mathematical evaluation, to understand the storage process and towards redesigning the storage configuration and storage process. In the storage process, besides climate control and ventilation strategy, the development of and interaction between the quality of product quality and climate play a key role. Secondly, the model can be used as a basis for new control applications.

Hence, this study has the two following aims:

i) Present spatially distributed mathematical frying-potato models that describe the development of quality of potatoes stored in a bulk storage facility and the interaction between the climate and the potato quality;

ii) Analysis of the optimisation of storage strategy, storage configuration as well as actuator and sensor placement.

A long-term storage process takes weeks, if not months, and conducting quality measurements within bulk is complicated. The use of model simulations, and integrated with experimental data, should be an efficient way to provide knowledge faster than only experiments can, and in a more structured way.

\section{$1.2 \quad$ Background}

Good-quality food and animal feed products are essential for human life. Food and feed, also known as agro-materials, are affected by environmental conditions at each link in 
the food chain. The growth process of agro-materials is one of the first important steps in the food chain, and is season-dependent. To be able to provide them throughout the whole year, agro-materials therefore need to be stored, making storage another important process in the food chain.

On a global scale, roughly 1.3 billion tons of food for human consumption is lost or wasted per year. On average 4 to $20 \%$ of this loss and waste occurs during the post-harvest and storage stages (Gustavsson et al., 2011; Fan, 2017).

The quality of the product changes during storage as a result of various internal and external processes. In some cases, the time of storage takes up the biggest part of the entire food chain. These long storage times and the changing product composition make it a challenge to guarantee the same, or even better, quality of the stored materials relative to the initial agro-materials.

The changes that occur in agro-materials during storage are the result of both physical processes and enzymatic activities, which often depend on product, climate and time. This study focuses in particular on the bulk storage of potatoes in large-scale industrial facilities. Typical processes that occur during potato storage are dormancy, cold-induced sweetening and processes in the product and at the product-air interface, such as respiration and evaporation. Especially the interaction between the potatoes and air exerts a major influence on quality. Consequently, climate control, making use of ventilation, is massively applied in bulk storage facilities for potatoes.

In spite of the climate control, long-term storage losses of 6 to $30 \%$ are still seen in practice. One reason for this is that the design of storage facilities and operational regimes are based on older potato varieties, while in practice, there is a demand for new varieties with different properties, hence other storage requirements. Another reason is that growth, climate and storage conditions are not constant. Currently, the adaptation of the storage process, so that it includes new potato varieties and responds to variations in growth and storage conditions, proceeds only slowly, by trial and error and through experiments. This slow convergence is related to the fact that a full crop and storage cycle takes a whole year, with its own specific growth and storage conditions.

To speed up the process of storage optimisation, the exploration of the needs of potatoes during storage (Aben, The Netherlands, 2016) has to be accelerated. With modern techniques that make use of simulation software and optimal control, this adaptation should be possible. However, it is also widely known that having a good storage climate does not automatically guarantee the quality of the stored product. Controlling product quality instead of climate would therefore improve the storage process considerably (Verdijck, 2003). To that end, it is necessary to have more knowledge available on the interactions between the product and the surrounding storage climate, including the spatial distribution of and changes in those interactions. 


\section{Chapter 1}

Such knowledge can be obtained through experiments or through computational fluid dynamic (CFD) simulations. Drawbacks of real-time experimentation are the time it takes, the seasonal dependency, and the costs of experimentation. Using CFD simulations makes it possible to evaluate each scenario numerically, in a structured way and at any time. However, CFD simulations can only be appropriately used if the underlying mathematical model is calibrated and validated against experimental data.

\subsubsection{Ventilated bulk storage}

Various bulk storage methods are available for potatoes. The simplest method is to pile potatoes outdoors, with some straw insulation around them. Another often applied method is bulk storage in a facility where the conditions are controlled, and measured with sensors. Potato storage in a bulk storage facility offers more opportunities to protect the bulk from the outside climate in comparison with the pile method. Bulk storage in a facility has the advantage over other storage systems, such as box or sack storage, that it is a low-cost system in terms of investment as well as handling cost (Pringle et al., 2009). A disadvantage of bulk storage is the reduced flexibility in handling, however.

Bulk storage facilities can be equipped with actuators and sensors to influence and monitor the storage process. The most advanced facilities deploy actuators to control all kinds of disturbances that influence the climate in the storage facility. This can be implemented for both open and closed systems. In an open system, the actuators use air from outside the facility to influence the climate inside the storage facility. In a closed system, the climate in the facility can only be influenced by actuators inside the facility, such as cooling, heating and humidifying devices. The research presented in this thesis concerns open controlled systems equipped with two types of actuators, namely hatches and ventilators (see Figure 1.1). The open controlled system is exposed to external and internal changes that influence the temperature, moisture content and carbon dioxide levels in the storage. In the conventional bulk storage facilities (as in Figure 1.1), with a cellar and perforated floor, the ventilation strategy is to use an overpressure to control the climate, on base of rules of thumb, to maintain good quality during the storage season.

In controlled bulk storage facilities, the living agro-materials can be stored for several months. During these months, various physical and physiological processes cause the quality of the material to change. In most cases, this occurs as a function of temperature, moisture/humidity, gas concentrations and temperature-dependent enzymatic activities over time. Thus, product quality can be influenced by controlling the temperature, moisture/humidity and gas concentrations of the air in the facility. In this study, we have numerically and experimentally investigated how the quality changes and to what extent the conditions of the air and the product quality in a bulk storage facility can be affected by the hatches and fan, as shown in Figure 1.1. 


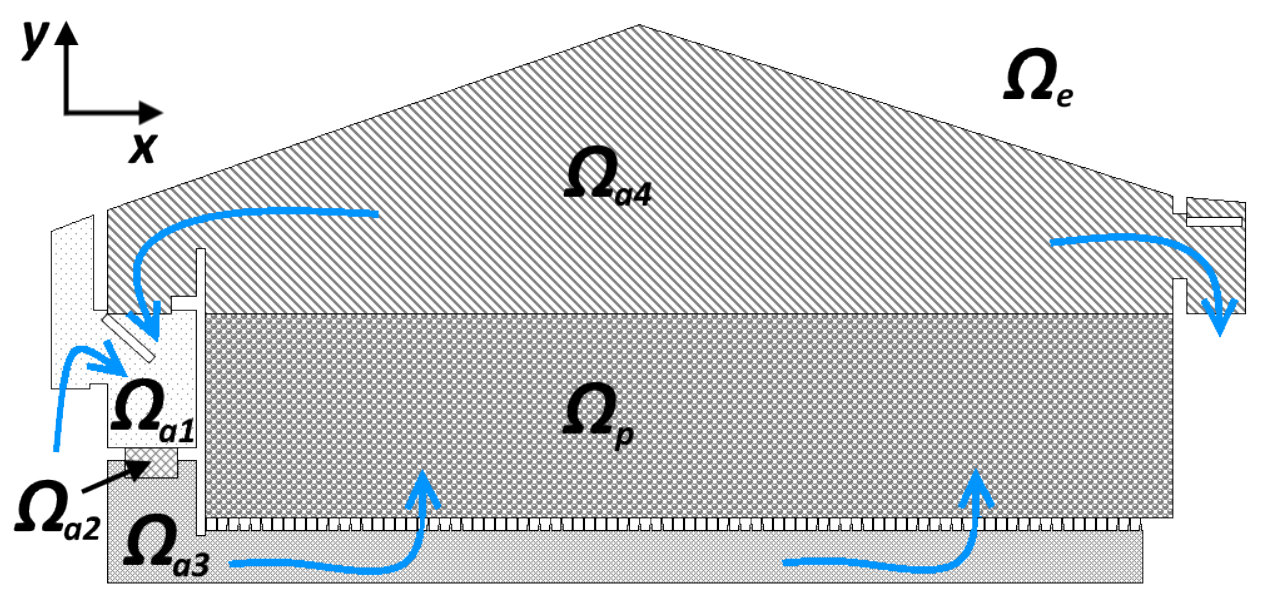

Figure 1.1: Schematic overview of a ventilated bulk storage facility with perforated floor, two hatches and a fan. Three different main domains $(\Omega)$ can be distinguished: the environment around the facility, $\left(\Omega_{e}\right)$, the product domain, $\left(\Omega_{p}\right)$, and the four different air domains, $\left(\Omega_{a i}\right)$. The outdoor environment can influence the indoor climate by ventilation of air from outside $\left(\Omega_{e}\right)$ and inside $\left(\Omega_{a 1}\right)$. This is done via fan $\Omega_{a 2}$ into channel $\Omega_{a 3}$ through the porous medium into the air space above the porous medium $\Omega_{a 4}$. The air in $\Omega_{a 4}$ can either leave the facility or be recirculated.

\subsubsection{Climate control}

Generally, modern bulk storage facilities are climate-controlled, but this is mostly based on rules of thumb, which are mainly the result of practical knowledge obtained throughout the years. The indoor climate conditions influence various processes, such as respiration, evaporation, wound healing, bacterial and fungal infections, suberisation, sweetening, dormancy and other enzymatic activities.

The rules of thumb for temperature, moisture and gas concentrations in a potato storage facility depend on the potato variety, the growing season, the skin set, the specific facility and on time. For initially high-quality potatoes, four main periods in bulk storage can generally be distinguished (see e.g. Brook et al., 1995; Van 't Ooster, 1999; Pringle et al., 2009). These periods are the early storage period, cooling period, long-term storage period, and the pre-loading period. Each period has its own desired climate conditions, depending on the condition of the potatoes; see Figure 1.2.

The early storage period consists of two different stages. These are the equalisation and drying stage, and the wound healing or suberisation stage.

Equalisation refers to the fact that, specially for large bulk facilities, the potatoes most likely enter the storage with some temperature differences. Therefore, there is first a need to create a homogeneous bulk climate. In other words, the bulk needs to be equalised. If the potatoes enter the storage under wet conditions, the freely available moisture needs also to be removed. Freely available water moisture is also present if there is a certain 


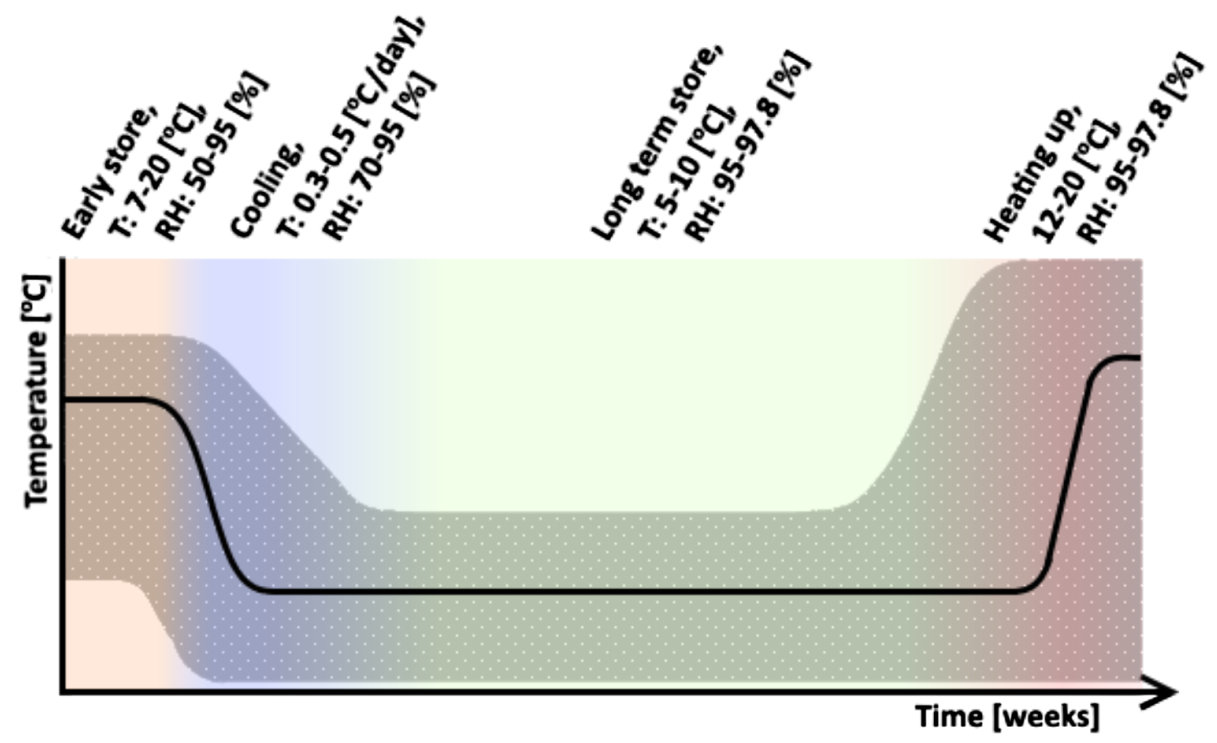

Figure 1.2: The four main periods during bulk storage of potatoes used for frying. In the early storage period equalisation, drying and wound healing determine the climate settings. During the cooling period, the potatoes are cooled down to the long-term storage temperature. During the long-term storage period, the temperature should be kept constant and low to postpone dormancy break. At the end of the storage period, the potatoes are typically heated up, to minimise quality defects.

percentage of rot. Also in the case of rot, the free water moisture needs to be removed from the facility first. This removal of free water moisture in the drying stage can take some time, but should preferable occur rapidly. It is typically accelerated by applying a bulk temperature of around 18 degrees Celsius.

Wound healing or suberisation is also important at the beginning of the storage period. Once the potato is out of the soil and especially during pre-storage processes and activities, the tuber is vulnerable to damage. This damage can take the form of bruising or cutting. These wounds need to be healed quickly, so that the potato is protected against bacteria and fungi. This stage is important for further quality development. Van 't Ooster (1999) reported a general rule for the time it takes to heal the wounds, which is as follows:

$$
\sum_{i=1}^{n}\left(T_{p}(i)-5\right) \geq 150
$$

Here, $T_{p}$ is the potato temperature in the bulk and $n$ the number of days to obtain at least 150 degree days. The wound healing process depends on the potato variety, season and storage conditions. In the literature (e.g. Wigginton, 1974; Van 't Ooster, 1999; Lulai, 2007), temperature ranges of 7 to 35 degrees Celsius can be found. However, in this stage the spread of bacteria and fungi also needs to be subdued, as the wounded potatoes are vulnerable to infection. The temperature should therefore not exceed 22 degrees Celsius, 
and the relative humidity should be between 80 and $95 \%$.

Once the wounds have healed, the potato bulk needs to be cooled down to the long-term storage temperature, to decrease respiration and increase the dormancy break time. In the literature (e.g. Pringle et al., 2009), the advice to cool the potato by no more than 0.5 degrees Celsius per day, with a relative humidity of $97.8 \%$, can be found. In practice, cooling takes place at 0.2 to 1.5 degrees Celsius per day.

The long-term storage temperature for frying potatoes lies between 6 and 15 degrees Celsius, with an optimal relative humidity between 95 and $97.8 \%$ Pringle et al. (2009). In the long-term storage period, temperature fluctuations are not desirable, as fluctuations in temperature will lead to early dormancy break. The air humidity should be relatively high to prevent dehydration. In addition to the variety, the growing season of the potato also determines the desired storage temperature. A lower temperature will decrease respiration, with the tipping point around 3 degrees Celsius, but it will also increase cold-induced sweetening. In addition to temperature effects, in the long-term storage period, the carbon dioxide $\left(\mathrm{CO}_{2}\right)$ level also becomes more important. In the literature (see e.g. Daniels-Lake, 2013; Martin, Romania, 2015), levels of $\mathrm{CO}_{2}$ acceptance range from 0.2 to $2 \%$. When exposing the potatoes to high carbon dioxide levels for a longer time, higher sugar levels will be obtained. The exact amount of carbon dioxide level that effects the sugar accumulation strongly depends on the variety (Martin, Romania, 2015). Daniels-Lake (2013) reported that having increased $\mathrm{CO}_{2}$ levels (3-9\%) during suberisation at 18 degrees Celsius does not affect the colour of fried potato chips. Having increased $\mathrm{CO}_{2}$ levels during suberisation at lower temperatures or during long-term storage results in a significantly darker frying colour, however. In practice, low carbon dioxide levels are usually obtained during the wound healing and cooling process, as fresh air is ventilated into the facility in this stage most of the time, and at least once a day, either for drying or for cooling.

In the final storage period, the product is generally heated up. In the case of potatoes, they are heated to a temperature in the range of 12 to 20 degrees Celsius, for two reasons. One reason is related to the formation of black spot, because after storage and during all further handling, relatively cold potatoes are more susceptible to black spot. Another reason is reconditioning of the potato to reduce the effect of cold-induced sweetening during long-term storage.

\subsubsection{Product quality control}

The most important quality indicators for high-quality potatoes used for frying and that have been stored in bulk storage facilities are the (mass) dry matter/moisture content, pressure bruising, the reducing sugar (RS) content and sprouting. Besides these four main quality indicators, other quality indicators can be thought of. Especially when (world- 


\section{Chapter 1}

wide) high yields are obtained, it could be interesting from an economical point of view to focus on other markets besides the frying market. For other markets, other indicators can be more important. An example is the protein content, which has gained more interest in recent years (Løkra and Strætkvern, 2009).

For each potato variety, the quality during storage, in particular the mass, depends on the quality of the potato skin, active metabolism, ventilation rate and climate conditions as already mentioned in subsection 1.2.2. The basis of the quality as well as of the postharvest reaction of the potato tissue is established during the growing season. In general, the dry matter content of potatoes is around $20 \%( \pm 4 \%)$, whereas the industry for frying potatoes demands a relative high dry matter content of at least $20 \%$. This implies that about $80 \%$ of the potato consists of water, and in general contributes most on the weight loss during storage, which makes the moisture content an important factor. About 97.6 $\%$ of the moisture loss occurs by evaporation, and only $2.4 \%$ by respiration (Pinhero and Yada, 2016). During storage, the rate of moisture loss from the tuber is proportional to the difference between the water vapour pressure (WVP) in the cells of the potato skins and the WVP of the air in the voids between the potatoes. Hence, if the deficit of the WVP between the skin and air is positive, evaporation takes place. The average water loss from mature undamaged tubers is approximately 0.14 to $0.17 \%$ of the tuber weight per week per mbar vapour pressure deficit. The evaporation increases 100 to 150 times during sprouting (Van Es and Hartmans, 1987). Removing the skin will even increase the evaporation by a factor of 300 to 500 (Pinhero and Yada, 2016).

When a potato loses moisture, its tissue becomes softer and softer tissue is more susceptible to pressure bruising. Pressure bruising is a defect that typically occurs in bulk storage facilities. If the average bulk density is determined as $655\left[\mathrm{~kg} / \mathrm{m}^{3}\right]$, with a common storage height of 4 metres, the lowest part of the bulk is exposed to 2.6 tonnes per square meter. This pressure, in combination with the potatoes' moisture loss, results first in pressure flattening. After long-term exposure to pressure and dehydration, blackish bruises develop, known as pressure bruises (Castleberry, 2013). These bruises are caused by the oxidation of phenolics into melanins (Lulai et al., 1996). In addition to pressure, moisture loss and time, temperature can have an effect as well, as reported by Solomon and Jindal (2007).

The reducing-sugars (RS) content influences the frying colour of the potatoes as reducing sugars - in particular, glucose and fructose - determine the non-enzymatic browning reaction (Maillard reaction). The higher the $\mathrm{RS}$ content, the darker the frying colour. The amount of RS is determined, in addition to RS formed during the growing season, by cold-induced sweetening and senescent sweetening during storage. Cold-induced sweetening is influenced by the bulk temperature, whereas senescent sweetening is caused by the ageing of the tuber. The sweetening is the result of the constant release of carbohydrates from starch for respiration. This constant release seems to be reversible. When the net 
release of sugars from starch exceeds their turnover, sugars accumulate (Hertog et al., 1997).

Sprouting is the visible bud growth that happens when the dormancy is broken. Sonnewald and Sonnewald (2014) defined dormancy as the sprouts being unable to develop, even in conditions favourable to sprouting. Optimal conditions for sprouting are darkness, a temperature of 15 to 20 degrees Celsius and a relative humidity (RH) of around $90 \%$. Higher $\mathrm{CO}_{2}$ concentrations $(2.2$ to $8.8 \%$ ) also stimulate sprouting. The length of dormancy is determined by the growth and storage conditions as well as by physiological and hormonal control mechanisms (Mani et al., 2014). Once sprouting begins, respiration (heat, carbon dioxide and moisture) and moisture loss from the potatoes increase. Also, during sprouting, starch breakdown in the tubers accelerates with concomitant accumulation of undesirable RS. For long-term storage, the mere application of low temperatures (around the 7-8 degrees Celsius) and low carbon dioxide levels is not enough to prevent sprouting. Therefore, storage facilities mostly use chemical forms of sprout control, like CIPC (chloor-IPC; chlorpropham).

In addition to these four main quality indicators, particularly potato protein content is gaining interest Schmidt (2016). The potato contains roughly $1.7 \%$ protein (Waglay and Karboune, 2016), of which the three major fractions are patatin, protease inhibitors and other proteins (of high molecular weight) (Pots et al., 1999). During storage, the protein content can increase, remain stable or decrease. The size and development of the protein content during storage depends on potato variety and temperature (Brasil et al., 1993).

\subsubsection{Modelling of bulk storage facilities}

Physical modelling aims to create a representation of the reality in order to better understand and quantify mass, energy and/or momentum balances. Throughout this thesis, mainly spatially distributed parameter models but also lumped parameter models are used. See Chapter 2 for a more detailed description of the models. Lumped parameter models use one or more multi-zone ordinary differential equations (ODE) to represent the physical behaviour of component $X$ over time, i.e.,

$$
V \frac{d X}{d t}=\phi_{V} X_{i n}-\phi_{V} X+V r_{X}
$$

Here, $X$ is the state, $V$ represents the volume, $\phi_{V}$ represent the volumetric flow rate of $X$ and $r_{X}$ represents the reaction of $X$. In addition, a spatially distributed parameter model characterises the physical behaviour of the system through a set of partial differential 


\section{Chapter 1}

equations (PDE) over time and in one, two or three spatial dimensions:

$$
\left(\frac{\partial X}{\partial t}+\boldsymbol{v} \cdot \nabla X\right)=\nabla \cdot(c \nabla X)+r_{X}
$$

Here, $\nabla:=\left[\frac{\partial}{\partial x} \frac{\partial}{\partial y} \frac{\partial}{\partial z}\right]^{T}, X$ is the state, $t$ represents time, $\boldsymbol{v}$ the convection or velocity vector, $c$ the diffusion coefficient and $r_{X}$ the reaction term. In this thesis, the states represent climate properties, such as air temperature $T_{a}$, air moisture content $X_{a}$ and carbon dioxide level $\mathrm{CO}_{2}$, or product properties such as product temperature $T_{p}$, product moisture content $X_{p}$, reducing-sugar level $R S$ and total protein content $T P$. Most of the states are coupled in the reaction term.

Throughout this thesis, the convection is assumed to be piecewise constant (Chapters $2,4,5,6)$ or varying, and calculated using the momentum equation (Chapters 2 and 3). In practice, the potato storage cycle is a time-varying system. This means that during growth and storage, the parameters of the mathematical model can change over time. For the sake of simplicity, however, the models in this thesis assume constant model parameters and only one storage season. This assumption makes the models timeinvariant. As the mathematical models contain non-linear relations throughout this thesis, the mathematical models of the storage facility are described by sets of non-linear timeinvariant (partial) differential equations.

The combination of ODE and PDE models can be used to obtain more insight into the storage process through mathematical simulations. Especially computation fluid dynamics (CFD) simulations help to visualise (coupled) PDEs over time and in spatial dimensions (see Figure 1.3).

In this research, only one type of controllers was included, namely bang-bang controllers. Chapter 4 discusses how on the basis of a bang-bang controller, the temperature and carbon dioxide concentration can be controlled. The bang-bang controller switches between on and off to control the air stream that can enter the storage facility. The switching intervals are predefined by the pre-specified upper and lower bounds on temperature and carbon dioxide concentration.

\subsection{Research scope}

This thesis provides spatially distributed climate-product quality models and new insights in the potato storage process on the basis of validated mathematical models, and largescale experimental data using a multidisciplinary approach. As a guideline during this research, five research questions were addressed, and three additional hypotheses evaluated. Each of these research questions is explored in more detail in Chapters 2 to 6. 

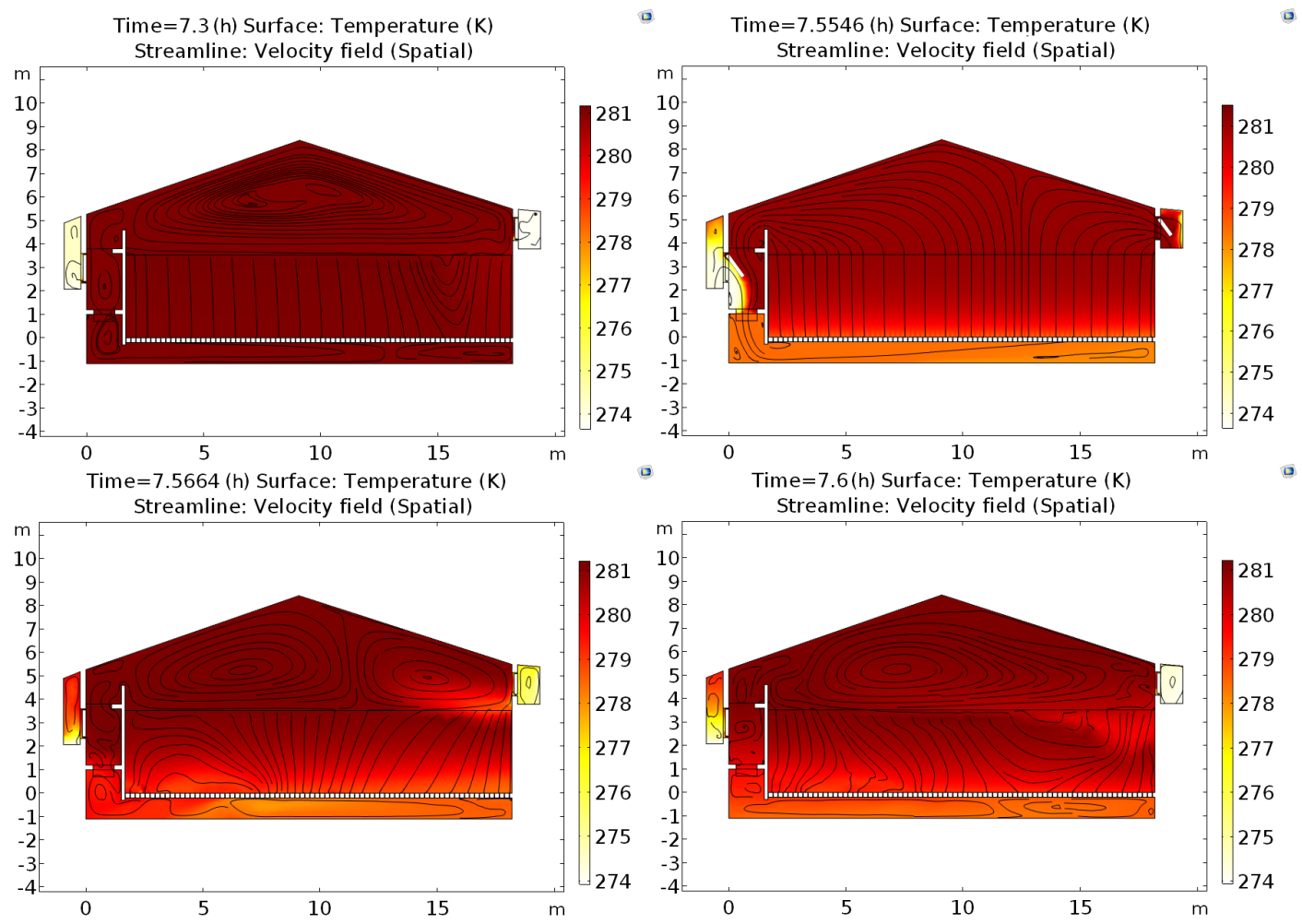

Figure 1.3: CFD simulation results for the development of air temperature profiles when switching from natural convection (top left panel) with fan off and hatches closed, to forced convection (top right panel) with fan on and hatches open, and switching back to natural convection (bottom left and right panel) with fan off and hatches closed. 


\section{Chapter 1}

\section{Research questions}

Plenty of studies related to long-term storage of agro-materials can be found in the literature, but studies that integrate spatially distributed modelling, calibration, validation and control of climate and product quality for large-scale storage facilities are scarce. Due to the changing needs and optimisation of the potato-processing industry, storage losses and the need for sustainable storage strategies, there is a need for more knowledge on the relationship between storage climate and product quality development. One way to investigate the interaction between storage climate and product quality development is by making use of model simulations. Different types of models, expressed in different product quality indicators, have been proposed in the literature. Therefore, the first research question tackled in this thesis, is postulated as:

$\mathrm{Q}_{1}$ : What is a suitable model structure for obtaining detailed insight into the development of product quality and the interactions between product quality and ventilation strategies?

With the right model structure and quality indicators, model simulations for large-scale bulk storage facilities can be performed. Large-scale facilities pose basically three challenges for a numerical CFD simulation, namely that they $(i)$ contain fast and slow dynamics, (ii) contain actuators that physically change position, and (iii) have a configuration that is not symmetric. Through the use of CFD simulations, the storage process and the facility configuration can probably be optimised, which would result in a better end product. This can be summarised in the following question:

$\mathrm{Q}_{2}$ : How can a potato bulk storage model be used for the (re)design and efficient operation of a storage facility so as to guarantee a uniformly high product quality?

In addition to the (re)design of a storage facility, operational strategies of the storage process play an important role to minimise storage losses and maintain good product quality, e.g. moisture content and sugar levels in the potato. As mentioned, there is a need for more and better knowledge to enable the optimisation of storage strategies, taking specific potato varieties and changing growing conditions into account. Simulations could be used to test new strategies. Therefore, research question three was postulated as:

$\mathrm{Q}_{3}$ : How can a climate-product quality model be used to obtain system knowledge for a complete potato storage season?

The growth of potatoes shows a strong climate-dependency. This dependency causes 
fluctuations in the yield every year, which affects the price of frying potatoes. Recently, the valorisation of the potato protein that is produced as a by-product in the starch industry has been gaining interest. When the prices for frying potatoes are low and the prices for protein are high, it could be of interest to adapt the storage regime to yield potatoes with a higher protein content.

$\mathrm{Q}_{4}$ : How can storage strategies influence the protein content?

A bulk storage model can be used for simulations, but also for control. Most of the basic states of a storage model, which are the temperature and moisture content of the air and of the potato, are described by convection-diffusion-reaction (CDR) equations. These states are monitored and controlled in practice, but for the proper control and monitoring of such systems, system properties such as controllability and observability play a central role. The use of classical systems theory for controllability and observability analysis depends on the discretisation steps of spatially discretised systems, which is difficult to apply in a general setting. Therefore, the next research question is:

$\mathrm{Q}_{5}$ : Given a bulk storage model, how can knowledge for actuator and sensor location be obtained?

\section{Hypotheses}

In addition to the research questions, the research presented in Chapters 3 and 4 also address the following hypotheses:

- $\mathrm{H}_{1}$ : Combining underpressure and overpressure instead of the conventional application of only overpressure results in faster homogenisation of the bulk.

- $\mathrm{H}_{2}$ : A 1-D model is an appropriate approximation of a conventional real full-scale bulk storage facility.

- $\mathbf{H}_{3}$ : Slow cooling is more beneficial for quality indicators related to moisture and sugar content than rapid cooling.

\subsection{Outline of the thesis}

The five research questions and three hypotheses served as the guidelines for the research presented in this thesis. Each chapter addresses one of the research questions, structured 


\section{Chapter 1}

as depicted in Figure 1.4. All chapters and their exploration of the research questions and hypotheses contribute new insights into the bulk potato storage process.

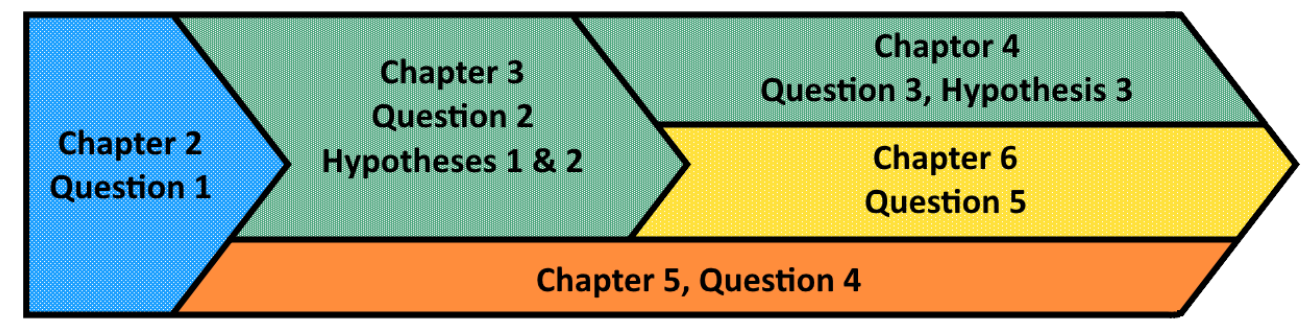

Figure 1.4: Schematic overview of the interconnection of the thesis chapters, research questions and hypotheses. The blue area (Chapter 2) is the starting point of this thesis, a review on storage models. The orange area (Chapter 5) only focuses on product quality modelling. The green areas (Chapter 3 and 4) contain a combination of presented models and system analysis. The yellow area (Chapter 6 ) focuses on the system analysis using a temperature model.

As shown in Figure 1.4, Chapter 2 is the starting point of the research. It presents a review of the status of the art in potato storage modelling. As a result of Chapter 2, two different types of models are proposed in Chapters 3 and 5. Chapter 3 introduces a climate-product quality model based on a physical modelling approach and used for CFD simulations to analyse the storage process. Chapter 5 proffers a new protein model based on experimental data and following a lumped parameter modelling approach. On the basis of Chapter 3, two additional steps are described in Chapters 4 and 6 . In the research presented in Chapter 4, an additional quality indicator was included in the climate-product quality model, and used to simulate a complete storage season. Chapter 6 explains how a 2D coupled temperature model of the bulk was used to analyse the actuator and sensor locations on the basis of sensitivity fields instead of CFD simulations. 


\section{References}

S. Aben. Storage techniques fitting the needs of potatoes for processing worldwide: Lamb Weston's view on storage. In EAPR Post Harvest Section meeting, The Netherlands, 2016.

P.J. Brasil, A.B. César, and H.P. Marcio. Effects of different storage temperatures on protein quantities of potato tubers. Revista Brasileira de Fisiologia Vegetal, 5(2):167170, 1993.

R.C. Brook, R.J. Fick, and T.D. Forbush. Potato storage design and management. American Potato Journal, 72:463-479, 1995.

H.C. Castleberry. Development of methods to estimate or reduce pressure flattening of potatoes during storage. PhD thesis, Colorado State University, 2013.

B.J. Daniels-Lake. Carbon dioxide and ethylene gas in the potato storage atmosphere and their combined effect on processing colour. PhD thesis, Wageningen University, 2013.

A. van Es and K.J. Hartmans. Storage of potatoes; post-harvest behavious, store design, storage practice and handling. Centre for Agricultural Publishing and Documentation, 1987.

S. Fan. Global food security and wellness. Springer, 2017.

J. Gustavsson, C. Cederberg, U. Sonesson, R. van Otterdijk, and A. Meybeck. Global food losses and food waste. Technical report, FAO, 2011.

M.L.A.T.M. Hertog, L.M.M. Tijskens, and P.S. Hak. The effects of temperature and senescence on the accumulation of reducing sugars during storage of potato (Solanum tuberosum L.) tubers: A mathematical model. Postharvest Biology and Technology, 10 (1):67-79, 1997.

S. Løkra and K.O. Strætkvern. Industrial proteins from potato juice. A review. Food, 3(1):88-95, 2009.

E.C. Lulai. Potato biology and biotechnology advances and perspectives. Elsevier, 2007.

E.C. Lulai, M.T. Glynn, and P.H. Orr. Cellular changes and physiological responses to tuber pressure-bruising. American Potato Journal, 73:197-209, 1996.

F. Mani, T. Bettaieb, N. doudech, and C. Hannachi. Physiological mechanisms for potato dormancy release and sprouting: A review. African Crop Science Journal, 22(2):155$174,2014$.

M. Martin. $\mathrm{CO}_{2}$ concentration influence during storage on frying ability of tubers. In The international potato processing $\mathscr{G}$ storage convention, Romania, 2015.

A. van 't Ooster. CIGR Handbook of Agricultural Engineering Volume IV Agro-Processing engineering. American Society of Agricultural Engineers, 1999. 


\section{Chapter 1}

R.G. Pinhero and R.Y. Yada. Advances in potato chemistry and technology. Academic Press, 2016.

A.M. Pots, H. Gruppen, R. van Diepenbeek, J.J. van der Lee, M.A.J.S. van Boekel, G. Wijngaards, and A.G.J. Voragen. The effect of storage of whole potatoes of three cultivars on the patatin and protease inhibitor content; a study using capillary electrophoresis and MALDI-TOF mass spectrometry. Journal of the Science of Food and Agriculture, 79:1557-1564, 1999.

B. Pringle, C. Bishop, and R. Clayton, editors. Potatoes postharvest. CABI, 2009.

J.M. Schmidt. Purification and functional properties of potato protein fractions. $\mathrm{PhD}$ thesis, Aarhus University, 2016.

W.K. Solomon and V.K. Jindal. Modeling changes in rheological properties of potatoes during storage under constant and variable conditions. LWT-Food Science and Technology, 40(1):170-178, 2007.

S. Sonnewald and U. Sonnewald. Regulation of potato tuber sprouting. Planta, 239: 27-38, 2014.

G.J.C. Verdijck. Product quality control. PhD thesis, University of Eindhoven, 2003.

A. Waglay and S. Karboune. Advances in potato chemistry and technology. Academic Press, 2016.

M.J. Wigginton. Effects of temperature, oxygen tension and relative humidity on the wound-healing process in the potato tuber. Potato Research, 17:200-214, 1974. 


\section{Chapter 2}

\section{MODELLING VENTILATED BULK STORAGE OF AGROMATERIALS: A REVIEW}

Published as:

N.L.M. Grubben and K.J. Keesman. Modelling ventilated bulk storage of agromaterials:

A review. Computers and Electronics in Agricultrue, 114:285-295, 2015 


\section{Chapter 2}

\section{Abstract}

Storage of season-dependent agro-materials is a key process in providing food, feed and biomass throughout the whole year. We review the state of the art in physical modelling, simulation and control of ventilated bulk storage facilities, and in particular the storage of potatoes, from a state-space perspective. The basic physical relations that describe the dynamic behaviour of air and potatoes in a storage facility use laws of conservation of mass, energy and momentum and corresponding constitutive laws. However, a very complex physically based storage model is obtained if the macro climate in the air channels and the micro climate around the potato and all the interactions between air and potato are taken into consideration. Therefore, lumped, 1-D, 2-D and 3-D macro, and also some micro climate storage models were developed. These models basically focus on heat and moisture generation and transportation. The latest developments give more and more insight into the spatial distribution of the macro climate, using CFD simulation techniques. Traditionally, the indoor climate instead of the potato quality is controlled, to maintain a good product quality. However, quality control of the product can be realised if there is knowledge between the spatial distribution of temperature and moisture and the product quality. With the developments in CFD simulation, control algorithms and the state space framework, modelling and control of product quality is within reach.

\subsection{Introduction}

The storage of agro-materials is an important part of the season-dependent agro-business chain. Storing products helps overcome the seasonality in production and results in a continuous flow of food and biomass to the processing industries. Furthermore, in combination with smart market anticipation, storing products can lead to higher profits (Guenthner, 1995).

Storage quality can be improved by decreasing storage losses or improving pre-processing conditions for enhanced industrial processing. Consequently, sustainable storage facilities should be realised, with low energy consumption and conservation of high product quality. To achieve this, more insight in the relationship between ventilation strategies and product quality is needed.

A suited agricultural product for storage quality investigation is the potato. Worldwide, the potato is an important agricultural product; at a production of 364 million tonnes per year, it is the fifth most produced product in the world (FAO, 2012). The potato has the largest ratio of product per unit area to food energy per product (Pishgar-Komleh et al., 2012). In addition to water and starch, potatoes contain valuable proteins, sugars, minerals and vitamins. 200 grams of potato provides around $20 \%$ of the recommended 
daily requirement for vitamin B (Gumul et al., 2011) and approximately $61 \%$ for vitamin C (Blauer et al., 2013). Because of its content, the potato is not only usable as traditional food and feed, but also as a source for bioplastics (Kim, 2003), bio-glue (Mayer, 1998), hydroxymethylfurfural (HMF) (Yi et al., 2012) and bioethanol (Tasic et al., 2009; Koga et al., 2013). Furthermore, the potato is considered a model product for storage, as all processes that occur during storage of bulk produce are crucial for potato storage as well. Hence, in what follows, we focus on the modelling of potato storage.

Maintaining the quality of agro-materials during storage is realised by minimising respiratory heat generation, retarding ripening and sprouting, and preventing moisture loss and microbial spoilage (Ambaw et al., 2013). Current facilities use climate-based control to maintain the air quality at a certain level. However, a good climate does not guarantee a high quality of the end product.

Modern simulation techniques, such as computational fluid dynamics (CFD), enable obtaining more insight in the relationship between the spatially distributed storage climate, natural and convective ventilation conditions and actual product quality. Furthermore, CFD simulation can support the design of new control strategies based on the current or predicted product quality instead of on measured indoor climate parameters. Physical relations between spatially distrusted climate, ventilation conditions and product quality can be covered in a mathematical model. This model not only supplies the basis for dynamics simulations and control, but also amplifies our understanding of product quality changes.

Figure 2.1 presents a commonly used configuration of a storage facility for potatoes (see Section 3 for more details about domains). This type of facility contains a forced-air system with ventilation, cooling, heating and humidifying devices. Nevertheless, natural quality losses over time cannot be avoided yet.

Rastovski (1987) investigated natural quality losses of potatoes. These losses depend on the climate conditions, potato variety and ventilation conditions, defined by the air velocity as created by a fan and the corresponding air composition. Moisture loss can range from 1\% (Hunter, 1986) to 1.66\% (Fennier et al., 2003) per month and causes shrinkage, which becomes visible over a larger storage period. At least as important as moisture loss is the conversion of components like starch, sugars, proteins and vitamins. These irreversible processes do not depend much on the air velocity, but temperature has a direct influence.

Modern simulation techniques allow the inclusion of processes affecting potato quality in spatially distributed potato storage models. This article reviews models of potato storage facilities defined for quality investigation, simulation and control. It also indicates new trends and makes recommendations for future research. 


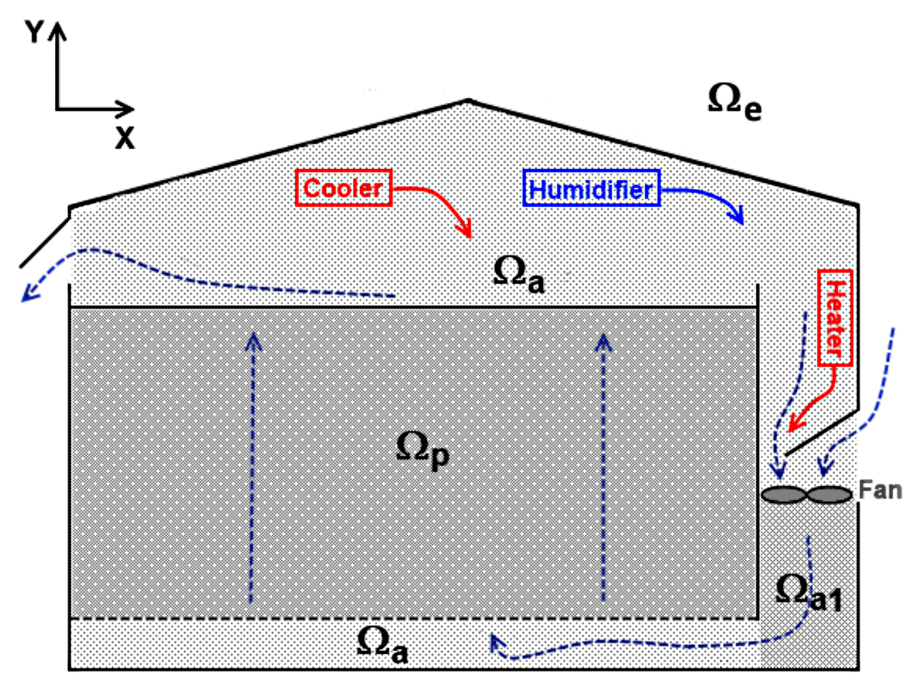

Figure 2.1: 2-D bulk storage facility with $\Omega_{a}$ the air domain, $\Omega_{a 1}$ air domain of the pressure chamber, $\Omega_{p}$ the porous medium domain and $\Omega_{e}$ the environment.

\subsection{Modelling potato storage}

Good product quality and maximum profits are two important elements for storage facility managers. To maximise profits, the aim should be on high potato prices and low storage costs. The costs of storage cover ownership and operating costs (Guenthner, 1995). The operating costs are mainly determined by energy usage of the ventilation system, including the cooler/heater and humidifier, to maintain the desired climate conditions. As climate conditions directly or indirectly influence product quality, previous research focussed on the relationship between quality of the product and storage climate. These predominantly experimental investigations led to proposed control strategies.

In the past decades, the research focus shifted towards modelling of storage climate processes. With modern simulation software, it is now possible to provide more detailed insight in the relationship between product quality and ventilation strategies, including all the dynamics induced by flow and transport phenomena. This has resulted in three dominant modelling trends, namely modelling for quality and control as well as dynamic simulation modelling.

Many investigations related to potato quality were conducted in the past few years. Potato quality models describe one or more process variables related to potato quality. Rastovski (1987), for instance, described the main quality-determining processes, such as evaporation, respiration and water loss. Schippers (1977) published a review article related to respiration of the potato. Investigations of ventilation rate, moisture loss and temperature were carried out by Misener and MacDonald (1975), Misener and Shove (1976), Ofoli and Burgess (1986), Marchant et al. (1994), Wang and Brennan (1995) and Fennier et al. 
(2003). Other quality aspects were explored as well, such as the relationship with sugar content (Hertog et al., 1997; Nourian et al., 2003), the effect of the surface water vapour flux on drying of potatoes (Kalbasi and Mehraban, 2000), proteins as well as lipids and minerals in potatoes (Karenlampi and White, 2009), the amino acid profiles for unusual storage temperatures (Davids et al., 2004) and the change in ascorbate and associated gene expression during storage (Blauer et al., 2013).

Most of the investigations related to climate control use temperature and moisture content as process states (see e.g. Marchant et al., 1994; Gottschalk, 1996; Price et al., 1999; Verdijck et al., 1999; Keesman et al., 2003; Lukasse et al., 2007; Van Mourik et al., 2012). The same basics were also used by e.g. Verdijck and Tijskens (2003), Verdijck (2003), Gottschalk et al. (2003) and Van Mourik et al. (2010). Verdijck and van Straten (2002) used a combined modelling and control structure, whereas optimisation studies were carried out by Verdijck et al. (2005b) and Lukasse et al. (2009).

For the simulation of the spatial distribution in potato storage facilities, computational fluid dynamic (CFD) software is most commonly used, see for instance $\mathrm{Xu}$ and Burfoot (1999), Kondrashov (2000), Xu et al. (2002), Verboven et al. (2006), Kondrashov (2007) and Chourasia and Goswami (2007).

\subsection{State-space framework}

A storage facility is a dynamic physical system. Typically, the modelling process of a physical system proceeds along the following steps: (i) process definition, (ii) model boundaries, (iii) process variables and (iv) model structure.

Five basic process domains (Verdijck and Tijskens, 2003) can be defined for a storage facility, namely product, direct domain, indirect domain, environment and control domain (Figure 2.2). These domains pertain to the products in the facility, the air between the products, the air in the channels and head space, the domain outside the facility and the control component, respectively. The control component includes controllers and control algorithms, but also sensors and actuators, such as coolers, heaters and humidifiers.

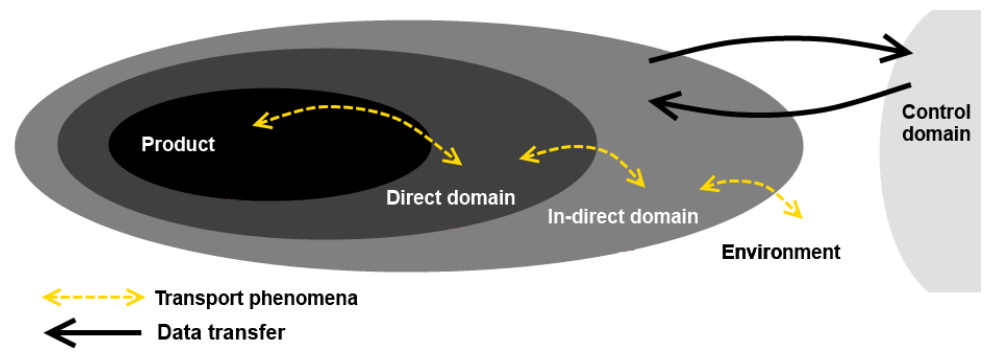

Figure 2.2: Domains defining the processes in a storage facility. 


\section{Chapter 2}

The model boundaries of a potato bulk facility can be defined in several ways. The configuration introduced in Figure 2.1 is one option; it contains the five physical domains (Figure 2.2) with their boundaries, and gives a complete overview of a bulk storage facility. In Figure 2.1, $\Omega_{p}$ represents the product and the direct domain (porous medium); $\Omega_{a}$ and $\Omega_{a 1}$ stand for the indirect domain (air) and $\Omega_{e}$ denotes the environment. The domain boundaries require boundary conditions to be defined for a solution of the complete simulation problem.

The process variables in a storage facility are typically dictated by flow and transport phenomena. Transport phenomena, however, can be defined on the micro and the macro level. On the macroscopic level, there is interaction between air and product (temperature and moisture). On the microscopic level, biological processes take place in the product, under the influence of the macroscopic conditions. The current storage facilities are climate-controlled. Therefore, only temperature, moisture content and sometimes gas concentrations $\left(\mathrm{CO}_{2}\right)$ are monitored during the storage periods and the mainstream research focuses on temperature and moisture content. This results in models that describe physical transport phenomena using the laws of conservation for mass and energy. For the simulation of full-scale facilities also the flow properties are taken into account, using the law of conservation of momentum and the continuity equation.

Three basic model structures exist for the description of the dynamic behaviour of physical systems, namely data-based mechanistic, lumped parameter and distributed parameter. Each of these model structures describes the behaviour of the process variables in the physical system. For instance, in a data-based mechanistic (DBM) model, transfer functions describe the relationships between inputs and outputs of the system. A lumped parameter model uses one or more multi-zone ordinary differential equations to represent the physical behaviour over time. A distributed parameter model characterises the physical behaviour of the system with a set of partial differential equations over time and in one, two or three spatial dimensions.

For system theoretic process analysis and controller synthesis, the state space framework is very convenient. A general state space model is given by (see for instance Friedland, $2005)$ :

$$
\begin{array}{r}
\dot{\boldsymbol{X}}(t):=\frac{\partial \boldsymbol{X}(t)}{\partial t}=f(t, \boldsymbol{X}, \boldsymbol{u}, \boldsymbol{d}) \\
\boldsymbol{Y}(t)=g(t, \boldsymbol{X}, \boldsymbol{u}, \boldsymbol{d})
\end{array}
$$

Here, $\dot{\boldsymbol{X}}$ is the time derivative of the state vector $\boldsymbol{X}$ containing the process variables and $\boldsymbol{Y}$ is the output vector. For distributed parameter models, this notation is extended to: 


$$
\begin{aligned}
\frac{\partial \boldsymbol{X}}{\partial t} & =f\left(t, \boldsymbol{X}, \boldsymbol{n}, \frac{\partial \boldsymbol{X}}{\partial \boldsymbol{n}}, \frac{\partial^{2} \boldsymbol{X}}{\partial \boldsymbol{n}^{2}}, \boldsymbol{u}, \boldsymbol{d}\right) \\
\boldsymbol{Y} & =g\left(t, \boldsymbol{X}, \boldsymbol{n}, \frac{\partial \boldsymbol{X}}{\partial \boldsymbol{n}}, \frac{\partial^{2} \boldsymbol{X}}{\partial \boldsymbol{n}^{2}}, \boldsymbol{u}\right)
\end{aligned}
$$

In this equation, $\boldsymbol{X}:=\left[X_{1}, X_{2}, \ldots X_{l}\right]^{T}$ the states of the system, $\boldsymbol{Y}:=\left[Y_{1}, Y_{2}, \ldots Y_{g}\right]^{T}$ the outputs of the system, $\boldsymbol{n}:=\left[n_{1}, n_{2}, n_{3}\right]^{T}$ the Cartesian coordinate system, $\boldsymbol{u}:=$ $\left[u_{1}, u_{2}, \ldots u_{m}\right]^{T}$ the control inputs and $\boldsymbol{d}:=\left[d_{1}, d_{2}, \ldots d_{h}\right]^{T}$ the disturbances acting on the system.

For food storage systems, we distinguish states related to transport phenomena $\left(\boldsymbol{X}_{t p}\right)$ and states related to flow $\left(\boldsymbol{X}_{f}\right)$. Tables $2.1,2.2$ and 2.3 present the most commonly used states for potato storage models. This results, for instance, in two state vectors $\boldsymbol{X}_{t p}=\left[T_{p} T_{a} M_{p} M_{a} C O_{2} C S t S H\right]^{T}$, with potato temperature $T_{p}$, air temperature $T_{a}$, moisture content in the potato $M_{p}$, moisture content in the air $M_{a}, \mathrm{CO}_{2}$ concentration $\mathrm{CO}_{2}$, colour $C$, starch concentration $S t$, sugar concentration $S$ and quality aspects $H$ like hardness and stiffness, and $\boldsymbol{X}_{f}=\left[\begin{array}{llll}v_{x} & v_{y} & v_{z} P\end{array}\right]^{T}$, with $v_{n}$ the velocities in $x, y$ and $z$ direction and $P$ the pressure. The velocity and pressure follow from the Navier-Stokes or Darcy's equations and will be explained later on. The vector of the control input of the system can be defined as $\boldsymbol{u}=\left[\theta \phi \omega \psi \chi T_{i} M_{i}\right]^{T}$ with valve position $\theta$, air flow $\phi$, cooling $\omega$, heating $\psi$, humidifier $\chi$, preconditioned incoming temperature $T_{i}$ and moisture content $M_{i}$. For noise-free simulation, the disturbances acting on the system are neglected, but for controller design, for instance, $\boldsymbol{d}=\left[\begin{array}{ll}T_{e n} & M_{e n}\end{array}\right]^{T}$ with $T_{e n}$ the temperature and $M_{e n}$ moisture content of the environment.

\subsection{Overview of applications and model struc- tures}

Table 2.1 provides an overview of models for potato storage. Use of different boundary conditions results in models with different states. In the classification of Table 2.1, several models (e.g. 1-D: Ofoli and Burgess, 1986; Van 't Ooster, 1999, 3-D: Xu and Burfoot, 1999; Chourasia and Goswami, 2007; Kondrashov, 2007) seem similar; Tables 2.2 and 2.3 offer a further specification.

Models used for control and quality applications generally only take temperature and moisture content into account. The 3-D models used for simulation also account for flow properties. Only four models include micro-scale processes. So far, only the potato and direct domain (Figure 2.2) have been modelled. In the next subsections, we will present and evaluate the potato storage models in more detail. 


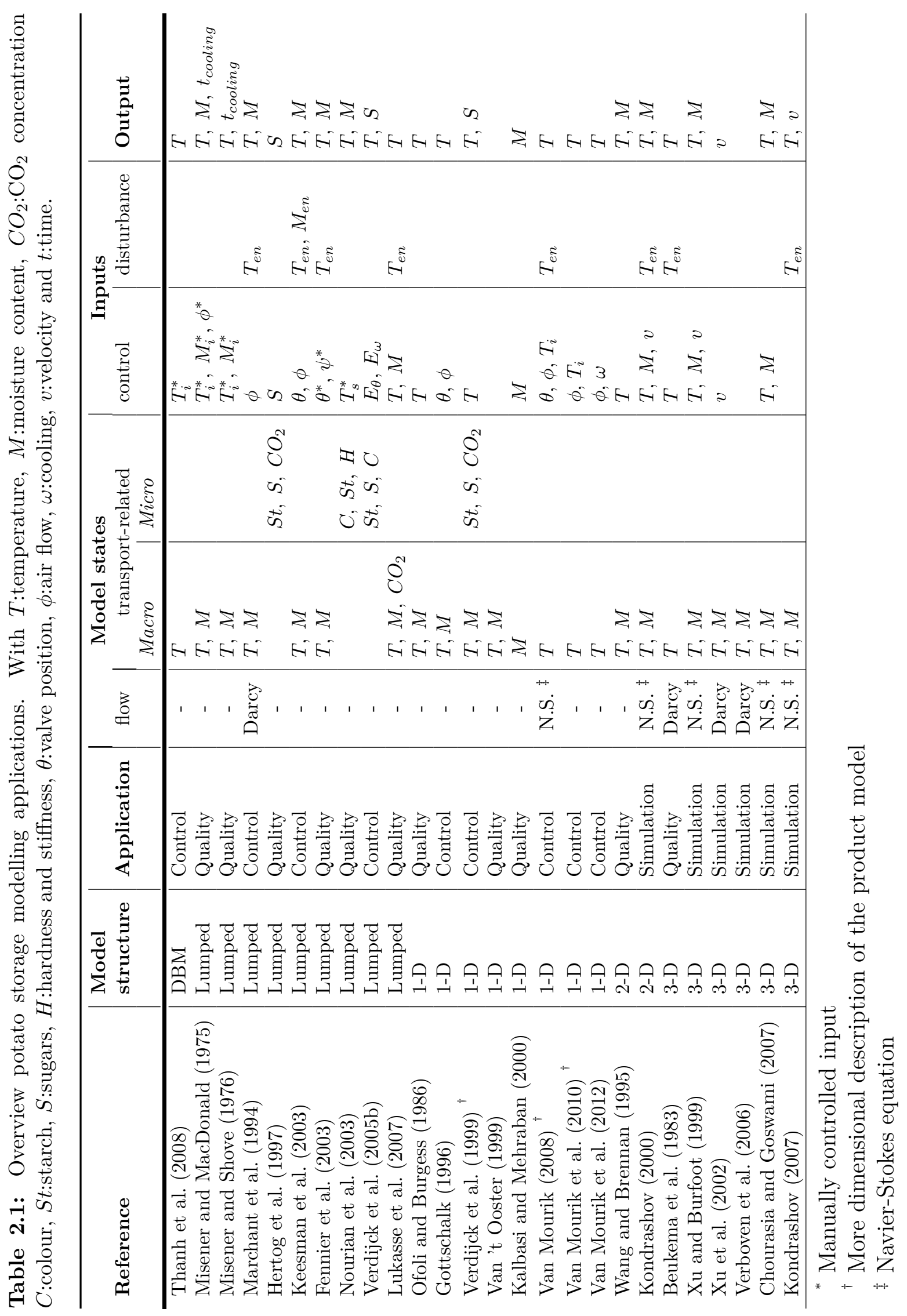




\subsubsection{DBM models}

A DBM model, generally in the form of a transfer function, describes the linear and timeinvariant behaviour of a physical system on the basis of observed time series of the real system. Hence, the DBM method starts from identification and subsequently tries to find out if the transfer function allows a reasonable physical interpretation. Therefore, the model is only considered valid if the data is explained well and the transfer function has some relevance to the physical system.

DBM models for agricultural storage were introduced and applied by Price et al. (1999) and Desta et al. (2004). Thanh et al. (2008) defined a model describing the energy flow between two well-mixed zones and the biological material (boxes of potatoes). This resulted in a third-order transfer function that describes the input-output relationship of the temperature in a three-dimensional ventilated room filled with biological material. A model with a low standard error $(\mathrm{SE}<0.01)$ was obtained and used for adaptive control of the temperature distribution. This type of modelling is not often used, because storage systems also allow a physically based modelling approach, making use of the laws of conservation and thus having a wider range of application than the DBM approach.

\subsubsection{Lumped parameter models: macro and micro scale}

A lumped parameter model contains a set of ordinary differential equations, where each ordinary differential equation corresponds to a mass, energy or momentum balance of the physical system. For the storage models, each ordinary differential equation describes the dynamics of one state (for instance, potato temperature) as a function of time $(t)$. Therefore, no spatial distribution in the facility is described. Implicitly, a homogeneous air distribution and a predefined air velocity are considered, and thus no flow model is needed. To gain some insight in the vertical distribution of, for instance, temperature, a multi-zonal decomposition of the bulk domain can be used. In that case, the bulk is split into several horizontal layers (see Figure 2.3) to describe the vertical potato temperature gradients. Lukasse et al. (2007) and Marchant et al. (1994) used such a multi-zonal decomposition.

Marchant et al. (1994) combined a multi-zonal model with natural convection. Therefore, a flow model based on Darcy's law is included in the model as proposed by Beukema et al. (1983), and explained in subsection 4.3.

Model states, flow and reactions: macro-scale

As already mentioned, the laws of conservation for energy and mass can be used to describe the dynamics of the temperature and moisture content. A general expression for a control 


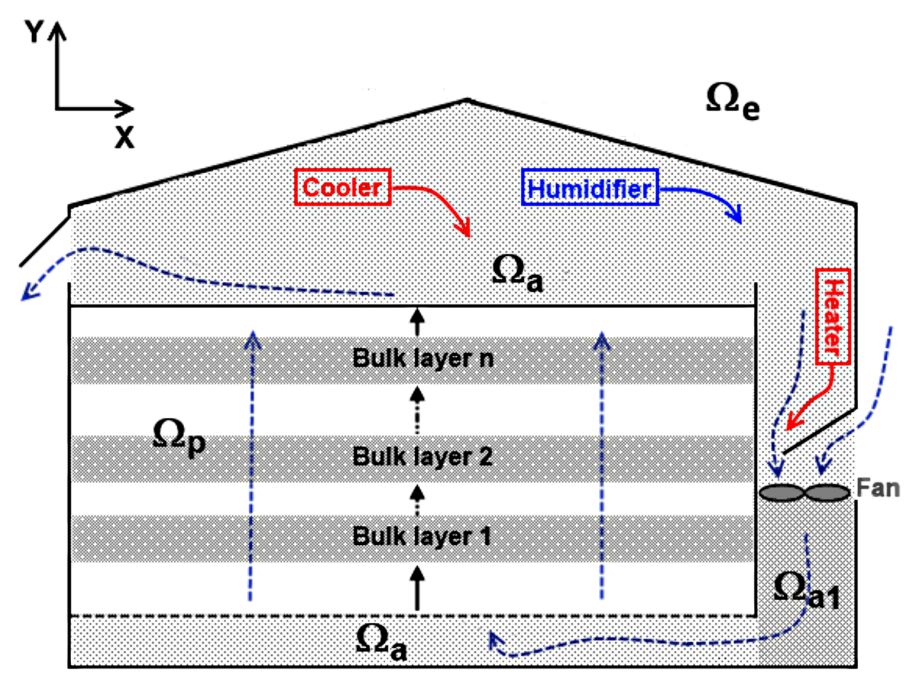

Figure 2.3: Zonal decomposition of a potato store for modelling purposes.

volume in a lumped model with a constant flow rate $\left(\phi_{v}\right)$ can be stated as:

$$
V \frac{d X}{d t}=\phi_{v} X_{i n}-\phi_{v} X+V r_{X}
$$

Here, $V$ represents the volume of the compartment $\left[\mathrm{m}^{3}\right]$. The constant volume flux of $X$ in $\mathrm{kg} / \mathrm{m}^{3}$ (mass) or $\mathrm{J} / \mathrm{m}^{3}$ (energy) is denoted by $\phi_{v}\left[\mathrm{~m}^{3} / \mathrm{s}\right]$. The volumetric production $r_{X}$ in $\mathrm{kg} /\left(\mathrm{m}^{3} \mathrm{~s}\right)$ (mass) or $\mathrm{J} /\left(\mathrm{m}^{3} \mathrm{~s}\right)$ (energy) represents the effect of reaction processes. All of the lumped models contain temperature and moisture content as states, except the three models that use a micro-scale model approach (Hertog et al., 1997; Nourian et al., 2003; Verdijck et al., 2005b). Although, six of the models use the temperature and moisture balances, they differ in the modelling of the transport phenomena and production terms $\left(r_{X}\right)$. Some researchers modelled only the product (potato) without the indirect domain (air); others included the indirect domain $\left(\Omega_{a}\right)$. Table 2.2 gives an overview of the five macro-scale modelling approaches.

Table 2.2 lists lumped parameter models and makes a distinction between heat and mass transfer, evaporation and respiration. Evaporation is also a type of mass transport, but has a different thermodynamic and mathematical interpretation in these models. The transfer phenomena and their corresponding fluxes are given by the following equations: 


$$
\begin{aligned}
\text { Heat transfer: } & \dot{Q}=h_{c} A\left(T_{a}-T_{p}\right) \\
\text { Mass transfer: } & \dot{M}=k_{v} A\left(M_{a}-M_{p}\right) \\
\text { Latent heat (evap.): } & \dot{T}_{e v}=h_{f g} k_{v} A\left(M_{a}-M_{p}\right) \\
\text { Evaporation mass: } & \dot{M}_{e v}=K_{e v a p} \\
\text { Respiration heat: } & \dot{T}_{r}=p_{r 1}-p_{r 2} T_{p}+p_{r 3} T_{p}^{2} \\
\text { Respiration mass: } & \dot{M}_{r}=E_{r} T_{r}
\end{aligned}
$$

Here, the dot represents the flux related to the state.

Table 2.2: Overview of lumped parameter models

\begin{tabular}{l|l|c|c|c|c}
\hline Reference & State & \multicolumn{2}{|c|}{$\begin{array}{c}\text { Transport } \\
\text { heat }\end{array}$} & \multicolumn{2}{|c|}{$\begin{array}{c}\text { Production } \\
\text { evap. }\end{array}$} \\
& & resp. \\
\hline Misener and Shove (1976) & $T_{a}$ & $\sqrt{ }$ & & & \\
& $T_{p}$ & $\sqrt{ }$ & & $\sqrt{ }$ & $\sqrt{ }$ \\
& $M_{p}$ & & & $\sqrt{ }$ & \\
\hline Marchant et al. (1994) & $E_{a}$ & $\sqrt{ }$ & & & \\
& $E_{p}$ & $\sqrt{ }$ & & & $\sqrt{ }$ \\
& $M_{p}$ & & & $\sqrt{ }$ & \\
\hline Keesman et al. (2003) & $T_{a}$ & $\sqrt{ }$ & & & \\
& $M_{a}$ & & $\sqrt{ }$ & & \\
& $T_{p}$ & $\sqrt{ }$ & & $\sqrt{ }$ & $\sqrt{ }$ \\
\hline Fennier et al. (2003) & $T_{p}$ & $\sqrt{ }$ & & $\sqrt{ }$ & \\
& $M_{p}$ & & & $\sqrt{ }$ & \\
\hline Lukasse et al. (2007) & $T_{a}$ & $\sqrt{ }$ & & & \\
& $M_{a}$ & & $\sqrt{ }$ & & \\
& $T_{p}$ & $\sqrt{ }$ & & $\sqrt{ }$ & $\sqrt{ }$ \\
& $M_{p}$ & & $\sqrt{ }$ & & $\sqrt{ }$ \\
& $C O_{2}$ & & & & $\sqrt{ }$ \\
\hline
\end{tabular}

Misener and Shove (1976) used an extended model to simulate potato quality based on the model defined by Misener and MacDonald (1975); for that reason, the latter is not included in Table 2. Table 2.2 shows that Misener and Shove (1976) modelled the temperature of both air and potato; they included a moisture content model for the potato instead of for the air. The model was used to perform scenario studies.

Marchant et al. (1994) defined a model with three states. They used energy balances instead of temperature balances for the potatoes and air, and added a simple moisture content model. The model was included in a control system using various artificial intelligence techniques.

Keesman et al. (2003) defined a model that describes the temperature and moisture content of the air and the temperature of the potato. A model reduction step, using singular perturbation theory, was accomplished as well as the design of a receding horizon 


\section{Chapter 2}

optimal controller (RHOC), using the reduced-order model.

Fennier et al. (2003) investigated the respiration rate of the potato. A mathematical model was defined for potato temperature and moisture content. The relationship with respect to $\mathrm{CO}_{2}$ concentration was investigated as well, but not included in the model.

Lukasse et al. (2007) developed the most complete lumped parameter model so far. The temperature and moisture content of both potato and air were modelled as well as the dynamics of the $\mathrm{CO}_{2}$ concentration. The model was calibrated and the effect of one-zone and multi-zonal ordinary differential equations was investigated with respect to potato temperature.

The lumped parameter models found in the literature mainly include the temperature of potatoes and air. The moisture content is generally not defined for both domains. Misener and Shove (1976), Marchant et al. (1994) and Fennier et al. (2003) defined relatively simple moisture content models, based on respiration rates or the change in the humidity ratio between air entering and air leaving the potato pile (Fennier et al., 2003).

\section{Model states and reactions: micro-scale}

Only four articles presented a model describing potato quality on the micro level. Verdijck et al. (1999) and Verdijck et al. (2005b) used the micro scale model of Hertog et al. (1997), which describes the change in sugar content in five chemical reaction steps in three biological processes: cold-induced sweetening $\left(\operatorname{En}_{\text {cold }}\right)$, senescent sweetening $\left(\operatorname{En}_{\text {sene }}\right)$ and respiration. If a constant starch concentration is assumed over the storage period, the conversion of starch into sugar follows from:

$$
\begin{aligned}
\frac{d E n_{\text {cold }}}{d t} & =-k_{\text {dena }} E n_{\text {cold }} \\
\frac{d E n_{\text {sene }}}{d t} & =k_{\text {form }} E n_{\text {sene }} \\
\frac{d S}{d t} & =k_{\text {cold }} E n_{\text {cold }} S t+k_{\text {sene }} E n_{\text {sene }} S t-k_{r} S O_{2}
\end{aligned}
$$

Here, En represents different enzymes, $S$ is the sugar content, $S t$ the starch level and $k_{i}$ the reaction rate. The reaction rates are assumed to be only temperature-dependent and can be modelled according to the Arrhenius law, i.e.

$$
k_{i}=k_{r e f} \cdot e^{\frac{E_{i}}{R} \cdot\left(\frac{1}{T_{r e f}}-\frac{1}{T}\right)}
$$

In this equation, $R$ is the gas constant, $E_{i}$ the activation energy and $k_{r e f}$ the reaction rate constant at the reference temperature $T_{r e f}$. A similar quality model for a wide range of vegetables, though not potatoes, was done by Tijskens and Polderdijk (1996). Nourian 
et al. (2003) proposed the following relationship between the starch concentration and sugar content:

$$
S t[\%]=0.9 S[\%]
$$

Nourian et al. (2003) also investigated the frying colour of the potato on the basis of experiments, but presented no dynamical model. For sprouting, they proposed the following temperature-based model:

$$
\ln \left(\frac{133}{S P}\right)=-0.0687 T
$$

$S P$ represents the time at which sprouting starts, and $T$ the storage temperature. For frying and chips potatoes, the eventual frying colour is considered a quality indicator, as it plays an important role in customer satisfaction. Verdijck et al. (2005b) presented a frying colour index. They defined the colour index $(C)$ as:

$$
C=\left(\frac{S}{0.02}\right)^{0.49}
$$

A colour index of $C<4$ is acceptable. Verdijck et al. (2005b) came up with a modelpredictive controller, that keeps the measured climate temperature between certain bounds on basis of only sugar content and energy usage by the ventilation system.

\subsubsection{Distributed parameter models: macro-scale}

A spatially distributed parameter model contains one or more partial differential equations. Like for ordinary differential equations, each partial differential equation corresponds to a state of the physical system. Each partial differential equation has at least two independent variables and typically contains derivatives with respect to time and space. In this way, a 1-D, 2-D or 3-D distributed model can be defined, describing the spatial distribution over the whole facility. The 1-D models are primarily used for quality and control applications, whereas the 2-D and 3-D models are primarily used for CFD simulation.

Especially models used for CFD simulation include a description of the flow. In the absence of a flow model, a constant velocity in the bulk is assumed. For simulating fluid flow, a mathematical model that describes the flow over a pre-specified domain is needed. In general, these physics are represented by continuity and momentum equations. In all models, the bulk (the potato and direct domain) is taken as one domain, generally known as the porous medium. Typically, flow through porous media is modelled by either (i) Navier-Stokes equations (2.10) or (ii) Darcy's law (2.12).

The Navier-Stokes equations contain a special form of the momentum balances in $\left[\mathrm{N} / \mathrm{m}^{3}\right]$ 


\section{Chapter 2}

and include the continuity equation in $\left[\mathrm{kg} /\left(\mathrm{m}^{3} \mathrm{~s}\right)\right]$ :

$$
\begin{aligned}
\rho\left(\frac{\partial \boldsymbol{v}}{\partial t}+\boldsymbol{v} \cdot \nabla \boldsymbol{v}\right) & =-\nabla P+\nabla \cdot \boldsymbol{\tau}-\rho \boldsymbol{g}+\boldsymbol{F} \\
\frac{\partial \rho}{\partial t}+\nabla(\rho \boldsymbol{v}) & =Z
\end{aligned}
$$

For the 3-D case, $\boldsymbol{v}=\left[\begin{array}{lll}v_{x} & v_{y} & v_{z}\end{array}\right]^{T}$ is the velocity vector, $\rho$ is the density, $\nabla=\left[\frac{\partial}{\partial x} \frac{\partial}{\partial y} \frac{\partial}{\partial z}\right]^{T}$ the vector differential operator nabla, $P$ the pressure, $\boldsymbol{\tau}=\left[\begin{array}{ll}\tau_{x} & \tau_{y} \\ \tau_{z}\end{array}\right]^{T}$ the deviatoric stress component of the Cauchy stress, $\boldsymbol{g}=\left[\begin{array}{lll}0 & g & 0\end{array}\right]^{T}$ the gravity vector, if $y$ is in vertical direction, $F$ a vector with external body forces, and $Z$ is the (de)generation of the quantity $\rho$. The external body forces $(\boldsymbol{F})$ can be defined as forces acting on a volume, for instance the aerodynamic resistance in the porous medium, which should be taken into account. For porous media, also the Forchheimer resistance model can be used, which combines the Darcy equation with a term that covers the inertial forces due to kinetic energy. In the Forchheimer resistance model, the external body force $F_{n}$ with $n=\left[\begin{array}{ll}x y & z\end{array}\right]^{T}$ is given by:

$$
F_{n}=\underbrace{-\frac{\mu}{\alpha} v_{n}}_{\text {Darcy coefficient }} \underbrace{-C_{2} \frac{1}{2} \rho_{a} v v_{n}}_{\text {inertial term }}
$$

$\mu$ represents the dynamic viscosity, $\alpha$ is the permeability, and $C_{2}$ is an internal resistance factor, which can be found empirically. A general approximation for spherical packed beds was given by Ergun (1952) and used by Xu and Burfoot (1999), Chourasia and Goswami (2007) and Van Mourik (2008). Other approximations are possible as well, such as the Kozeny-Carman equation (Kondrashov, 2007).

Darcy's law is a simplification of the Navier-Stokes equations, achieved by making use of a homogenisation step (see for instance, Whitaker, 1986, Allaire, 1992 or Hornung, 1997). By this simplification, the use of Darcy's law significantly reduces the required computational effort relative to the use of the Navier-Stokes equations. Roughly speaking, by linearising the steady state Navier-Stokes equations and neglecting the inertial forces $\left(\rho\left(\frac{\partial v}{\partial t}+\boldsymbol{v} \nabla \boldsymbol{v}\right) \approx 0\right)$ the Stokes equation can be obtained, i.e. by assuming a stationary and incompressible flow. Then, assuming the viscous force is linear, we end up with Darcy's law, which yields the following simplified relationship between the pressure gradient and the velocity:

$$
\nabla P=-\frac{\mu}{\alpha} \boldsymbol{v}
$$

The laws of conservation of mass and energy, used to describe the temperature and moisture content for constant velocity $v$, can be generally stated as:

$$
\left(\frac{\partial X}{\partial t}+\boldsymbol{v} \cdot \nabla X\right)=\boldsymbol{c} \Delta X+r_{X}
$$


Here, $\Delta:=\nabla^{2}=\left[\frac{\partial^{2}}{\partial x^{2}} \frac{\partial^{2}}{\partial y^{2}} \frac{\partial^{2}}{\partial z^{2}}\right]^{T}, X$ a specific state and $r_{X}$ the production term.

Six of the distributed parameter models presented in Table 2.1 define only one process variable, namely temperature (Van Mourik, 2008; Van Mourik et al., 2010; Van Mourik et al., 2012; Royer and Flores (1994); Beukema et al., 1983) or moisture content (Kalbasi and Mehraban, 2000). The other models define a temperature and moisture content state. Verdijck et al. (1999) included a micro-scale model, proposed by Hertog et al. (1997). The production terms in the temperature and moisture content balance differ in each model; see Table 2.3 for an overview. In Table 2.3 the same interpretation of the transport and production terms as in Eq. (2.4) is used.

Notice that not all studies listed in Table 2.1 that use a 1-D, 2-D or 3-D model are included in Table 2.3. For instance, Verboven et al. (2006) basically presented an overview of onephase and two-phase models, and is therefore not included in Table 2.3. Van Mourik et al. (2010) and Van Mourik et al. (2012) used the same balances as used by Van Mourik (2008). Kalbasi and Mehraban (2000) used the same states and model as Wang and Brennan (1995) and added some tests on the surface water vapour flux during the drying of potatoes. The work of Xu et al. (2002) is not included in Table 2.3 because these authors used the same model as Xu and Burfoot (1999) for the heat and moisture transfer; only the flow model is different.

The 1-D models used for product quality and control contain the most generally applicable and complete energy and mass balances, but do not use a momentum balance to describe the flow. Ofoli and Burgess (1986), Gottschalk (1996) and Verdijck et al. (1999) used all temperature and moisture content states. Ofoli and Burgess (1986) proposed mathematical models for potato storage, taking a thermodynamic approach, and testing the models for a bed of potatoes. Gottschalk (1996) described a mathematical model for a potato pile, and used it to design a fuzzy controller. The model of Verdijck et al. (1999) contains sub-models for the macro and micro scale. It was developed with the intention to use it for a model-based process controller.

The other three 1-D models are less complete, probably because they were developed for a specific application. For instance, Van 't Ooster (1999) defined a model by making use of a finite element method, which can be seen as the core of a model description of a potato storage. Van Mourik (2008) defined a basis for a bulk model and used it to apply several control techniques, such as physical parameter estimation (Van Mourik et al., 2012) and feedback control design (Van Mourik et al., 2010).

The 2-D model of Wang and Brennan (1995) was used to investigate the quality of the potato during drying, and therefore included the states relevant for potato quality. Kondrashov (2000) defined a potato storage model of coupled heat and moisture exchange for the heat and moisture transfer, which is used for CFD simulation of a potato storage facility. 
Table 2.3: Overview of distributed parameter models overview

\begin{tabular}{|c|c|c|c|c|c|c|}
\hline \multirow[t]{2}{*}{ Reference } & \multirow[t]{2}{*}{ Dimension } & \multirow{2}{*}{$\begin{array}{l}\text { State } \\
\text { heat }\end{array}$} & \multicolumn{2}{|c|}{ Transport } & \multicolumn{2}{|c|}{ Production } \\
\hline & & & mass & evap. & resp. & \\
\hline Ofoli and Burgess (1986) & $1-\mathrm{D}$ & $\begin{array}{l}T_{a} \\
M_{a} \\
T_{p} \\
M_{p} \\
\end{array}$ & $\begin{array}{l}\sqrt{ } \\
\sqrt{ }\end{array}$ & $\sqrt{ }$ & $\begin{array}{l}\sqrt{ } \\
\sqrt{ } \\
\sqrt{ }\end{array}$ & $\sqrt{ }$ \\
\hline Gottschalk (1996) & $1-\mathrm{D}$ & $\begin{array}{l}T_{a} \\
M_{a} \\
T_{p} \\
M_{p}\end{array}$ & $\begin{array}{l}\sqrt{ } \\
\sqrt{ }\end{array}$ & $\begin{array}{l}\sqrt{ } \\
\sqrt{ }\end{array}$ & $\begin{array}{l}\sqrt{ } \\
\sqrt{ }\end{array}$ & $\sqrt{ }$ \\
\hline Verdijck et al. (1999) & $1-\mathrm{D}$ & $\begin{array}{l}T_{a} \\
M_{a} \\
T_{p} \\
M_{p}\end{array}$ & $\begin{array}{l}\sqrt{ } \\
\sqrt{ }\end{array}$ & & $\begin{array}{l}\sqrt{ } \\
\sqrt{ } \\
\sqrt{ } \\
\sqrt{ }\end{array}$ & $\begin{array}{l}\sqrt{ } \\
\sqrt{ }\end{array}$ \\
\hline Van ’t Ooster (1999) & $1-\mathrm{D}$ & $\begin{array}{l}T_{a} \\
M_{a} \\
T_{p}\end{array}$ & $\begin{array}{l}\sqrt{ } \\
\sqrt{ }\end{array}$ & $\sqrt{ }$ & $\begin{array}{l}\sqrt{ } \\
\sqrt{ }\end{array}$ & $\sqrt{ }$ \\
\hline Van Mourik (2008) & $1-\mathrm{D}$ & $\begin{array}{l}T_{a} \\
T_{p}\end{array}$ & $\begin{array}{l}\sqrt{ } \\
\sqrt{ }\end{array}$ & & & \\
\hline Van Mourik et al. (2012) & $1-\mathrm{D}$ & $\begin{array}{l}T_{a} \\
T_{p}\end{array}$ & $\begin{array}{l}\sqrt{ } \\
\sqrt{ }\end{array}$ & & & \\
\hline Wang and Brennan (1995) & $2-\mathrm{D}$ & $\begin{array}{l}T_{p} \\
M_{p}\end{array}$ & $\sqrt{ }$ & & $\begin{array}{l}\sqrt{ } \\
\sqrt{ }\end{array}$ & \\
\hline Kondrashov (2000) & $2-\mathrm{D}$ & $\begin{array}{l}T_{a} \\
M_{a} \\
T_{p}\end{array}$ & $\begin{array}{l}\sqrt{ } \\
\sqrt{ }\end{array}$ & $\sqrt{ }$ & $\sqrt{ }$ & $\sqrt{ }$ \\
\hline Beukema et al. (1983) & $3 \mathrm{D}$ & $T_{p}$ & $\sqrt{ }$ & & $\sqrt{ }$ & \\
\hline $\mathrm{Xu}$ and Burfoot (1999) & $3-\mathrm{D}$ & $\begin{array}{l}E_{a} \\
M_{a} \\
E_{p} \\
M_{p}\end{array}$ & $\sqrt{ }$ & $\begin{array}{l}\sqrt{ } \\
\sqrt{ }\end{array}$ & $\sqrt{ }$ & $\sqrt{ }$ \\
\hline Chourasia and Goswami (2007) & $3-\mathrm{D}$ & $\begin{array}{l}E_{a p} \\
M_{a}\end{array}$ & & $\sqrt{ }$ & $\sqrt{ }$ & $\sqrt{ }$ \\
\hline Kondrashov (2007) & $3-\mathrm{D}$ & $\begin{array}{l}T_{a} \\
M_{a} \\
T_{p}\end{array}$ & $\begin{array}{l}\sqrt{ } \\
\sqrt{ }\end{array}$ & $\sqrt{ }$ & $\sqrt{ }$ & $\sqrt{ }$ \\
\hline
\end{tabular}

Beukema et al. (1983) introduced a 3-D model that was not intended for simulation, but for quality purposes. Experiments were performed to investigate the relationship between conduction and natural convection while taking into account the internal heat generation of the produce.

The other three models were developed for CFD simulations. Xu and Burfoot (1999) provided a complete bulk model, using Navier-Stokes (continuity and momentum) and 
mass and energy equations. This model predicts air flows, temperature and moisture changes of the air in the bulk and of the potato. A small-scale experiment was set up for testing. Xu et al. (2002) applied the same mass and energy balances, but used only a Darcy model to describe the flow. Aim of this study was to investigate the air distribution of a specific storage building. Chourasia and Goswami (2007) used a single-phase model to describe the temperature distribution. A CFD-based scenario study was performed to explore the transport phenomena in a sack of potatoes. Kondrashov (2007) developed a model that describes the heat and mass transfer in an outdoor potato pile, with the aid of CFD calculations.

Notice from Table 2.3 that the models used for quality and control applications contain the greatest number of production terms (Ofoli and Burgess, 1986; Gottschalk, 1996; Verdijck et al., 1999). For more advanced controller design or for specific modelling applications (Van 't Ooster, 1999), simplifications were made concerning the modelled balances and production terms (Van Mourik, 2008; Van Mourik et al., 2010; Van Mourik et al., 2012; Wang and Brennan, 1995; Beukema et al., 1983).

The models used for CFD simulation include simplifying assumptions related to the production terms and states. All of the CFD models covered by this review describe the transport phenomena in the air as well as in the potato bulk, thus in the product and direct domain. From a modelling point of view, this can be seen as one domain, namely the porous medium. This means that the flow pattern in the bulk is influenced by the following factors:

- Geometry of the facility;

- Resistance that follows from Darcy's law or Forchheimer's resistance model;

- Fluxes at the boundaries.

Figure 2.4 shows this one-domain simulation.

Another approach frequently used for CFD simulation of food storage is to take the air and product domain of the bulk separately. As Figure 2.5 shows, the actual products are drawn in this case. The mathematical relationships are different than when air and product domain are seen as one domain; the simulation has to take the interaction in terms of mass and energy at the boundary between product and air into account. This way of modelling and simulation is common in several post-harvest food applications (such as Zou et al., 2006; Ferrua and Singh, 2009; Tutar et al., 2009; Page et al., 2009; Dehghannya et al., 2011; Delele et al., 2013).

In the past decade, several review articles reported on CFD usage in the post-harvest food sector. Verboven et al. (2006) described the various mathematical approaches, including some CFD application, to model the flow, heat and mass balances in food bulks, packages and stacks. Norton and Sun (2006) reviewed studies that used CFD for simulating the flow 

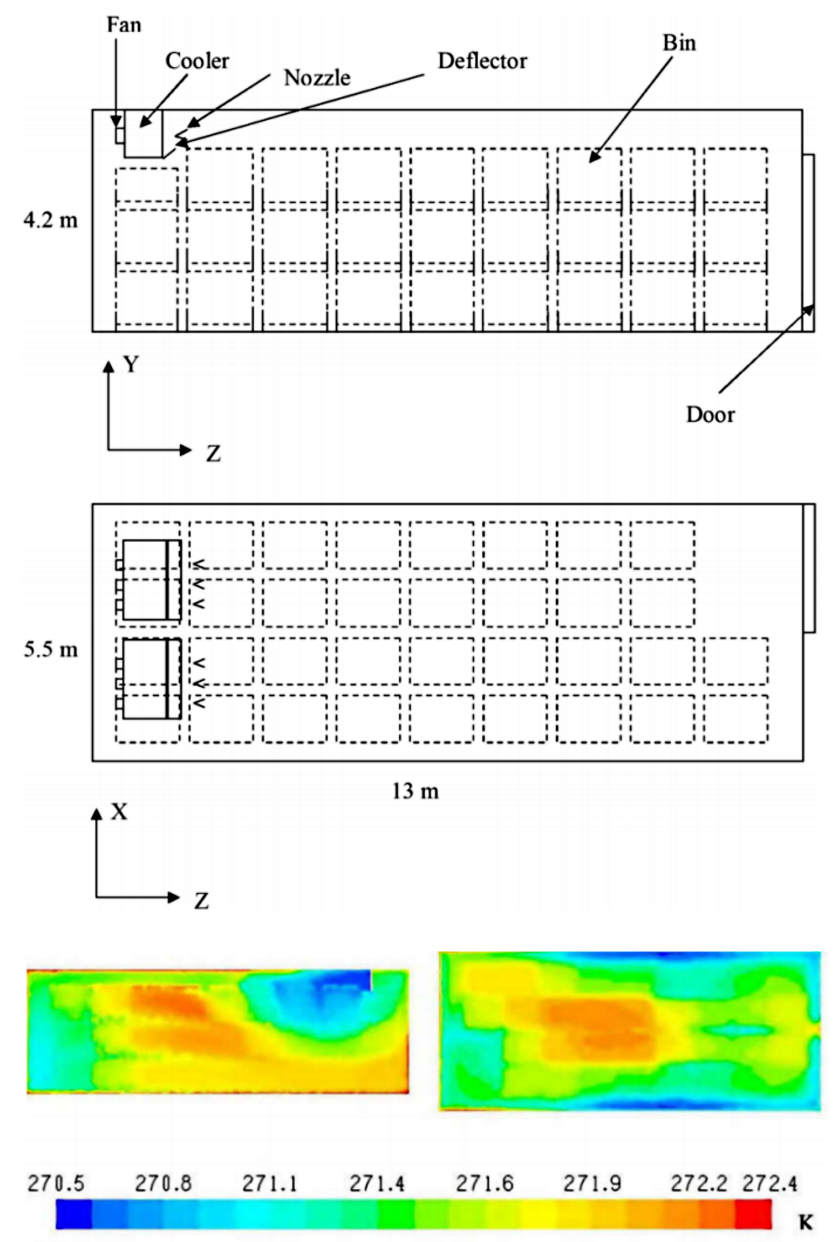

(a)
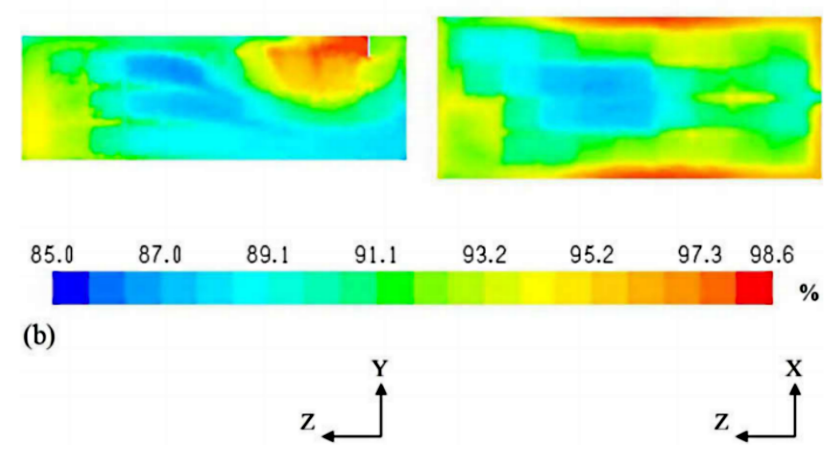

Figure 2.4: CFD simulation taking the porous medium (product and direct domain, inside the boxes) as one domain, including the indirect (air) domain. The top picture gives a visual 2-D representation of the box storage. The picture beneath gives the results of the stationary simulation for (a) the temperature and (b) the humidity (Delele et al., 2009a)

for ventilation, sterilisation and mixing of various types of food products. The authors pointed out that the accuracy of the models should always be validated against experimental data. With the progress in computing power, more precise CFD models will be able to provide more insight in fluid flow, heat and mass transfer phenomena. Smale et al. 


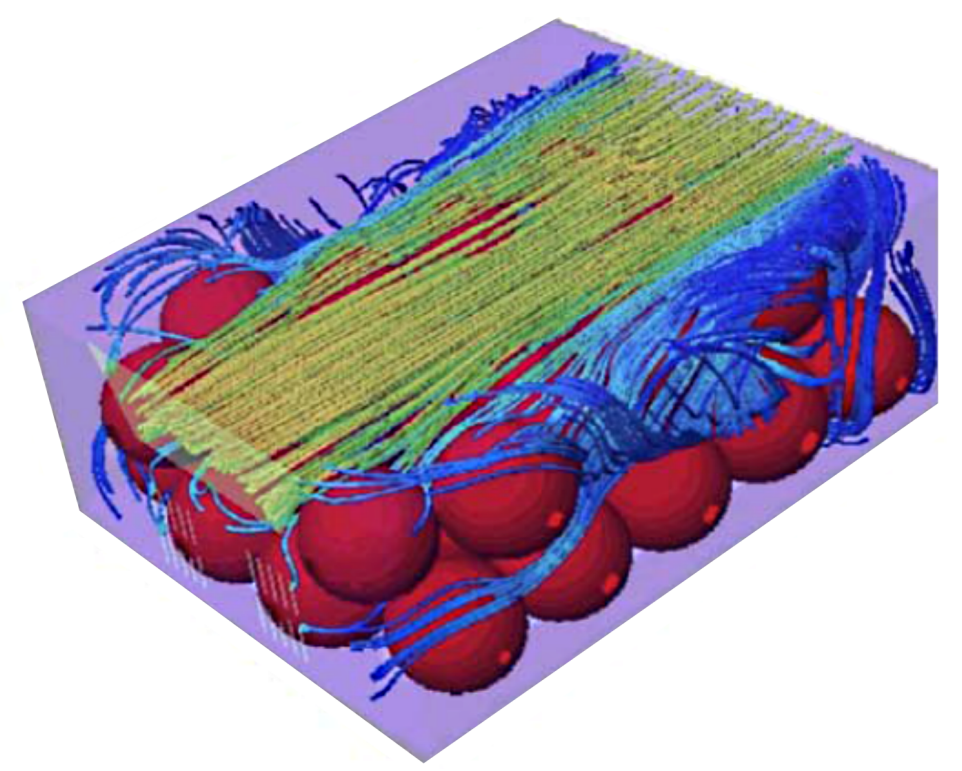

Figure 2.5: CFD simulation with the physical product drawn (Verboven et al., 2006)

(2006) listed numerical models describing airflow in refrigerated food applications, in particular refrigerated rooms. Delele et al. (2010) reviewed articles describing mathematical modelling of post-harvest refrigeration processes in the fruit sector. They concluded that if a food bulk is taken into account, the mainstream CFD models consider the product in boxes as a porous medium. To obtain more information about the local flow in the boxes, separate domains should be taken into consideration. Ambaw et al. (2013) found that the separate domains approach is an established simulation practice when they reviewed the usage of CFD to characterise and design post-harvest storage facilities. When the CFD calculations were based on a porous medium, the CFD simulations to predict flow were all stationary.

In these studies, three different CFD simulation approaches can be distinguished. One approach is to simulate only the air stream and neglect the porous medium (e.g. Amara et al., 2008; D'Agaro et al., 2006; Moureh et al., 2009; Xie et al., 2006). The second approach is to take the porous medium into account, and use separate domains (e.g. Alvarez and Flick, 2007; Delele et al., 2012; Zou et al., 2006; Martins et al., 2011). The third category approach is to model the porous medium as one domain (Delele et al., 2009a; Delele et al., 2009b; Rennie and Tavoularis, 2009a).

In summary, we can say that the mainstream CFD models are used for stationary simulations of the air flow in and around products, product packages and room ventilation (flow-along) ventilation systems. A new trend in CFD simulations is the inclusion of a more detailed description of the heat and mass transfer, but more advanced models that also look at microscopic levels of agromaterials in bulk storage facilities do not yet appear to exist. 


\section{Chapter 2}

\subsection{Conclusions and future challenges}

Our review of 26 studies found that various types of bulk storage models have been proposed so far (Table 2.1). All these models describe transport phenomena in product, direct, indirect and control domain (see Figure 2.2). Most of the models simulate a food bulk as one domain (taking the agro-materials and air as one domain) or as two separated domains (drawing the actual food geometry). Some of the models also take the indirect domain (air) or the surrounding environment into account. Only a few include a cooling and ventilation unit (see e.g. Van Mourik et al., 2012; Verdijck et al., 2005b; Marchant et al., 1994).

A few of the models are data-based mechanistic models. The other models are mainly lumped, 1-D and 2-D distributed models that describe the behaviour of the (potato) bulk over a storage period. 3-D models were primarily used for CFD simulation, and in particular to solve problems of specific storage facilities. Some of these CFD studies combined the product and direct domain as one domain and coupled this combined domain to the indirect domain (see Delele et al., 2009a; Delele et al., 2009b; Rennie and Tavoularis, 2009b; Rennie and Tavoularis, 2009a).

Attention for the location and capacity of components within the indirect domain is absent in the existing models. Although sensor and actuator locations influence the observability and controllability of the climate, they were usually taken as a given in the studies that we looked at, and never thoroughly investigated. In practice, climate is controlled by rules of thumb and PID control, with as key factor the relationship between ventilation and heat transfer from potato to air. This lack of good insight hampers the optimal design of sensor and actuator networks.

An example of a quality aspect that has not yet been modelled is the presence of ethylene in the air. In the case of potatoes, the ethylene concentration influences the frying colour (Bethke, 2013) and sprouting (Kleinkopf et al., 2003). Control of the ethylene concentration can serve as a natural sprout inhibition method (Briddon, 2006).

We found no published studies that examined the relationships between several quality aspects and active control during a complete storage period sufficiently. Rastovski (1987) investigated the relationship between the air velocity created by ventilation and the moisture loss of a potato, but did not include the influence of increasing the ventilation duration at decreased air velocities. Verdijck et al. (2002) proposed a model for product quality in the processing of agro-materials for process control purposes, but did not design a matching controller. Verdijck et al. (2005a) used the model of Verdijck et al. (2002) to design and test an energy-efficient product controller on base of optimal climate conditions, but is not test it on (potatoes) storage facilities. Verdijck et al. (2005b) came up with a model-predictive controller, based on a lumped parameter model. The controller 
keeps the climate temperature between certain bounds on the basis of potato quality (only sugar content) and energy usage by the ventilation system. Another model-predictive controller, based on weather forecasts and with the aim to reduce the ventilation costs was proposed by Keesman et al. (2003).

This indicates that it is possible to use model-predictive control on the basis of actual product quality, but it is not yet implemented in industry. To achieve acceptance of model-based control strategies in post-harvest industries, more quality aspects should be included, such as ethylene and $\mathrm{CO}_{2}$ concentrations and aspects like sprouting.

In conclusion, what is still lacking is an overall investigation into the relationships between all aspects of product quality, energy efficiency and advanced control strategies. This is, however, needed to be able to arrive at sustainable storage strategies. In the case of potatoes, this would enable control of product quality on the basis of actual data (sugar, starch, $\mathrm{CO}_{2}$, ethylene, temperature and moisture content of potatoes) in combination with market prices and weather forecasts as well as factors like desired frying colour.

Modern simulation techniques, using for instance CFD techniques, could certainly provide the required insight. The basis of such a dynamic simulation would have to be a complete spatially distributed storage model, preferably 3-D. The spatially distributed models we encountered in the literature were all developed for specific storage configurations or for quality investigation(see Table 2.1), not for control applications, and therefore not generally applicable.

This new spatial distributed parameter model should include mass, energy and momentum balances of the air as well as mass and energy balances of the product, but also microscale processes, such as related to $\mathrm{CO}_{2}$, ethylene, sugar, starch and frying colour aspects in the case of potatoes. To obtain useful detailed insight in the relationship between product quality and ventilation strategies the indirect domain (air channels, ventilation vents, coolers, heaters and humidifiers) should all be incorporated. 


\section{Chapter 2}

\begin{tabular}{|c|c|c|c|c|c|}
\hline \multicolumn{6}{|c|}{ List of symbols } \\
\hline \multicolumn{3}{|c|}{ Variables } & \multicolumn{3}{|c|}{ Subscript } \\
\hline $\bar{A}$ & Area & {$\left[\mathrm{m}^{2}\right]$} & $a$ & Air & \\
\hline C & Colour & {$[-]$} & $a p$ & Bulk & \\
\hline$C_{2}$ & Resistance & {$[1 / \mathrm{m}]$} & cold & During cold storage & \\
\hline$c$ & Constant & {$[-]$} & cooling & Cooling & \\
\hline$d$ & Disturbance & {$[-]$} & dena & Denaturation & \\
\hline E & Energy & {$[\mathrm{J} / \mathrm{kg}]$} & $e$ & Evaporation & \\
\hline En & Enzyme & {$[-]$} & en & Environment & \\
\hline$E_{r}$ & $\begin{array}{l}\text { Respiration mass per en- } \\
\text { ergy }\end{array}$ & {$[\mathrm{kg} / \mathrm{kJ}]$} & $f$ & Flow & \\
\hline$F$ & Force & {$[\mathrm{N}]$} & form & Formation & \\
\hline$g$ & Gravity & {$\left[\mathrm{m} / \mathrm{s}^{2}\right]$} & $g$ & Number of & \\
\hline$H$ & $\begin{array}{l}\text { Quality (hardness, stiff- } \\
\text { ness) }\end{array}$ & {$[-]$} & $h$ & Number of & \\
\hline$h_{c}$ & Heat transfer coefficient & {$\left[\mathrm{W} / \mathrm{m}^{2} \mathrm{~K}\right]$} & $l$ & Number of & \\
\hline$h_{f g}$ & Enthalpy of evaporation & {$[\mathrm{J} / \mathrm{kg}]$} & $m$ & Number of & \\
\hline$K_{\text {evap }}$ & Evaporation coefficient & {$\left[\mathrm{kg} / \mathrm{m}^{3}\right]$} & $p$ & Product & \\
\hline$k$ & Reaction rate constant & {$[1 / \mathrm{s}]$} & $r$ & Respiration & \\
\hline$k_{v}$ & Mass transfer coefficient & {$\left[\mathrm{kg} / \mathrm{m}^{2} \mathrm{~s}\right]$} & ref & Reference & \\
\hline$M$ & Mass & {$[\mathrm{kg}]$} & sene & During senescence & \\
\hline$\dot{M}$ & Mass flux & {$[\mathrm{kg} / \mathrm{s}]$} & $t p$ & $\begin{array}{l}\text { Transport phenom- } \\
\text { ena }\end{array}$ & \\
\hline$n$ & Cartesian coordinates & {$[-]$} & $v$ & Volume & \\
\hline$P$ & Pressure & {$[\mathrm{Pa}]$} & & & \\
\hline$p_{r 1}$ & Respiration constant & {$[\mathrm{W} / \mathrm{kg}]$} & & & \\
\hline$p_{r 2}$ & Respiration constant & {$[\mathrm{W} / \mathrm{kg} \mathrm{K}]$} & Symbols & & \\
\hline$p_{r 3}$ & Respiration constant & {$\left[\mathrm{W} / \mathrm{kg} \mathrm{K}^{2}\right]$} & $\alpha$ & Permeability & {$\left[\mathrm{m}^{2}\right]$} \\
\hline$\dot{Q}$ & Energy flow & {$[\mathrm{W}]$} & $\theta$ & Valve position & {$[-]$} \\
\hline$R$ & Gas constant & {$[\mathrm{J} / \mathrm{mol} \mathrm{K}]$} & $\mu$ & Dynamic viscosity & {$\left[\begin{array}{ll}\mathrm{Pa} & \mathrm{s}\end{array}\right]$} \\
\hline$r_{X}$ & Production term & {$[-]$} & $\rho$ & Density & {$\left[\mathrm{kg} / \mathrm{m}^{3}\right]$} \\
\hline$S$ & Sugars & {$[-]$} & $\phi$ & Flow rate & {$\left[\mathrm{m}^{3} / \mathrm{s}\right]$} \\
\hline$S t$ & Starch & {$[-]$} & $\chi$ & Humidifying rate & {$[-]$} \\
\hline$S p$ & Sprouting time & {$[\mathrm{s}]$} & $\psi$ & Heating rate & {$[-]$} \\
\hline$T$ & Temperature & {$[\mathrm{K}]$} & $\omega$ & Cooling rate & {$[-]$} \\
\hline$\dot{T}$ & Heat flux & {$[\mathrm{K} / \mathrm{s}]$} & & & \\
\hline$t$ & Time & {$[\mathrm{s}]$} & & & \\
\hline$u$ & Control input & {$[-]$} & & & \\
\hline$V$ & Volume & {$\left[\mathrm{m}^{3}\right]$} & & & \\
\hline$v$ & Velocity & {$[\mathrm{m} / \mathrm{s}]$} & & & \\
\hline$X$ & State variable & {$[-]$} & & & \\
\hline $\boldsymbol{x}$ & State vector & {$[-]$} & & & \\
\hline$Y$ & Output variable & {$[-]$} & & & \\
\hline$y$ & Output vector & {$[-]$} & & & \\
\hline$Z$ & Force & {$[\mathrm{N}]$} & & & \\
\hline
\end{tabular}




\section{References}

G. Allaire. Homogenization of the unsteady stokes equations in porous media. Pitman Research Notes in Mathematics Series, 267:109-123, 1992.

G. Alvarez and D. Flick. Modelling turbulent flow and heat transfer using macro-porous media approach used to predict cooling kinetics of stack of food products. Journal of Food Engineering, 80(2):391-401, 2007.

S.B. Amara, O. Laguerre, M.-C. Charrier-Mojtabi, B. Lartigue, and D. Flick. Piv measurement of the flow field in a domestic refrigerator model: Comparison with 3D simulations. International Journal of Refrigeration, 31(8):1328-1340, 2008.

A. Ambaw, M.A. Delele, T. Defraeye, Q.T. Ho, L.U. Opara, B.M. Nicolai, and P. Verboven. The use of CFD to characterize and design post-harvest storage facilities: Past, present and future. Computers and Electronics in Agriculture, 93(0):184-194, 2013.

P. Bethke. Ethylene update. Proceedings Wisconsin Annual Potato Meetings, page 141, 2013.

K.J. Beukema, S. Bruin, and J. Schenk. Three-dimensional natural convection in a confined porous medium with internal heat generation. International Journal of Heat and Mass Transfer, 26(3):451-458, 1983.

J.M. Blauer, G.N.M. Kumar, L.O. Knowles, A. Dhingra, and N.R. Knowles. Changes in ascorbate and associated gene expression during development and storage of potato tubers (Solanum tuberosum L.). Postharvest Biology and Technology, 78(0):76-91, 2013.

A. Briddon. The use of ethylene for sprout control. Technical report, British Potato Council, 2006.

M.K. Chourasia and T.K. Goswami. Three dimensional modeling on airflow, heat and mass transfer in partially impermeable enclosure containing agricultural produce during natural convective cooling. Energy Conversion and Management, 48(7):2136-2149, 2007.

P. D'Agaro, G. Cortella, and G. Croce. Two- and three-dimensional CFD applied to vertical display cabinets simulation. International Journal of Refrigeration, 29(2):178190, 2006.

S.J. Davids, V.A. Yaylayan, and G. Turcotte. Use of unusual storage temperatures to improve the amino acid profile of potatoes for novel flavoring applications. Food Science and Technology, 37(6):619-626, 2004.

J. Dehghannya, M. Ngadi, and C. Vigneault. Mathematical modeling of airflow and heat transfer during forced convection cooling of produce considering various package vent areas. Food Control, 22(8):1393 - 1399, 2011. 


\section{Chapter 2}

M.A. Delele, A. Schenk, H. Ramon, B.M. Nicolai, and P. Verboven. Evaluation of a chicory root cold store humidification system using computational fluid dynamics. Journal of Food Engineering, 91(1):110-121, 2009a.

M.A. Delele, A. Schenk, E. Tijskens, H. Ramon, B.M. Nicolai, and P. Verboven. Optimization of the humidification of cold stores by pressurized water atomizers based on a multiscale CFD model. Journal of Food Engineering, 91(2):228-239, 2009b.

M.A. Delele, P. Verboven, Q.T. Ho, and B.M. Nicolai. Advances in mathematical modelling of postharvest refrigeration processes. Stewart Postharvest Review, 2(1):1-8, 2010 .

M.A. Delele, B. Vorstermans, P. Creemers, A.A. Tsige, E. Tijskens, A. Schenk, U.L. Opara, B.M. Nicolai, and P. Verboven. CFD model development and validation of a thermonebulisation fungicide fogging system for postharvest storage of fruit. Journal of Food Engineering, 108(1):59-68, 2012.

M.A. Delele, M.E.K. Ngcobo, S.T. Getahun, L. Chen, J. Mellmann, and U.L. Opara. Studying airflow and heat transfer characteristics of a horticultural produce packaging system using a 3-d CFD model. part ii: Effect of package design. Postharvest Biology and Technology, 86(0):546 - 555, 2013.

T.Z. Desta, A.Van Brecht, J. Meyers, M. Baelmans, and D. Berckmans. Combining CFD and data-based mechanistic (DBM) modelling approaches. Energy and Buildings, 36 (6):535-542, 2004.

S. Ergun. Fluid flow through packed columns. Chemical Engineering Progress, 48:89-94, 1952.

FAO. Food and agriculture organization (fao), 2012, 2012. URL http://faostat3.fao. org/.

M.A. Fennier, J.A. Landry, and G.S.V. Raghavan. Respiration rate of potatoes (Solanum tuberosum L.) measured in a two-bin research scale storage facility, using heat and moisture balance and gas analysis techniques. Canadian Biosystems Engineering, 45: $1-9,2003$.

M.J. Ferrua and R.P. Singh. Modeling the forced-air cooling process of fresh strawberry packages, Part i: Numerical model. International Journal of Refrigeration, 32(2):335 348, 2009.

B. Friedland. Control system design, An introduction to state-space methods. Dover Publications, Inc, 2005.

K. Gottschalk. Mathematical modelling of the thermal beharviour of stored potatoes \& developing of fuzzy control algorithms to optimise the climate in storehouses. Acta Horticulturae., 406, 1996.

K. Gottschalk, L. Nagy, and I. Farkas. Improved climate control for potato stores by 
fuzzy controllers. Computers and Electronics in Agriculture, 40(1):127-140, 2003.

N.L.M. Grubben and K.J. Keesman. Modelling ventilated bulk storage of agromaterials: A review. Computers and Electronics in Agriculture, 114:285-295, 2015.

J.F. Guenthner. Econnomics of potato storage. American Potato Journal, 72(8):493-502, 1995.

D. Gumul, R. Ziobro, M. Noga, and R. Sabat. Characterisation of five potato cultivars according to their nutritional and pro-health components. Acta Scientiarum Polonorum. Technologia Alimentaria, 10 (1):73-81, 2011.

M.L.A.T.M. Hertog, L.M.M. Tijskens, and P.S. Hak. The effects of temperature and senescence on the accumulation of reducing sugars during storage of potato (Solanum tuberosum L.) tubers: A mathematical model. Postharvest Biology and Technology, 10 (1):67-79, 1997.

U. Hornung. Homogenization and Porous Media. Springer-Verslag New York, Inc., 1997.

J. Hunter. Potato respiration and weight lossfloss potatoes in storage. Engineering for Potatoes, pages 511-550, 1986.

M. Kalbasi and M.R. Mehraban. The effect of surface water vapour flux on drying of potato. Food and Bioproducts Processing, 78(4):204-206, 2000.

S.O. Karenlampi and P.J. White. Advances in potato chemistry and technology. Academic Press Amsterdam; Boston, 2009.

K.J. Keesman, D. Peters, and L.J.S. Lukasse. Optimal climate control of a storage facility using local weather forecasts. Control Engineering Practice, 11:505-516, 2003.

M. Kim. Evaluation of degradability of hydroxypropylated potato starch/polyethylene blend films. Carbohydrate Polymers, 54(2):173-181, 2003.

G.E. Kleinkopf, N.A. Oberg, and N.L. Olsen. Sprout inhibition in storage: Current status, new chemistries and natural compounds. American Journal of Potato Research, 80(5): 317-327, 2003.

N. Koga, T. Kajiyama, K. Senda, S. Iketani, S. Tamiya, and S. Tsuda. Energy efficiency of potato production practices for bioethanol feedstock in northern japan. European Journal of Agronomy, 44:1-8, 2013.

V.I. Kondrashov. Mathematical simulation of the coupled heat and moisture exchange in storehouses of agricultural production. Heat and Mass Transfer, 36:381-385, 2000.

V.I. Kondrashov. Modeling of heat and mass transfer and aerodynamics in a bulk of stored agricultural raw material. Journal of engineering Physics and Thermophysics, 80(4):833-839, 2007.

L.J.S. Lukasse, J.E. de Kramer-Cuppen, and A.J. van der Voort. A physical model to predict climate dynamics in ventilated bulk-storage of agricultural produce. International 


\section{Chapter 2}

Journal of Refrigeration, 30(1):195-204, 2007.

L.J.S. Lukasse, J. van Maldegem, E. Dierkes, A.-J. van der Voort, J. de Kramer-Cuppen, and G. van der Kolk. Optimal control of indoor climate in agricultural storage facilities for potatoes and onions. Control Engineering Practice, 17(9):1044-1052, 2009.

A.N. Marchant, P.H. Lidstone, and T.W. Davies. Artificial intelligence techniques for the control of refrigerated potato stores. Part 2: Heat and mass transfer simulation. Journal of Agricultural Engineering Research, 58(1):27-36, 1994.

M.A. Martins, L.S. de Oliveira, and J.A.O. Saraz. Numerical study of apple cooling in tandem arrangement. Dyna, 78(166):158-165, 2011.

F. Mayer. Potato pulp: properties, physical modification and applications. Polymer Degradation and Stability, 59:231-235, 1998.

G.C. Misener and M.L. MacDonald. Simulated moisture loss and cooling time for bulk potatoes. Canadian Agricultural Engeneering, 17(2):72-74, 1975.

G.C. Misener and G.C. Shove. Simulated cooling of potatoes. American Society of Agricultural and Biological Engineers, 19(5):954-957, 1976.

J. Moureh, M. Tapsoba, and D. Flick. Airflow in a slot-ventilated enclosure partially filled with porous boxes: Part i measurements and simulations in the clear region. Computers \& Fluids, 38(2):194-205, 2009.

S. van Mourik. Model and control of systems with flow. PhD thesis, University of Twente, 2008.

S. van Mourik, H. Zwart, and K.J. Keesman. Switching input controller for a food storage room. Control Engineering Practice, 18:507-514, 2010.

S. van Mourik, D. Vries, J.P.M. Ploegaert, H. Zwart, and K.J. Keesman. Physical parameter estimation in spatial heat transport models with an application to food storage. Biosystems Engineering, 112(1):14-21, 2012.

T. Norton and D.W. Sun. Computational fluid dynamics (CFD) - an effective and efficient design and analysis tool for the food industry: A review. Trends in Food Science \& Technology, 17:600-620, 2006.

F. Nourian, H.S. Ramaswamy, and A.C. Kushalappa. Kinetics of quality change associated with potatoes stored at different temperatures. Food Science and Technology, 36(1): 49-65, 2003.

R.Y. Ofoli and G.J. Burgess. A thermodynamic approach to heat and mass transport in stored agricultural products. Journal of Food Engineering, 5:195-216, 1986.

A. van 't Ooster. CIGR Handbook of Agricultural Engineering Volume IV Agro-Processing engineering. American Society of Agricultural Engineers, 1999.

J.-F. Le Page, C. Chevarin, A. Kondjoyan, J.-D. Daudin, and P.-S. Mirade. Development 
of an approximate empirical-CFD model estimating coupled heat and water transfers of stacked food products placed in airflow. Journal of Food Engineering, 92(2):208 $216,2009$.

S.H. Pishgar-Komleh, M. Ghahderijani, and P. Sefeedpari. Energy consumption and CO2 emissions analysis of potato production based on different farm size levels in iran. Journal of Cleaner Production, 33(0):183-191, 2012.

L. Price, P. Young, D. Berckmans, K. Janssens, and J. Taylor. Data-based mechanistic modelling (DBM) and control of mass and energy transfer in agricultural buildings. Annual Reviews in Control, 23(0):71-82, 1999.

A. Rastovski. Storage of potatoes; post-harvest behaviours, store design, storage practice and handling. Centre for Agricultural Publishing and Documentation, 1987.

T.J. Rennie and S. Tavoularis. Perforation-mediated modified atmosphere packaging. part II implementation and numerical solution of a mathematical model. Postharvest Biology and Technology, 51(1):10-20, 2009a.

T.J. Rennie and S. Tavoularis. Perforation-mediated modified atmosphere packaging. part I development of a mathematical model. Postharvest Biology and Technology, 51: 10-20, 2009b.

J.J. Royer and L. Flores. Two-dimensional natural convection in an anisotropic and heterogeneous porous medium with internal heat generation. International Journal of Heat and Mass Transfer, 37(9):1387-1399, 1994.

P.A. Schippers. Storage of respiration of potato tubers during storage, 1. review of literature. Potato Research, 20:173-188, 1977.

N.J. Smale, J. Moureh, and G. Cortella. A review of numerical models of airflow in refrigerated food applications. International Journal of Refrigeration, 29(6):911-930, 2006.

M.B. Tasic, B.V. Konstantinovic, M.L. Lazic, and V.B. Veljkovic. The acid hydrolysis of potato tuber mash in bioethanol production. Biochemical Engineering Journal, 43(2): 208-211, 2009.

V.T. Thanh, E. Vranken, and D. Berckmans. Data-based mechanistic modelling of threedimensional temperature distribution in ventilated rooms filled with biological material. Journal of Food Engineering, 86(3):422-432, 2008.

L.M.M. Tijskens and J.J. Polderdijk. A generic model for keeping quality of vegetable produce during storage and distribution. Agricultural Systems, 51(4):431-452, 1996.

M. Tutar, F. Erdogdu, and B. Toka. Computational modeling of airflow patterns and heat transfer prediction through stacked layers' products in a vented box during cooling. International Journal of Refrigeration, 32(2):295 - 306, 2009.

P. Verboven, D. Flick, B.M. Nicolai, and G. Alvarez. Modelling transport phenomena 


\section{Chapter 2}

in refrigerated food bulks, packages and stacks: basics and advances. International Journal of Refrigeration, 29(6):985-997, 2006.

G.J.C. Verdijck. Product quality control. PhD thesis, University of Eindhoven, 2003.

G.J.C. Verdijck and L.M.M. Tijskens. Quality control in the storage of potatoes for industrial processing. Acta Horticulturae, 599:479-487, 2003.

G.J.C. Verdijck and G. van Straten. A modelling and control structure for product quality control in climate-controlled processing of agro-material. Control Engineering Practice, 10(5):533-548, 2002.

G.J.C. Verdijck, M.L.A.T.M. Hertog, M. Weiss, and H.A. Preisig. Modelling of a potato storage facility for product quality control purposes. Computers $\&$ Chemical Engineering, 23, Supplement(0):S911-S914, 1999.

G.J.C. Verdijck, J.J.M. Sillekens, and H.A. Preisig. A model structure for product quality in processing agro-material for process control purposes. Journal of Food Engineering, 51(2):151-161, 2002.

G.J.C. Verdijck, H.A. Preisig, and G. van Straten. Direct product quality control for energy efficient climate controlled transport of agro-material. Journal of Process Control, 15(2):235-246, 2005a.

G.J.C. Verdijck, G. van Straten, and H.A. Preisig. Optimisation of proeuct quality and minimisation of its variation in climate concontrol operations. Computers and Electronics in Agriculture, 48:103-122, 2005b.

N. Wang and J.G. Brennan. A mathematical model of simultaneous heat and moisture transfer during drying of potato. Journal of Food Engineering, 24(1):47-60, 1995.

S. Whitaker. Flow in porous media i: A theoretical derivation of Darcy's law. Transport in Porous Media, 1(1):3-25, 1986.

J. Xie, X.-H. Qu, J.-Y. Shi, and D.-W. Sun. Effects of design parameters on flow and temperature fields of a cold store by CFD simulation. Journal of Food Engineering, 77 (2):355-363, 2006.

Y. Xu and D. Burfoot. Simulating the bulk storage of foodstuffs. Journal of Food Engineering, 39(1):23-29, 1999.

Y. Xu, D. Burfoot, and P. Huxtable. Improving the quality of stored potatoes using computer modelling. Computers and Electronics in Agriculture, 34(1):159-171, 2002.

Y-B. Yi, J-W. Lee, Y-H. Choi, S-M. Park, and Ch-H. Chung. Simple process for production of hydroxymethylfurfural from raw biomasses of girasol and potato tubers. Biomass and Bioenergy, 39(0):484-488, 2012.

Q. Zou, L. U. Opara, and R. McKibbin. A CFD modeling system for airflow and heat transfer in ventilated packaging for fresh foods: II computational solution, software 
development, and model testing. Journal of Food Engineering, 77(4):1048-1058, 2006. 



\section{Chapter 3}

\section{A SPATIALLY DISTRIBUTED PHYSICAL MODEL FOR DYNAMIC SIMULATION OF VENTILATED AGRO-MATERIAL IN BULK STORAGE FACILITIES}

In preparation as:

N.L.M. Grubben and K.J. Keesman. A spatially distributed physical model for dynamic simulation of ventilated agro-material in bulk storage facilities Computers and Electronics in Agriculture, provisionally accepted for publication, 2018 


\section{Chapter 3}

\section{Abstract}

To maintain a high quality and limit storage losses of agro-materials in bulk storage, the dynamic interaction between climate in the facility and product needs to be better understood. In this paper, we present a (2-D) spatially distributed, dynamic full-scale bulk storage model. Also, model calibration and validation results using data from a fullscale potato storage facility are presented. The model predicts convection and diffusion of heat, mass and carbon dioxide as well as the heat, mass and carbon dioxide transfer between bulk and air, respiration and evaporation of the food product and the natural and forced convection in the storage facility. In the CFD model two actuators, a moving hatch and a fan, were successfully implemented. The validated model was used as a tool to investigate the cooling process within the full-scale storage facility. When applying a combination of under- and overpressure instead of the conventionally applied overpressure, a reduction of the temperature gradient in vertical direction and an increased temperature gradient of the temperature gradient in horizontal direction was obtained. A reduction on this horizontal temperature gradient was accomplished by adding an air channel near the roof.

\subsection{Introduction}

Maintaining product quality of agro-materials is essential for the production and supply of excellent quality food products. Product quality is affected at each link in the food chain, hence also during storage (Jongen and Meulenberg, 2005). Throughout this paper the potato is used as an example of agro-material. During the storage process, the quality of the potato can change as a result of, for instance, internal temperature-dependent processes such as dormancy or cold-induced sweetening. In addition, processes in the product and at the product-air interface, such as respiration and evaporation, also affect the product quality. These processes determine, in particular, weight losses of the product and the level of carbon dioxide around the product. Hence, as the environment in and around the storage facility affects product quality, climate control is massively applied in bulk storage facilities for agro-materials.

Climate control in bulk storage facilities has improved in the past decades. Optimisation of ventilation strategies is only proceeding slowly, however, because of a lack of knowledge on the interaction between climate, a wide range of different and season-dependent agro-materials and the limited quality evaluation at the end of the season. To increase our understanding of the dynamics and interactions of a full-scale storage process and speed up the optimization of ventilation strategies, computational fluid dynamics (CFD) simulations could be of great help. 


\begin{tabular}{|c|c|c|c|c|c|}
\hline \multicolumn{6}{|c|}{ Nomenclature } \\
\hline \multicolumn{3}{|c|}{ Subscript } & \multirow{2}{*}{$\begin{array}{l}E_{\text {resp }} \\
F_{m}\end{array}$} & \multicolumn{2}{|c|}{ Respiration mass per unit of energy $\left[\frac{\mathrm{kg}}{\mathrm{J}}\right]$} \\
\hline$a$ & Air & & & Potato surface & {$\left[\frac{\mathrm{m}^{2} \text { produce }}{\mathrm{m}^{3} \text { bulk }}\right]$} \\
\hline$p$ & Produce & & $F_{e b}$ & External body force & {$\left[\frac{\mathrm{Pa}}{\mathrm{m}}\right]$} \\
\hline \multicolumn{3}{|c|}{ Parameters } & $G_{1}$ & Gain parameter & \\
\hline$\alpha_{c}$ & Heat transfer coefficient & {$\left[\frac{\mathrm{W}}{\mathrm{m}^{2} \cdot \mathrm{K}}\right]$} & $g$ & Gravity & {$\left[\frac{\mathrm{m}}{\mathrm{s}^{2}}\right]$} \\
\hline$\kappa$ & Permeability & {$\left[\mathrm{m}^{2}\right]$} & $h_{f g}$ & Enthalpy of vaporisation & {$\left[\frac{\mathrm{J}}{\mathrm{kg}}\right]$} \\
\hline$\lambda$ & Heat conduction coefficient & {$\left[\frac{\mathrm{W}}{\mathrm{m} \cdot \mathrm{K}}\right]$} & $K_{\text {evap }}$ & Product evaporation coefficient & {$\left[\frac{\mathrm{kg}}{\mathrm{m}^{2} \cdot \mathrm{s}}\right]$} \\
\hline$\mu$ & Dynamic viscosity & {$[\mathrm{Pa} \cdot \mathrm{s}]$} & $\begin{array}{l}\Lambda_{\text {evap }} \\
M\end{array}$ & Molar mass & {$\left[\frac{\mathrm{kg}}{\mathrm{mol}}\right]$} \\
\hline$\Omega$ & Domain & & $P$ & Pressure & {$[\mathrm{Pa}]$} \\
\hline$\rho$ & Density & {$\left[\frac{\mathrm{kg}}{\mathrm{m}^{3}}\right]$} & $R$ & Gas constant & {$\left[\frac{\mathrm{J}}{\mathrm{mol} \cdot \mathrm{K}}\right]$} \\
\hline$\tau$ & Cauchy stress & & $\operatorname{Resp}$ & Product respiration rate & {$\left[\frac{\mathrm{W}}{\mathrm{kg}}\right]$} \\
\hline$\theta$ & $\begin{array}{l}\text { Porosity } \\
\text { Parameter vector }\end{array}$ & & $r_{1}$ & Product respiration parameter & {$\left[\frac{\mathrm{W}}{\mathrm{kg} \cdot \mathrm{K}}\right]$} \\
\hline$\nabla$ & Vector differential operator nabla & & $r_{2}$ & Product respiration parameter & {$\left[\frac{\mathrm{W}}{\mathrm{kg} \cdot \mathrm{K}^{2}}\right]$} \\
\hline $\mathrm{CO}_{2}$ & Carbon dioxide concentration & {$[\mathrm{ppm}]$} & $r_{3}$ & Product respiration parameter & {$\left[\frac{\mathrm{W}}{\mathrm{kg} \cdot \mathrm{K}^{3}}\right]$} \\
\hline$C_{2}$ & Internal resistance & {$\left[\frac{1}{m}\right]$} & $t$ & Time & {$[\mathrm{s}]$} \\
\hline$C$ & Specific heat & {$\left[\frac{\mathrm{J}}{\mathrm{kg} \cdot \mathrm{K}}\right]$} & $T$ & Temperature & {$[\mathrm{K}]$} \\
\hline $\mathbb{D}$ & Diffusion coefficient & {$\left[\frac{\mathrm{m}^{2}}{\mathrm{~s}}\right]$} & $v$ & Velocity vector & {$\left[\frac{\mathrm{m}}{\mathrm{s}}\right]$} \\
\hline$d_{p}$ & Diameter of produce & {$[\mathrm{m}]$} & $X$ & Moisture content & {$\left[\frac{\mathrm{kg}}{\mathrm{kg}}\right]$} \\
\hline$E_{\mathrm{CO}_{2}}$ & Respiratory $\mathrm{CO}_{2}$ per unit of energy & $y \quad\left[\frac{\mathrm{kg}}{\mathrm{J}}\right]$ & $X_{s}$ & Saturated vapour concentration & $\mathrm{n}\left[\frac{\mathrm{kg} \text { water }}{\mathrm{kg} \text { air }}\right]$ \\
\hline
\end{tabular}

To perform CFD simulations, a spatially distributed mathematical model that captures all relevant physical, physiological and actuator processes should be build. In the case of frying potato bulk storage, temperature, moisture content and carbon dioxide are important processes that directly influence the product quality. The temperature, moisture content and carbon dioxide can be controlled by forced ventilation of (fresh) air through the storage facility. As generally known, the temperature and moisture content of a product has influence on all kinds of processes, like respiration, dormancy, rot, infection or sweetening. The moisture content has also a direct influence on the pressure bruising (Castleberry and Jayanty, 2012). Carbon dioxide levels affect the sugar content of the potato (see e.g. Mazza and Siemens, 1990; Daniels-Lake, 2013). Therefore, a CFD model that contains temperature, moisture content, carbon dioxide balances and actuators dynamics, of an appropriate air distribution is desirable.

In the literature both physically-based models (see e.g. Ofoli and Burgess, 1986; Verdijck et al., 1999; Jia et al., 2001; Nahor et al., 2004; Lukasse et al., 2007; Dehghannya et al., 2011) and empirical models based on physiological experiments (e.g. Tijskens and Polderdijk, 1996; Hertog et al., 1997; Peppelenbos et al., 1996; Burg, 2004; Florkowski et al., 2014) are available for potato storage. Research related to CFD simulation of storage 


\section{Chapter 3}

facilities can be found in the literature as well (see e.g. Kondrashov, 2000; Xu et al., 2002; Nahor et al., 2005; Chourasia and Goswami, 2007; Delele et al., 2009; Moureh et al., 2009; Delele et al., 2012; Ambaw et al., 2013; Hong et al., 2017). A calibrated and validated physically-based model that includes temperature, moisture content, carbon dioxide for both the air and product domain, and hatch and fan dynamics, as can be found in most storage facilities, is lacking.

The objective of the paper is to define, calibrate and validate a dynamic, spatially distributed model of the above mentioned processes in a full-scale potato storage facility for scenario studies. The proposed model in this paper describes the physical transport phenomena of both heat and mass. The flow of air is modelled by using the momentum balance and continuity equation. The complete dynamic model of the actual potato bulk storage facility with actuators (fan and hatches) with their corresponding air flows, was implemented in a CFD simulation tool. The CFD simulations were successfully used in the calibration and validation of the model. In a case study, the validated model was used to investigate a scenario with switching over- and underpressures, instead of the conventional applied overpressure.

In a conventional bulk storage facility overpressure is applied in the pressure chamber (left part in domain $\Omega_{a 3}$ in Figure 3.1), such that by means of forced convection the air streams from the bottom to the top of the bulk (blowing). From a construction point of view, this is an efficient way to apply a homogeneous distribution of air in the horizontal direction. However, from practise and the results presented in Grubben and Keesman (2017), controlling the temperature at the top of the bulk cannot be reached in short time periods, and temperature and moisture gradients in vertical direction are seen. Hence, to control the top of the bulk more efficiently, the air should also stream from the top to bottom of the bulk. This can be realised by applying underpressure in the pressure chamber (suction). As conventional storage facilities are not constructed to supply a homogeneous distribution in suction mode, a CFD model will provide insight into the development of the climate and product quality in the storage facility using a combination of blowing and suction ventilation.

This paper is structured as follows. First, we set out the modelling procedure. Second, we show how we calibrated and validated the resulting CFD model, with experimental data from a full-scale potato storage facility under active control of temperature, moisture content and carbon dioxide. The results of the calibration, validation and case study are given in Section 3. The results are discussed in Section 4. 


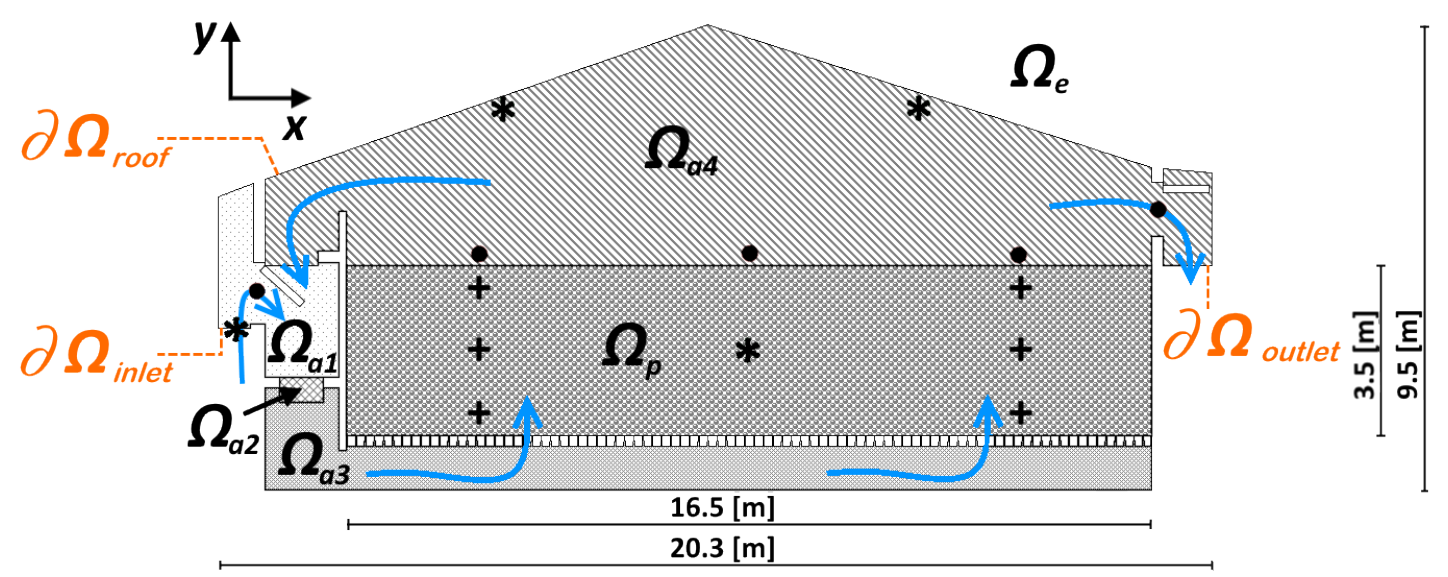

Figure 3.1: 2 -D configuration of the potato storage facility, with $\Omega_{a}$ the air domain, $\Omega_{p}$ the porous medium domain and $\Omega_{e}$ the environment domain. The climate is controlled by mixing and ventilating air from the outside $\Omega_{a 1}$ and the inside $\Omega_{a 4}$, via fan $\Omega_{a 2}$ and air channel $\Omega_{a 3}$ through the porous medium $\Omega_{p}$. The air can leave the facility or can be recirculated. The symbols $\bullet, *$ and + represent measuring points for air velocity, and for temperature, moisture content and carbon dioxide. The inlet, outlet and roof boundaries are denoted by $\partial \Omega_{\text {inlet }}$, $\partial \Omega_{\text {outlet }}$ and $\partial \Omega_{\text {roof }}$

\subsection{Material and methods}

This section presents a description of the full-scale potato storage facility including the actuators and sensors locations. Subsequently, the model assumptions are presented, followed by a mathematical description of the relevant processes. Next, the simulation and calibration procedure is described. Finally the case study is introduced.

\subsubsection{Large scale storage facility}

To obtain data for calibration and validation of the model, we monitored a full-scale potato storage facility in the Netherlands, (Flevoland) during the storage season of 20152016. The used variety was Ramos, that was grown for 173 days and the haulm was killed 14 days before harvesting. The potatoes were harvested on 6th October, and treated with $150 \mathrm{ml}$ Grow-Stop ready (CIPC) per $1000 \mathrm{~kg}$ during storage filling, for sprout inhibition. The potatoes were stored in a bulk storage facility in a pile of 3.5 meters high for 259 days. For the calibration and validation data from 13-14 March and from 6-7 April were collected, respectively. Figure 3.1 depicts the facility with width of $x=20.3$, height of $y=9.5$, and a length of $z=12.5$ meters, which was storing around 500 tonnes of potatoes. For modelling purposes, we defined four different air domains $\Omega_{a i}$, with $i=1, \ldots, 4$, one porous domain $\Omega_{p}$ and an environment domain $\Omega_{e}$. We placed sensors at several positions in the facility; see Figure 3.1. Table 3.1 lists the specifications of the sensors and its 
Table 3.1: Overview of measuring points.

\begin{tabular}{l|c|c|c|c}
\hline Point & Domain & Sensor & Specifications & Accuracy \\
\hline$\bullet$ & $\Omega_{a 1}$ & $v$ & Anemometer $^{\dagger}$ & $\pm 0.1[\mathrm{~m} / \mathrm{s}]$ \\
\hline$\bullet$ & $\Omega_{a 4}$ & $v$ & Anemometer $^{\dagger}$ & $\pm 0.1[\mathrm{~m} / \mathrm{s}]$ \\
\hline$*$ & $\Omega_{a 1}$ & $T_{a}$ & Pt100 $^{\dagger}$ & $\pm 0.1\left[{ }^{\circ} \mathrm{C}\right]$ \\
& & $X_{a}$ & $\mathrm{HC101}^{\dagger}$ & $\pm 3[\%]$ \\
& & $\mathrm{CO}_{2}$ & Transmitter $^{\dagger}$ & $\pm 50[\mathrm{ppm}]$ \\
\hline$*$ & $\Omega_{a 4}$ & $T_{a}$ & Pt100 $^{\dagger}$ & $\pm 0.1\left[{ }^{\circ} \mathrm{C}\right]$ \\
\hline$*$ & $\Omega_{p}$ & $T_{p}$ & Pt100 $^{\dagger}$ & $\pm 0.1\left[{ }^{\circ} \mathrm{C}\right]$ \\
& & $X_{p}$ & Load cell ${ }^{\dagger}$ & $\pm 5[\mathrm{~g}]$ \\
& & $C O_{2}$ & Transmitter & $\pm 50[\mathrm{ppm}]$ \\
\hline+ & $\Omega_{p}$ & $T_{p}$ & Pt100 $^{\dagger}$ & $\pm 0.1\left[{ }^{\circ} \mathrm{C}\right]$ \\
\hline$\dagger$
\end{tabular}

positions. The considered 2-D plane in the middle of the facility, hence at $z=6.25$ $[\mathrm{m}]$.

In the storage facility the temperature, air humidity and carbon dioxide level were controlled. The climate was controlled with only 2 actuators, namely the fan and the inlet and outlet hatches. When the temperature or carbon dioxide level exceeded a certain level, the hatches opened and through a forced convection, colder and fresh air entered the store. This was only done when the air humidity of the incoming air was in an acceptable range. When the temperature distribution exceeded a pre-specified level of heterogeneity, the fan homogenized the bulk with the hatches closed. From Figure 3.1 the corresponding flows can be described in more detail. In domain $\Omega_{a 1}$ air from the environment $\left(\Omega_{e}\right)$ can enter the store of can be mixed with air from within the facility using the hatch. This air is ventilated into the air channel $\left(\Omega_{a 3}\right)$ by making use of a fan $\left(\Omega_{a 2}\right)$, that creates an overpressure. From the air channel the air is ventilated through the perforated floor into the product domain $\left(\Omega_{p}\right)$. Once the air is ventilated through the product domain, the air can leave the facility or can be recirculated $\left(\Omega_{a 4}\right)$. In general, the climate conditions are set by rules of thumb. For the Ramos cultivar the temperature was set at 8 degrees, the humidity around the $95 \%$ and the carbon dioxide level should never exceed $4000 \mathrm{ppm}$. The facility is operated with an overpressure over the bulk.

\subsubsection{Model assumptions}

In a dynamic simulation of a complete bulk storage facility, the model boundaries are determined by the physical borders of the storage facility. Disturbances in the ambient environment can influence the internal domains of the facility, through the borders and actuators, such as fan and hatches. For a full-scale storage facility, air domains and a 


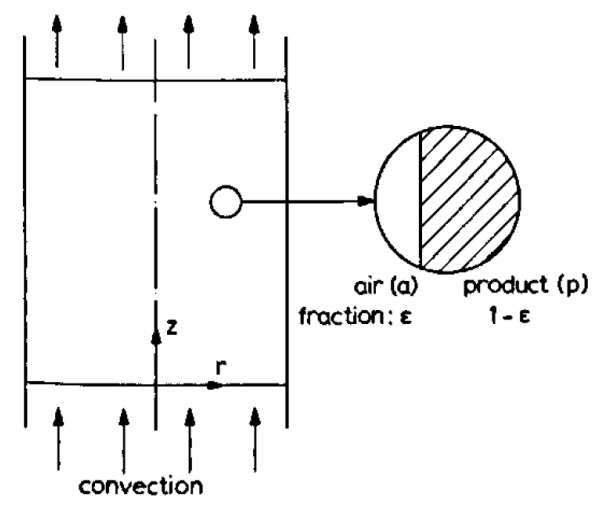

Figure 3.2: Two-phase modelling approach for porous medium (Beukema et al., 1982).

porous media domain are distinguished (see Figure 3.1).

As the model should be used to investigate ventilation strategies in full-scale potato facility, the relevant dynamics should be described by a spatially distributed model. Therefore, only the processes that contribute most to short-term changes in product quality are modelled. The model describes the dynamics of temperature, moisture content, carbon dioxide in air and product domain, and includes a flow model. In the CFD implementation also two types of actuators, hatches and fan, are included.

The following assumptions with respect to bulk potato storage are part of our model:

- The interior of the potato and the potato skin are modelled by a combined diffusion coefficient.

- The distribution of the potatoes in the bulk is uniform and is modelled as a large spherical packed beds approximation (Van der Sman, 2002). This simplification also allows a two-phase modelling approach, which implies that it is not necessary to draw the actual physical potatoes and knowing the ratio between air $\left(\varepsilon_{a}=\varepsilon\right)$ and product $\left(\varepsilon_{p}=1-\varepsilon\right)$ suffices (see Figure 3.2).

- The quality of the potato is defined in terms of temperature-dependent evaporation and respiration that both drive product weight losses. Furthermore it is assumed that the product weight loss is equal to the product moisture loss, thus neglecting weight loss due to other mass losses.

- Condensation is negligible.

- No internal rotting is present. (If a percentage of rot is observed during harvesting or during the intake of the product, the average rates of rotting-related processes, such as respiration of the potatoes, should be adjusted in the model.) 


\section{Chapter 3}

\subsubsection{Spatially distributed model}

In the following, we propose a dynamic and spatially distributed model, based on the work of Van der Sman (2002), Lukasse et al. (2007), Chourasia and Goswami (2007) and Kondrashov (2007), to describe the spatially distributed physically and physiologically related processes.

In the model, each individual process variable is described by a partial differential equations (PDE) and called a state equation. The processes in the facility take place in two different domains $\left(\Omega_{a i}\right.$ and $\left.\Omega_{p}\right)$, which are linked to each other. The air domains $\left(\Omega_{a i}\right)$ contain both air and the control variables, defined as the ventilator pressure and angular displacement of the moving hatches. Hence, the air domains contain only state equations related to physical phenomena. The porous domain $\left(\Omega_{p}\right)$ is described by a two-phase model, including the product and air domain. The state equations describe physical phenomena and physiologically related processes in the porous domain. These state equations follow from the laws of conservation of energy and mass. The air flow is described by the law of conservation of momentum and the continuity equation.

The law of conservation of energy describes the temperature $(T[K])$ change in the porous medium $\left(\Omega_{p}\right)$ and in the air domains $\left(\Omega_{a i}, i=1, \ldots, 4\right)$. For the porous medium and air domain, the following three state equations describe the temperature profiles:

$$
\begin{array}{r}
\frac{\partial T_{a}}{\partial t}+\frac{1}{\varepsilon_{a}} \boldsymbol{v} \cdot \boldsymbol{\nabla} T_{a}-\nabla\left(\frac{\lambda_{a}}{\rho_{a} C_{p a}} \nabla T_{a}\right)=\frac{\alpha_{c} F_{m}}{\rho_{a} C_{p a} \varepsilon_{a}}\left(T_{p}-T_{a}\right) \text { in }(0, T] \times \Omega_{p} \\
\frac{\partial T_{p}}{\partial t}-\nabla\left(\frac{\lambda_{p}}{\rho_{p} C_{p}} \nabla T_{p}\right)=-\frac{\alpha_{c} F_{m}}{\rho_{p} C_{p} \varepsilon_{p}}\left(T_{p}-T_{a}\right)+\frac{R e s p}{C_{p}} \\
\quad-h_{f g} K_{\text {evap }} \frac{F_{m}}{\rho_{p} C_{p} \varepsilon_{p}}\left(X_{s}-X_{a}\right) \text { in }(0, T] \times \Omega_{p} \\
\frac{\partial T_{a}}{\partial t}+\boldsymbol{v} \cdot \nabla T_{a}-\nabla\left(\frac{\lambda_{a}}{\rho_{a} C_{p a}} \nabla T_{a}\right)=0 \text { in }(0, T] \times \Omega_{a i}
\end{array}
$$

Here, $T_{a}:=T_{a}(x, y)$ is the air temperature as a function of the spatial coordinates, $T_{p}:=$ $T_{p}(x, y)$ is the potato temperature, $\nabla:=\left[\begin{array}{ll}\frac{\partial}{\partial x} & \frac{\partial}{\partial y}\end{array}\right]^{T}$ the vector differential operator nabla, $\boldsymbol{v}=\left[\begin{array}{ll}v_{x} & v_{y}\end{array}\right]^{T}$ the velocity vector $[\mathrm{m} / \mathrm{s}], X_{a}$ the moisture content of the air $[\mathrm{kg} / \mathrm{kg}]$ and $\varepsilon$ the porosity $\left(\varepsilon_{a}=0.36\right), h_{f g}$ the enthalpy of vaporisation $\left(2490 \cdot 10^{3}[\mathrm{~J} / \mathrm{kg}]\right), K_{\text {evap }}$ the product evaporation coefficient $\left[\mathrm{kg} /\left(\mathrm{m}^{2} \mathrm{~s}\right)\right]$, and estimated during a calibration step. Furthermore, $\lambda$ is the heat conduction coefficient $[\mathrm{W} /(\mathrm{m} \mathrm{K})], \rho$ the density $\left[\mathrm{kg} / \mathrm{m}^{3}\right]$ and $C$ the specific heat $\left(C_{p a}\right.$ and $C_{p}$ for air and product, respectively) $[\mathrm{J} /(\mathrm{kg} \mathrm{K})]$. For air these coefficients are calculated dynamically by COMSOL, for the potato these are taken as 0.4, 1014 and 3516 respectively. At last, $F_{m}$ represents the specific surface of the mount $\left[\mathrm{m}^{2} / \mathrm{m}^{3}\right]$, Resp the respiration $[\mathrm{W} / \mathrm{kg}], X_{s}$ the average vapour concentration around the potato $[\mathrm{kg} / \mathrm{kg}]$ 
and $\alpha_{c}$ the heat transfer coefficient $\left[\mathrm{W} /\left(\mathrm{m}^{2} \mathrm{~K}\right)\right]$ and these are explained below.

The first term on the right-hand side of the PDEs for $T_{a}$ and $T_{p}$ in the porous domain in Eq. (3.1) and (3.2) characterizes the heat transfer between air and product. In this term, the specific surface of the bulk $F_{m}$ stands for potato surface per cubic meter in the bulk (Lukasse et al., 2007), which is given by:

$$
F_{m}=\frac{\pi d_{p}^{2}}{(1 / 6) \pi d_{p}^{3}} \varepsilon_{p}
$$

Here, $d_{p}$ the potato diameter $(0.06[\mathrm{~m}])$. The second and third reaction term on the right-hand side of the PDE for $T_{p}$ in Eq. (3.2) define the respiration and evaporation, respectively. The product respiration rate Resp in Eq. (3.2) is given by the following equation (Lukasse et al., 2007):

$$
\operatorname{Resp}=r_{1}+r_{2}\left(T_{p}-273.15\right)+r_{3}\left(T_{p}-273.15\right)^{2}
$$

Here, $r_{1}, r_{2}$ and $r_{3}$ are the product respiration parameters $\left([\mathrm{W} /(\mathrm{kg} \mathrm{K})],\left[\mathrm{W} /\left(\mathrm{kg} \mathrm{K}^{2}\right)\right]\right.$ and $\left[\mathrm{W} /\left(\mathrm{kg} \mathrm{K}^{3}\right)\right]$ respectively), and are estimated during the model calibration step. For the evaporation, the latent heat of evaporation $h_{f g}$ and the product evaporation coefficient $K_{\text {evap }}$ are taken as constants (Lukasse et al., 2007). The evaporation is influenced by the equilibrium with the moisture content in air, which is temperature-dependent. The average vapour concentration at the potato surface is approximated by the Antoine equation for water vapour (Lukasse et al., 2007):

$$
X_{s}=\frac{e^{\left(23.5-\frac{3991}{T_{\text {skin }}-39.15}\right)}}{\frac{1}{M_{w}} \rho_{a} R T_{a}}
$$

Here, $M_{w}$ is the molar mass of water $(0.018[\mathrm{~kg} / \mathrm{mol}]), R$ the gas constant $(8.31446$ $[\mathrm{J} /(\mathrm{mol} \mathrm{K})])$ and $T_{\text {skin }}$ the temperature of the skin implemented likewise as in Lukasse et al. (2007). The heat transfer coefficient $\alpha_{c}$ represents the transfer of heat between the potatoes and the air (Kondrashov, 2007), and is given by:

$$
\alpha_{c}=\alpha_{c 1} d_{p}+\frac{\alpha_{c 2} v^{0.67}}{d_{p}^{0.33}}
$$

Here, $\alpha_{c 1}=0.05\left[\mathrm{~W} /\left(\mathrm{m}^{3} \mathrm{~K}\right)\right]$ and $\alpha_{c 2}\left[\mathrm{~J} /\left(\mathrm{m}^{2} \mathrm{~K}\right)\right]$ is estimated in a calibration step.

The law of conservation of mass describes the moisture profiles for the porous domain $\left(X_{p}\right.$ [kg/kg product], $X_{a}[\mathrm{~kg} / \mathrm{kg}$ air $\left.]\right)$ and air domain $\left(X_{a}[\mathrm{~kg} / \mathrm{kg}\right.$ air $\left.]\right)$. Similarly as for the temperature-related states, the moisture profile in the porous medium and air domains is 


\section{Chapter 3}

modelled with three different state equations, as follows:

$$
\begin{array}{r}
\frac{\partial X_{a}}{\partial t}+\frac{1}{\varepsilon_{a}} \boldsymbol{v} \cdot \boldsymbol{\nabla} X_{a}-\boldsymbol{\nabla}\left(\mathbb{D}_{a} \boldsymbol{\nabla} X_{a}\right)=K_{\text {evap }} \frac{F_{m}}{\rho_{a} \varepsilon_{a}}\left(X_{s}-X_{a}\right) \text { in }(0, T] \times \Omega_{p} \\
\frac{\partial X_{p}}{\partial t}-\boldsymbol{\nabla}\left(\mathbb{D}_{p} \boldsymbol{\nabla} X_{p}\right)=-K_{\text {evap }} \frac{F_{m}}{\rho_{p} \varepsilon_{p}}\left(X_{s}-X_{a}\right)-E_{\text {resp }} R e s p \text { in }(0, T] \times \Omega_{p} \\
\frac{\partial X_{a}}{\partial t}+\boldsymbol{v} \cdot \nabla X_{a}-\nabla\left(\mathbb{D}_{a} \nabla X_{a}\right)=0 \text { in }(0, T] \times \Omega_{a i}
\end{array}
$$

Here, $X_{a}:=X_{a}(x, y)$ is the moisture content in the air, and $X_{p}:=X_{p}(x, y)$ the moisture content of the potato. The first reaction term on the right-hand side of the PDEs for $X_{a}$ and $X_{p}$ in the porous domain in Eq. (3.8) and (3.9) captures the moisture exchange between air and product. The second term on the right-hand side of the PDE for $X_{p}$ describes the moisture production due to respiration. This respiration is temperaturedependent (Eq. (3.5)), with the respiration mass per energy $\left(E_{\text {resp }}=2.5 \cdot 10^{-8}[\mathrm{~kg} / \mathrm{J}]\right)$ taken as a constant. Here, $\mathbb{D}_{a}$ the diffusion coefficient in air $\left(2.2 \cdot 10^{-5}\left[\mathrm{~m}^{2} / \mathrm{s}\right]\right)$ and $\mathbb{D}_{p}$ the diffusion coefficient in the potato $\left(\left[\mathrm{m}^{2} / \mathrm{s}\right]\right)$ and is taken as (Xu and Burfoot, 1999):

$$
\mathbb{D}_{p}=5.1 \cdot 10^{-3} \cdot e^{\left(-13.5 X_{p}\right)\left[-3151.5\left(\frac{1}{T_{p}}-\frac{1}{313.15}\right)\right]}
$$

The $\mathrm{CO}_{2}$ concentration is modelled with the aid of two state equations for $\mathrm{CO}_{2, a}[\%]$, in the porous medium and air domain, using the law of conservation of mass:

$$
\begin{array}{r}
\frac{\partial C O_{2, a}}{\partial t}+\frac{1}{\varepsilon_{a}} \boldsymbol{v} \cdot \boldsymbol{\nabla C O _ { 2 , a }}-\boldsymbol{\nabla}\left(\mathbb{D}_{C O 2, a} \boldsymbol{\nabla} C O_{2, a}\right)=E_{C O 2} \operatorname{Resp} \text { in }(0, T] \times \Omega_{p} \\
\frac{\partial C O_{2, a}}{\partial t}+\boldsymbol{v} \cdot \nabla C O_{2, a}-\nabla\left(\mathbb{D}_{C O 2, a} \boldsymbol{\nabla} C O_{2, a}\right)=0 \text { in }(0, T] \times \Omega_{a i}
\end{array}
$$

Here, $C O_{2, a} ;=C O_{2, a}(x, y)$ is the $\mathrm{CO}_{2}$ content in the air, $\mathbb{D}_{C O 2, a}$ the diffusion coefficient $\left(1.6 \cdot 10^{-5}\left[\mathrm{~m}^{2} / \mathrm{s}\right]\right)$. The production term of the $\mathrm{CO}_{2}$ in the porous domain is driven by the respiration of the potato (Eq. (3.5)). The respiratory $\mathrm{CO}_{2}$ concentration per energy $E_{\mathrm{CO} 2}([\mathrm{~kg} / \mathrm{J}])$ is taken as a constant (Lukasse et al., 2007), and estimated in a calibration step.

Air flow is described by an incompressible, Reynolds Averaged Navier Stokes (RANS) with Algebraic yPlus turbulence model. Additional, a volume force in domain $\left(\Omega_{a 2}\right)$ simulates the fan and an aerodynamic resistance is taken into account in the porous domain $\left(\Omega_{p}\right)$ (Chourasia and Goswami, 2007). This porous domain experiences small (natural) as well as large (forced) convective flows. In the natural convection case, the airflow is proportional to the pressure drop and Darcy's law is valid for small air flows. In the case of forced convection, the air in the porous medium has a relative low viscosity. Owing to this low viscosity, the inertial forces in the Reynolds number have a dominant effect, which is described by the Forchheimer resistance. Hence, the total external body force 
$\left(F_{e b}[\mathrm{~Pa} / \mathrm{m}]\right)$ is a combination of the Darcy coefficient and a term that covers the inertial force caused by the kinetic energy of the air.

$$
F_{e b}=\underbrace{-\frac{\mu}{\kappa} v_{i}}_{\text {Darcy coefficient }} \underbrace{-C_{2} \frac{1}{2} \rho_{a} \bar{v} v_{i}}_{\text {inertial term }}
$$

Here, $\mu$ is the dynamic viscosity $[\mathrm{Pa} / \mathrm{s}]$, and calculated dynamically by COMSOL, $\kappa$ is the permeability $\left[\mathrm{m}^{2}\right]$ and $C_{2}$ an internal resistance factor $[1 / \mathrm{m}]$. The permeability is a property that indicates the ability of the air to flow through the porous domain. The resistance term $C_{2}$ is an internal resistance factor. Ergun (1952) has given general approximations for spherical packed beds. Chourasia and Goswami (2007) have expressed the permeability and internal resistance on the basis of Ergun's equation for the potato bulk as follows:

$$
\begin{aligned}
\kappa & =\frac{d_{p}^{2} \varepsilon_{a}^{3}}{c_{1}\left(\varepsilon_{p}\right)^{2}} \\
C_{2} & =\frac{c_{2} \varepsilon_{p}}{d_{p} \varepsilon_{a}^{3}}
\end{aligned}
$$

Here, the parameters $c_{1}$ and $c_{2}$ were estimated in a calibration step.

\subsubsection{Numerical simulation}

CFD simulation software (COMSOL version 5.2a) was used for simulate and analyse the model, as defined in equations (3.1)-(3.15). To simulate the movement of the hatches, we implemented a moving mesh. A moving mesh allows to describe a displacement of a spatial frame by automatic generating a new mesh when needed. A new mesh is needed as the spatial frame (hatch) disturbs the mesh quality during dynamic simulations. If the mesh quality reaches a certain level of inaccuracy, automatically a new mesh grid is created.

The flow model was decoupled from the product (quality-related) model in the calibration step in view of the temporal and spatial complexity of the facility. In the validation step, the complete model was simulated, however, including the dynamic behaviour of the fan and moving hatches.

\section{Boundary conditions}

For the storage facility simulation, with configuration as in Figure 3.1, different boundary conditions related to the proposed states in section 3.2.3 were used. All boundary conditions for the boundary of the facility, as shown in Figure 3.1, are taken as no flux (Neumann) through the boundary for temperature, moisture content and carbon dioxide, with some exceptions for the three boundary conditions $\partial \Omega_{\text {roof }}, \partial \Omega_{\text {inlet }}$ and $\partial \Omega_{\text {outlet }}$. 


\section{Chapter 3}

For the roof $\left(\partial \Omega_{\text {roof }}\right)$ a Dirichlet condition is set for the temperature $\left(T_{a}=T_{\text {roof }}\right)$. For the inlet $\left(\partial \Omega_{\text {inlet }}\right)$ Dirichlet conditions were set for temperature $\left(T_{a}=T_{a, \text { inlet }}\right)$, moister concentration $\left(X_{a}=X_{a, \text { inlet }}\right)$ and carbon dioxide concentration $\left(\mathrm{CO}_{2}=\mathrm{CO}_{2, \text { inlet }}\right)$. For the outlet $\left(\partial \Omega_{\text {outlet }}\right)$ Nuemann conditions, in the form of an outflow condition were used for temperature $\left(\frac{\lambda_{a}}{\rho_{a} C_{p a}} \nabla T_{a}=0\right)$, moister concentration $\left(\mathbb{D}_{a} \nabla X_{a}=0\right)$ and carbon dioxide concentration $\left(\mathbb{D}_{C O 2, a} \nabla C O_{2, a}=0\right)$. For the flow model no slipping boundary conditions were used except for the inlet and outlet. For these boundaries $\left(\partial \Omega_{\text {inlet }}\right.$ and $\left.\partial \Omega_{\text {outlet }}\right)$ both zero static pressure inlet- and outlet boundary condition were used.

\subsubsection{Calibration}

A calibration of the bulk storage model needs to be performed before the model can realistically simulate the behaviour of air and a specific agro-material. All unknown or uncertain model parameters that are product-specific or related to the climate should be estimated. We carried out the parameter estimation with data from measurements in a full-scale bulk storage facility for potatoes. To limit the number of parameters and thus the computation time, the system was decoupled into a fast (air) model and a slow (product) model.

In the first calibration step, we only took the flow properties of the complete bulk storage facility into account. The flow is governed by convection and diffusion, and we therefore estimated the parameters $c_{1}, c_{2}$ and the fan pressure $P_{\text {fan }}$ first. The parameter estimates from the flow model simulations were then compared with data obtained at four locations in the facility over a period of 48 hours. The data pertain to the air velocity in the inlet, outlet, and three points right above the bulk (see Figure 3.1).

Next, the parameters of the product model, $K_{\text {evap }}, r_{1}, r_{2}, r_{3}, \alpha_{c 2}$ and $E_{\mathrm{CO}_{2}}$ were estimated. In this second calibration step, the geometry was decoupled to limit computation time and only the porous domain $\left(\Omega_{p}\right)$ was taken into account. The product model simulation results were compared with data obtained in the facility (see Figure 3.1) over a period of 48 hours. Only the potato temperature $T_{p}$, moisture content of the potato $X_{p}$, and the carbon dioxide concentration $\mathrm{CO}_{2}$ at the centre of the bulk were measured and used for the calibration. Once all parameters were estimated, we coupled the system again to analyse the validity of the complete dynamic CFD simulation model. In addition to the midpoint validation, also six other points in the bulk (as shown in Figure 3.1 and Table 3.1) were used to validate the spatial distribution of the temperature.

For the model calibration, a range of parameter combinations was evaluated, using a parameter sweep. We defined the range of parameters on the basis of physical knowledge and after running some model simulations. This parameter sweep approach works more efficiently than a (non)-linear least squares optimisation method (LSQ) for this full-scale system. Unlike a LSQ method with potential local minima, a parameter sweep approach 
yields, for a predefined number of grid points, quantitative knowledge about the feasible parameter domain.

\section{Flow model calibration}

The exchange between climate and product in the bulk storage facility takes place by diffusion and natural convection, and is amplified by forced convection. Most of the diffusion rates are known from the literature, and we assumed that these rates hold for all bulk storage facilities. The air flow is defined by the RANS model, including a DarcyForchheimer resistance that describes the resistance of the porous medium; see Eq. (3.15). For the parameter sweep, we first calculated the physically possible range for parameters $c_{1}, c_{2}$ and $P_{f a n}$ on the basis of the experiments of Irvine et al. (1993).

Irvine et al. (1993) defined resistance factors for different clean and soiled potato species, and used a $0.95 \mathrm{~m}^{3}$ measuring set-up. Van der Sman (2002) used the clean potato data of Irvine et al. (1993) to prove, in particular that the Darcy-Forchheimer resistance is able to describe the bulk resistance for clean potatoes. However, in practice, soil contents between 2 and 5\% are present. Hence, we first used the data of Irvine et al. (1993) to provide a first guess of the range for the parameters $c_{1}$ and $c_{2}$. Second, we carried out a parameter sweep to estimate the parameters $c_{1}, c_{2}$ and $P_{\text {fan }}$ for the monitored full-scale bulk storage facility.

The available data from Irvine et al. (1993) comprise two different sets related to two bulk compositions. The first set is related to a bulk with a potato diameter of $d p=65$ [mm] and a porosity of $\varepsilon_{a}=0.36$, whereas the second set pertains to a potato diameter of $d p=61[\mathrm{~mm}]$ and a porosity of $\varepsilon_{a}=0.38$. Using CFD simulations of the complete flow field in the facility, we performed the parameter sweep for soil percentages of $0,2.5$, 4 and $6 \%$ in the bulk. The parameter sweep used the following intervals: $c_{1} \in[100,260]$ with $\Delta c_{1}=5$ and $c_{2} \in[0,20]$ with $\Delta c_{2}=0.1$, and $P_{\text {fan }} \in[80,150]$ with $\Delta P_{\text {fan }}=5$.

\section{Product model calibration}

Subsequently, we calibrated the product model on $\Omega_{p}$ only. The product model states are the temperature $\left(T_{p}\right)$, moisture content $\left(X_{p}\right)$ and carbon dioxide $\left(C_{2}\right)$ concentration. These states show relatively slow dynamics in comparison with air flow. For the porous domain, we calculated three respiration coefficients $r_{1}, r_{2}, r_{3}$ of the respiration term $R$, the coefficient of the heat transfer coefficient $\alpha_{c 2}$, the evaporation coefficient $K_{\text {evap }}$, the respiratory $\mathrm{CO}_{2}$ concentration per energy $E_{\mathrm{CO}_{2}}$ and a gain parameter $G_{1}$ on the velocity $\left(\boldsymbol{v}_{\text {eff }}=G_{1} \cdot \boldsymbol{v}\right)$.

As described before, we used a parameter sweep instead of a formal LSQ optimisation method to estimate the parameters. For the product model literature values can be 


\section{Chapter 3}

found (see Table 3.3). On base of the literature values three times a hypercube on three levels is performed. To determine the influence of changes in a parameter estimate on the output-weighted mean squared error $\left(\mathrm{WMSE}^{x}\right)$, with weights $w(x)=1 / \operatorname{var}(x)$, we also calculated the sensitivity of $\mathrm{WMSE}^{x}$ with respect to a specific parameter $\theta_{i}$. The normalised sensitivities, around the specific parameter estimate $\theta_{i}^{*}$, were obtained with the following equation:

$$
S_{\theta_{i}}^{x}=\frac{W M S E^{x}\left(1.1 * \theta_{i}^{*}\right)-W M S E^{x}\left(0.9 * \theta_{i}^{*}\right)}{0.2 * \theta_{i}^{*}} \times \frac{\theta_{i}^{*}}{W M S E^{x}\left(\theta^{*}\right)}
$$

Here, $x$ is $T_{p}, X_{p}$ or $C_{2}$, and a large sensitivity $\left(S_{\theta_{i}}^{x}\right)$ implies a large influence of a specific parameter estimate $\left(\theta_{i}\right)$ on the weighted mean squared error related to state $x, \mathrm{WMSE}^{x}$. This analysis makes it possible to determine the dominant parameters from the seven parameters we initially chose.

\subsubsection{Case study}

For (frying) potatoes, in general, a constant temperature and minimal weight loss is desirable. The temperature and temperature fluctuations have influence, on for instance, the respiration, sugar development (Hertog et al., 1997), ageing (Coleman, 2000) and dormancy (Struik and Wiersema, 2012; Muthoni et al., 2014). Weight loss has influence on the net yield at the end of the storage period, process ability of the potato and on pressure bruising defects. Since the potato is a living organism and produces heat, in practice, at least once a day the facility is ventilated with cool and fresh air. As shown in Figure 3.1, the cool air is only ventilated into the storage by making use of an overpressure. Therefore, relative large temperature and weight loss gradients in vertical direction are obtained. As a result, the lower part of the bulk storage are exposed to colder and dryer air. This heterogeneity can cause condensation (Pringle et al., 2009), and a higher weight loss in the bottom part of the facility. Especially, the weight loss, in combination of the pressure in the bottom layer from the potatoes on top of it, are a cause of pressure flattening defects in the bottom layers.

In this case study (case study 1) the affect of a combination of over and underpressure is investigated for existing facilities. We hypothesize that a smaller gradient in vertical direction is obtained if a combination of over- and underpressure is applied. In the case study the simulation of the first cooling period, 8.6 to 10.0 [h] of the validation data set will be used. In the original case from 8.6 to 10.0 [h] an overpressure was applied. For the case study from 8.6 to 9.3 [h] an overpressure and from 9.3 to 10.0 [h] an underpressure is applied at the fan. 
Table 3.2: Forchheimer resistance.

\begin{tabular}{l|c|c|c|c}
\hline Soil percentage & 0 & 2.5 & 4 & 6 \\
\hline $\mathrm{dp}=65 \mathrm{~mm}, \varepsilon_{a}=0.36$ & $c_{2}=3.6$ & $c_{2}=5.8$ & $c_{2}=10.4$ & $c_{2}=13.6$ \\
$\mathrm{dp}=61 \mathrm{~mm}, \varepsilon_{a}=0.38$ & $c_{2}=4.2$ & $c_{2}=6.9$ & $c_{2}=11.3$ & $c_{2}=14.5$
\end{tabular}

\subsection{Results}

This section first presents the results of the calibration of the flow and product model, followed by the validation of the complete CFD model. The simulations for validation with a data set of 36 hours was performed on an Intel(R) Xeon(T) SPU Ed5-1650 0, 6 cores, $3.2 \mathrm{GHz}, 24 \mathrm{~GB}$ RAM and took eventuality 36h 06m 40s. Finally, in Section 3.4 the results of the case study will be presented.

\subsubsection{Flow model calibration}

For unsoiled potatoes, a potato diameter of $d_{p}=65[\mathrm{~mm}]$ and a porosity of $\varepsilon_{a}=0.36$, Van der Sman (2002) derived values of $c_{1}=180$ and $c_{2}=3.6$, which are typical values for spherical products (Macdonald et al., 1979). This result corresponds to our findings, as shown in Table 3.2. The performed parameter estimation procedure resulted in a constant value for $c_{1}=180$ and a varying value for $c_{2}$ with $c_{2} \in[3.6,14.5]$.

The potato diameter $d_{p}$ that we used was estimated as $60 \mathrm{~mm}$ with a porosity of $\varepsilon_{a}=0.36$. The tare average of soil is $4.5 \%$. Since these values are different from the data of Irvine et al. (1993), we needed to conduct a new parameter estimation step. From the first parameter estimation step (Table 3.2), we found that $c_{1}=180$. For the estimation of $c_{2}$ and $P_{f a n}$, again a parameter sweep was performed. From the literature, we knew that the pressure $P$ is between 80 and 150 [Pa] (Rastovski, 1987), and $c_{2}$ is between 4 and 14 . Figure 3.3 shows the result of the second parameter sweep.

In Figure 3.3, a valley of parameter estimates with a small normalised mean squared error (NMSE) can be observed. This valley indicates a strong positive correlation between the estimates. The smallest NMSE $\left(1.710^{-6}\right)$ occurs for the parameter estimates $\hat{c}_{2}=12.5$ and $\hat{P}_{\text {fan }}=130[\mathrm{~Pa}]$.

\subsubsection{Product model calibration}

Table 3.3 lists the parameter estimates $\left(\hat{\theta}_{i}\right)$ using the measured states and the original parameters as found in the literature $\left(\theta_{\text {Lit }}\right)$ (columns 3 and 2 respectively) and Figure 3.4 depicts the corresponding calibration results. 


\section{Chapter 3}

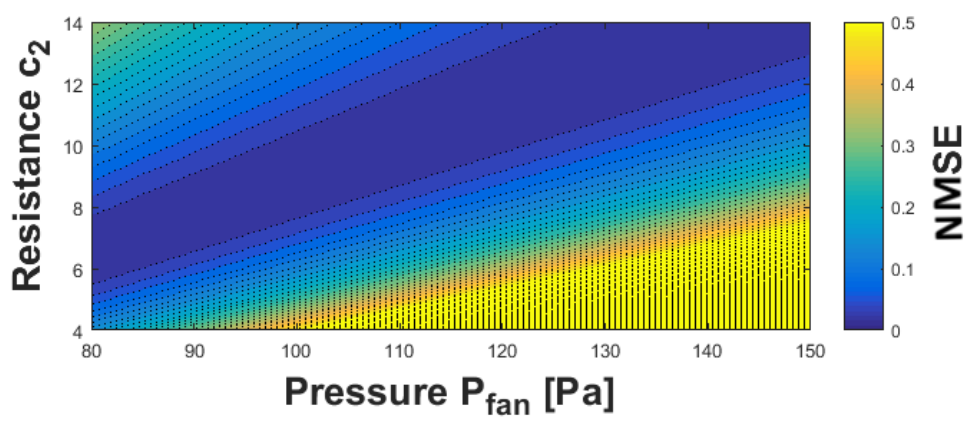

Figure 3.3: Normalised mean squared error of the Darcy-Forchheimer resistance calibrated with data of a full-scale facility, with $\mathrm{dp}=0.060[\mathrm{~m}]$ and $\varepsilon_{a}=0.360$

Table 3.3: Product model parameter estimation

\begin{tabular}{l|c|c|c|c|c}
\hline \multirow{2}{*}{$\theta_{i}$} & \multirow{2}{*}{$\theta_{i, \text { Lit }}$} & $\hat{\theta}_{i}$ & \multicolumn{3}{|c}{ Sensitivity of WMSE } \\
& & & $S_{\theta_{i}}^{T_{p}}$ & $S_{\theta_{i}}^{X_{p}} \cdot \mathrm{e}-1$ & $S_{\theta_{i}}^{C O_{2}}$ \\
\hline$r_{1}{ }^{\ddagger \ddagger}$ & $1.1 e-2$ & $7.0 e-3$ & 0.6907 & 0.1382 & 0.8811 \\
$r_{2}^{\ddagger \ddagger}$ & $-1.9 e-3$ & $-1.0 e-3$ & -0.6983 & -0.1634 & -1.0410 \\
$r_{3}^{\ddagger \ddagger}$ & $1.7 e-4$ & $2.5 e-4$ & 0.6355 & 0.3402 & $\mathbf{2 . 1 5 1 8}$ \\
$\alpha_{c 2}{ }^{\dagger \dagger}$ & 7.5 & 3.0 & -0.8999 & -0.0205 & -0.0542 \\
$K_{\text {evap }} \ddagger$ & $9.0 e-5$ & $1.4 e-4$ & $\mathbf{4 . 4 2 9 1}$ & $\mathbf{1 . 2 5 1 7}$ & 0.1960 \\
$E_{C O_{2}}{ }^{\ddagger \ddagger}$ & $9.0 e-3$ & $7.0 e-4$ & -0.0412 & 0.0125 & 1.8932 \\
$G_{1}$ & 1.0 & 1.8 & $\mathbf{- 2 . 9 8 4 2}$ & -0.4426 & -0.0721 \\
\hline
\end{tabular}

‡: literature parameter value taken from Lukasse et al. (2007)

$\dagger \dagger$ : literature parameter value taken from Kondrashov (2007)

From the calibration results, a good fit is obtained for all three states. The simulated potato temperature follows the potato temperature measurements within the sensor accuracy. The potato weight was measured only twice. Hence, the exact intermediate dynamics cannot be verified. However, the moisture loss after 48 hours gives a good fit. The $\mathrm{CO}_{2}$ concentration is in a good range. Only between $t=28-31$ hours the concentration is lower compared to the data, but the results are much better than those obtained with the literature parameter values.

Table 3.3 contains the parameter values found in the literature $\left(\theta_{i, \text { Lit }}\right)$, the parameters estimates $\left(\hat{\theta}_{i}\right)$ with the minimum WMSE, and the sensitivities of the output to the parameters $\left(S_{\theta_{i}}^{x}\right)$. The simulations performed with the parameters found in the literature $\left(\theta_{\text {Lit }}\right)$ and the parameter estimates $(\hat{\theta})$ resulted in a WMSE of 56.39 and 1.81 , respectively.

Six of the parameter estimates $\left(\hat{\theta}_{i}\right)$ are in the same range as the parameter values found in the literature. The estimate of $E_{\mathrm{CO}_{2}}$ is one order lower relative to the value reported in the literature. This result can be ascribed to the fact that another potato variety was used, other growing conditions and probably the usage of sprout inhibitors. The sensitivity results indicate that a change in the parameter estimate of evaporation $\left(K_{\text {evap }}\right)$ 

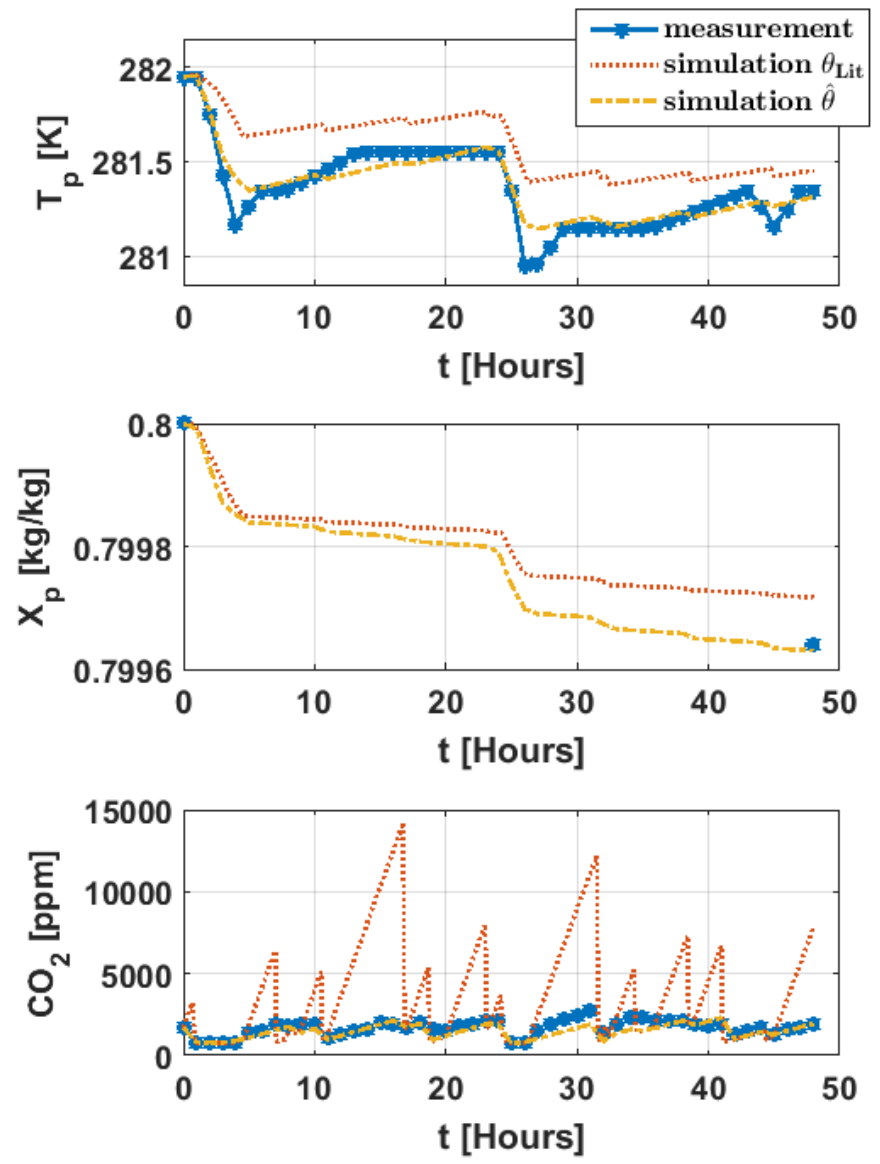

Figure 3.4: Calibration results, with the parameter estimates given in Table 3.3. In all panels, the blue stars indicate the measuring points, the dashed red line is the simulation result using the parameters found in the literature and the dash-dotted yellow line is the model calibration output of the optimal parameter estimates. The top panel shows the temperature of the potato, the middle panel the moisture content of the potato, and the bottom panel the $\mathrm{CO}_{2}$ concentration.

has the greatest influence on the temperature $T_{p}$, as well as, on the moisture content $X_{p}$. The results also show that the gain parameter $G_{1}$ has a considerable influence on $T_{p}$. A change in the parameter $r_{3}$ and $E_{\mathrm{CO}_{2}}$ have the most influence on the carbon dioxide state $\left(\mathrm{CO}_{2}\right)$

\subsubsection{Validation}

The validation of the model was performed using data from the same storage facility, storage season, and potato tubers as for the calibration. The only difference is that we took data from a different period of 36 hours. For the validation run the complete bulk-storage model was simulated without decompositions. 


\section{Chapter 3}

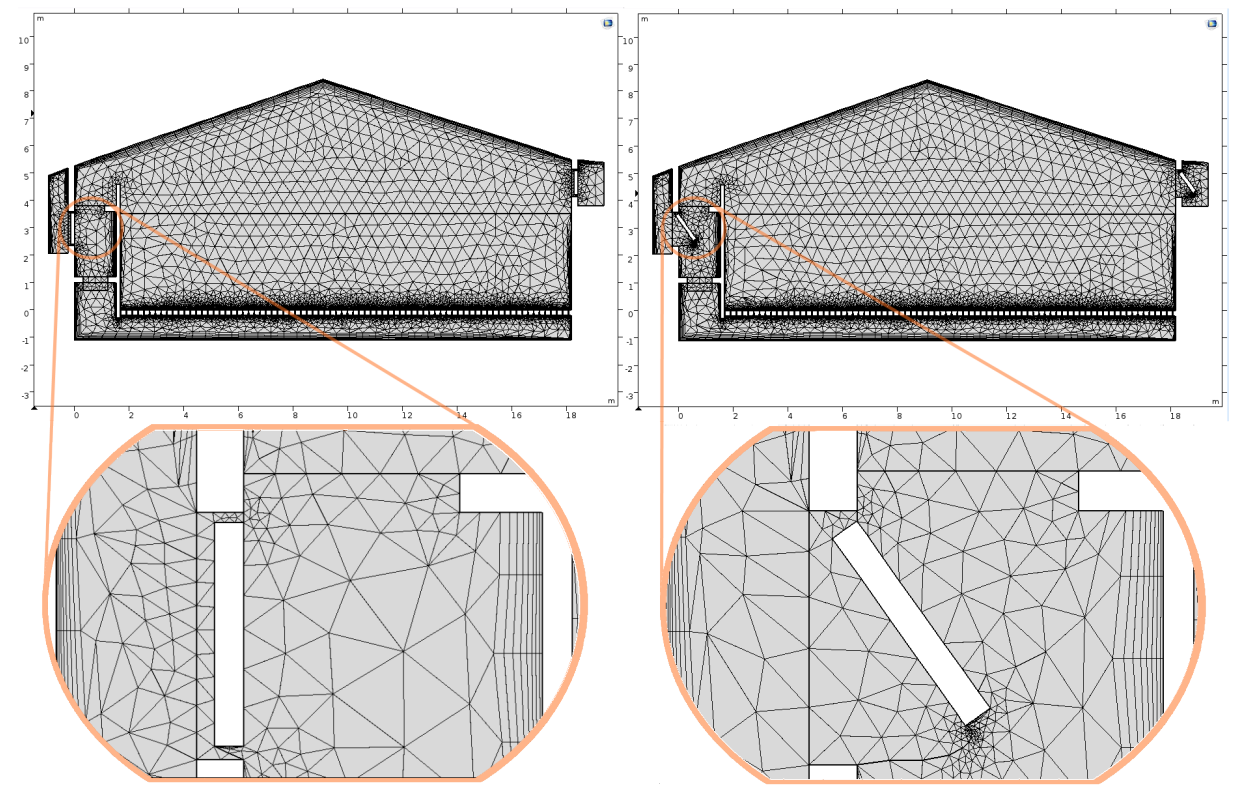

Figure 3.5: Mesh configuration of the storage facility. Left panels: initial mesh configuration. Right panels: mesh configuration after some re-meshing steps $(\mathrm{t}=26.81[\mathrm{~h}])$.

To perform a dynamic simulation of the complete storage facility, a moving mesh was used to open and close the hatches repeatedly. Having a suitable mesh to solve the storage facility problem is essential. Choosing a mesh that is too coarse will result in inaccurate results. Taking a very fine mesh will lead to long computation times due to the large number of grid points, and is susceptible to errors in the repeated re-meshing of the moving mesh. We used 15466 triangular mesh elements and 2515 boundary elements for the facility (see Figure 3.5). The spatial discretisation error (DE) of the mesh for the most important states were estimated by means of a Richardson extrapolation (Roache, 1997). The DE for velocity, temperature, moisture content and the carbon dioxide state were $2.41 \%, 1.03 \%, 0.14 \%$ and $0.01 \%$, respectively.

As the hatches opens and closes repeatedly during the simulations, the mesh is adapted during the time simulation. In Appendix 3 A., Figure 3.15, nine close-up frames from the first time the hatch opens and closes, between 0.4 and $0.7[\mathrm{~h}]$ of the validation simulation are shown. The frames show that after the first time opening and closing the hatch, a significant smaller mesh around the down part of the hatch is created.

\section{Flow model validation}

Figure 3.6 provides an impression of the situation with forced and natural convection. The two top panels show the air velocity at two different time instances, and the two bottom panels show the corresponding air temperature profiles. In the forced convection case (left panels), a homogeneous distribution of air and temperature is obtained, as a 


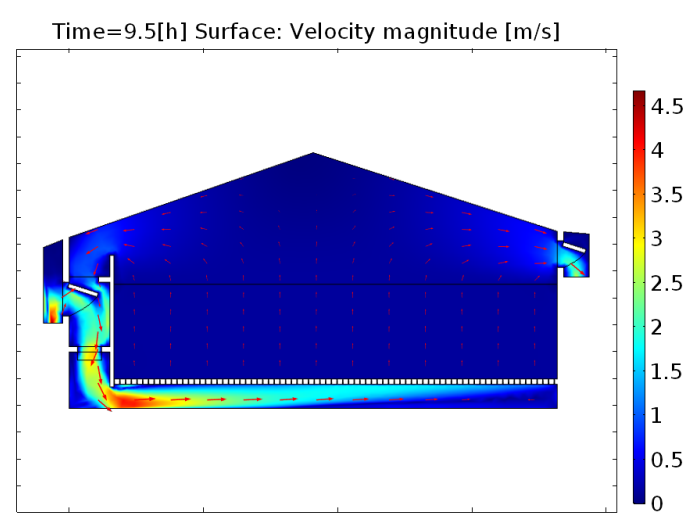

Time=9.5 [h] Surface: Temperature [K]

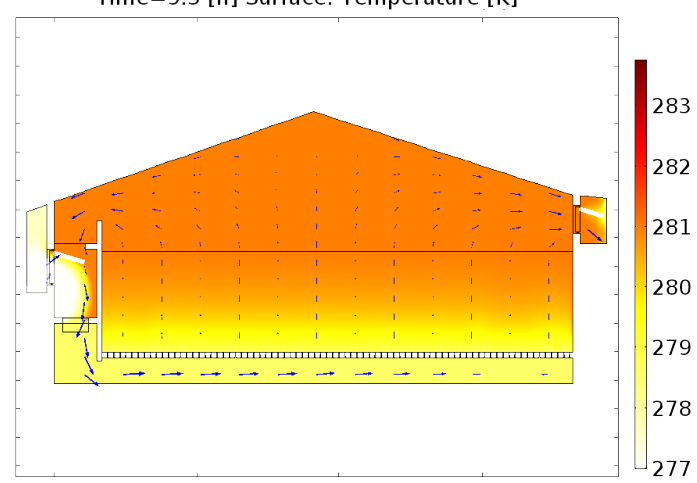

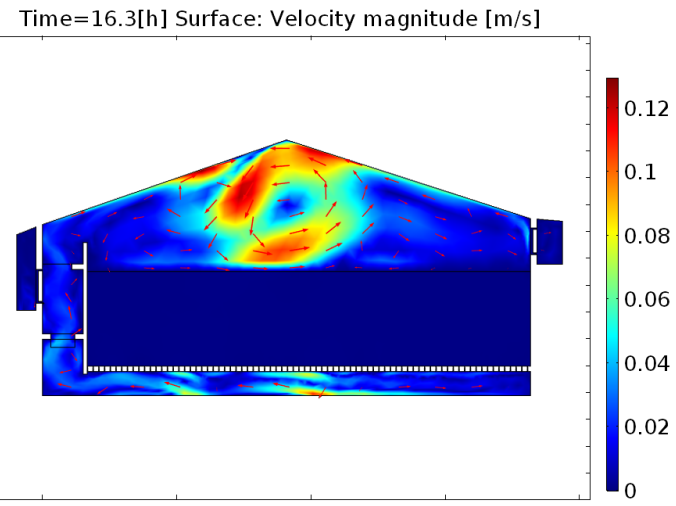

Time=16.3 [h] Surface: Temperature $[K]$

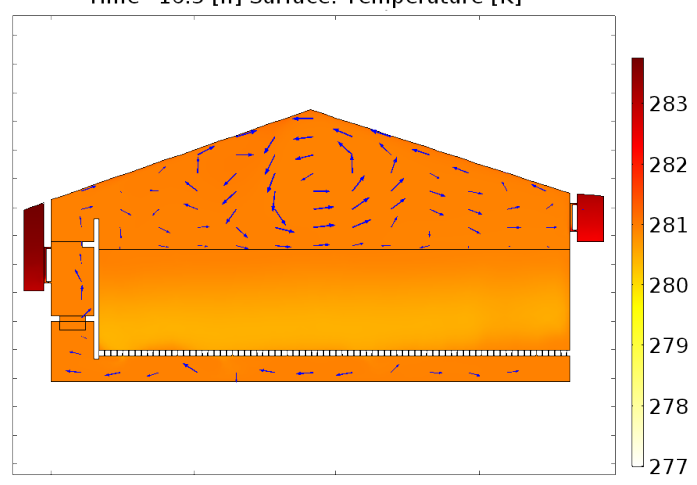

Figure 3.6: Validation results. Top left panel: air velocity during forced convection with open hatch. Bottom left panel: air temperature during forced convection with open hatch. Top right panel: air velocity during natural convection with closed hatches. Bottom right panel: air temperature during natural convection with closed hatches.

result of the perforated floor. Including the perforated floor in the model results in longer computational times (small mesh elements), but represents the reality well. In the natural convection case (right panels), there is air circulation due to temperature differences. Both cases show realistic velocity and temperature distributions as conformed in Figure 3.7 for the four validation points (see Figure 3.1).

The velocity profile of the simulation shows the same behaviour compared to the measurements. The temperature profile above the fan shows a good fit, but after a ventilation action the temperature stays lower compared to the measurements. The roof temperature follows the same trend, but between $t=6$ and $7.5[\mathrm{~h}]$ a significant higher temperature is obtained in the facility.

\section{Product model validation}

Figure 3.8 shows the validation results of the product model. Likewise as in the calibration, appropriate fits were obtained. The potato temperature $\left(T_{p}\right)$ and moisture content $\left(X_{p}\right)$ are within the sensor accuracy. The carbon dioxide $\left(\mathrm{CO}_{2}\right)$ level shows a comparable 

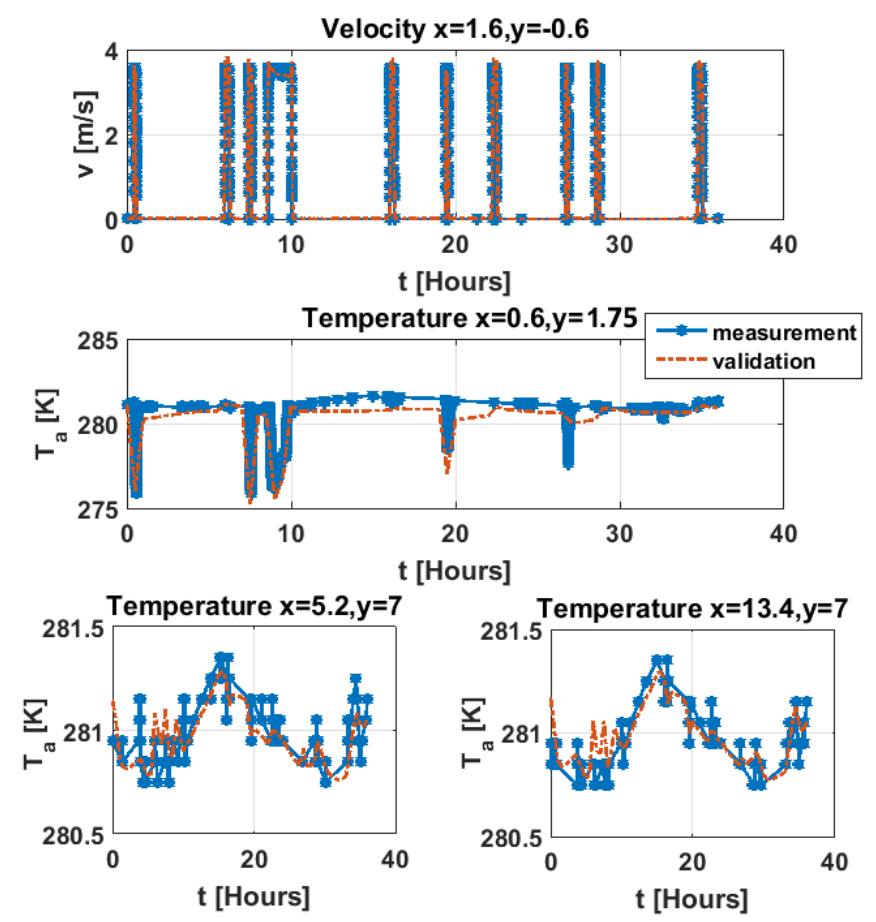

Figure 3.7: Validation results. Top left panel: air velocity in air channel. Middle panel: air temperature above the fan. Bottom left panel: air temperature left part under roof. Bottom right panel: air temperature right part under roof.

fit as in the calibration. However, directly after opening the hatches and switching on the forced ventilation, a rapid decrease followed by a rapid increase can be seen in the measurements, but not in the simulation. The simulations and measurements show the same trend after this rapid decrease and increase. In the validation step, the WMSE is equal to 2.48 , which is lower than the simulation with literature parameters (WMSE $=56.39$ ), but slightly higher compared with the calibration WMSE of 1.81 .

Additionally to the midpoint validation, the potato temperature $\left(T_{p}\right)$ was validated on six other points in the bulk (Figure 3.9). Four of the six points, in the top and middle layer of the bulk with coordinates [4.4, 3.0], [15.4,3.0], [4.4, 1.75] and [15.4, 1.75], show a good fit within the sensor accuracy. For two of the six points, on the bottom layer, on the points $[4.4,0.5]$ and $[15.4,0.5]$, a same trend as the measurements are obtained, however, a larger offset is seen. The MSE of the points [4.4, 3.0], [15.4, 3.0], [4.4, 1.75], [15.4, 1.75], $[4.4,0.5]$ and $[15.4,0.5]$, are $0.0150,0.0042,0.0034,0.0019,0.0395,0.0529$ respectively.

\subsubsection{Case study}

From the measured data and the validated model simulations, mainly gradients in the vertical direction were obtained for air and product temperature. For the moisture content 

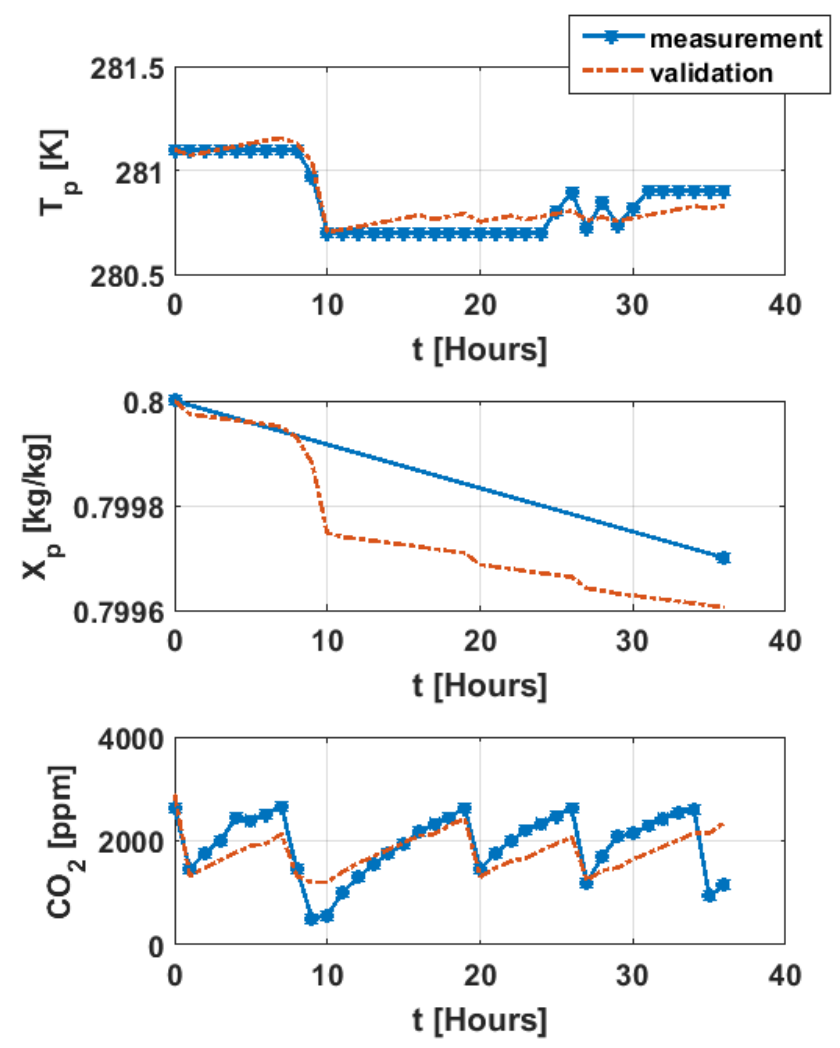

Figure 3.8: Validation result of product model. In all panels, the blue stars are the measuring points and the dash-dotted red line is the simulation output. The top panel presents the temperature of the potato, the middle panel the moisture content of the potato, and the bottom panel the $\mathrm{CO}_{2}$ concentration.

no significant gradients were obtained, probably due the relative short time simulation. In Figure 3.10 the air and product temperatures are shown for $t=36$ [h]. The gradients are unwanted, as described in section 3.2.6. To minimize the heterogeneity in the bulk, a new ventilation strategy is taken into consideration. In our case study a combination of over- and underpressure is applied to minimise the vertical gradient. A simulation of 10.5 hours is performed, using the inlet and outlet data of the validation data set. We show only the results for the forced convective period, i.e. $t=8.5-10.5[\mathrm{~h}]$.

In this case study (case study 1 ) the pressure profile changes around $t=9.3$ [h], from over- to underpressure. The influence on the air temperature profile at time $t=9.5[\mathrm{~h}]$ is shown in Figure 3.11. The influence on the potato temperature profiles for 9 different locations is shown in Figure 3.12. The vertical gradient at the end of the cooling period are listed in Table 3.4. As we can conclude from the results the potato temperature gradient is much lower applying over- and underpressure. However, the temperature gradients in horizontal direction are bigger compared to the original simulation, see Table 3.5. The average temperature in the bulk for the original and the case study simulation at $t=10.5$ is $280.59[\mathrm{~K}]$ and $280.60[\mathrm{~K}]$ respectively. The average moisture content for 

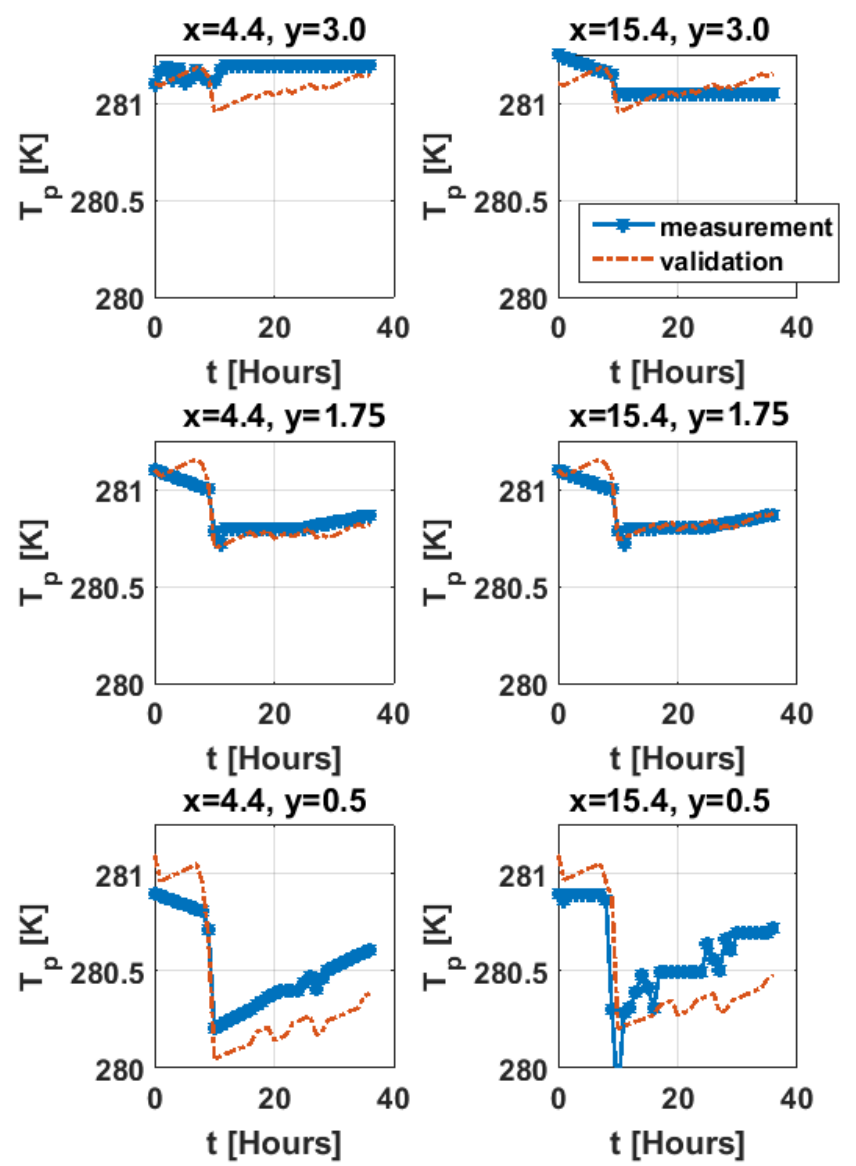

Figure 3.9: Validation result of product model. In all panels, the blue stars are the measuring points and the dash-dotted red line is the simulation output. The top panels presents the temperature of the potato at coordinates $[4.4,3.0]$ and $[15.4,3.0]$, the middle panels presents the temperature of the potato at coordinates $[4.4,1.75]$ and $[15.4,1.75]$, and presents the temperature of the potato at coordinates $[4.4,0.5]$ and $[15.4,0.5]$.

the original and the case study simulation at $t=10.5$ is is $0.79974[\mathrm{~kg} / \mathrm{kg}]$ and 0.79975 $[\mathrm{kg} / \mathrm{kg}]$ respectively. This implies that on average more or less the same cooling effect is achieved, with smaller gradients in vertical direction and slightly lower weight loss for the case study with over- and underpressure. Thus this result shows that the gradient in vertical direction is reduced, if a combination of over- and underpressure is applied. However, the gradients in horizontal direction becomes bigger.

\subsection{Discussion}

As described, we have developed a dynamic potato storage model, which we calibrated by decoupling the fast and slow dynamics of the model. For each, a parameter sweep is performed to gain an impression of the feasible parameter region. While this approach is 

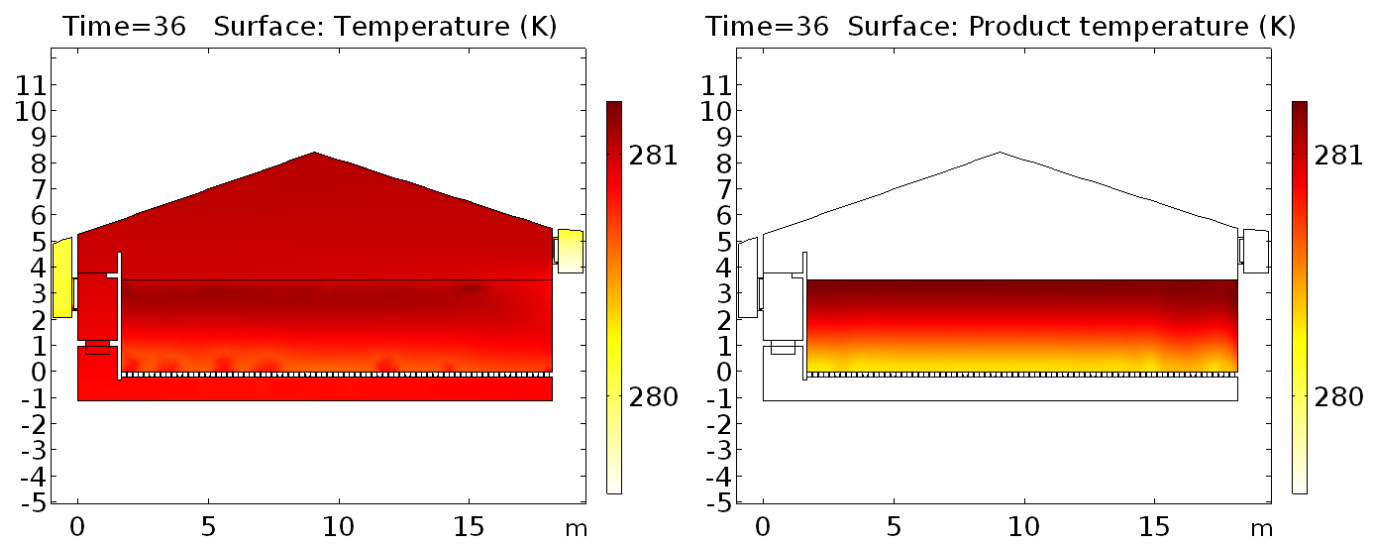

Figure 3.10: Air and Product temperature profiles for the original simulation for time $\mathrm{t}=36[\mathrm{~h}]$.

Table 3.4: Product temperature gradients in vertical direction

\begin{tabular}{c|c|c|c|c}
\hline & study & $x=4.4$ & $x=9.4$ & $x=15.4$ \\
\hline$T_{p}(x, 3.0)-T_{p}(x, 0.5)$ & original & 0.91 & 0.89 & 0.75 \\
& case 1 & 0.36 & -0.01 & -0.23 \\
\hline
\end{tabular}

effective in finding feasible parameter vectors for complex models, its drawback is that it generally does not yield optimal parameter estimates.

Consequently, the calibration of the flow model produces a hypercube with width $[5,0.1$, 5] of feasible parameter vectors. This calibration result shows that the Darcy-Forchheimer model can be used for the modelling of full-scale storage facility, albeit that the estimates of $P_{f a n}$ and $c_{2}$ are highly correlated. The product model was also successfully calibrated (see Figure 3.4).

Next, we used CFD simulation software as this is a great tool to visualise spatially distributed dynamical behaviour. The dynamic behaviour of the bulk storage facility was described in our study by a spatially distributed model with moving hatches and timevarying fan pressure. Simulating the full facility, without decomposition, presented a challenge due to the different time scales in the facility, the relatively small changes in dynamics and the moving mesh. The mesh selection is of great importance for obtaining a satisfying solution. Simulating a full-scale facility relative to simulating a small object automatically means that for the same accuracy, many more mesh elements are needed. To limit memory problems, however, we constrained the mesh of the bulk facility at the price of some acceptable numerical errors and gaining potential numerical instabilities.

The COMSOL CFD simulation tool provides a basis to simulate all relevant dynamics described in this paper. Solving the case with intermittent forced and natural convection in one go while combining the product model with a moving mesh, however, is also challenging. Repeated re-meshing is a good option for simulating a hatch that opens and 
Table 3.5: Product temperature gradients in horizontal direction

\begin{tabular}{l|c|c|c|c}
\hline & study & $y=3.0$ & $y=1.75$ & $y=0.5$ \\
\hline$T_{p}(15.4, y)-T_{p}(4.4, y)$ & original & 0 & 0.05 & -0.38 \\
& case 1 & -0.65 & -0.19 & -0.06 \\
\hline
\end{tabular}
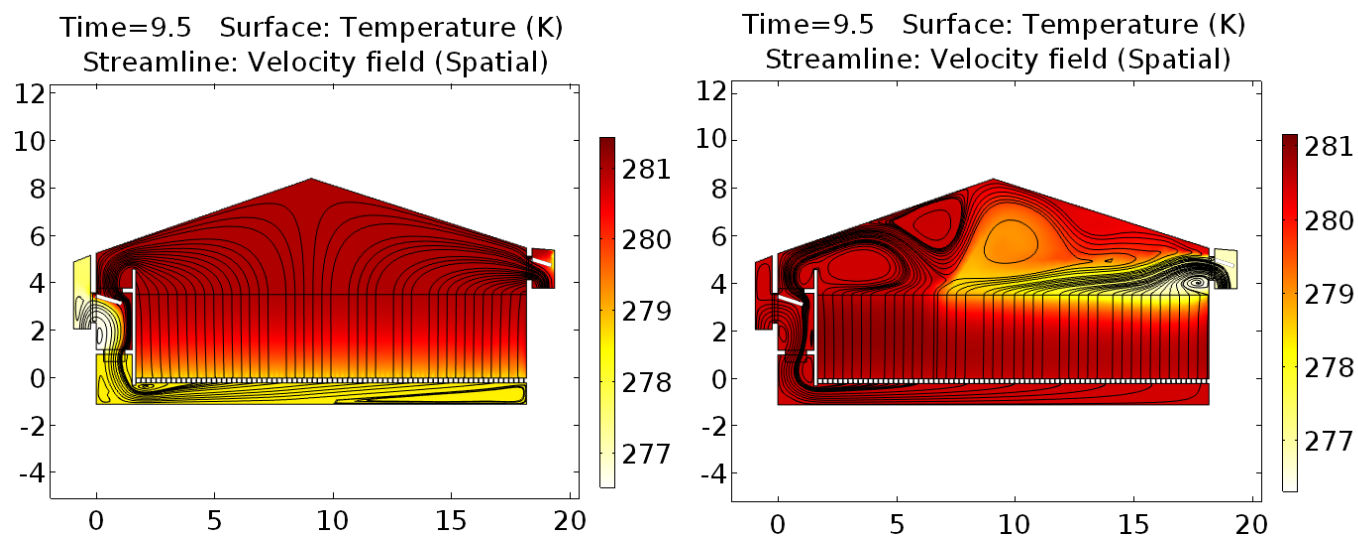

Figure 3.11: CFD temperature profiles for two different simulations at time $t=9.5$ [h]. Left panel: the original simulation, only over-pressure is applied. Right panel: the simulation with an over- and underpressure applied.

closes, but there is a limit to the shifting of the mesh elements. For our configuration and mesh choice, the mesh elements could no longer be shifted after 36 hours of simulation (see Figure 3.8). If we had chosen a smaller mesh, this behaviour would have been occurred even sooner. As a consequence, numerical errors occurred, especially in the $\mathrm{CO}_{2}$ state. We therefore added numerical diffusion to the diffusion of the carbon dioxide to make the solution stable. This adjustment implies that there are some differences between the calibration and validation models.

The validation of the product model was performed on the same data set of 36 hours as we used for the flow model validation. The temperature and moisture states of the potato $\left(T_{p}\right.$ and $\left.X_{p}\right)$ show differences between measured and predicted states but these are within the sensor accuracy. The spatial distribution of the model is validated using seven potato temperature measurement points. The middle and top part show good results, the lower part of the bulk shows the same trend but not all steep fluctuation seen in the measurements are seen in the simulation. As the correlation of the potato temperature and potato moisture content of the simulation data was found to be 0.89 , we assume that the partial distribution found for the temperature distribution also holds for the moisture content, but this needs to be further investigated. The carbon dioxide state $\left(\mathrm{CO}_{2}\right)$ shows lower concentrations for three time ranges, but follows the same trend as the measured data.

The mismatch in the carbon dioxide is particularly seen after a forced ventilation action 

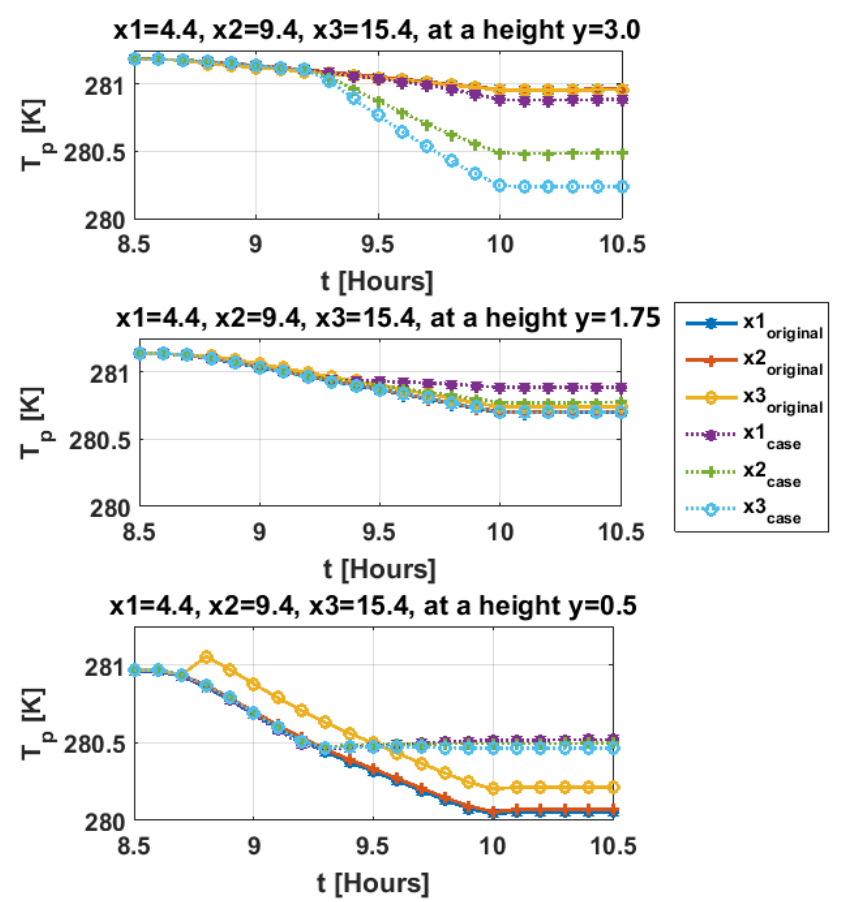

Figure 3.12: Product temperature profiles for the original simulation and the case study using over- and underpressure.

with open hatches. The measurements show a rapid decrease and increase of the carbon dioxide concentration, whereas this behaviour is not observed in the model simulations. The mismatch could be caused by the added numerical diffusion as it changes the dynamic behaviour of carbon dioxide diffusion. After the forced convection, natural convection occurs. Because of the added numerical diffusion, extra carbon dioxide produced by the potatoes is transferred to the air spaces $\left(\Omega_{a i}\right.$ Figure 3.1$)$, while in reality this diffusiondriven movement takes more time.

The case study showed that by using an combination of over- and underpressure, instead of only the conventionally applied overpressure, reduces the vertical gradient. However the gradient in horizontal direction becomes bigger, due to the absent of an ideal mixed air stream above the bulk in domain $\Omega_{a 4}$. Introducing an extra air channel near the roof will minimize the effect of the non-ideally mixed air. This extra adjustment is simulated in a second case study (case study 2), and the results are shown in Figure 3.13. From Figure 3.13 it is seen that a more homogeneous air distribution is obtained compared to the case study 1, were underpressure is applied without the air channel at the roof, see right panel Figure 3.11. Using the extra air channel leads to a more homogeneous distribution of the product temperature after a cooling period, see Figure 3.14. From Figure 3.14 we also see that for the bottom part $(y=0.5)$ the temperature is $280.5[\mathrm{~K}]$, in the middle the temperature is around $280.75[\mathrm{~K}]$, and at the top around $280.7[\mathrm{~K}]$. The product temperature gradients, therefore, are lower compared to the original case and the 


\section{Chapter 3}
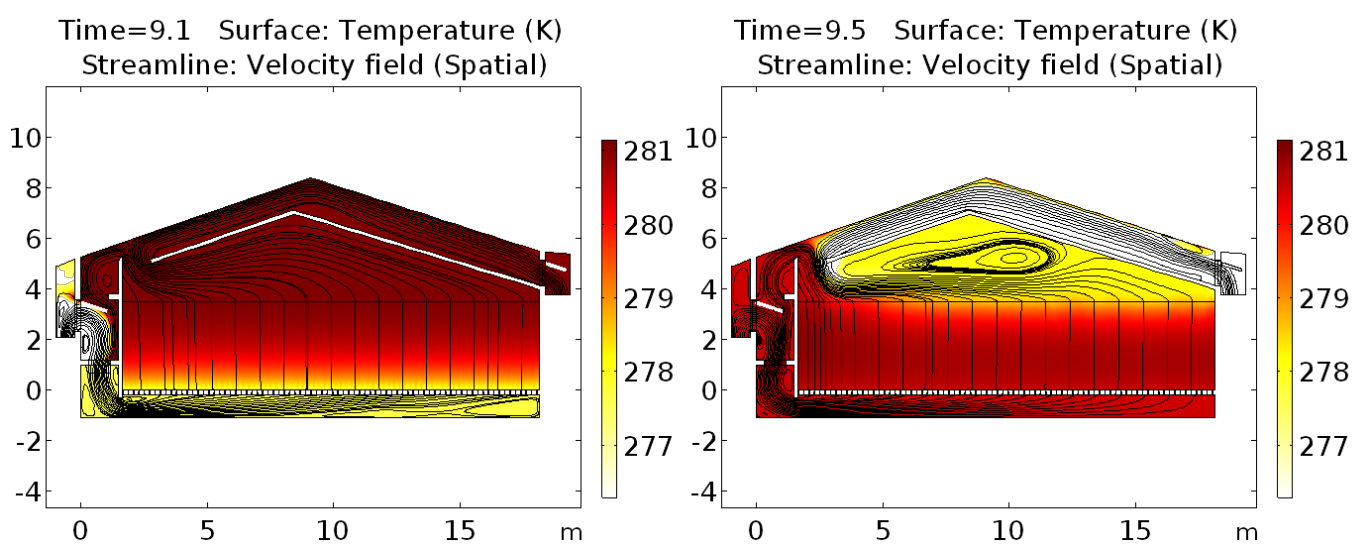

Figure 3.13: CFD temperature profiles for an adjusted configuration using an extra air channel near the roof. Left panel: overpressure at $t=9.1[\mathrm{~h}]$. Right panel underpressure at $t=9.5[\mathrm{~h}]$.

case study without the additional channel. This is confirmed by the product temperature gradients, see Table 3.6 and 3.7.

Table 3.6: Product temperature gradients in vertical direction

\begin{tabular}{l|c|c|c|c}
\hline & study & $x=4.4$ & $x=9.4$ & $x=15.4$ \\
\hline$T_{p}(x, 3.0)-T_{p}(x, 0.5)$ & original & 0.91 & 0.89 & 0.75 \\
& case 2 & 0.32 & 0.18 & 0.17 \\
\hline
\end{tabular}

Table 3.7: Product temperature gradients in horizontal direction

\begin{tabular}{l|c|c|c|c}
\hline & study & $y=3.0$ & $y=1.75$ & $y=0.5$ \\
\hline$T_{p}(15.4, y)-T_{p}(4.4, y)$ & original & 0 & 0.05 & -0.38 \\
& case 2 & 0.16 & 0.05 & 0.01 \\
\hline
\end{tabular}

The moisture content did not show significant changes in the case study compared to the conventional case. From practise it is known that for a conventional bulk system most weight losses occur at the bottom layer of the facility, due to the exposure of air with a lower humidity during forced (blowing) ventilation with outside air. When using overand underpressure it is likely that the bottom part is exposed shorter to dry air, and probably the weight loss will decrease in the bottom part and increase in the top part. This was not confirmed in the simulation, as the simulation time was to short and hence, further investigation on a complete storage season is needed.

In Appendix 3 A., Figure 3.16 shows the three cases (for existing facilities) at time $t=10.5$ [h]. From Figure 3.16 we see that the potato temperature distribution in the case study 2 is more homogeneous distributed compared to the other two cases. However, in the left corner and in the middle still some warmer areas and at the bottom a slightly colder area 

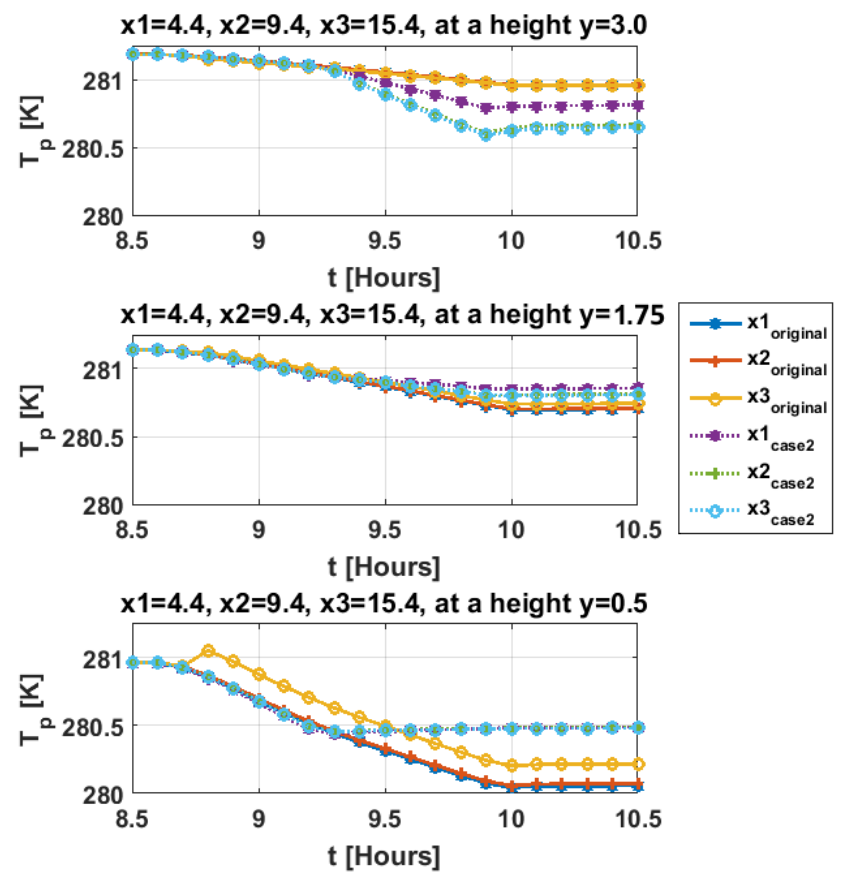

Figure 3.14: Product temperature profiles for the original simulation and the case study using over- and underpressure, and an extra air channel near the roof.

can be seen. For improved air mixing for over- and underpressure in new facilities, the right outlet hatch could be placed at the left side, such that the fan is in between two hatches.

\subsection{Conclusion}

In this paper, we have proposed a modelling approach and a spatially distributed airproduct model for an industrial full-scale potato bulk storage facility with dynamic control elements. The model was successfully calibrated after decoupling the fast (air-related) and slow (product-related) dynamics. The calibrated CFD model was also successfully validated with full-scale bulk storage data.

Since this model contains all relevant dynamics and control components (fan and hatches), it can be used to obtain more insight in the relation between storage climate, quality development and storage configuration. 


\section{Appendix 3 A. Additional figures}
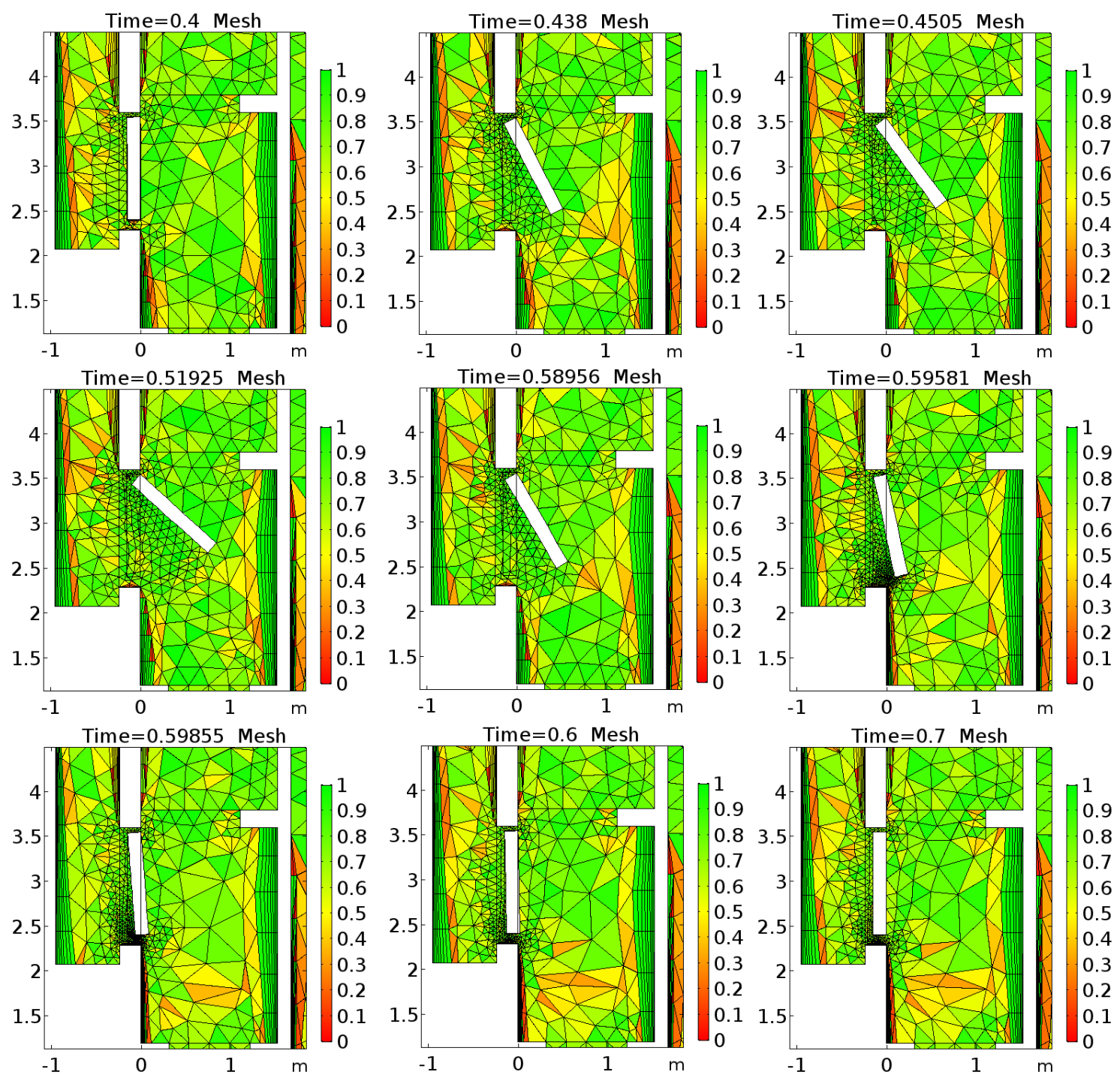

Figure 3.15: Dynamic implementation of opening and closing the inlet hatch, using a moving mesh. Results shown for time: $t=0.4[\mathrm{~h}]$ to $0.7[\mathrm{~h}]$. The colours indicate the equiangular skewness. 

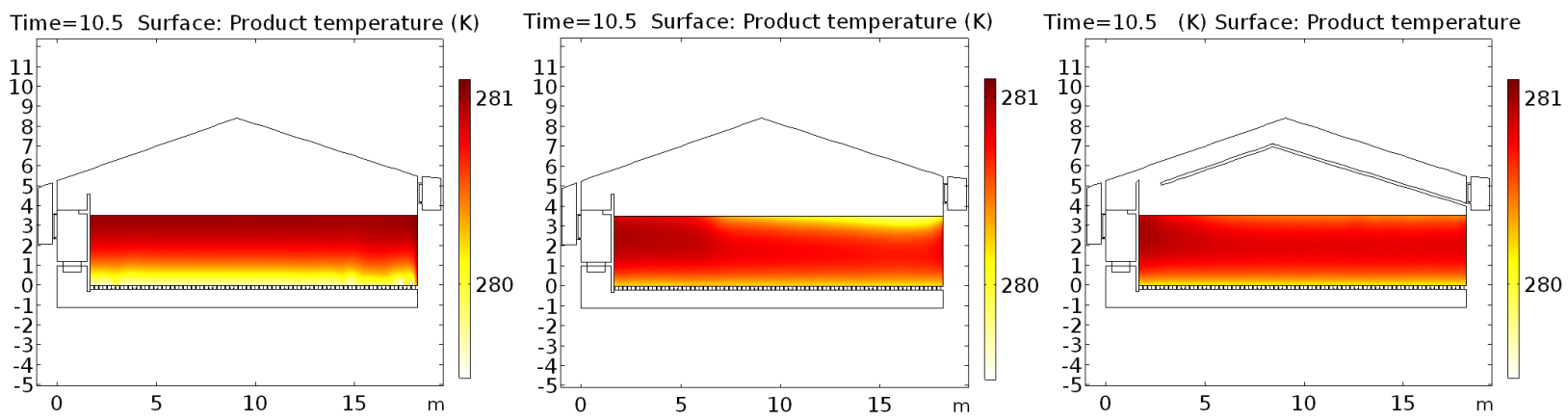

Figure 3.16: Product temperature at time $t=10.5[\mathrm{~h}]$. Temperature distribution after forced convection of the original case (left panel), the case study using over- and underpressure (middle panel) and case study 2 with an over- and underpressure and an extra air channel near the roof (right panel)

\section{References}

A. Ambaw, M.A. Delele, T. Defraeye, Q.T. Ho, L.U. Opara, B.M. Nicolai, and P. Verboven. The use of CFD to characterize and design post-harvest storage facilities: Past, present and future. Computers and Electronics in Agriculture, 93(0):184-194, 2013.

K.J. Beukema, S. Bruin, and J. Schenk. Heat and mass transfer during cooling and storage of agricultural products. Chemical Engineering Science, 37(2):291-298, 1982.

S.P. Burg. Postharvest physiology and hypobaric storage of fresh produce. CABI, 2004.

H.C. Castleberry and S.S. Jayanty. An experimental study of pressure flattening during long-term storage in four russet potato cultivars with differnces in at-harvest tuber moisture loss. American Journal of Potato Research, 89:269-276, 2012.

M.K. Chourasia and T.K. Goswami. Three dimensional modeling on airflow, heat and mass transfer in partially impermeable enclosure containing agricultural produce during natural convective cooling. Energy Conversion and Management, 48(7):2136-2149, 2007.

W. K. Coleman. Physiological ageing of potato tubers: A review. Annals of Applied Biology, 137:189-199, 2000.

B.J. Daniels-Lake. Carbon dioxide and ethylene gas in the potato storage atmosphere and their combined effect on processing colour. PhD thesis, Wageningen University, 2013.

J. Dehghannya, M. Ngadi, and C. Vigneault. Mathematical modeling of airflow and heat transfer during forced convection cooling of produce considering various package vent areas. Food Control, 22(8):1393 - 1399, 2011.

M.A. Delele, A. Schenk, H. Ramon, B.M. Nicolai, and P. Verboven. Evaluation of a chicory root cold store humidification system using computational fluid dynamics. Journal of Food Engineering, 91(1):110-121, 2009. 


\section{Chapter 3}

M.A. Delele, B. Vorstermans, P. Creemers, A.A. Tsige, E. Tijskens, A. Schenk, U.L. Opara, B.M. Nicolai, and P. Verboven. CFD model development and validation of a thermonebulisation fungicide fogging system for postharvest storage of fruit. Journal of Food Engineering, 108(1):59-68, 2012.

S. Ergun. Fluid flow through packed columns. Chemical Engineering Progress, 48:89-94, 1952.

W.J. Florkowski, R.L. Shewfelt, B. Brueckner, and S.E. Prussia, editors. Postharvest handling. Academic Press, San Diego, 2014.

N.L.M. Grubben and K.J. Keesman. Controllability and observability of 2D thermal flow in bulk storage facilities using sensitivity fields. International Journal of Control, 91(7): 1554-1566, 2017.

N.L.M. Grubben and K.J. Keesman. A spatially distributed physical model for dynamic simulation of ventilated agro-material in bulk storage facilities. Computers and Electronics in Agriculture, provisionally accepted for publication, 2018.

M.L.A.T.M. Hertog, L.M.M. Tijskens, and P.S. Hak. The effects of temperature and senescence on the accumulation of reducing sugars during storage of potato (Solanum tuberosum L.) tubers: A mathematical model. Postharvest Biology and Technology, 10 (1):67-79, 1997.

S.W. Hong, V. Exadaktylos, I.B. Lee, T. Amon, A.Youssef, T. Norton, and D. Berckmans. Validation of an open source CFD code to simulate natural ventilation for agricultural buildings. Computers and Electronics in Agriculture, 138:80-91, 2017.

D.A. Irvine, D.S. Jayas, and G. Mazza. Resistance to airflow through clean and soiled potatoes. American Society of Agricultural Engineers, 36:1405-1410, 1993.

C. Jia, D.-W. Sun, and C. Cao. Computer simulation of temperature changes in a wheat storage bin. Journal of Stored Products Research, 37:165-177, 2001.

W.M.F. Jongen and M.T.G. Meulenberg, editors. Innovation in agri-food systems. Wageningen Academic Publishers, 2005.

V.I. Kondrashov. Mathematical simulation of the coupled heat and moisture exchange in storehouses of agricultural production. Heat and Mass Transfer, 36:381-385, 2000.

V.I. Kondrashov. Modeling of heat and mass transfer and aerodynamics in a bulk of stored agricultural raw material. Journal of engineering Physics and Thermophysics, 80(4):833-839, 2007.

L.J.S. Lukasse, J.E. de Kramer-Cuppen, and A.J. van der Voort. A physical model to predict climate dynamics in ventilated bulk-storage of agricultural produce. International Journal of Refrigeration, 30(1):195-204, 2007.

I.F. Macdonald, M.S. El-Sayed, K. Mow, and F.A.L. Dullien. Flow through porous mediathe ergun equation revisited. Industrial Engineering Chemistry and Fundamentals, 18: 
199-208, 1979.

G. Mazza and A. J. Siemens. Carbon dioxide concentration in commercial potato storages and it effect on quality of tubers for processing. American Potato Journal, 97:121-132, 1990.

J. Moureh, M. Tapsoba, and D. Flick. Airflow in a slot-ventilated enclosure partially filled with porous boxes: Part ii measurements and simulations within porous boxes. Computers \&f Fluids, 38(2):206-220, 2009.

J. Muthoni, J. Kabira, H. Shimelis, and R. Melis. Regulation of potoat ruber dormancy: A review. Australian Journal of Crop Science, 8(5):754-759, 2014.

H.B. Nahor, N. Scheerlinck, P. Verboven, J. Van Impe, and B.M. Nicolaï. Continuous/discrete simulation of controlled atmosphere (CA) cool storage systems: model development and validation using pilot plant CA cool storage. International Journal of Refrigeration, 27(8):884-894, 2004.

H.B. Nahor, M.L. Hoang, P. Verboven, M. Baelmans, and B.M. Nicolaï. Cfd model of the airflow, heat and mass transfer in cool stores. International Journal of Refrigeration, 28(3):368-380, 2005.

R.Y. Ofoli and G.J. Burgess. A thermodynamic approach to heat and mass transport in stored agricultural products. Journal of Food Engineering, 5:195-216, 1986.

H.W. Peppelenbos, L.M.M. Tijskens, J. van 't Leven, and E.C. Wilkinson. Modelling oxidative and fermentative carobn dioxide production of fruits and vegetables. Postharvest Biology and Technology, 9:283-295, 1996.

B. Pringle, C. Bishop, and R. Clayton, editors. Potatoes postharvest. CABI, 2009.

A. Rastovski. Storage of potatoes; post-harvest behaviours, store design, storage practice and handling. Centre for Agricultural Publishing and Documentation, 1987.

P. J. Roache. Quantification of uncertainty in computational fluid dynamics. Annual Review of Fluid Mechanics, 29:123-160, 1997.

R.G.M. van der Sman. Prediction of airflow through a vented box by the Darcy-Forcheimer equation. Journal of Food Engineering, 55:49-57, 2002.

P. C. Struik and S. G. Wiersema, editors. Seed potato technology. Wageningen Academic Publishers, 2012.

L.M.M. Tijskens and J.J. Polderdijk. A generic model for keeping quality of vegetable produce during storage and distribution. Agricultural Systems, 51(4):431-452, 1996.

G.J.C. Verdijck, M.L.A.T.M. Hertog, M. Weiss, and H.A. Preisig. Modelling of a potato storage facility for product quality control purposes. Computers $\&$ Chemical Engineering, 23, Supplement(0):S911-S914, 1999.

Y. Xu and D. Burfoot. Simulating the bulk storage of foodstuffs. Journal of Food Engi- 


\section{Chapter 3}

neering, 39(1):23-29, 1999.

Y. Xu, D. Burfoot, and P. Huxtable. Improving the quality of stored potatoes using computer modelling. Computers and Electronics in Agriculture, 34(1):159-171, 2002. 


\section{Chapter 4}

\section{POSTHARVEST FRYING POTATO QUALITY DEVELOPMENT IN A LARGE-SCALE BULK STORAGE FACILITY}

In preparation as:

N.L.M. Grubben, S.C.M. Witte and K.J. Keesman. A spatially distributed physical model for dynamic simulation of ventilated agro-material in bulk storage facilities Postharvest Biology and Technology, accepted for publication, 2018 


\section{Chapter 4}

\section{Abstract}

During long-term storage, the quality in terms of moisture content and frying colour of frying potatoes declines and losses occur. This paper introduces a dynamic 1-D mathematical model that contains relevant quality indicators for frying potatoes and climate-related factors. The relevant quality indicators are temperature, moisture content and reducing sugar content of the potato, the climate-related factors are temperature, moisture content and carbon dioxide of the air. Parameter estimation and validation was performed with data from two large-scale storage facilities for the storage season 2016/2017, with good results. The validated model was subsequently used in a scenario study to investigate how the cooling trajectory of stored frying potatoes can be improved. For the Ramos variety, faster cooling leads to a decrease in weight loss and an increase in sugar content, but still within acceptable levels for industrial application.

\subsection{Introduction}

The potato, in addition to sugar cane, maize, rice and wheat, is one of the world's staple foods (FAOSTAT, 2017), and has multiple uses (Gancarz, 2016). Frying is one of its common preparation methods, resulting in a large number of pre-fried potato products (Kmiecik et al., 2017). As potatoes are seasonal, high-quality storage of potatoes is essential to provide a good quality product throughout the whole year (Singh and Kaur, 2016).

In the postharvest stage, potatoes are a perishable commodity and undergo active metabolism. Potato storage therefore has to maintain or improve the quality of the stored product, such that a well-textured, flavourful and non-toxic product is obtained. The quality of frying potatoes is highly determined by their mass and sugar levels. During storage the mass decreases mainly caused by evaporative moisture loss and the reducing sugar (RS) level increases mainly due to senescence and cold-induced sweetening. The moisture content has, in particular, effects on the hardness of the tissue and the cutting process. The glucose and fructose sugar levels, generally known as the reducing sugar level, are related to the browning (Maillard) reaction, taste and texture (Miranda and Aguilera, 2006), but also to acrylamide formation during frying (Mesias et al., 2016). Moisture content as well as sugar (and acrylamide) levels are influenced by the climate around the stored potato and by the temperature of the potato itself (Singh and Kaur, 2016; Grubben and Keesman, 2015; Heltoft et al., 2016).

As the climate in storage facilities can be manipulated relatively easily, climate control is widely applied. Under the right conditions, potatoes can be stored for over ten months (Wustman and Struik, 2007). However, from practice we know that a good storage cli- 


\begin{tabular}{|c|c|c|c|c|}
\hline \multicolumn{5}{|c|}{ Nomenclature } \\
\hline \multicolumn{3}{|c|}{ Subscript } & $E_{i}$ & Activation energy \\
\hline$a$ & Air & & $E_{r e s p}$ & Respiration mass per unit of energy $\left[\frac{\mathrm{kg}}{\mathrm{J}}\right]$ \\
\hline cold & Cold-induced sweetening & & En & Enzyme \\
\hline dena & Denaturation & & $F_{m}$ & Potato surface \\
\hline eff & Effective & & $F_{e b}$ & External body force \\
\hline form & Formation & & $g$ & Gravity \\
\hline$p$ & $\begin{array}{l}\text { Produce } \\
\text { Beference }\end{array}$ & & $h_{f g}$ & Enthalpy of vaporisation \\
\hline $\begin{array}{l}\text { ref } \\
\text { resp }\end{array}$ & $\begin{array}{l}\text { Reference } \\
\text { Respiration }\end{array}$ & & $K_{R S}$ & Gain parameter \\
\hline sene & Senescent sweetening & & $K_{\text {evap }}$ & Product evaporation coefficient \\
\hline \multicolumn{3}{|c|}{ Parameters } & $k_{i}$ & Reaction rate \\
\hline$\alpha_{c}$ & Heat transfer coefficient & {$\left[\frac{\mathrm{W}}{\mathrm{m}^{2} \cdot \mathrm{K}}\right]$} & $M$ & Molar mass \\
\hline$\lambda$ & Heat conduction coefficient & {$\left[\frac{\mathrm{W}}{\mathrm{m} \cdot \mathrm{K}}\right]$} & $\mathrm{O}_{2}$ & Oxygen concentration \\
\hline$\mu$ & Dynamic viscosity & {$[\mathrm{Pa} \cdot \mathrm{s}]$} & $P$ & Pressure \\
\hline$\Omega$ & Domain & & $R S$ & Reducing sugar concentration \\
\hline$\rho$ & Density & {$\left[\frac{\mathrm{kg}}{\mathrm{m}^{3}}\right]$} & $R$ & Gas constant \\
\hline$\theta$ & Parameter & & Resp & Product respiration rate \\
\hline$\epsilon$ & Porosity & & $r_{1}$ & Product respiration parameter \\
\hline $\begin{array}{l}\nabla \\
C I\end{array}$ & $\begin{array}{l}\text { Vector differential operator nabla } \\
\text { Colour index }\end{array}$ & & $r_{2}$ & Product respiration parameter \\
\hline $\mathrm{CO}_{2}$ & Carbon dioxide concentration & [ppm] & $r_{3}$ & Product respiration parameter \\
\hline$C$ & Specific heat & {$\left[\frac{\mathrm{J}}{\mathrm{kg} \cdot \mathrm{K}}\right]$} & $t$ & Time \\
\hline $\mathbb{D}$ & Diffusion coefficient & {$\left[\frac{\mathrm{m}^{2}}{\mathrm{~s}}\right]$} & $T$ & Temperature \\
\hline$d_{p}$ & Diameter of produce & {$[\mathrm{m}]$} & $v$ & Velocity \\
\hline$E_{\mathrm{CO}_{2}}$ & Respiratory $\mathrm{CO}_{2}$ per unit of energy & {$\left[\frac{\mathrm{kg}}{\mathrm{J}}\right]$} & $X$ & Moisture content \\
\hline$E_{O}$ & Oxidation energy & {$\left[\frac{\mathrm{J}}{\mathrm{mol}}\right]$} & $X_{s}$ & Saturated vapour concentration $\left[\frac{\mathrm{kg} \text { water }}{\mathrm{kg} \text { air }}\right]$ \\
\hline
\end{tabular}

mate does not automatically guarantee the high quality of the stored potatoes. Also, the divergence of and developments in potato varieties demand continued optimisation of storage conditions. In practice, optimisation of climate conditions proceeds only slowly, as a result of the seasonal dependency, long storage periods and quality evaluations only once a season. Optimisation of climate conditions throughout a storage season can be accelerated by making use of simulations that focus on quality indicators such as moisture content and sugar level. To realise reliable simulations over a storage season, a multidisciplinary approach is required that combines physics and physiology, together with model data integration.

To that end, detailed knowledge is needed of the development of the quality and climate, and the interactions between them during storage. The literature contains various studies that focus on potato quality, (e.g. Barker and el Saifi, 1953; Amir et al., 1977; Marangoni 


\section{Chapter 4}

et al., 1997; Krause et al., 1998; Hajirezaei et al., 2003), on storage climate (e.g. Rastovski, 1987; Irvine et al., 1993; Van 't Ooster, 1999; Lukasse et al., 2007; Pringle et al., 2009) and on the interactions between product quality and climate (e.g. Claassen et al., 1990; Hertog et al., 1997; Gokmen et al., 2007; Driskill et al., 2007; Viklund et al., 2008; Knowles et al., 2009; Saray et al., 2009; Castleberry and Jayanty, 2012; Daniels-Lake, 2013; Olsen et al., The Netherlands, 2016; Heltoft et al., 2016). However, a study that investigates the behaviour of climate properties (temperature, moisture content and carbon dioxide content) and quality indicators for the potatoes (moisture content and sugar level) in large-scale facilities and integrates spatially distributed modelling with experimental data is lacking.

In Verdijck (2003) and Verdijck et al. (2005) product quality control for agro-material, on base of lumped models is proposed. In the work of Verdijck et al. (1999) and Verdijck and Tijskens (2003) a combination of lumped (product quality) and spatially distributed (climate properties) were presented, and eventually used in a model predictive control strategy, to control the sugar and temperature. However, the implementation of quality control in industrial facilities has not been applied yet on large scale. The dissemination of quality control is probably lacking due to vital gaps in the knowledge on biological (season-dependent) variations, manipulation constraints during the different store periods, heterogeneously spatial distribution and the lack of a spatially distributed product quality model.

In this paper, we report on a study in which we took a similar approach as in Hertog et al. (2011) to obtain multidisciplinary knowledge of the quality development of frying potatoes in a large-scale facility during a complete storage season. We set up a large-scale experiment to collect the main quality and storage climate data throughout a complete storage season. We used a physical modelling approach for the construction of the storage model and applied the experimental data from the large-scale facilities to calibrate and validate the model. We subsequently used the validated model to investigate the influence of temperature, especially during the early cooling stage, on quality indicators. We conducted a numerical study to explore the hypothesis that slow cooling is more beneficial for all quality indicators than rapid cooling. The remainder of this paper is structured as follows. Section 2 describes the materials and methods used in the large-scale experimental set-up as well as for the modelling. Section 3 presents the results of the calibration, validation and scenario study. Sections 4 and 5 contain the discussion and conclusions. 


\subsection{Materials and methods}

\subsubsection{Large-scale facility set-up}

For the collection of experimental data, two different large-scale storage facilities in the Netherlands (Flevoland and Zeeland) were monitored during the storage season 20162017. Each facility stored approximately 600 tonnes of the potato variety Ramos. These potatoes were grown for $146 \mathrm{~d}$ and $143 \mathrm{~d}$ on clay soil; the haulm was killed $30 \mathrm{~d}$ and $23 \mathrm{~d}$ before harvesting, that took place on 7 and 4 October 2016, respectively. For both stores the Ramos were treated (spraying) during store loading with $150 \mathrm{ml}$ Grow-Stop ready (CIPC) per tonne potatoes for sprout inhibition. The measurements of temperature took place on three different locations in the bulk: bottom layer $(0.5 \mathrm{~m})$, middle layer $(2.0 \mathrm{~m})$ and top layer $(3.5 \mathrm{~m})$. Weight loss and the carbon dioxide level were measured in the middle $(2.0 \mathrm{~m})$, and the samples for the sugar analysis were taken approximately 20-50 $\mathrm{cm}$ beneath the top of the bulk. The tubers were stored for $253 \mathrm{~d}$ and $239 \mathrm{~d}$. The two storage facilities were equipped with forced ventilation of approximately 150 and 110 $\mathrm{m}_{\text {air }}^{3} / \mathrm{m}_{\text {product }}^{3} / \mathrm{h}$ and had a target storage temperature of 279.85 Kelvin $\left(6.7^{\circ} \mathrm{C}\right)$ and 280.95 Kelvin $\left(7.8^{\circ} \mathrm{C}\right)$, respectively. The relative humidity of the air in the storage facilities was between 93 and $98 \%$.

Figure 4.1 provides a schematic presentation of the storage facilities. The bulk was $4 \mathrm{~m}$ high and forced convection was applied through a perforated floor. From the results of work by Grubben and Keesman (2018), we know that with this combination of cellar and perforated floor, the air is optimally mixed in the pressure chamber and that pressure in the horizontal direction is homogeneous. Having negligible gradients in the horizontal direction allow us to set up a 1-D model of the facility in the vertical direction.

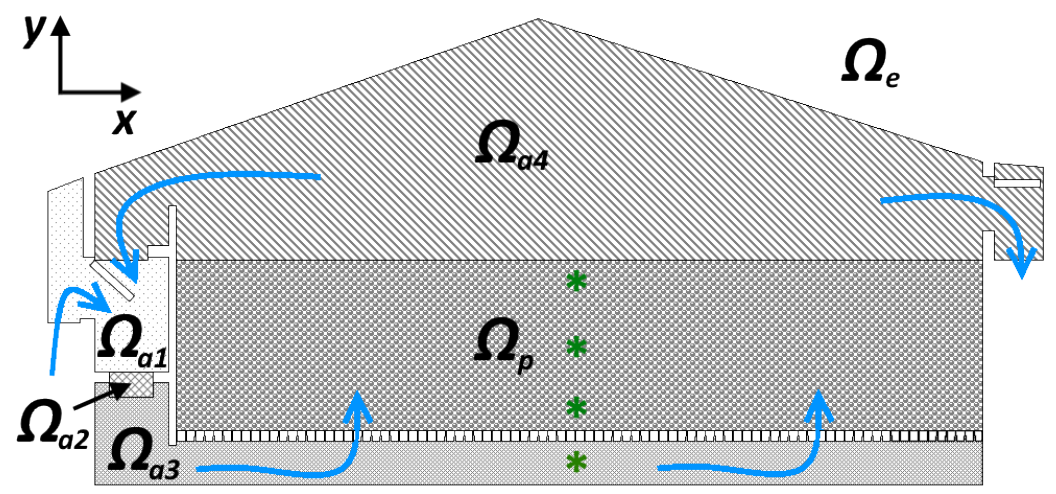

Figure 4.1: 2-D schematic configuration of the storage facility, with $\Omega_{a}$ the air domain, $\Omega_{p}$ the porous medium domain and $\Omega_{e}$ the environment. The climate is controlled by mixing and ventilating air from outside $\Omega_{a 1}$ and inside $\Omega_{a 4}$, via the air channel $\Omega_{a 3}$ through the porous medium $\Omega_{p}$. The air in $\Omega_{a 4}$ can leave the facility environment or can be recirculated. The symbol $*$ represents the measuring points in the different layers. 


\section{Chapter 4}

\section{Temperature measurements}

The temperatures of the air and of the potatoes were measured in the bottom $(0.5 \mathrm{~m})$, middle $(2.0 \mathrm{~m})$ and top $(3.5 \mathrm{~m})$ layers of the bulk, with Pt100 $\operatorname{sensors}^{1}\left( \pm 0.1{ }^{\circ} \mathrm{C}\right)$. The sensors were placed in the airspace between the potatoes, as well as inside some potatoes. Also the air temperature at the roof, air channel (in domain $\Omega_{a 3}$ ) were measured. A sample frequency of 1 minute was used.

\section{Mass and moisture content measurements}

The change in the potato moisture loss was measured in the form of weight loss. Potatoes were measured using a weighing platform, in the centre of the bulk. The weighing platform was placed inside a wooden box. A sample of $17 \mathrm{~kg}$ of potatoes was placed on the weighing platform. The weighing platform was equipped with a load cell ${ }^{2}( \pm 5[\mathrm{~g}])$, with a sample frequency of once per day. We monitored the air moisture content in the air channel (in domain $\Omega_{a 3}$ ) with $\mathrm{HC101}$ humidity $\operatorname{sensors}^{1}( \pm 3[\%]$ ), with a sample frequency of 1 minute. In addition to the weighing platform in the centre of the bulk, in the bottom and top layers 3 net-bags (in total 6 net-bags) filled with $15 \mathrm{~kg}$ of potatoes were placed. At the end of the storage season these bags were weighed to evaluate the weight loss in these layers of the bulk. In this paper, the potato moisture content $\left(X_{p}\right)[\mathrm{kg} / \mathrm{kg}$ product] is modelled but the change of this moisture content is evaluated on base of weight loss $\left(X_{p, l o s s}\right)[\%]$.

\section{Carbon dioxide measurements}

The carbon dioxide concentration $\left(\mathrm{CO}_{2}\right)$ was measured in the centre of the bulk and in the the air channel (in domain $\Omega_{a 3}$ ). $\mathrm{A} \mathrm{CO}_{2}$ transmitter $^{1}( \pm 50[\mathrm{ppm}]$ ) with a sample frequency of 5 minutes was used. In this paper, $\mathrm{CO}_{2}$ values are given in [\%].

\section{Sugar measurements}

For the determinations of the sugar content, we took a sample of 50 tubers, approximately 20-50 cm beneath the top of the bulk, with a sample frequency of once per week. These potatoes were washed, and the peel was scrubbed off mechanically. Two or three strips of 10x10 mm were taken from each of these tubers, from the centre and in longitudinal direction. One or two were used for the sugar measurement and one was used for the determination of the frying colour. A 200-g random sub-sample from the strips was

\footnotetext{
${ }^{1}$ Manufacturer: E+E electronics, Australia.

${ }^{2}$ Manufacturer: AllScales Europe, Netherlands.
} 
extracted (Wilson et al., 1981), using a Magimix Le Duo Plus juicer. After juicing, the pulp left in the juicer was flushed 3 times with $100 \mathrm{~mL}$ cold water (Sowokinos, 1978), until we obtained $500 \mathrm{~mL}$ diluted potato juice. We waited two minutes between these three flushing steps. The samples were mixed and stored for a few months at $-28{ }^{\circ} \mathrm{C}$. An HPLC instrument was used to measure the sucrose, glucose and fructose levels. Before measuring, the defrosted samples were centrifuged for ten minutes at $19000 \mathrm{rpm}$. To extract sugars that might interfere with the HPLC measurements, $1 \mathrm{~mL}$ of the centrifuged samples was filtered over a Strata-X $33 \mu 200 \mathrm{mg} / 3 \mathrm{ml}$ polymeric reversed phase filter. The filter was preconditioned with $2 \mathrm{~mL}$ methanol and rinsed with $2 \mathrm{~mL}$ of Milli-Q water. The final solutions were extracted from the samples using a Phenex-RC $0.2 \mu \mathrm{m}$ syringe filter. The prepared samples were analysed in the HPLC instrument with RI detector, using an Aminex HPX-87H Bio-Rad column and eluent $5 n M \mathrm{H}_{2} \mathrm{SO}_{4}$. In this paper, sugar values are given in [\%], on a fresh-weight basis.

\section{Frying colour}

The frying colour was determined, likewise as in industry, with the colour evaluation of the United States Department of Agriculture (USDA) using the Munsell colour chart for frozen french fried potatoes. Weekly, from 20 tubers a slice of $10 \times 10 \mathrm{~mm}$ out of the core was fried for 3 minutes at 180 degrees Celsius. The colour evaluation ranges from 000 to $4(000,00,0,1,2,3,4)$, with 000 considered as no browning after frying. The colour index $(C I)$ is determined as the weighted sum of slices of a certain colour with $0,1,2,3$, $4,5,6$, respectively, divided by the total amount of tuber slices. For example if from the 20 slices 5 scores a 00,5 a 0 , and 10 a 1 , that the $C I=\frac{5 \times 1+5 \times 2+10 \times 3}{20}=2.25$. A colour index $<3$ indicates excellent quality, $C I 3-4$ indicates acceptable quality and a $C I>4$ can lead to a discount on the potato price or rejection of the potatoes.

\subsubsection{Climate and product model}

In our physically based modelling approach, we took two different domains into consideration, namely the air domain $\Omega_{a}$ and the product domain $\Omega_{p}$, the latter containing the product bulk and the air between the potatoes (see Figure 4.1).

The five states of potato temperature $\left(T_{p}\right)$, air temperature $\left(T_{a}\right)$, potato moisture content $\left(X_{p}\right)$, air moisture content $\left(X_{a}\right)$ and carbon dioxide $\left(\mathrm{CO}_{2}\right)$ and corresponding equations follow from the work of Grubben and Keesman (2018). We used the modelling approach of Hertog et al. (1997) for the dynamic behaviour of the reducing sugars.

The law of conservation of energy describes the air- and product temperature $\left(T_{a}\right.$ and $T_{p}$ $[\mathrm{K}])$ change in the porous medium $\left(\Omega_{p}\right)$ and in the air domains $\left(\Omega_{a}\right)$ by a set of coupled 


\section{Chapter 4}

partial differential equations, as follows:

$$
\begin{array}{r}
\frac{\partial T_{a}}{\partial t}+\frac{1}{\varepsilon_{a}} v_{e f f} \cdot \nabla T_{a}-\nabla\left(\frac{\lambda_{a}}{\rho_{a} C_{p a}} \nabla T_{a}\right)=\frac{\alpha_{c} F_{m}}{\rho_{a} C_{p a} \varepsilon_{a}}\left(T_{p}-T_{a}\right) \text { in }(0, T] \times \Omega_{p} \\
\frac{\partial T_{p}}{\partial t}-\nabla\left(\frac{\lambda_{p}}{\rho_{p} C_{p}} \nabla T_{p}\right)=-\frac{\alpha_{c} F_{m}}{\rho_{p} C_{p} \varepsilon_{p}}\left(T_{p}-T_{a}\right)+\frac{\operatorname{Resp}}{C_{p}} \\
-h_{f g} K_{\text {evap }} \frac{F_{m}}{\rho_{p} C_{p} \varepsilon_{p}}\left(X_{s}-X_{a}\right) \text { in }(0, T] \times \Omega_{p} \\
\frac{\partial T_{a}}{\partial t}+v_{e f f} \cdot \nabla T_{a}-\nabla\left(\frac{\lambda_{a}}{\rho_{a} C_{p a}} \nabla T_{a}\right)=0 \text { in }(0, T] \times \Omega_{a i}
\end{array}
$$

Here, $X_{a}$ is the moisture content of the air $[\mathrm{kg} / \mathrm{kg}], \varepsilon$ the porosity $\left(\varepsilon_{a}=0.36\right)$ and $h_{f g}$ the enthalpy of vaporisation $\left(2490 \cdot 10^{3}[\mathrm{~J} / \mathrm{kg}]\right)$. The velocity is represented by $v_{\text {eff }}[\mathrm{m} / \mathrm{s}]$ and $K_{\text {evap }}$ is the product evaporation coefficient $\left[\mathrm{kg} /\left(\mathrm{m}^{2} \mathrm{~s}\right)\right]$, and both are estimated during the calibration step. Here, $\lambda$ is the heat conduction coefficient $[\mathrm{W} /(\mathrm{m} \mathrm{K})], \rho$ the density $\left[\mathrm{kg} / \mathrm{m}^{3}\right]$ and $C$ the specific heat $\left(C_{p a}\right.$ and $C_{p}$ for air and product, respectively) $[\mathrm{J} /(\mathrm{kg} \mathrm{K})]$. For air these coefficients are calculated dynamically by COMSOL, for the potato these are taken as $0.4,1014$ and 3516, respectively. $X_{s}$ the average vapour concentration around the potato $[\mathrm{kg} / \mathrm{kg}]$ (see Lukasse et al., 2007). Here, $F_{m}$ is the specific surface of the mount $\left[\mathrm{m}^{2} / \mathrm{m}^{3}\right]$, Resp the respiration $[\mathrm{W} / \mathrm{kg}]$ and $\alpha_{c}$ the heat transfer coefficient $\left[\mathrm{W} /\left(\mathrm{m}^{2} \mathrm{~K}\right)\right]$ and are defined below. The specific surface of the mount depends on porosity and the potato diameter $\left(d_{p}[\mathrm{~m}]\right): F_{m}=\frac{\pi d_{p}^{2}}{(1 / 6) \pi d_{p}^{3}} \varepsilon_{p}$. The respiration is modelled as $\operatorname{Resp}=r_{1}+r_{2} T_{p}+r_{3} T_{p}^{2}$, where $r_{1}, r_{2}$ and $r_{3}$ are the product respiration parameters $\left([\mathrm{W} /(\mathrm{kg} \mathrm{K})],\left[\mathrm{W} /\left(\mathrm{kg} \mathrm{K}^{2}\right)\right]\right.$ and $\left[\mathrm{W} /\left(\mathrm{kg} \mathrm{K}^{3}\right)\right]$ respectively), and are estimated during the model calibration step. The heat transfer coefficient is modelled as: $\alpha_{c}=\alpha_{c 1} d_{p}+\frac{\alpha_{c 2} v_{e f f}^{0.67}}{d_{p}^{0.33}}$, with $\alpha_{c 1}=0.05\left[\mathrm{~W} /\left(\mathrm{m}^{3} \mathrm{~K}\right)\right]$ and $\alpha_{c 2}\left[\mathrm{~J} /\left(\mathrm{m}^{2} \mathrm{~K}\right)\right]$ and estimated in the calibration step.

The law of conservation of mass describes the moisture profiles for the porous domain $\left(X_{p}[\mathrm{~kg} / \mathrm{kg}\right.$ product $], X_{a}[\mathrm{~kg} / \mathrm{kg}$ air $\left.]\right)$ and air domain $\left(X_{a}[\mathrm{~kg} / \mathrm{kg}\right.$ air $\left.]\right)$ :

$$
\begin{array}{r}
\frac{\partial X_{a}}{\partial t}+\frac{1}{\varepsilon_{a}} v_{\text {eff }} \cdot \nabla X_{a}-\nabla\left(\mathbb{D}_{a} \nabla X_{a}\right)=K_{\text {evap }} \frac{F_{m}}{\rho_{a} \varepsilon_{a}}\left(X_{s}-X_{a}\right) \text { in }(0, T] \times \Omega_{p} \\
\frac{\partial X_{p}}{\partial t}-\nabla\left(\mathbb{D}_{p} \nabla X_{p}\right)=-K_{\text {evap }} \frac{F_{m}}{\rho_{p} \varepsilon_{p}}\left(X_{s}-X_{a}\right)-E_{\text {resp }} R e s p \text { in }(0, T] \times \Omega_{p} \\
\frac{\partial X_{a}}{\partial t}+v_{\text {eff }} \cdot \nabla X_{a}-\nabla\left(\mathbb{D}_{a} \nabla X_{a}\right)=0 \text { in }(0, T] \times \Omega_{a i}
\end{array}
$$

Here, $E_{\text {resp }}$ represents the respiration mass per energy $\left(2.5 \cdot 10^{-8}[\mathrm{~kg} / \mathrm{J}]\right)$ taken as a constant. $\mathbb{D}_{a}$ is the diffusion coefficient in air $\left(2.2 \cdot 10^{-5}\left[\mathrm{~m}^{2} / \mathrm{s}\right]\right)$ and $\mathbb{D}_{p}$ the diffusion coefficient in the potato $\left(\left[\mathrm{m}^{2} / \mathrm{s}\right]\right)$ (see $\mathrm{Xu}$ and Burfoot, 1999).

The $\mathrm{CO}_{2}$ concentration is modelled using two state equations for $\mathrm{CO}_{2, a}$ [\%], namely in 
the porous and in the air domain, using the law of conservation:

$$
\begin{array}{r}
\frac{\partial C O_{2, a}}{\partial t}+\frac{1}{\varepsilon_{a}} \boldsymbol{v} \cdot \nabla C O_{2, a}-\nabla\left(\mathbb{D}_{C O 2, a} \nabla C O_{2, a}\right)=E_{C O 2} \operatorname{Resp} \text { in }(0, T] \times \Omega_{p} \\
\frac{\partial C O_{2, a}}{\partial t}+\boldsymbol{v} \cdot \nabla C O_{2, a}-\nabla\left(\mathbb{D}_{C O 2, a} \nabla C O_{2, a}\right)=0 \text { in }(0, T] \times \Omega_{a i}
\end{array}
$$

Here, $\mathbb{D}_{C O 2, a}$ is the diffusion coefficient $\left(1.6 \cdot 10^{-5}\left[\mathrm{~m}^{2} / \mathrm{s}\right]\right)$. The production term of $\mathrm{CO}_{2}$ in the porous domain is driven by the respiration of the potato (Resp). The respiratory $\mathrm{CO}_{2}$ concentration per unit of energy $E_{\mathrm{CO} 2}([\mathrm{~kg} / \mathrm{J}])$ is taken as a constant (Lukasse et al., 2007), and estimated in the calibration step.

The reducing sugar $(R S[\%])$ content depends on enzyme-catalysed reactions, activated by senescence, cold-induced sweetening and respiration. The sugar and enzyme $(E n)$ contents are temperature-dependent, and are described by ordinary differential equations:

$$
\begin{array}{r}
\frac{d R S}{d t}=k_{\text {cold }} \cdot E n_{\text {cold }}+k_{\text {sene }} \cdot E n_{\text {sene }}-\frac{M_{R S}}{E_{o}} R e s p \cdot R S \cdot O_{2} \text { in }(0, T] \times \Omega_{p} \\
\frac{d E n_{\text {cold }}}{d t}=-k_{\text {dena }} \cdot E n_{\text {cold }} \text { in }(0, T] \times \Omega_{p} \\
\frac{d E n_{\text {sene }}}{d t}=k_{\text {form }} \cdot E n_{\text {sene }} \text { in }(0, T] \times \Omega_{p}
\end{array}
$$

Here, he reaction rates $k_{i}$ are temperature-dependent and follow from the Arrhenius equation:

$$
k_{i}=k_{i_{r e f}} \cdot e^{\frac{E_{i}}{R} \cdot\left(\frac{1}{T_{r e f}}-\frac{1}{T_{p}}\right)}
$$

Here, $R$ represents the gas constant $[\mathrm{J} /(\mathrm{mol} \mathrm{K})]$, and $T_{\text {ref }}$ was taken as $285.15[\mathrm{~K}] . M_{R S}$ is the molar mass $[\mathrm{kg} / \mathrm{mol}], E_{o}$ the oxidation energy $[\mathrm{J} / \mathrm{mol}]$ and $O_{2}$ the oxygen concentration. A combination of these three terms will be estimated in the model calibration step.

We implemented the model in the COMSOL 5.3 simulation software for simulation, calibration and validation. As described in Section 4.2.1, negligible gradients in horizontal direction are seen in bulk storage facilities with cellar and a perforated floor. Hence, a 1-D model in the $y$-direction is used, and in Eqs. (4.1)-(4.8), $\nabla:=\frac{\partial}{\partial y}$. The simulation contains a part of the air channel $\left(\Omega_{a 3}\right)$ and the bulk $\left(\Omega_{p}\right)$, see also the green asterisks in Figure 4.1. 


\section{Chapter 4}

\section{Boundary conditions}

The boundary conditions at the top of the 1-D model are defined as (Neumann) no flux through the boundary conditions, for all of the states, i.e., $\frac{\partial \text { State }}{\partial y}=0$. Also, no flux through the boundary conditions are set for the bottom layer of the bulk domain $\left(\Omega_{p}\right)$. For the boundary at the bottom at the interface with the air channel domain $\left(\Omega_{3 a}\right)$, Dirichlet boundary conditions were used for temperature $\left(T_{a}=T_{a, i n}\right)$, moisture content $\left(\mathrm{X}_{a}=\mathrm{X}_{a, \text { in }}\right)$ and carbon dioxide $\left(\mathrm{CO}_{2}=\mathrm{CO}_{2, \text { in }}\right)$ levels. The Dirichlet boundary conditions were specified on base of the measured states in the air channel.

\subsubsection{Calibration and validation}

For the calibration of the model, we used the data measured for the stored potatoes of the Ramos variety in one of the facilities. The potato diameter was estimated as $64 \mathrm{~mm}$. The model contains fourteen parameters that need to be estimated, namely $r_{1}, r_{2}, r_{3}, K_{\text {evap }}$, $\alpha_{c 2}, v_{\text {eff }}, E_{\mathrm{CO}_{2}}, k_{\text {cold }_{\text {ref }}}, E_{\text {cold }}, k_{\text {dena } a_{\text {ref }}}, E_{\text {dena }}, k_{\text {form } m_{\text {ref }}}, E_{\text {form }}$ and $K_{R S} . K_{R S}$ represents a combined term of $\frac{M_{R S}}{E_{o}} \cdot O_{2}$.

In the calibration step, we decoupled the model because of the complexity of coupling fast and slow states in the model. This decoupling allows the use of non-linear least-squares parameter estimation techniques. The parameter estimation was set-up by making use of the optimisation interface and the standard Levenberg-Marquardt solver of COMSOL. In general, and as a result of the curse of dimensionality, a least-squares method can typically handle five to six parameters in one estimation step. Also, non-linear leastsquares estimations can be sensitive to the initial guesses of the parameters. In this study, we used a seven-stage parameter estimation procedure. The complete model was used in all stages; only a selected number of states and parameters were used in the parameter estimation. The clusters were chosen such that no more than five parameters were estimated, using the knowledge of the parameter sensitivities in each stage as given by Grubben and Keesman (2018).

In the seven-stage procedure (see Table 4.1), we estimated several parameters twice, using different measurements for the second estimation. Table 4.1 gives an overview of the estimated parameters and used measurements. In the first stage, the final estimates of parameter $\alpha_{c 2}$ were calculated, by making use of the temperature measurements and the initial guess found in the literature. The parameter $\alpha_{c 2}$ has a relatively large influence on $T_{p}$. Since changes in $r_{1}, r_{2}, r_{3}, K_{\text {evap }}$ influence the estimate of $\alpha_{c 2}$, these four parameters were also taken into account. After stage 1, the estimates of $\alpha_{c 2}$ were fixed and in stage 2 the parameters $r_{1}, r_{2}, r_{3}, K_{\text {evap }}$ and $v_{\text {eff }}$ were estimated, by making use of the values that follow from stage 1 and measurements of $X_{p}$. Stage 2 was performed to get suitable initial values for stage 3 , in which $r_{1}, r_{2}, r_{3}, K_{\text {evap }}$ and $v_{\text {eff }}$ were estimated again, now with both measurements of $T_{p}$ and $X_{p}$. From stage 3 , the final parameter estimates of $r_{1}$, 
Table 4.1: Calibration procedure

\begin{tabular}{|c|c|c|}
\hline Stage & Parameter estimated & Measurements \\
\hline 1 & $r_{1}, r_{2}, r_{3}, K_{\text {evap }}, \alpha_{c 2}$ & $T_{p}$ \\
\hline 2 & $r_{1}, r_{2}, r_{3}, K_{\text {evap }}, v_{e f f}$ & $X_{p}$ \\
\hline 3 & $r_{1}, r_{2}, r_{3}, K_{\text {evap }}, v_{\text {eff }}$ & $T_{p}, X_{p}$ \\
\hline 4 & $E_{C O_{2}}$ & $E_{\mathrm{CO}_{2}}$ \\
\hline 5 & $\begin{array}{c}k_{\text {cold }}{ }_{r e f}, E_{\text {cold }}, k_{\text {dena }_{\text {ref }}}, E_{\text {dena }} \\
k_{\text {form }}, \\
k_{\text {ref }}, E_{\text {form }}\end{array}$ & $R S$ \\
\hline 6 & $K_{R S}$ & $R S$ \\
\hline 7 & $\begin{array}{c}k_{\text {cold }}, E_{r e f}, E_{\text {cold }}, k_{\text {dena }}, E_{\text {ref }}, E_{\text {dena }} \\
k_{\text {form }}, \\
\text { ref } \\
E_{\text {form }}\end{array}$ & $R S$ \\
\hline
\end{tabular}

$r_{2}, r_{3}, K_{\text {evap }}$ and $v_{\text {eff }}$ were determined. In stage 4 , only measurements of $\mathrm{CO}_{2}$ were used to estimate $E_{\mathrm{CO}_{2}}$, as $E_{\mathrm{CO}_{2}}$ only affects the carbon dioxide state. In stages 5,6 and 7, the parameters related to the reducing sugar $(R S)$ content were estimated. In stage 5 , the

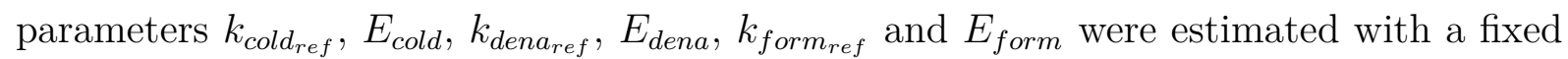
$K_{R S}$. The result of stage 5 gave good initial conditions to perform a parameter sweep for $K_{R S}$ in stage 6 . In stage 7 , the initial values for $k_{\text {cold }}$ ref $, E_{\text {cold }}, k_{\text {dena } a_{r e f}}, E_{\text {dena }}, k_{f_{\text {form }} \text { ref }}$ and $E_{\text {form }}$ from the parameter estimates of stage 5 were taken with the best parameter estimate from stage 6 for $K_{R S}$.

For the calibration of the storage model two different measuring points in the bulk were selected. For the temperature and reducing sugar states a point in the top layer of the bulk $(3.5 \mathrm{~m})$ were taken. For the weight loss of the potato and carbon dioxide measurements at the centre of the bulk $(2.0 \mathrm{~m})$ were taken. In the validation step the dynamics of the model were evaluated on the same points as in the calibration step. For the validation of the spatial distribution of the temperature, in addition to the top layer $(3.5 \mathrm{~m})$, the predicted temperatures in the bottom and middle layers $(0.5 \mathrm{~m}$ and $2.0 \mathrm{~m})$ were also compared to the measurements. For the validation of the spatial distribution of the weight loss, in addition to the middle layer $(2.0 \mathrm{~m})$, the weight loss was also validated using the net-bag weight losses in the bottom and top layers $(0.5 \mathrm{~m}$ and $3.5 \mathrm{~m})$. As in the experiments the weight loss was measured, the potato moisture content $\left(X_{p}\right)$ was evaluated using these weight loss $\left(X_{p, l o s s}\right)$ measurements.

For the validation of the model, a data set for the same potato variety (Ramos) was used, but from the other storage facility. The potato diameter was estimated as $65 \mathrm{~mm}$. To evaluate the influence of the original parameters and the parameter estimates for the calibration and validation data sets on the outputs, a weighted mean squared error (WMSE) was introduced. The weight $w(x)=\frac{1}{\operatorname{var}(x)}$, with $x$ the states $T_{p}, X_{p}, C O_{2}$, and $R S$. In addition to the direct influence of the parameter estimates on the WMSE, also the influence of a change in the parameters on a change in the normalised WMSE $\left(S_{\theta_{i}}^{x}\right)$ of the validation set was determined, $S_{\theta_{i}}^{x}=\frac{\Delta W M S E\left(\theta_{i}^{*}\right) \cdot \theta_{i}^{*}}{\Delta \theta_{i}^{*} \cdot W M S E\left(\theta_{i}^{*}\right)}$, with $\theta_{i}$ a specific parameter 


\section{Chapter 4}

(see Grubben and Keesman, 2018). This one-at-a-time sensitivity analysis gives some initial insight into the dominant parameter for each state. A large absolute value of the sensitivity means that a change in the parameter has a relatively large influence on the WMSE. This one-at-a-time sensitivity also indicates that a parameter with a higher sensitivity can be identified more accurately than a parameter with a low sensitivity.

\subsubsection{Simulation}

The validated model was subsequently used for scenario study simulations. The scenario study aimed to examine the cooling trajectory between the period of wound healing, in the first weeks, and the long-term storage temperature. The simulations should help evaluate the hypothesis that a slow cooling trajectory is more beneficial for all quality indicators than a fast cooling trajectory. Five different cooling trajectories were taken into consideration, in which the potatoes are cooled from $286.3 \mathrm{~K}\left(13.15{ }^{\circ} \mathrm{C}\right)$ to 281.15 $\mathrm{K}\left(8{ }^{\circ} \mathrm{C}\right)($ by $5.15 \mathrm{~K})$, within a time period of $5 \mathrm{~d}, 10 \mathrm{~d}, 21 \mathrm{~d}, 31.5 \mathrm{~d}$ and $52 \mathrm{~d}$. In the original validation data set, cooling the potatoes from $286.3 \mathrm{~K}$ to the desired $281.51 \mathrm{~K}$ took $40 \mathrm{~d}$. For our scenario study, two bang-bang controllers, on the product temperature and the carbon dioxide level, were implemented. The product temperature was controlled with an inlet temperature of 1 degree lower than the potato temperature, and the relative humidity at the inlet was set at $80 \%$. The switching interval of the temperature controller is determined by the lower and upper feasible temperature ranges. In the five trajectories, cooling per day was $1{ }^{\circ} \mathrm{C}, 0.5^{\circ} \mathrm{C}, 0.25^{\circ} \mathrm{C}, 0.16^{\circ} \mathrm{C}$ and $0.1{ }^{\circ} \mathrm{C}$. Once the cooling trajectory is reached, the lower bound is set to $281.15 \mathrm{~K}$ and the upper bound to $281.45 \mathrm{~K}$. The carbon dioxide switching interval follows from a lower bound of $0.08 \%$ and an upper bound of $0.2 \%$.

\subsection{Results}

\subsubsection{Measurements}

Figure 4.2 and 4.3 show the detailed measurement results of the calibration and validation data set, respectively. For both storage facilities the same trends are seen for temperature, sucrose, glucose, fructose, weight loss, carbon dioxide levels and colour index. However, in all measured states some minor differences can be seen. The long term storage temperature of the calibration data set is slightly lower compared to the temperature of the validation data set. The calibration set shows higher initial values for all sugars, and for glucose and fructose a larger accumulation of the production of the reducing sugar, compared to the validation data set is seen. The weight loss in the calibration set is slightly higher compared to the validation set. The carbon dioxide levels in the storage facility 
Table 4.2: WMSE before and after calibration and validation

\begin{tabular}{l|c|c|c}
\hline State & $\mathrm{WMSE}_{\text {lit }}$ & $\mathrm{WMSE}_{\text {cal }}$ & $\mathrm{WMSE}_{\text {val }}$ \\
\hline$T_{p}$ & 1.56 & 0.13 & 0.10 \\
\hline$X_{p}$ & 0.84 & 0.08 & 0.01 \\
\hline$C O_{2}$ & $4.89 e+3$ & 1.18 & 0.73 \\
\hline$R S$ & 389.11 & 0.15 & 1.47 \\
\hline$\sum X$ & $5.29 e+3$ & 1.53 & 2.31 \\
\hline
\end{tabular}

both stay approximately below the $0.5 \%$, and around week 20 in both cases a slightly increased carbon dioxide level occurs. The colour indices are between 2 and 2.2 for the complete storage season, and hence considered as excellent frying quality. An impression of the frying colour at the beginning and at the end of the storage season are shown in Figure 4.8, in Appendix 4 A..

\subsubsection{Calibration}

Table 4.2 lists the WMSE results of the model calibration. The simulation, using parameters reported in the literature (Hertog et al., 1997; Lukasse et al., 2007; Kondrashov, 2007; Grubben and Keesman, 2018), only performs within a reasonable range for the temperature and moisture content, as opposed to the carbon dioxide and sugar content. The total WMSE of the four states is $5.29 \cdot 10^{3}$. Table 4.2 lists the total WMSE as well as the individual WMSE for each of the measured states.

Table 4.3 contains the estimates after the parameter estimation step, in addition to the parameters found in the literature. As Table 4.2 show, the model gives a better WMSE with the calibrated parameters than with parameters from the literature, and shows a good fit on the measurements see Figure 4.4. All four states give a lower WMSE and the summed WMSE is 1.53. Especially the carbon dioxide and sugar level states perform much better. For the carbon dioxide state, the value of $E_{c o 2}$ reported in the literature (Lukasse et al., 2007) is too high for this potato variety. The literature parameters that were used for the sugar level were based on the Bintje variety.

Table 4.3 shows that eight of the fourteen parameter estimates are in the same order of magnitude as the literature-based parameters. The parameters $K_{\text {evap }}$ and $K_{R S}$ seem to be larger than the literature-based values, whereas the parameters $E_{c o 2}, k_{c o l d}$ ref,$E_{c o l d}$ and $k_{\text {dena }}$ are smaller.

\subsubsection{Validation}

Figure 4.5 shows the dynamic model outputs using the parameter estimates from the calibration set. All of the states perform similarly as for the calibration data set. As can 

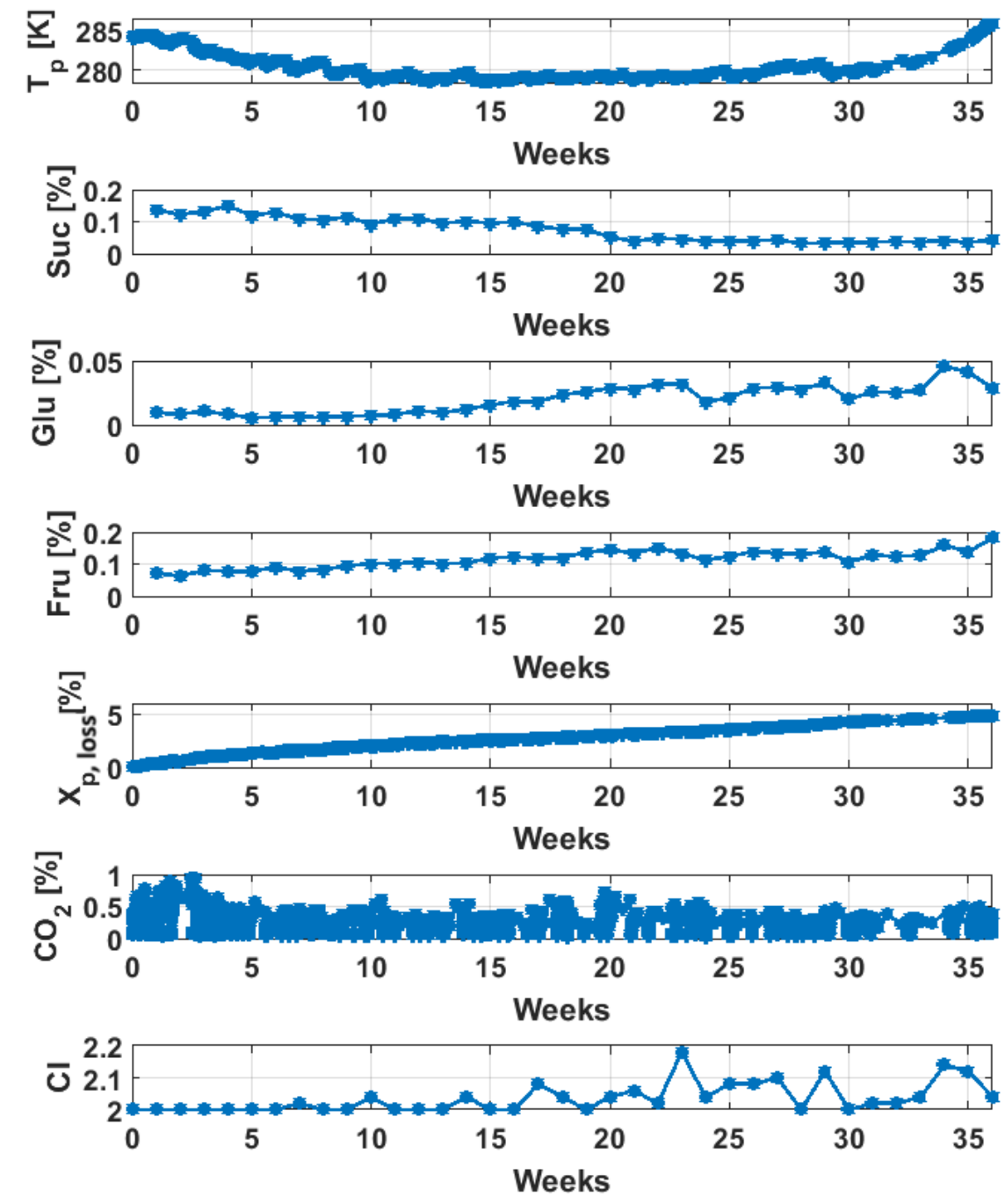

Figure 4.2: Measurements of the calibration data set, for 36 storage weeks. First the wounds were healed at a temperature of $284[\mathrm{~K}]\left(10.85{ }^{\circ} \mathrm{C}\right)$, cooled down to long-term storage temperature of $279.85[\mathrm{~K}]\left(6.7^{\circ} \mathrm{C}\right)$ in 47 days, the last 30 days the temperature raise to 287.1 $[\mathrm{K}]\left(13.95{ }^{\circ} \mathrm{C}\right)$. The sucrose (Suc) shows a small decrease, where glucose (Glu) and fructose (Fru) show a small increase. The weight loss is the biggest in the first weeks, during wound healing and cooling period. The carbon dioxide level was kept beneath the $0.5 \%$ with some exceptions in the beginning and between week 10 and 25. The Colour Index varies between the 2 and 2.2 . 

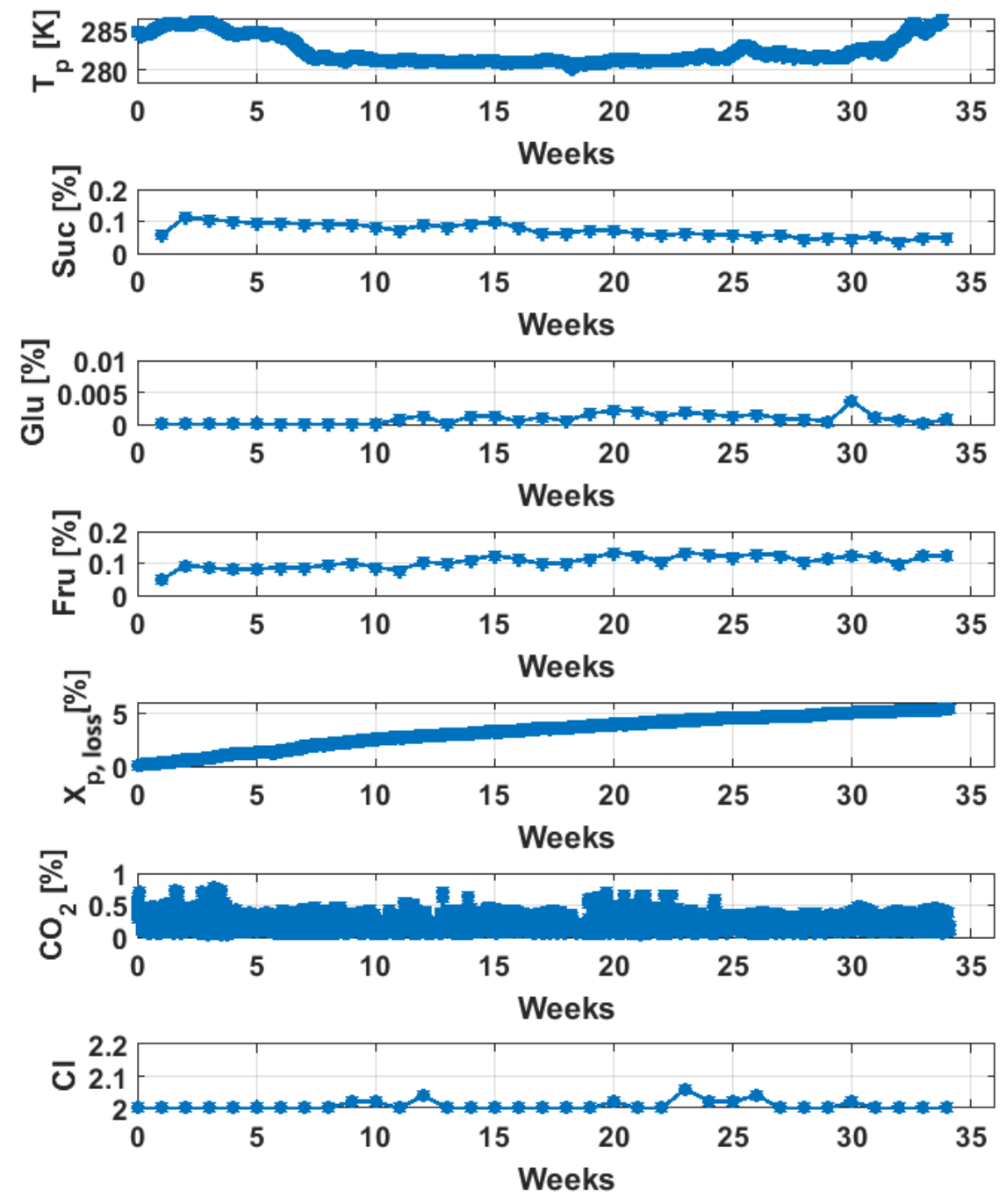

Figure 4.3: Measurements of the validation data set, for 34 storage weeks. First the wounds were healed at a temperature of $285.5[\mathrm{~K}]\left(12.35{ }^{\circ} \mathrm{C}\right)$, cooled down to long-term storage temperature of $280.95[\mathrm{~K}]\left(7.8^{\circ} \mathrm{C}\right)$ in 46 days, the last 30 days the temperature raise to 287.3 $[\mathrm{K}]\left(14.15^{\circ} \mathrm{C}\right)$. The sucrose (Suc) shows a small decrease, where glucose (Glu) and fructose (Fru) show a small increase. The weight loss is the biggest in the first weeks, during wound healing and cooling period. The carbon dioxide level was kept beneath the $0.6 \%$ with some exceptions in the beginning and between week 10 and 25. The Colour Index varies between the 2 and 2.1 . 

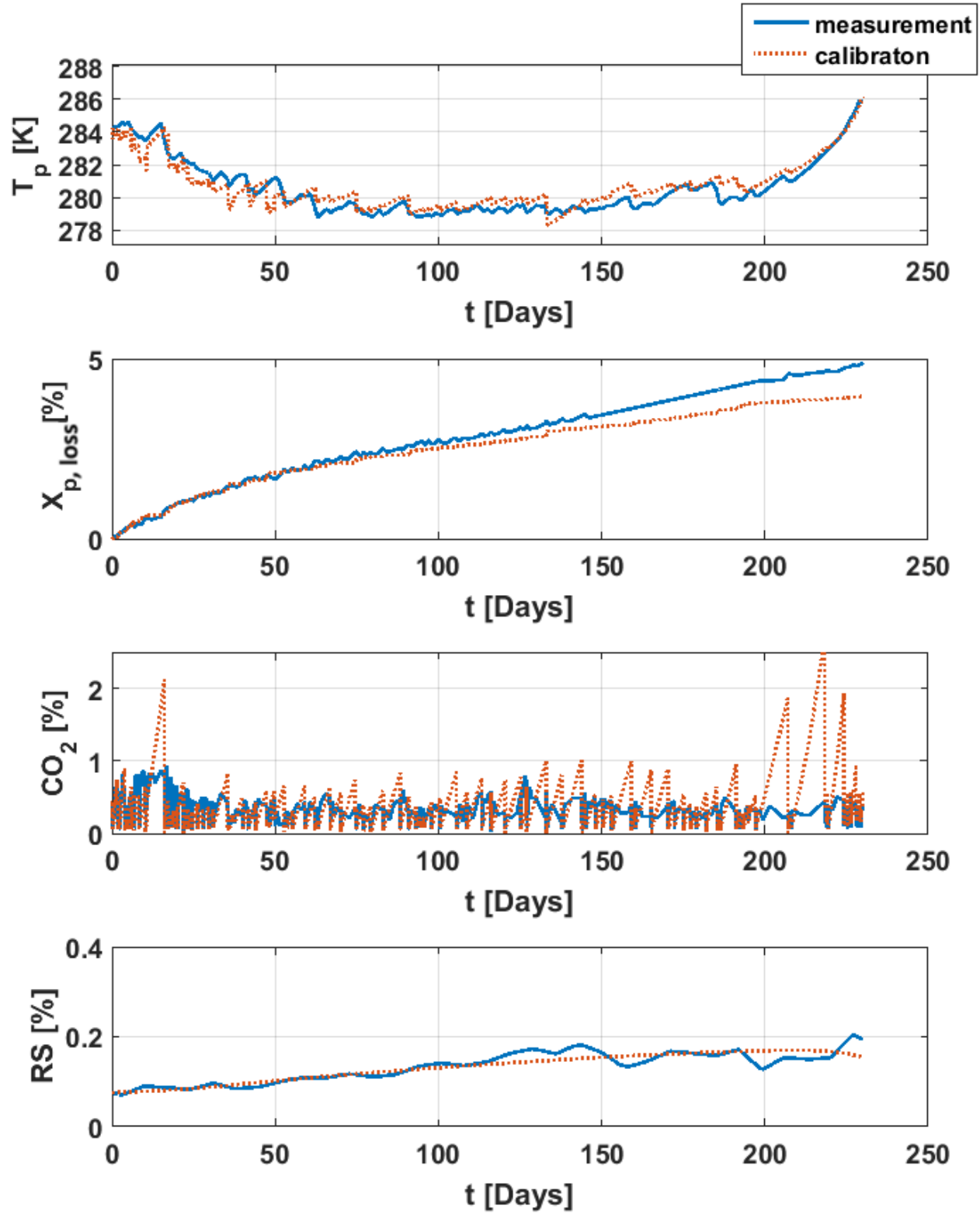

Figure 4.4: Calibration results for temperature, weight loss, $\mathrm{CO}_{2}$ content and sugar content. In the top frame, the results for $T_{p}(3.5 \mathrm{~m})$ are shown with in the second frame the results for $X_{p, l o s s}(2.0 \mathrm{~m})$. The third frame contains the $\mathrm{CO}_{2}$ concentrations $(2.0 \mathrm{~m})$. The bottom frame depicts the results for $R S(3.5 \mathrm{~m})$. The solid blue lines represent the measurements. The dashed orange lines represent the simulated model output. 

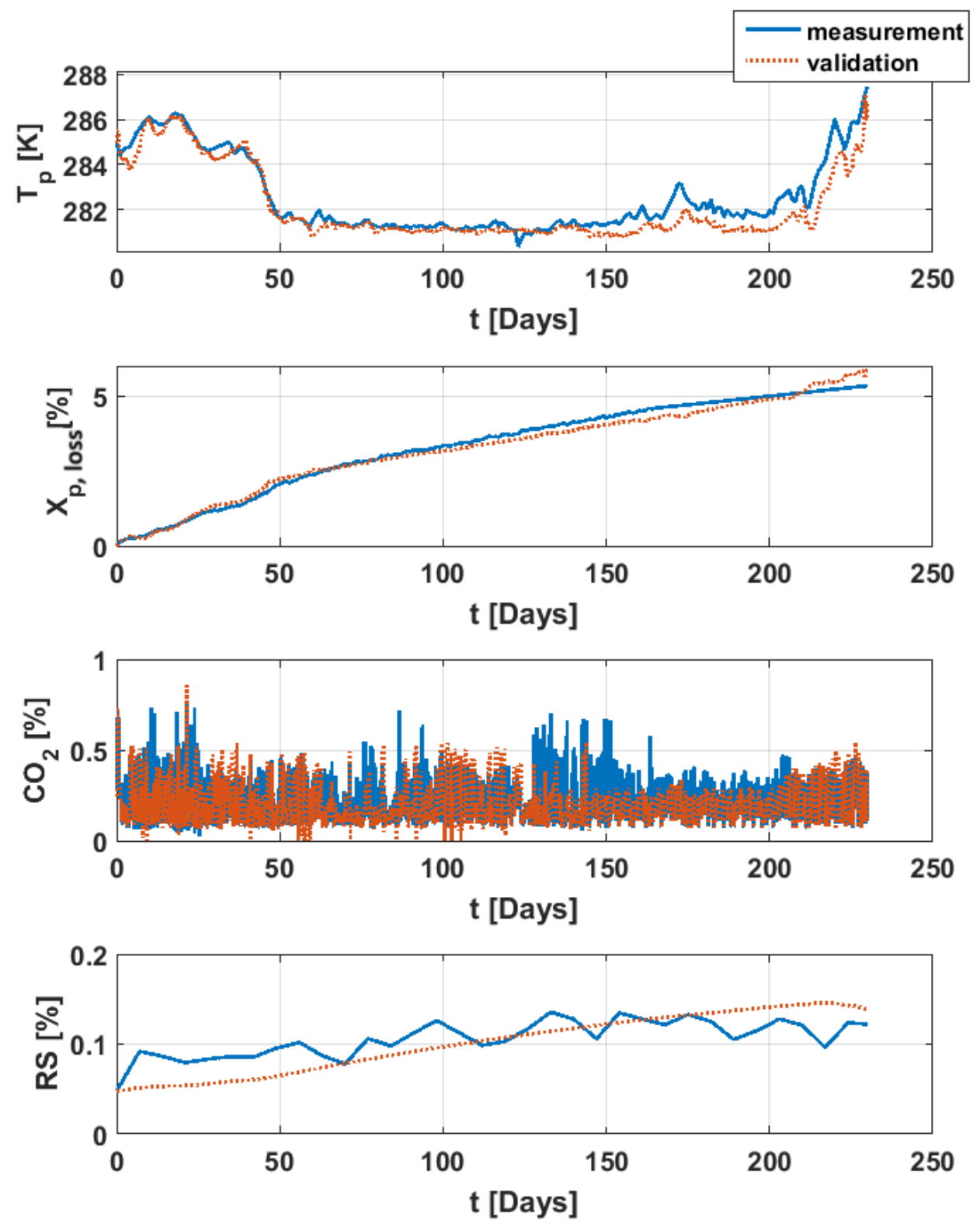

Figure 4.5: Validation result for temperature, weight loss, $\mathrm{CO}_{2}$ content and sugar content. In the top frame, the results for $T_{p}(3.5 \mathrm{~m})$ are shown with in the second frame the results for $X_{p, l o s s}(2.0 \mathrm{~m})$. The third frame contains the $\mathrm{CO}_{2}$ concentrations $(2.0 \mathrm{~m})$. The bottom frame depicts the results for $R S(3.5 \mathrm{~m})$. The solid blue lines represent the measurements. The dashed orange lines represent the predicted model output using the calibrated parameter values (Table 4.3). 

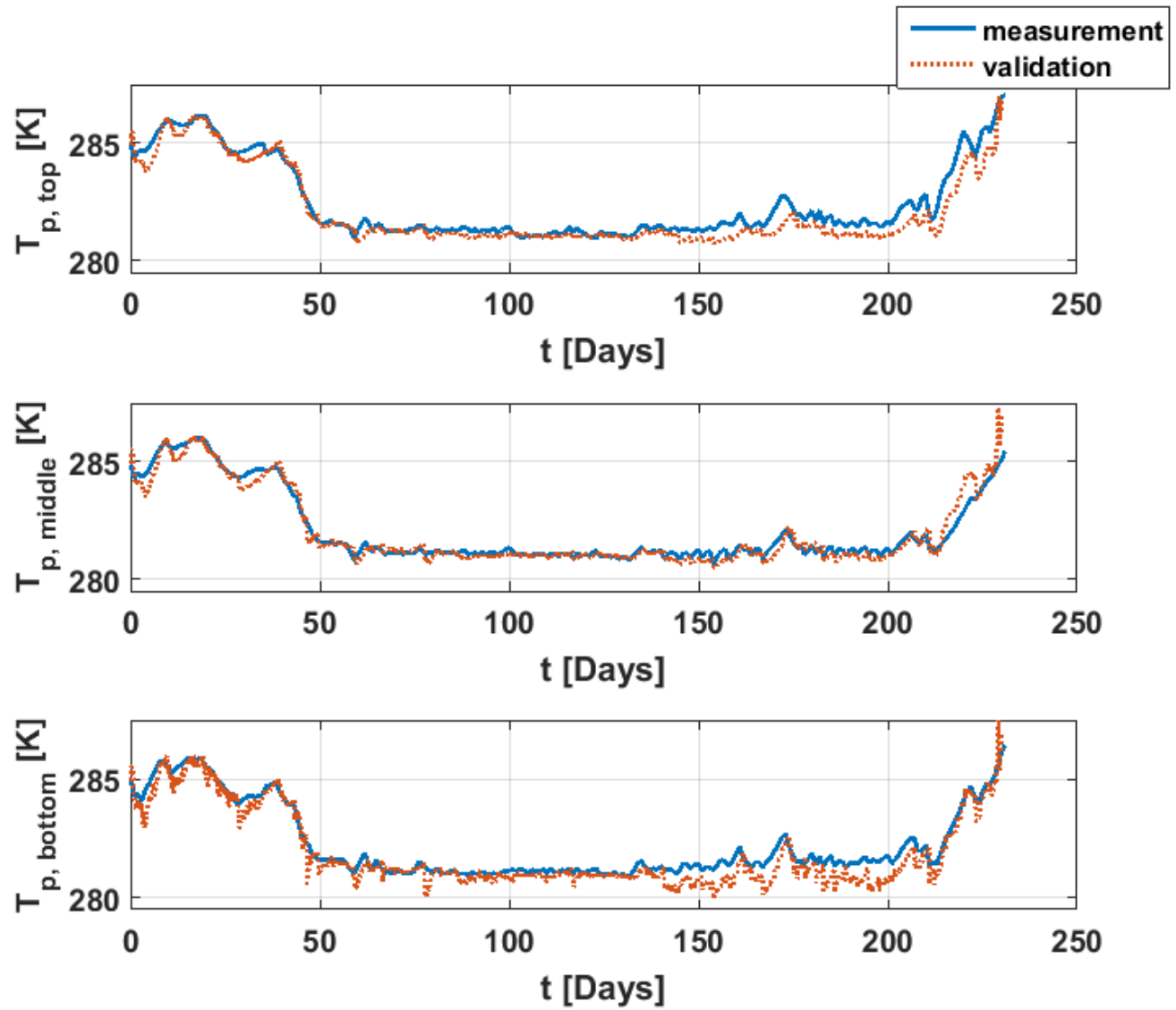

Figure 4.6: Validation result for the temperature distribution of the bottom, middle and top layer. The solid blue lines represent the measurements. The dashed orange lines represent the predicted model output for the calibrated parameters (Table 4.3).

be seen in Table 4.2, the states $T_{p}, X_{p}$, and $\mathrm{CO}_{2}$ have a lower WMSE than the calibration set and the reducing sugar state $R S$ has a greater WMSE. Figure 4.5 makes clear that the moisture content $X_{p}$ and the reducing sugar level $R S$ fit the measurements well. It also reveals that, although the temperature $T_{p}$ has a lower WMSE than the calibration, the simulation shows lower temperatures relative to the measurements from day 150 onwards. The predicted carbon dioxide level is consistently lower than the measured value.

In addition to the validation of the dynamics, the validation of the spatial distribution of the model states was done on base of temperature data in top, middle and bottom layers of the bulk, and data of the weight loss measured in top and bottom layer of the bulk at the end of the storage season (net-bags). Figure 4.6 shows the validation results for the bottom $(0.5 \mathrm{~m})$, middle $(2.0 \mathrm{~m})$ and top layer $(3.5 \mathrm{~m})$ of the bulk. These results are within temperature sensor accuracy, except for the bottom layer from day 150-220 were, likewise as in the top layer, some lower temperatures relative to the measurements were obtained in the simulation. 
The weight loss results are shown in Table 4.4. For the top and middle layers of the bulk the model performs within reasonable bounds. The bottom layer shows a overestimation of the moisture loss.

\subsubsection{Sensitivity analysis}

Table 4.5 presents the results of the sensitivity analysis for the four states. The dominant parameters, with relatively large absolute normalised parameter sensitivity, are the parameters related to the product respiration rate $\left(r_{1}, r_{2}\right.$ and $\left.r_{3}\right)$. A change in the activation energy $E_{i}$ has a negligible effect on the temperature $T_{p}$, moisture content $X_{p}$ and the carbon dioxide level $\mathrm{CO}_{2}$, and also a relatively low influence on the reducing sugar state $R S$.

\subsubsection{Scenario}

In the scenario study, five different cooling trajectories were simulated, in which cooling by $5.15{ }^{\circ} \mathrm{C}$ took $5 \mathrm{~d}, 10 \mathrm{~d}, 21 \mathrm{~d}, 31.5 \mathrm{~d}$ and $52 \mathrm{~d}$. The results (Figure 4.7) reveal that a fast cooling trajectory results in a higher sugar content but less weight loss compared with a slow cooling trajectory. In the fast cooling trajectory, the desired temperature of $281.15 \mathrm{~K}$ $\left(8{ }^{\circ} \mathrm{C}\right)$ is reached in five days. Because the low temperature is reached relative fast, there is less respiration and less ventilation is needed to cool the product relative to the slow cooling trajectory of $52 \mathrm{~d}$. The combination of less respiration and less ventilation results in less dehydration. With regards to the sugars, more reducing sugars are produced as a result of the lower temperatures. With regards to the carbon dioxide level, we only can see that it is kept at a low level roughly beneath the 2000 [ppm] $(0.2 \%)$.

For a complete overview of the cooling strategy at the end of the season, the cooling scenario simulations for $5 \mathrm{~d}$ and $52 \mathrm{~d}$ were extended to $230 \mathrm{~d}$. For the short cooling trajectory (5 d) eventually 220 ventilations hours were needed to keep the store temperature at its set point, with a weight loss of $5.45[\%]$ and a reducing sugar concentration of 0.17 [\%]. For the long cooling trajectory (52 d) eventually 256 ventilations hours were needed to keep the store temperature at its set point, with a weight loss of 6.49 [\%] and a reducing sugar concentration of $0.16[\%]$.

\subsection{Discussion}

Notice from the preceding section, that the dynamic one-dimensional frying potato storage model for the variety Ramos was successfully calibrated. The cross-validation, with data sets gathered at the same time at a different storage facility, also gave good results. 

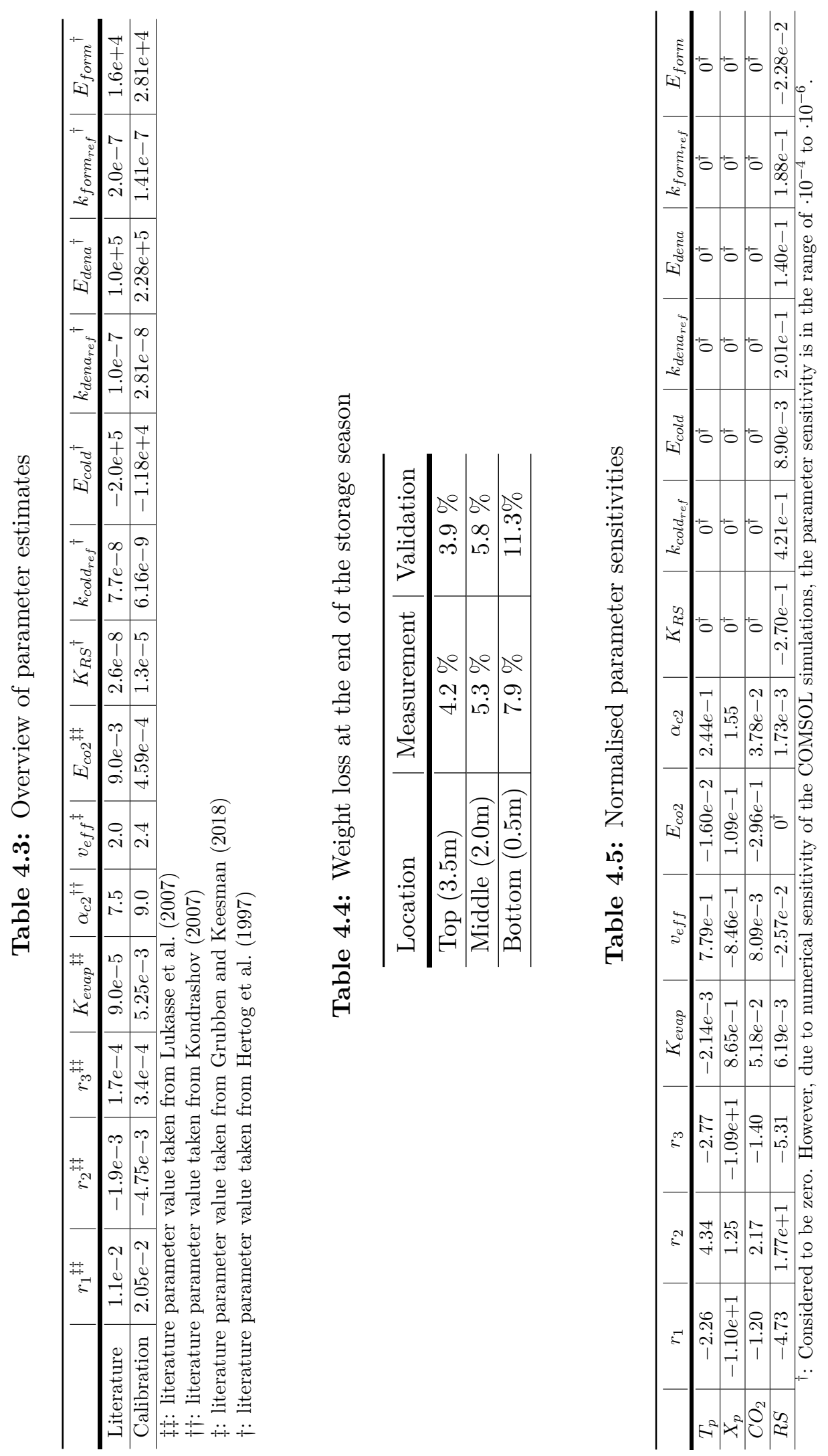

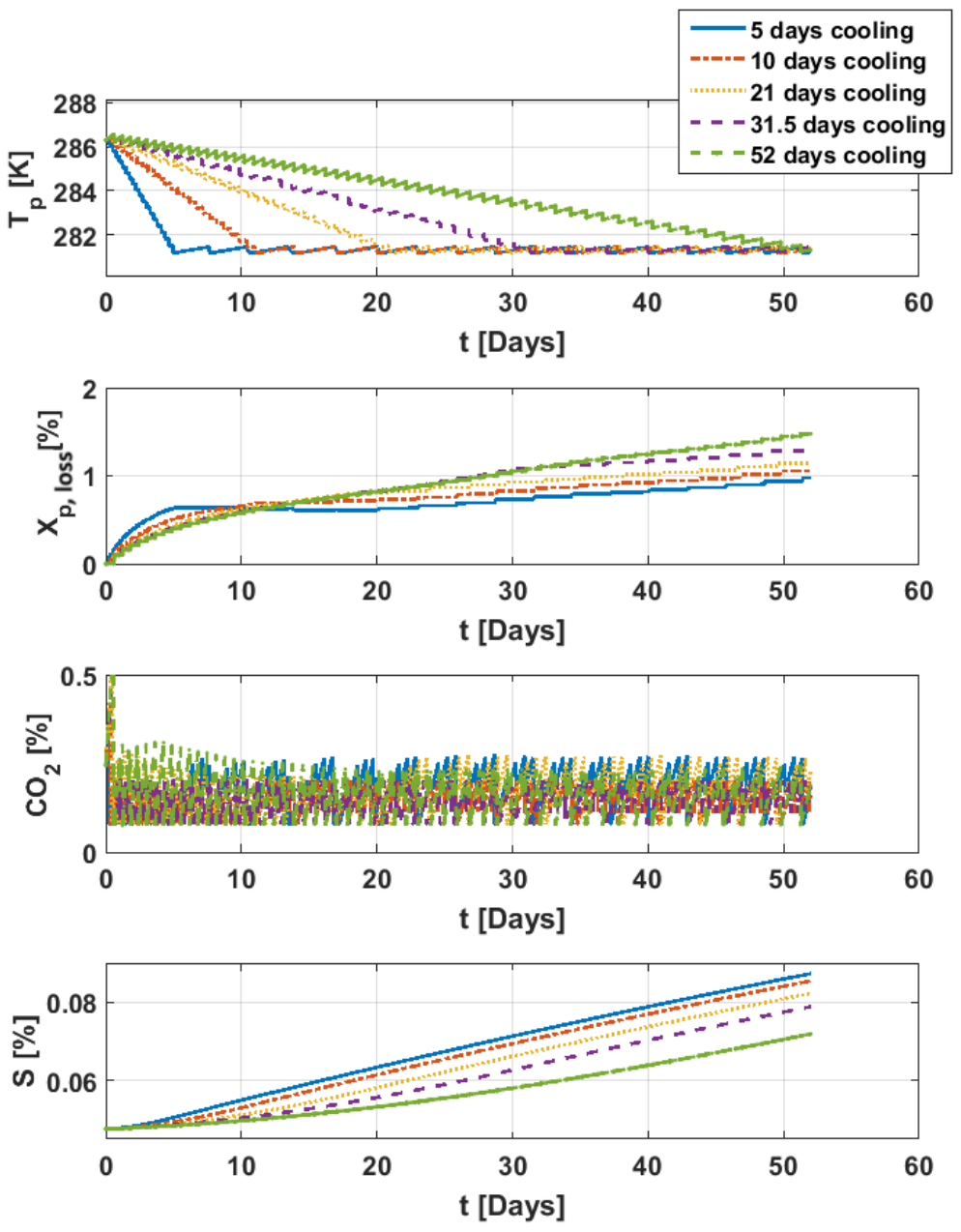

Figure 4.7: Scenario study result for temperature, weight loss, $\mathrm{CO}_{2}$ content and sugar content. Five different cooling trajectories are simulated, i.e. cooling in $5 \mathrm{~d}$ (solid blue line), $10 \mathrm{~d}$ (dash-dotted orange line), $21 \mathrm{~d}$ (dashed yellow line), $31.5 \mathrm{~d}$ (short-dashed purple line) and $52 \mathrm{~d}$ (dashed green line), respectively. The represents the results for the $5 \mathrm{~d}$ scenario.

To cross-validate the model, data from two different storage locations with a comparable amount of potatoes in the same storage season were used. This approach implies that replicates of storage facilities, but no replicates of storage seasons were taken into account. Therefore, the conclusions drawn in this paper hold for the Ramos variety cultivated in the same season. Validation on different storage seasons, in combination with other varieties, will provide more insight on the performance of the model and the variation in the estimated model parameters and conclusions drawn based on the presented work.

For the calibration of the model, we used a multistage least-squares estimation method because this approach allowed us to estimate the fourteen parameters in a systematic way. A one-stage non-linear least-squares method does not always guarantee a generally 


\section{Chapter 4}

applicable solution, however.

For eight of the fourteen parameters, the estimates were in the same order of magnitude as the values found in the literature. In particular, evaporation and respiration depend on potato variety and season, as especially the skin of the potato has a large influence on the evaporation and respiration rates (Singh and Kaur, 2016). Especially immature potatoes, and hence, immature skin-set, seems to have a permeable skin with a higher potential to losses moisture compared to mature potato with a higher degree of skin set (Heltoft et al., 2016). The evaporation parameter $K_{\text {evap }}$ and gain parameters for reducing sugars $K_{R S}$ are about one order of magnitude greater than the values found in the literature.

The reaction parameters, respiration mass per energy $E_{c o 2}$ and the once related to the sugar content $k_{\text {cold }}$ ref,$E_{\text {cold }}$ and $k_{\text {dena }_{\text {ref }}}$ are smaller than the values found in the literature. The literature parameters that were used for the sugar level were based on the Bintje variety, this caused the mismatch in the fit of the sugar level. The estimates of these parameters are not out of line, however, but reflect the Ramos variety. And hence, the Ramos variety tends to lose more moisture compared to the variety used in literature, and is lower in sugars than the Bintje.

The parameter estimates resulting from the calibration step performed well on the model validation sets (Figure 4.5 and 4.6 and Table 4.4). The validation especially showed a good fit for the moisture and sugar content. For the potato temperature, we saw a small underestimation from about day 150 onwards. Probably some physical processes were active, due to the higher overall storage temperature from about day 150 in the validation data set, which was not seen in the calibration set. Another cause could be a mismatch in the top boundary layer, as in warm periods the head-space above the bulk $\left(\Omega_{a 4}\right)$ slowly heats up. Therefore, a possible solution to this would be that during forced convection a Neumann boundary condition is used, and during the rest of the time a Dirichlet boundary condition using measured temperatures in the head-space. Also, notice that the model does not include any biological or enzymatic activity changes over time.

In the validation step for the carbon dioxide, we obtained values that were lower than the measurements. One possible cause is the difference in carbon dioxide production of the potatoes. A second possible cause could be the difference in natural leaks, which were not at all taken into account. If natural leakage was present in the storage facility of the calibration set, due to non-optimal insulation, carbon dioxide could have been leaving the facility, thus leading to underestimation of the carbon dioxide production.

The sensitivity analysis revealed that a small change in the parameters related to the respiration rates $r_{1}, r_{2}$ and $r_{3}$ have a large influence on the normalised WMSE of all states. It was also found that an incorrect potato diameter strongly influences the behaviour of the moisture content. Changing the diameter in the model with $10 \%$ results in $0.4 \%$ lower or higher weight loss at the end of the storage season. No significant changes in the 


\section{Postharvest frying potato quality development in a LS bulk storage facility}

other states were found, as a result of a potato diameter change.

From the scenario study, for the variety Ramos with relative low amount of sugars at the beginning of the season, the hypothesis that slow cooling is more beneficial for all quality indicators (moisture content and reducing sugar level) than rapid cooling should be rejected. The simulations show that the moisture content decreases faster during slow cooling as a result of the higher respiration rates that are present at higher temperatures in combination with the larger number of required ventilation hours. For the sugar content it was also found that, for a slow cooling trajectory, the sugar content is lower than with faster cooling as the higher temperature results in more respiration and higher rate of evaporation in combination with less cold-induced sweetening. However, also for the fast cooling trajectory the sugar contend formed at the end of the season was still in the same range compared to the measured data. From this it can be concluded that the reducing sugar levels are in the acceptable range for the processing industry.

The result that faster cooling is more beneficial compared to slower cooling, was only tested for Ramos variety harvested in the year 2016. As the Ramos variety seems to have low sugar levels, dedicated experiments needs to be performed to gather more insight on the sugar development. It is possible for other varieties, or during other growing conditions, that the potatoes contain higher sugar levels or that the accumulation of the reducing sugars proceeds faster. In that case, it is possible that during faster cooling concentrations of reducing sugars exceed the acceptable range at the end of the storage season.

In the case study, eventually the two most divers cases ( 5 days cooling and 52 days cooling) were simulated for 230 days. In Section 4.3 .5 it was show that for the fast cooling case (5 days) after 230 day a moisture loss of $5.45 \%$, a reducing sugar concentration of $0.17 \%$ and 220 ventilation hours were obtained. And, for the slow cooling case ( 52 days) after 230 days a moisture loss of $6.49 \%$, a sugar concentration of $0.16 \%$ and 256 ventilation hours were obtained. For the slow case and a bulk of 600 tons, 3 ventilators with an electrical power of $3 \mathrm{~kW}$, an electricity price of $0.12 \frac{€}{\mathrm{kWh}}$, and a potato selling price of 0.12 $\frac{€}{\mathrm{~kg}}$ the extra costs with respect to fast cooling are; $\left(6240 \mathrm{~kg} * 0.12 \frac{€}{\mathrm{~kg}}+3\right.$ fans $* 3 \mathrm{~kW} * 36$ $\left.\mathrm{h} * 0.12 \frac{€}{\mathrm{kWh}}\right)=787.68 €$.

In the scenario study a $\mathrm{CO}_{2}$ concentration of maximum 2000 [ppm] (0.2\%) was used, in order to not influence the frying colour due to a high $\mathrm{CO}_{2}$ concentration. As the influence of the $\mathrm{CO}_{2}$ is variety dependent, various maximum levels for $\mathrm{CO}_{2}$ are reported in literature. In the literature the maximum level of $\mathrm{CO}_{2}$ concentrations that has no potential negative influence on processing colour ranges between 0.15-2 \% (see e.g. Daniels-Lake, 2013; Martin, Romania, 2015). No specific value for the Ramos variety was found, therefore a maximum concentration of $0.2 \%$ was considered. However, further investigations are needed to obtain a better insight on the maximum $\mathrm{CO}_{2}$ level for the Ramos and other varieties. 


\section{Chapter 4}

\subsection{Conclusions}

In this paper, we have presented a 1-D spatially distributed convection-diffusion-reaction model for frying potato storage. The model contains dynamic interactions between relevant quality indicators (moisture content and sugar level) as well as interactions with the indoor climate. The model, with physical and physiological states $\left(T_{p}, X_{p}, C O_{2}\right.$ and $\left.R S\right)$, was successfully calibrated and validated for a full storage season, on unique data sets of two large scale facilities in the Netherlands for the variety Ramos.

In the scenario study, the hypothesis that slower cooling is beneficial for all quality indicators was rejected. Fast cooling lowers the respiration and ventilation cooling hours, and hence the dehydration of the potato. The sugar content is higher in the more rapidly cooled potato, but is for the variety Ramos still in an acceptable range for the processing industry. However, as the model is calibrated and validated only on the variety Ramos, the result can differ for other varieties.

Further research is needed to evaluate the performance of the model on other varieties, and to come up with optimal storage strategies for that specific variety. It would also be of interest to add other quality indicators to the model, like dormancy or pressure bruising.

\section{Appendix 4 A. Frying colour}
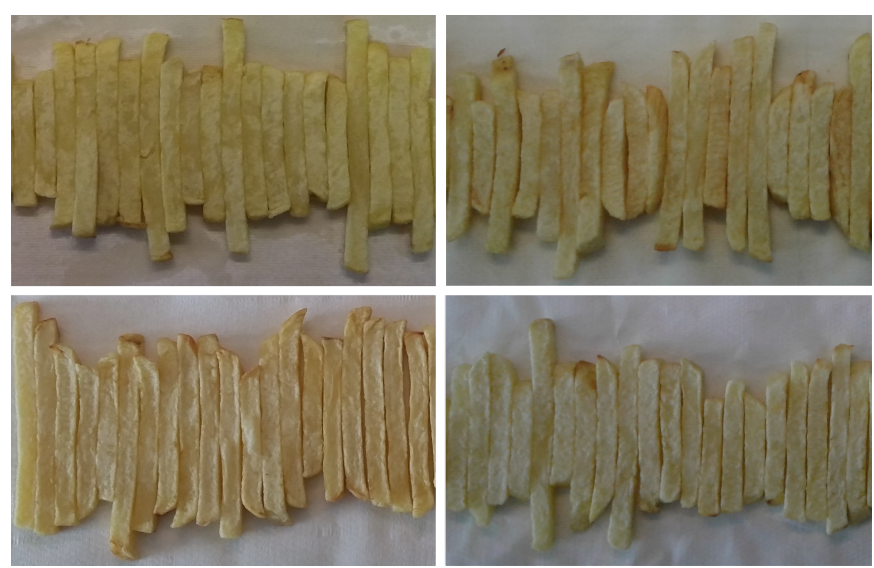

Figure 4.8: Frying colour impression for the fried Ramos potatoes. Top panels show the result of the calibration data set, top left panel storage week 1 and top right panel storage week 36 . Bottom panels show the results of the validation data set, bottom left panel storage week 1 and bottom right panel storage week 34 . 


\section{References}

J. Amir, V. Kahn, and M. Unterman. Respiration, ATP level, and sugar accumulation in potato tubers during storage at $4^{\circ}$. Phytochemistry, 16:1495-1498, 1977.

J. Barker and A. F. el Saifi. Studies in the respiratory and carbohydrate metabolism of plant tissues IV. The relation between the rate of carbon dioxide production in potato tubers in air following anaerobic conditions, and the accompanying changes in lactic acid content and sugar concentration. Proceedings of the Royal Society of London Series B, Biological Sciences, 140:522-555, 1953.

H.C. Castleberry and S.S. Jayanty. An experimental study of pressure flattening during long-term storage in four russet potato cultivars with differnces in at-harvest tuber moisture loss. American Journal of Potato Research, 89:269-276, 2012.

P.A.M. Claassen, M.A.W. Budde, H.J. de Ruyter, M.H. van Claker, and A. van Es. Potential role of pyrophosphate:fructose 6-phosphate phosphotransferase in carbohydrate metabolism of cold stored tubers of Solanum tuberosum cv Bintje. Plant Physiology, 95:1243-1249, 1990.

B.J. Daniels-Lake. Carbon dioxide and ethylene gas in the potato storage atmosphere and their combined effect on processing colour. PhD thesis, Wageningen University, 2013.

E.P.Jr. Driskill, L. O. Knowles, and N. R. Knowles. Temperature-induced changes in potato processing quality during storage are modulated by tuber maturity. American Journal of Potato Research, 84:367-383, 2007.

FAOSTAT. http://www.fao.org/. 2017.

M. Gancarz. Correlation between cell size and blackspot of potato tuber parenchyma tissue after storage. Postharvest Biology and Technology, 117:161-167, 2016.

V. Gokmen, B. Akbudak, A. Serpen, J. Acar, Z.M. Turan, and A. Eris. Effects of controlled atmosphere storage and low-dose irradiation on potato tuber components affecting acrylamide and color formations upon frying. European Food Research and Technology, 224:681-687, 2007.

N.L.M. Grubben and K.J. Keesman. Modelling ventilated bulk storage of agromaterials: A review. Computers and Electronics in Agriculture, 114:285-295, 2015.

N.L.M. Grubben and K.J. Keesman. A spatially distributed physical model for dynamic simulation of ventilated agro-material in bulk storage facilities. Computers and Electronics in Agriculture, provisionally accepted for publication, 2018.

N.L.M. Grubben, S.C.M. Witte, and K.J. Keesman. Postharvest quality development of frying potatoes in a large-scale bulk storage facility. Postharvest Biology and Technology, accepted for publication, 2018. 


\section{Chapter 4}

M.R. Hajirezaei, F. Bornke, M. Peisker, Y. Takahata, J. Lerchl, A. Kirakosyan, and U. Sonnewald. Decreased sucrose content triggers starch breakdown and respiration in stored potato tuber (Solanum tuberosum). Journal of Experimental Botany, 54: 477-488, 2003.

P. Heltoft, A.-B. Wold, and E.L. Molteberg. Effect of ventilation strategy on storage quality indicators of processing potato with different maturity levels at harvest. Postharvest Biology and Technology, 117:21-29, 2016.

M.L.A.T.M. Hertog, L.M.M. Tijskens, and P.S. Hak. The effects of temperature and senescence on the accumulation of reducing sugars during storage of potato (Solanum tuberosum L.) tubers: A mathematical model. Postharvest Biology and Technology, 10 (1):67-79, 1997.

M.L.A.T.M. Hertog, D.R. Rudell, R. Pedreschi, R.J. Schaffer, A.H. Geeraerd, B.M. Nicolai, and I. Ferguson. Where systems biology meets postharvest. Postharvest Biology and Technology, 62:223-237, 2011.

D.A. Irvine, D.S. Jayas, and G. Mazza. Resistance to airflow through clean and soiled potatoes. American Society of Agricultural Engineers, 36:1405-1410, 1993.

D. Kmiecik, J. Kobus-Cisowska, and J. Korczak. The content of anti-nutritional components in frozen fried-potato products. LWT - Food Science and Technology, 85:275-282, 2017.

N.R. Knowles, E.P. Driskill, and L.O. Knowles. Sweetening responses of potato tubers of different maturity to conventional and non-conventional storage temperature regimes. Postharvest Biology and Technology, 52:49-61, 2009.

V.I. Kondrashov. Modeling of heat and mass transfer and aerodynamics in a bulk of stored agricultural raw material. Journal of engineering Physics and Thermophysics, 80(4):833-839, 2007.

K.P. Krause, L. Hill, R. Reimholz, T. Hamborg Nielsen, U. Sonnewald, and M. Stitt. Sucrose metabolism in cold-stored potato tubers with decreased expression of sucrose phosphate synthase. Plant, Cell and Environment, 21:285-299, 1998.

L.J.S. Lukasse, J.E. de Kramer-Cuppen, and A.J. van der Voort. A physical model to predict climate dynamics in ventilated bulk-storage of agricultural produce. International Journal of Refrigeration, 30(1):195-204, 2007.

A.G. Marangoni, P.M. Duplessis, and R.Y. Yada. Kinetic model for carbon partitioning in Solanum tuberosum tubers stored at $2^{\circ} \mathrm{C}$ and the mechanism for low temperature stress-induced accumulation of reducing sugars. Biophysical Chemistry, 65:211-220, 1997.

M. Martin. $\mathrm{CO}_{2}$ concentration influence during storage on frying ability of tubers. In The international potato processing $\&$ storage convention, Romania, 2015. 
M. Mesias, F. Holgado, G. Marquez-Ruiz, and F.J. Morales. Impact of the characteristics of fresh potato available in-retail on exposure to acrylamide: Case study for french fries. Food Control, 73:1407-1414, 2016.

M.L. Miranda and J.M. Aguilera. Structure and texture properties of fried potato products. Food Reviews International, 22:173-201, 2006.

N. Olsen, M.J. Frazier, and S. Peck. Wound healing and early store management. In Presentations EAPR Post harvest section meeting June 29-30, The Netherlands, 2016.

A. van 't Ooster. CIGR Handbook of Agricultural Engineering Volume IV Agro-Processing engineering. American Society of Agricultural Engineers, 1999.

B. Pringle, C. Bishop, and R. Clayton, editors. Potatoes postharvest. CABI, 2009.

A. Rastovski. Storage of potatoes; post-harvest behaviours, store design, storage practice and handling. Centre for Agricultural Publishing and Documentation, 1987.

T. Saray, J. Felfoldi, A. Koncz, K. Horti, V. Zsom Muha, and A. Emekandoko. Product and quality characteristics for predictive purposes: A case for cold storage of potato (Solanum tuberosum L.). Acta Alimentaria, 38:369-380, 2009.

J. Singh and L. Kaur, editors. Advances in potato chemistry and technology. Academic Press, 2016.

J.R. Sowokinos. Relationship of harvest sucrose content to processing maturity and storage life of potatoes. American Potato Journal, 55:33-344, 1978.

G.J.C. Verdijck. Product quality control. PhD thesis, University of Eindhoven, 2003.

G.J.C. Verdijck and L.M.M. Tijskens. Quality control in the storage of potatoes for industrial processing. Acta Horticulturae, 599:479-487, 2003.

G.J.C. Verdijck, M.L.A.T.M. Hertog, M. Weiss, and H.A. Preisig. Modelling of a potato storage facility for product quality control purposes. Computers $\&$ Chemical Engineering, 23, Supplement(0):S911-S914, 1999.

G.J.C. Verdijck, G. van Straten, and H.A. Preisig. Optimisation of proeuct quality and minimisation of its variation in climate concontrol operations. Computers and Electronics in Agriculture, 48:103-122, 2005.

G.A. Viklund, K.M. Olsson, I.M. Sjoholm, and K.I. Skog. Variety and storage conditions affect the precursor content and amount of acrylamide in potato crisps. Journal of Science of Food and Agriculture, 88:305-312, 2008.

A.M. Wilson, T.M. Work, A.A. Bushway, and R.J. Bushway. Hplc determination of fructose, glucose, and sucrose in potatoes. Journal of Food Science, 46:300-301, 1981.

R. Wustman and P.C. Struik. The canon of potato science: 35. seed and ware potato storage. Potato Research, 50:351-355, 2007.

Y. Xu and D. Burfoot. Simulating the bulk storage of foodstuffs. Journal of Food Engi- 


\section{Chapter 4}

neering, 39(1):23-29, 1999. 


\section{Chapter 5}

\section{MODELLING POTATO PROTEIN CONTENT FOR LARGE-SCALE BULK STORAGE FACILITIES}

In preparation as:

N.L.M. Grubben, L. van Heeringen and K.J. Keesman. Modelling potato protein content for large-scale bulk storage facilities, under review, 2018 


\section{Chapter 5}

\section{Abstract}

The potato (Solanum tuberosum) is one of the main sources of natural starch. In recent decades, the valorisation of potato protein that results as a by-product in the starch industry has been gaining interest as well. As potato supply is seasonal and the protein content of potatoes during long-term storage is temperature-dependent, optimal storage of potatoes is of great importance. This paper explores a model describing potato protein content during a full storage season for the varieties Miss Malina and Agria. The model combines Michaelis-Menten protein kinetics with the Arrhenius equation. Laboratory analyses were performed to monitor the protein components in both potato varieties and to use for estimation of the kinetic parameters. The results indicate that the two varieties have different synthesis and degradation kinetics.

\subsection{Introduction}

One of the most important crops worldwide is the potato (Solanum tuberosum), accounting for about $45 \%$ of the global tuber crop production (WCRTC, 2016). Potato crops are not only grown for consumption, but also for starch production, with the starch extraction process yielding protein-rich waste water (Løkra and Strætkvern, 2009). The potato protein solution has been the subject of many studies to determine its composition and functional properties (Kapoor et al., 1975; Holm and Eriksen, 1980: Ralet and Guéguen, 2000). The total soluble protein content in the potato juice consists mainly of three groups: patatin (40-60\%), protease inhibitors (20-30\%) and other (high-molecularweight) proteins (Pots et al., 1999). Potatoes are a superior protein source relative to other vegetables and cereals because of their high nutritional quality (Seo et al., 2014). In addition to the present application as feed supplements, potato proteins are of great potential for specific biotechnological, pharmaceutical or food applications (Kong et al., 2015; Zhang et al., 2017).

Protein quality is therefore becoming increasingly important in the industrial production of potato proteins (Grommers and van der Krogt, 2009). The quality and amount of proteins in potatoes are determined by the conditions during the growing season. As potatoes are a seasonal crop, storage of potatoes is essential to be able to provide potatoes all year round. The economical optimum of potato protein production depends on the proteins formed during growth, the capacity of the processing industry and any protein losses or synthesis during storage.

During long-term storage, both protein degradation and protein synthesis take place continuously and, as previously found, total soluble protein levels fluctuate (Nowak, 1977; Brasil et al., 1993; Brierley et al., 1996). The dynamics and fluctuations of the protein 


\section{Nomenclature}

$\begin{array}{ll}\text { Subscript } \\ a \quad \text { Air } \\ E & \text { Energy } \\ e & \text { Environment } \\ f & \text { Final } \\ p & \text { Potato } \\ \text { prot } & \text { Protein } \\ P S & \text { Total protein (synthesis-related) } \\ P D & \text { Protein (degradation-related) } \\ P I & \text { Protease inhibitor (synthesis- } \\ \text { related) }\end{array}$

Parameters

$\rho \quad$ Density $\quad\left[\frac{\mathrm{kg}}{\mathrm{m}^{3}}\right]$
$C_{p} \quad$ Specific heat capacity

E Energy

$E_{a} \quad$ Activation energy

$K \quad$ Michaelis-Menten constant

$K_{i} \quad$ Inhibition constant

$M \quad$ Mass

PI Protease inhibitor content

Pat Patatin content

$R \quad$ Universal gas constant

TP Total protein content

$t \quad$ Time

T Temperature

$V \quad$ Volume

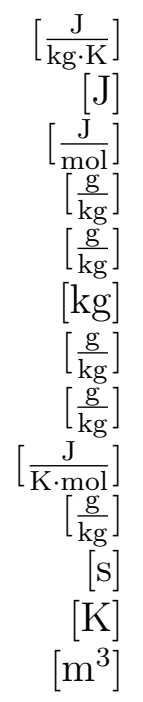

Table 5.1: Protein development and protein content ranges found in literature.

\begin{tabular}{|c|c|c|c|}
\hline Article & Protein development & Concentration range & Variety \\
\hline (Brierley et al., 1996) & Increase $^{\dagger}$ & $1.0-14.0 \mathrm{~g} / \mathrm{kg} \mathrm{FW}$ & Pentland Dell/Record \\
\hline (Brierley et al., 1997) & Increase & $1.5-13.5 \mathrm{~g} / \mathrm{kg} \mathrm{FW}$ & Pentland Dell \\
\hline (Pots et al., 1999) & Increase $^{\dagger}$ & $2.2-4.1 \mathrm{~g} / \mathrm{kg}$ DW & Elkana \\
\hline (Mazza, 1983) & Constant & $8-11.5 \%$ of DW & Russet Burbank/Norchip \\
\hline (Blenkinsop et al., 2002) & Constant & $4.8-10.9 \mathrm{~g} / \mathrm{kg} \mathrm{FW}$ & Novachip/Monona \\
\hline (Nowak, 1977) & Decrease & $9-24 \mathrm{~g} / \mathrm{kg} \mathrm{DW}$ & Baca/Bem \\
\hline (Kumar and Knowles, 1993) & Decrease & $3.75-5.75 \mathrm{~g} / \mathrm{kg} \mathrm{DW}$ & Russet Burbank \\
\hline (Pots et al., 1999) & Decrease & $1.5-3.9 \mathrm{~g} / \mathrm{kg} \mathrm{DW}$ & Bintje/Desiree \\
\hline
\end{tabular}

content vary, especially between different potato varieties. As Table 5.1 shows, some studies found an increase in protein content (Brierley et al., 1996, 1997) or a constant protein content (Mazza, 1983; Blenkinsop et al., 2002), while others reported a decrease (Nowak, 1977; Kumar and Knowles, 1993). The studies listed in Table 5.1 and, in particular, the study by Brasil et al. (1993), showed that, besides on variety, the protein content development also depends on storage temperature.

This means that a dedicated storage strategy is needed to yield potatoes with high protein levels for industrial extraction. As high protein levels are associated with low levels of free amino acids (Brierley et al., 1996), which are involved in the Maillard browning reaction (Khanbari and Thompson, 1993), protein-rich potatoes are also useful for frying. Optimal storage obviously depends on the eventual use of the potatoes. However, nei- 


\section{Chapter 5}

ther a mathematical model that describes the dependence of potato proteins on storage temperature nor a corresponding control strategy are currently available.

We have therefore carried out a study to investigate and model the development of potato protein content in potatoes in a large-scale bulk storage facility. We measured potato protein content throughout a single harvesting and storage season (2015-2016) and used Michaelis-Menten kinetics combined with the Arrhenius equation to describe how protein content depends on storage temperature. This combination is capable of capturing the temperature dependence of enzyme activity accurately (Davidson et al., 2012).

The next section of this paper describes the materials and methods used for protein extraction and the modelling procedure. Section 3 presents the results of the protein content measurements, parameter analyses and model simulations. Section 4 contains the discussion of the results and we present our conclusions in Section 5.

\subsection{Material and methods}

\subsubsection{Tuber storage and preparation}

Potato (Solanum tuberosum) tubers of two different varieties (Agria and Miss Malina) were obtained from storage facilities at local farmers in Flevoland, the Netherlands. All tubers were stored at 6 to $15{ }^{\circ} \mathrm{C}$ and 90 to $95 \%$ relative humidity. Weekly and in duplicate, five tubers from each variety were taken from storage, peeled and chopped, and pieces of several tubers with a combined weight of 200 grams were juiced. After juicing, the pulp left in the juicer was flushed three times with approximately $100 \mathrm{~mL}$ cold water (Sowokinos, 1978), until we obtained $500 \mathrm{~mL}$ diluted potato juice. We waited two minutes between these three flushing steps. Of the resulting potato juice, $2 \mathrm{~mL}$ was frozen at $-20{ }^{\circ} \mathrm{C}$ and stored until protein determination.

\subsubsection{Protein determination}

Total soluble protein of the stored potato tubers was determined by an adaptation of the Coomassie Blue dye-binding assay of Bradford (1976), with bovine serum albumin (Sigma-Aldrich) as a standard. The samples were diluted twice in Tris-HCl with a $\mathrm{pH}$ value of 7.0 and containing $0.1 \mathrm{mM}$ dithiothreitol (hereafter referred to as Tris buffer), so the final concentration was in the range of the protein standards. Next, we filtered the diluted protein samples through a $0.45 \mu \mathrm{m}$ pore size membrane. The assay was carried out by adding $1.5 \mathrm{~mL}$ of Bradford Reagent (Sigma-Aldrich) to $0.05 \mathrm{~mL}$ of sample. After twenty-five minutes, we measured the absorbance at $595 \mathrm{~nm}$ in a spectrophotometer and compared this with the absorbance of the protein standard. 
The fractions of patatin and protease inhibitors were determined by gel filtration as done before by Brierley et al. (1996). We diluted the protein samples five times, again in Tris buffer, and filtered them through a $0.2 \mu \mathrm{m}$ pore size membrane. We used a Biosep SECs2000 gel filtration column (Phenomenex) to separate the protein fractions. The patatin fraction was identified by comparison with a $45 \mathrm{kDa}$ glycoprotein standard (Phenomenex), and the area of the patatin peak was compared with the total peak area to give its proportion. We identified the protease inhibitor fraction by comparison with a $15 \mathrm{kDa}$ protein standard, and took the two peaks around this molecular weight (15 to $21 \mathrm{kDa}$ ). The area of these peaks was then compared with the total peak area to give the proportion of protease inhibitors.

\subsubsection{Protein model}

Both protein synthesis and degradation have been the subject of many studies investigating either their mechanics or their kinetics. While some researchers have modelled the rate of protein synthesis by describing the entire process of gene expression and subsequent protein synthesis by ribosomes (von Heijne et al., 1987; Antoun et al., 2006), others have tried approaching synthesis by using Michaelis-Menten kinetics for the entire process (Lancelot et al., 1986; Danfær, 1991). Several studies have found that protein degradation can be described by Michaelis-Menten kinetics (Hersch et al., 2004; Grilly et al., 2007; Gérard et al., 2016). However, there are also some indications that protein turnover is a temperature-dependent process (Strnadova et al., 1986). This can be incorporated in each term by combining the Michaelis-Menten kinetic model with the Arrhenius model, as reported by Davidson et al. (2012). The major protein components of potatoes (patatin, protease inhibitors, total protein content) can be described by mathematical models of protein synthesis and degradation with the aforementioned kinetics. The following model describes the temperature-dependent dynamics of total protein content $(T P)$, protease inhibitors $(P I)$ and patatin content $(P a t)$ in a potato.

$$
\begin{gathered}
\frac{d T P}{d t}=A_{P S} e^{-\frac{E_{P S}}{R T}}-A_{P D} e^{-\frac{E_{P D}}{R T}} \frac{T P}{K_{P D}\left(1+\frac{P I}{K_{i}}\right)+T P} \\
\frac{d P I}{d t}=A_{P I} e^{-\frac{E_{P I}}{R T}}-A_{P D} e^{-\frac{E_{P D}}{R T}} \frac{P I}{K_{P D}\left(1+\frac{P I}{K_{i}}\right)+P I} \\
\frac{d P a t}{d t}=-A_{P D} e^{-\frac{E_{P D}}{R T}} \frac{P a t}{K_{P D}\left(1+\frac{P I}{K_{i}}\right)+P a t}
\end{gathered}
$$

The model takes the temperature inside the potato as uniformly distributed and equal to the temperature inside the storage facility. The model also assumes a uniform protein distribution throughout the potato tuber, which means that the concentration of each 


\section{Chapter 5}

component does not depend on the location in the tuber. With regard to protein content, the model considers the potato a closed system that does not interact with its environment. This means that no excretion or uptake of proteins or amino acids takes place. Consequently, the rates of change for each component are the sums of their synthesis and degradation rates and do not depend on migration of components. As patatin cannot be synthesised during storage (see e.g. Racusen, 1983; Paiva et al., 1983; Rosahl et al., 1986; Bárta and Bártová, 2008), its rate of change is only dependent on its degradation. We also assumed that each component degrades at the same rate and with the same affinity constant $\left(K_{P D}\right)$.

As competitive inhibition is the most common mechanism of protease inhibition in plants (Ryan, 1990), it was assumed to be the mechanism of action. We therefore included the term $\left(1+\frac{P I}{K_{i}}\right)$ in the degradation terms to incorporate competitive inhibition of proteases by protease inhibitors, as used before in Michaelis-Menten models with inhibition (Nxumalo et al., 1998).

\subsubsection{Parameter estimation}

To use the protein model as represented by Eqs. 5.1-5.3 for simulation, the parameters first need to be estimated. We used the experimental data described in Sections 2.1 and 2.2 for the estimation of the kinetic parameters. As Eqs. 5.1-5.3 are non-linear in the kinetic parameters, we applied the non-linear least squares algorithm in Matlab lsqnonlin. This function finds the minimum of the sum of squares of the residuals between measured and predicted TP, $P I$ and $P a t$ contents, by changing the values in the parameter vector

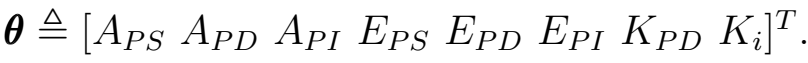

\subsection{Results}

\subsubsection{Protein content}

It is known that different varieties show different temporal trends regarding both total soluble protein as well as the individual fractions (see Table 5.1). In our study, the protein content of the Miss Malina variety appeared to decline, particularly at the beginning when the temperature had not reached its optimum yet, and the patatin and the protease inhibitor fractions exhibited similar behaviours; see the panels on the left in Figure 5.1. After the first seven weeks during which the temperature decreased gradually, there were ten weeks during which the temperature was kept constant at $8^{\circ} \mathrm{C}$. After week 27 , there were sudden changes, but these temperature changes at the end of the storage season were not reflected in the protein contents. 


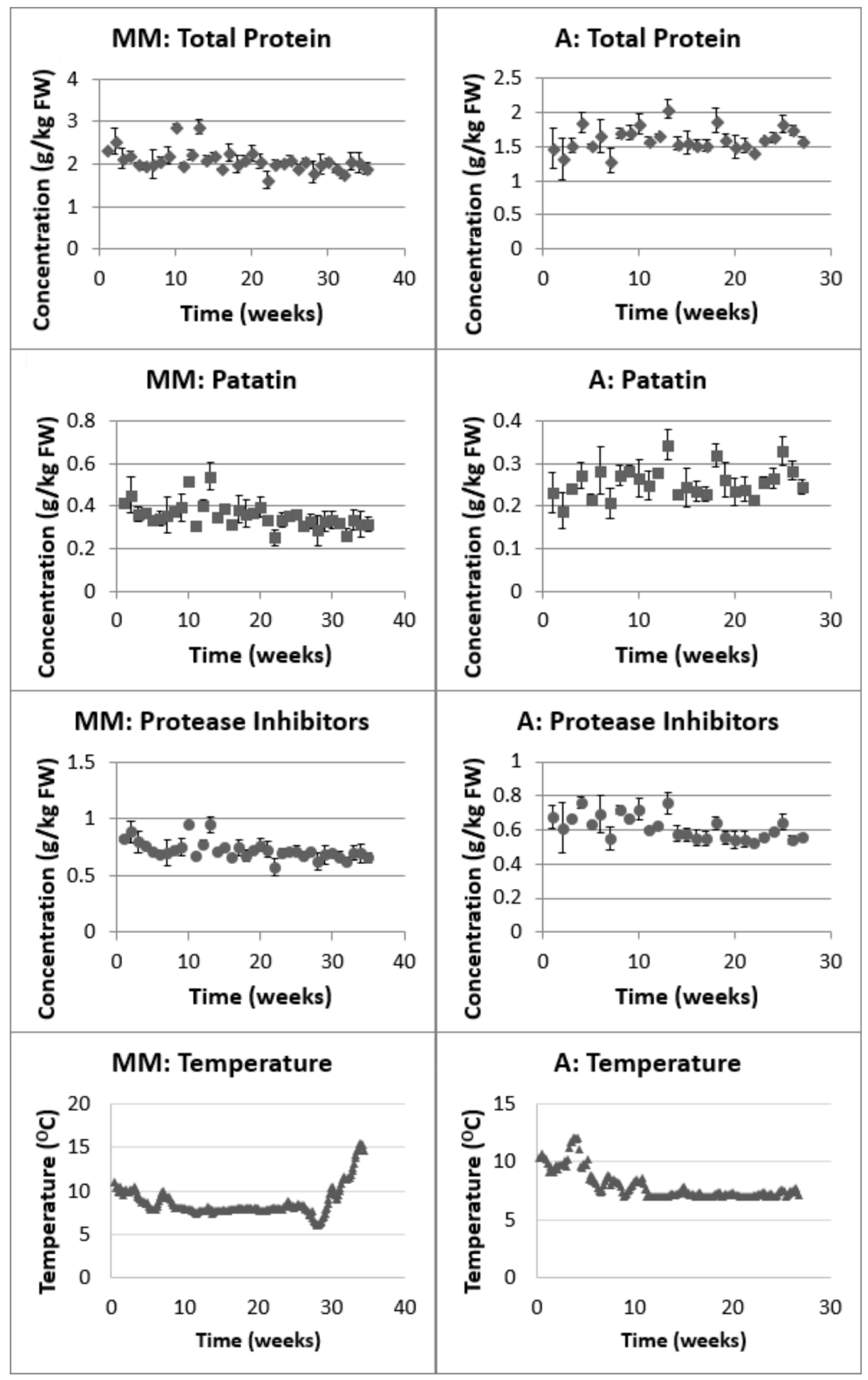

Figure 5.1: Measured protein content and temperature for Miss Malina (MM) in the left panel, and for Agria (A) in the right panel. From top to bottom, total protein, patatin, and protease inhibitor contents are shown as well as storage temperature, with standard deviation bars for the three protein contents. 


\section{Chapter 5}

The total protein level of the Agria variety appeared to fluctuate more, and increased slightly at the beginning of the storage period, again coinciding with a gradual lowering of the temperature; see right panels in Figure 5.1. While the patatin values fluctuated after that initial period, these fluctuations occurred within a fairly constant band. The protease inhibitor content showed a clear decrease from approximately 0.68 [g/kg FW] to around $0.56[\mathrm{~g} / \mathrm{kg} \mathrm{FW}$. As for Miss Malina, the temperature initially decreased until it reached the desired constant value. For Agria, this constant temperature was $6.5^{\circ} \mathrm{C}$ and there were no changes at the end.

\subsubsection{Parameter analysis}

An identifiability analysis showed that the model as proposed in Eqs. (5.1)-(5.3) is unidentifiable, so it is not possible to estimate the model parameters individually. As a remedy, we propose the following parameter estimation procedure with the following three stages:

I. Make the system linear in the parameters by setting $E_{P S}=E_{P D}=E_{P I}=K_{P D}=0$. Consequently, a linear regression model results, from which $A_{P S}, A_{P D}$ and $A_{P I}$ can be identified.

II. Fix the parameter estimates of $A_{P S}, A_{P D}$ and $A_{P i}$ found in stage I. Use a non-linear least squares algorithm to estimate the remaining set of parameters. To limit the number of parameters in this non-linear estimation step, set $E_{P S}=E_{P D}=E_{P I}=$ $E$, and thus estimate $E, K_{P D}$ and $K_{i}$.

In the results of stage I, we found that some of the parameter estimates of $A_{P S}, A_{P D}$ and $A_{P i}$ had negative values and thus were not physically interpretable. Stage II resulted in the finding that $E$ and $K_{i}$ were insensitive parameters. To deal with our first finding of negative estimates, while retaining the possibility of different slopes in each of the measured time series, we chose to split $K_{P D}$ into $K_{T P}, K_{P I}$ and $K_{P a t}$. On the basis of the results from I and II, we fixed both $E$ and $K_{i}$.

III. Iteratively process the following steps: (i) solve the linear regression problem by setting $E=1 e 3$ and $K_{i}=0.1$ found as appropriate estimates in stage II and use the initial guess $K_{T P}=K_{P I}=K_{P a t}=1$ to find parameter estimates for $A_{P S}, A_{P D}$ and $A_{P i}$, (ii) use a non-linear least squares algorithm to find $K_{T P}, K_{P I}$ and $K_{P a t}$, (iii) evaluate the accuracy of the estimates and adapt the parameter estimates of $K_{T P}, K_{P I}$ and $K_{P a t}$ in (i), then repeat steps (ii) and (iii) until convergence.

We found different parameter sets for each potato variety (Table 5.2). As mentioned in Subsection 5.3.1, the variety Miss Malina experienced a slight decrease in all protein fractions. This decrease is also visible in the predicted model outputs using the parameter values from 5.2; see the left panel of Figure 5.2. For the variety Agria, only the protease 
Table 5.2: Parameter estimates and standard deviations for varieties Miss Malina and Agria.

\begin{tabular}{c|c|c}
\hline Parameter & Miss Malina & Agria \\
\hline$A_{P S}$ & $0.0131 \pm 0.6834$ & $0.3813 \pm 1.7436$ \\
\hline$A_{P D}$ & $0.1362 \pm 2.8087$ & $0.8977 \pm 4.1693$ \\
\hline$A_{P I}$ & $0.0639 \pm 1.4736$ & $0.1865 \pm 0.9035$ \\
\hline$E$ & 1000 & 1000 \\
\hline$K_{i}$ & 0.100 & 0.100 \\
\hline$K_{T P}$ & $0.8004 \pm 0.0677$ & $0.3189 \pm 0.0089$ \\
\hline$K_{P I}$ & $0.0786 \pm 0.0045$ & $0.3115 \pm 0.0047$ \\
\hline$K_{P a t}$ & $1.1182 \pm 0.4739$ & 1000 \\
\hline
\end{tabular}
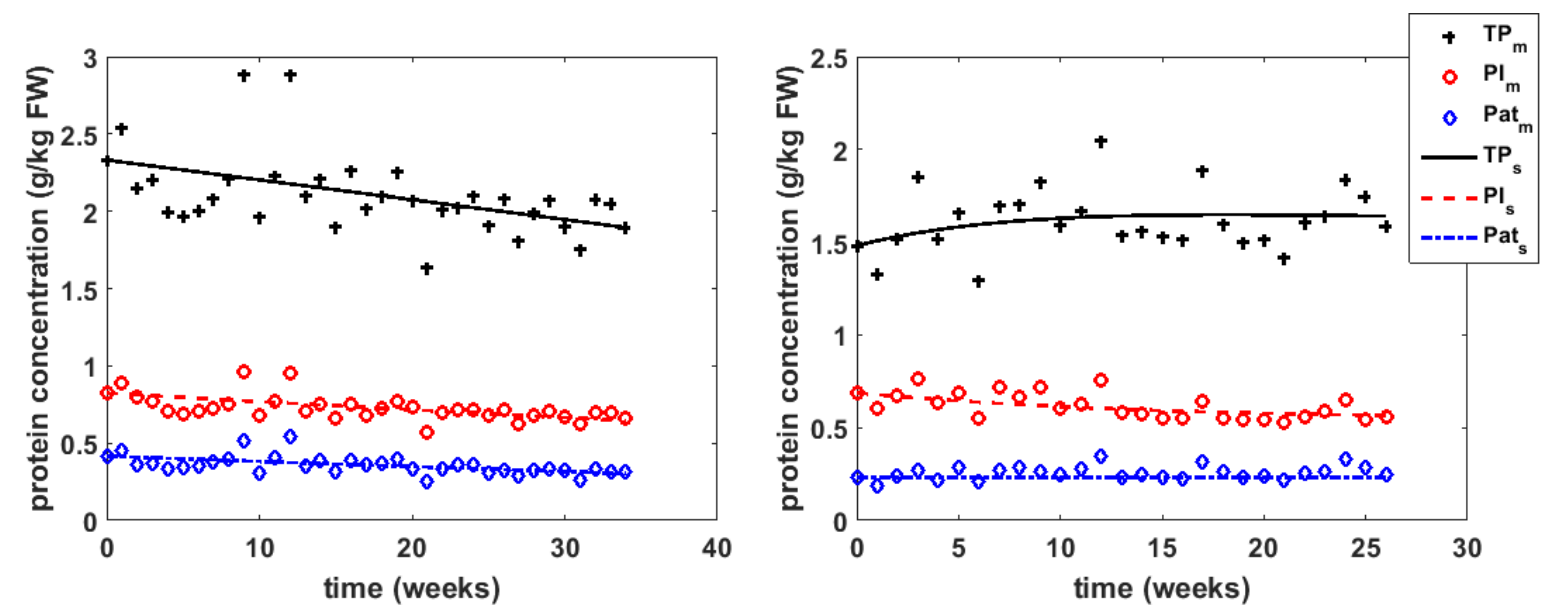

Figure 5.2: Model outputs and corresponding experimental data for total protein $(T P)$, protease inhibitors $(P I)$ and patatin (Pat) contents for the variety Miss Malina (left panel) and the variety Agria (right panel).

inhibitors decreased; total protein content increased slightly and the patatin content was more or less constant, which was also predicted by the model using the parameter values from 5.2; see the right panel of Figure 5.2. For both varieties, the model responses do not follow the fluctuations in the data, but provide reasonable overall fits.

The parameter estimation revealed the activation energy $E$ as an insensitive parameter. This low sensitivity is in line with the measurement data, showing no relationship between temperature fluctuations during storage and changes in protein content. The estimate of $K_{\text {Pat }}$ for the Agria variety is much higher than the estimate of $K_{P a t}$ for the Miss Malina variety. This difference could already have been deduced from the measured patatin content, as this was almost constant for the Agria variety, meaning that $K_{P a t}$ was very high, while the Miss Malina variety displayed a decreasing patatin content. 


\section{Chapter 5}

\subsection{Discussion}

Protein synthesis is a complicated process, which can briefly be summed up as follows. In order for protein synthesis to occur, genes first need to be expressed, resulting in RNA strands. These strands have to make their way out of the cell nucleus to ribosomes in the cytoplasm. Protein synthesis then proceeds by reading the RNA strand and constructing a line of amino acids that together form the protein. Mathematical modelling of detailed protein synthesis has been carried out before for prokaryotic organisms by Drew (2001), but still remains to be done for higher organisms such as plants or mammals.

In our experiments, we observed a decreasing total protein content for Miss Malina and a slightly increasing total protein content for Agria. The data for both Miss Malina and Agria display fluctuations over time in total protein, protease inhibitors and patatin content. The three components appear strongly correlated. Previous studies had a significantly lower sampling frequency than the sampling frequency of one week applied in this study; we have not been able to find any studies reporting fluctuations within a single week. From our experimental data, we are unable to conclude whether the protein content in the potato fluctuates as fast as seen in the measured data or whether these fluctuations are a result of sampling and measurement errors.

For the modelling of the protein content during long-term storage, we assumed that the protein turnover has a significant effect on protein dynamics. The total protein turnover consists of the sum of total protein synthesis and degradation and strongly depends on temperature (see e.g. Brasil et al., 1993). We therefore modelled the synthesis and degradation processes by using temperature-dependent Michaelis-Menten kinetics. The temperature dependence was expressed in terms of the Arrhenius equation.

Our parameter estimation results, however, showed that the activation energy $E$ is larger than zero, but it could only be estimated from the data with a large uncertainty. Furthermore, for the Miss Malina variety, significant changes in temperature at the end of the storage season did not lead to changes in the protein content. Consequently, $E$ was fixed at $10^{3}[\mathrm{~J} / \mathrm{mol}]$ and thus the factor $e^{-E / R T}$ is approximately equal to 0.65 . This choice of $E$ directly affects the estimated values of $A_{P D}, A_{P I}$ and $A_{P a t}$, which could not be estimated very accurately either (Table 5.2). We were able to estimate the affinity constants $K_{T P}$, $K_{P I}$ and $K_{P a t}$ for the Miss Malina variety accurately (Table 5.2). For the Agria variety, only $K_{P a t}$ could not be accurately estimated, as the corresponding patatin data did not show a clear increase or decrease. 


\subsection{Conclusions}

Our study appears to show that the protein content of potatoes depends on variety and possibly less straightforwardly on temperature. We propose that the total protein, protease inhibitors and patatin contents can be modelled using Michaelis-Menten kinetics, in combination with the Arrhenius equation. The proposed model provides insight into the dynamic behaviour of the protein content of potatoes in storage. However, more experimental research is needed to be able to estimate the model parameters accurately, except for the affinity constants, and to validate the model for multiple storage seasons. For a further understanding of protein turnover in potatoes, dedicated experiments for different varieties are needed to find explicit temperature effects on the synthesis and degradation of proteins. Once these relationships become available, the protein model (Eqs. (5.1)(5.3)) can be integrated into the potato storage model (Grubben and Keesman, 2018) and possibly extended with the sugar model as proposed by (Grubben et al., 2018b). 


\section{Chapter 5}

\section{References}

A. Antoun, M.Y. Pavlov, M. Lovmar, and M. Ehrenberg. How initiation factors tune the rate of initiation of protein synthesis in bacteria. The EMBO Journal, 25(11): 2539-2550, 2006.

J. Bárta and V. Bártová. Patatin, the major protein of potato (Solanum tuberosum L.) tubers, and its occurrence as genotype effect: Processing versus table potatoes. Czech Journal of Food Science, 26(5):347-359, 2008.

R.W. Blenkinsop, L.J. Copp, R.Y. Yada, and A.G. Marangoni. Changes in compositional parameters of tubers of potato (Solanum tuberosum) during low-temperature storage and their relationship to chip processing quality. Journal of Agricultural and Food Chemistry, 50(16):4545-4553, 2002.

M.M. Bradford. A rapid and sensitive method for the quantitation of microgram quantities of protein utilizing the principle of protein-dye binding. Analytical Biochemistry, 72(12):248-254, 1976.

P.J. Brasil, A.B. César, and H.P. Marcio. Effects of different storage temperatures on protein quantities of potato tubers. Revista Brasileira de Fisiologia Vegetal, 5(2):167170, 1993.

E.R. Brierley, P.L.R. Bonner, and A.H. Cobb. Factors influencing the free amino acid content of potato (Solanum tuberosum) tubers during prolonged storage. Journal of the Science of Food and Agriculture, 70:515-525, 1996.

E.R. Brierley, P.L.R. Bonner, and A.H. Cobb. Aspects of amino acid metabolism in stored potato tubers (cv. Pentland dell). Plant Science, 127(1):17-24, 1997.

A. Danfær. Mathematical modelling of metabolic regulation and growth. Livestock Production Science, 27:1-18, 1991.

E.A. Davidson, S. Samanta, S.S. Caramori, and K. Savage. The dual arrhenius and michaelis-menten kinetics model for decomposition of soil organic matter at hourly to seasonal time scales. Global Change Biology, 18(1):371-384, 2012.

D.A. Drew. A mathematical model for prokaryotic protein synthesis. Bulletin of Mathematical Biology, 63:329-351, 2001.

C Gérard, D. Gonze, and A. Goldbeter. Dependence of the period on the rate of protein degradation in minimal models for circadian oscillations. Philosophical Transactions of the Royal Society A, 367:4665-4683, 2016.

C. Grilly, J. Stricker, W.L. Pang, M.R. Bennett, and J. Hasty. A synthetic gene network for tuning protein degradation in saccharomyces cerevisiae. Molecular Systems Biology, $3: 127,2007$. 
H.E. Grommers and D.A. van der Krogt. Chemistry and technology: Starch. Academic press, 2009.

N.L.M. Grubben and K.J. Keesman. A spatially distributed physical model for dynamic simulation of ventilated agro-material in bulk storage facilities. Computers and Electronics in Agriculture, provisionally accepted for publication, 2018.

N.L.M. Grubben, L. van Heeringen, and K.J. Keesman. Modelling potato protein content for large-scale bulk storage facilities. -, under review, 2018a.

N.L.M. Grubben, S.C.M. Witte, and K.J. Keesman. Postharvest quality development of frying potatoes in a large-scale bulk storage facility. Postharvest Biology and Technology, accepted for publication, 2018b.

G.L. Hersch, T.A. Bakker, and R.T. Bakker. SspB delivery of substrates for ClpXP proteolysis probed by the design of improved degradation tags. Proceedings of the National Academy of Sciences of the United States of America, 101(33):12136-41, 2004.

F. Holm and S. Eriksen. Emulsifying properties of undenatured potato protein concentrate. International Journal of Food Science \& Technology, 15(1):71-83, 1980.

A.C. Kapoor, S.L. Desborough, and P.H. Li. Potato tuber proteins and their nutritional quality. Potato Research, 18(3):469-478, 1975.

O.S. Khanbari and A.K. Thompson. Effects of amino acids and glucose on the fry colour of potato crisps. Potato Research, 36(4):359-364, 1993.

X. Kong, L. Kong, Y. Ying, Y. Hua, and L. Wang. Recovering proteins from potato juice by complexation with natural polyelectrolytes. International Journal of Food Science and Technology, 50:2160-2167, 2015.

G.N.M. Kumar and N.R. Knowles. Age of potato seed-tubers influences protein synthesis during sprouting. Physiologia Plantarum, 89:262-270, 1993.

C. Lancelot, S. Mathot, and N. Owens. Modelling protein synthesis, a step to an accurate estimate of net primary production: Phaeocystis pouchetii colonies in belgian coastal waters. Marine Ecology Progress Series, 32:193-202, 1986.

S. Løkra and K.O. Strætkvern. Industrial proteins from potato juice. A review. Food, 3(1):88-95, 2009.

G. Mazza. Correlations between quality parameters of potatoes during growth and longterm storage. American Potato Research, 60(3):145-159, 1983.

J. Nowak. Biochemical changes in stored potato-tubers with different rest periods .1. influence of storage temperature and isopropyl phenylcarbamates (ipc and cipc) on protein changes. International Journal of Plant Physiology, 81(2):113-124, 1977.

F. Nxumalo, N.R. Glover, and A.S. Tracey. Kinetics and molecular modelling studies of the inhibition of protein tyrosine phosphatases by N,N-dimethylhydroxylamine com- 


\section{Chapter 5}

plexes of vanadium. Journal of Biological Inorganic Chemistry, 3(5):534-542, 1998.

E. Paiva, R.M. Lister, and W.D. Park. Induction and accumulation of major tuber proteins of potato in stems and petioles. Plant Physiology, 71(1):161-168, 1983.

A.M. Pots, H. Gruppen, R. van Diepenbeek, J.J. van der Lee, M.A.J.S. van Boekel, G. Wijngaards, and A.G.J. Voragen. The effect of storage of whole potatoes of three cultivars on the patatin and protease inhibitor content; a study using capillary electrophoresis and MALDI-TOF mass spectrometry. Journal of the Science of Food and Agriculture, 79:1557-1564, 1999.

D. Racusen. Occurrence of patatin during growth and storage of potato turbers. Canadian Journal of Botany, 61:370-373, 1983.

M.C. Ralet and J. Guéguen. Fractionation of potato proteins: Solubility, thermal coagulation and emulsifying properties. LWT - Food Science and Technology, 33(5):380-387, 2000 .

S. Rosahl, R. Schmidt, J. Schell, and L. Willmitzer. Isolation and characterization of a gene from solanum tuberosum encoding patatin, the major storage protein of potato tubers. Molecular and General Genetics, 203(2):214-220, 1986.

C.A. Ryan. Protease inhibitors in plants: genes for improving defenses against insects and pathogens. Annual Review of Phytopathology, 28(1):425-449, 1990.

S. Seo, S. Karboune, and A. Archelas. Production and characterisation of potato patatin galactose, galactooligosaccharides, and galactan conjugates of great potential as functional ingredients. Food Chemistry, 158:480-489, 2014.

J.R. Sowokinos. Relationship of harvest sucrose content to processing maturity and storage life of potatoes. American Potato Journal, 55:33-344, 1978.

M. Strnadova, R. Prasad, H. Kučerovcá, and J. Chaloupka. Effect of temperature on growth and protein turnover in Bacillus megaterium. Journal of Basic Microbiology, 26(5):289-298, 1986.

G. von Heijne, C. Blomberg, and H. Liljenström. Theoretical modelling of protein synthesis. Journal of Theoretical Biology, 125(1):1-14, 1987.

WCRTC. World congress on root and tuber crops, participants gcp21. http://www.gcp21.org/wcrtc/ Accessed on may 2018, 2016.

D.-Q. Zhang, T.-H. Mu, H.-N. Sun, J.-W. Chen, and M. Zhang. Comparative study of potato protein concentrates extracted using ammonium sulfate and isoelectric precipitation. International Journal of Food Properties, 20(9):2113-2127, 2017. 


\section{Chapter 6}

\section{CONTROLLABILITY AND OBSERVABILITY OF 2D THERMAL FLOW IN BULK STORAGE FACILITIES USING SENSITIVITY FIELDS}

Published as:

N.L.M. Grubben and K.J. Keesman. Controllability and observability of 2D thermal flow in bulk storage facilities using sensitivity fields. International Journal of Control, 91(7):1554-1566, 2017 


\section{Chapter 6}

\section{Abstract}

To control and observe spatially distributed thermal flow systems, the controllable field and observable field around the actuator and sensor, are of interest, respectively. For spatially distributed systems, the classical systems theoretical concepts of controllability and observability are, in general, difficult to apply. In this study, sensitivity fields were used to analyse the behaviour from input to state and from initial state to output. For the analysis of controllability and observability, a large-scale, bulk storage facility with coupled thermal flow of air and agro-products, was used. Analysis of this system using the classical systems theory results in controllability and observability results that are dependent on the step size of the spatially discretized system. Due to matrix multiplications, inaccurate results are calculated if the step size is too small. Our findings indicate that inputstate and initial-state output sensitivity fields provide sufficient information about the controllability and observability of large coupled spatially distributed systems, using finitedimensional state space representation with small discretization steps.

\subsection{Introduction}

Convection-diffusion-reaction (CDR) equations are used to describe the dynamic behaviour of mass and energy in a wide range of physical systems, such as, for instance, heat exchangers ,flow systems, all types of chemical reactors, but also bulk food-storage systems (see e.g. Nagarajan et al., 2015; Garzon-Alvarado et al., 2012; Lopes and QuitaFerreira, 2011; Chourasia and Goswami, 2007). In these systems, physical phenomena, such as the transfer of momentum, mass, energy or other physical quantities, typically occur within the system and through the system boundaries. To have some influence and information on these systems they are controlled and observed (see e.g. Brecht et al., 2005; Dochain et al., 2009; Mohammadi et al., 2012). For proper control and sensing of such systems, controllability and observability play central roles (Varga et al., 1995; Storkaas and Skogestad, 2007).

This article focuses on systems theoretical properties of one- and two-dimensional (i.e. $1 \mathrm{D}$ and 2D) thermal flow in porous media, as in, for example, bulk food-storage facilities (Grubben and Keesman, 2015). In such systems, flow is often described by the law of conservation of momentum, and continuity equation in one-, two- or three-dimensions (Chourasia and Goswami, 2007). Other transport phenomena, such as mass and energy transfer in the bulk, and between the food bulk and the air, are described by the laws of conservation for mass and energy, and constitutive laws. The modelling of such dynamicand spatially distributed systems most often results in a set of coupled, non-linear, partial differential equations (PDEs) that must be solved numerically. 


\section{Nomenclature}

$\begin{array}{ll}\boldsymbol{A} & \text { State matrix } \\ a_{a} & \text { Diffusion coefficient in air } \\ a_{p} & \text { Diffusion coefficient in product } \\ \boldsymbol{B} & \text { Input matrix } \\ \boldsymbol{C} & \text { Output matrix } \\ \mathcal{C} & \text { Controllability matrix } \\ \boldsymbol{c} & \text { Convection coefficient in air } \\ \boldsymbol{D} & \text { Feed-forward matrix } \\ h & \text { Step size } \\ L & \text { Length } \\ \boldsymbol{M} & \text { Matrix } \\ n & \text { Coordinates } \\ \mathcal{O} & \text { Observability matrix } \\ \mathcal{P} & \text { Péclet number } \\ r & \text { Reaction coefficient } \\ \boldsymbol{S} & \text { Sensitivity field } \\ T & \text { Temperature } \\ t & \text { Time }\end{array}$

$\mathcal{T} \quad$ Final time

$\boldsymbol{u}$ Input vector

$v \quad$ Velocity

$W_{c}$ Controllability Gramian

$\boldsymbol{W}_{o}$ Observability Gramian

$\boldsymbol{X}, \boldsymbol{x}$ State vector

$\dot{x} \quad$ Time differentiated state vector

$\boldsymbol{y}$ Output vector

$z \quad$ Coordinates

$\alpha \quad$ Input

$\Delta \quad$ Laplace operator

$\kappa \quad$ Condition number

$\lambda \quad$ Eigenvalue

$\mu \quad$ Weighted singular value

$\nabla \quad$ Vector differential operator nabla

$\tau \quad$ Response time

$\sigma \quad$ Singular value

In our specific example of a bulk food-storage facility used for the storage of potatoes, onion or wheat, the practical goal is to maintain the quality of the food products at a certain level for a longer time. Due to the interaction between the climate in the facility and the food product itself, the product quality is controlled by the climate, whereas the climate inside of the bulk is controlled by forced- or natural convection of air. In practice, and in the case of forced convection, most often, air with a piece-wise constant flow rate is supplied. The air is streamed from the bottom of the bulk, through the porous medium (bulk matter), to the top layer of the bulk. From there, it either leaves the facility through an outlet or is recirculated (Figure 6.1).

In the following, only thermal flow due to forced convection with zero or constant air velocity is considered. Hence, from a theoretical system perspective, a piece-wise, linear time-invariant (LTI), 2D coupled convection-diffusion-reaction system is obtained. The system states taken into consideration are the temperature of the air $\left(T_{a}\right)$ and the temperature of the product $\left(T_{p}\right)$, more precisely $T_{a}(z, t)$ and $T_{p}(z, t)$, where $z$ represents the spatial coordinate and $t$ time. From practice, it is known that these systems are unstable, due to biological processes. For instance, rotting- and ageing processes of the product are non-reversible, although these processes can be stabilised by recirculating air. State-of-the-art control in storage facilities aims to maintain temperature, and sometimes humidity, around a certain pre-specified level to prevent rotting and to diminish moisture 


\section{Chapter 6}

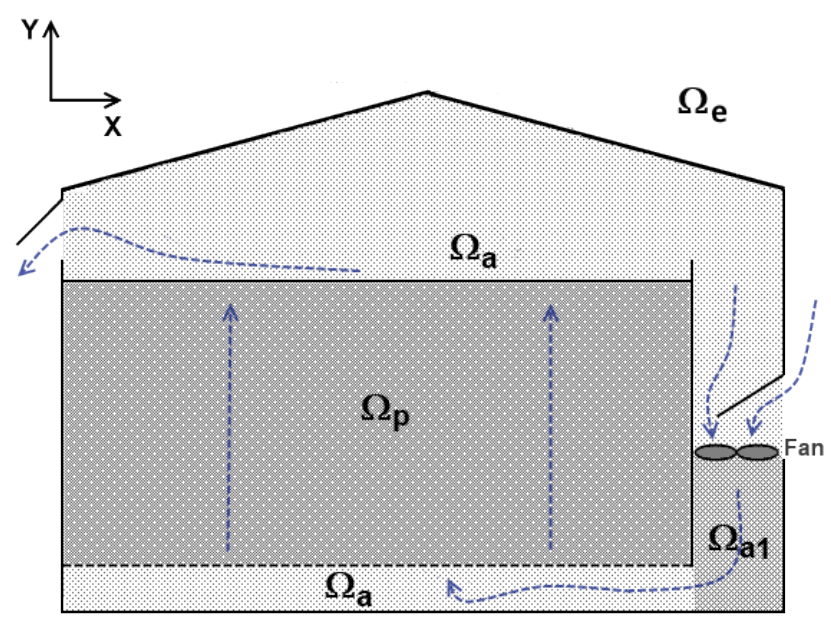

Figure 6.1: $2 \mathrm{D}$ configuration of a bulk storage facility. The climate is controlled by ventilating air from bottom to top through the porous medium. Here, $\Omega_{a}$ is the air domain, $\Omega_{a 1}$ the pressure chamber, $\Omega_{p}$ the porous medium domain and $\Omega_{e}$ the environment.

loss and the effects of ageing. Novel control concepts, however, aim to control product quality directly (Grubben and Keesman, 2015). In addition, it is preferable to have a homogeneous quality in the entire bulk, whilst minimising ventilation costs. These requirements necessitate a model-based control strategy. However, before designing such a control strategy, the key question is: Can the internal states of the system, $T_{a}$ and $T_{p}$, move from any initial-state to any other final-state in finite time? If this is the case, the system is referred to as controllable.

Formally, from a systems theory perspective, the system is said to be controllable if, and only if, it is possible to transfer the system from the zero state $x\left(t_{0}\right)$, at any initial time $t_{0}$, to any terminal state $x\left(t_{1}\right)=x_{1}$ within a finite time $t_{1}-t_{0}$ (Kwakernaak and Sivan, 1972). For the bulk storage system, this implies that at a specific time instant, it would be possible to create an arbitrary temperature profile, in, for instance, the vertical direction. In bulk-food storage practices, however, such a requirement is too strict. Therefore, the formal definition of controllability is not appropriate in this case.

To obtain current information about the states in the system, some observations should be available. In systems theory, a system is referred to as observable, if, and only if, it is possible to determine any (arbitrary) initial state $x\left(t_{0}\right)=x_{0}$ by using only finite output data records $y(t)$ for $t_{0} \leqslant t \leqslant t_{1}$ (Friedland, 2005). For sensor location in a spatially distributed system, however, the systems theoretical concept of observability does not provide sufficient information. In practice, for spatially distributed systems, the observable field around the sensor would be of interest. In conclusion, for practical insight into spatially distributed systems, the systems theoretical concepts of controllability and observability provide insufficient insight. 
For relatively simple, linear CDR systems, infinite- dimensional system theory (Curtain and Zwart, 1995) could be used to analyse the controllability and observability in depth (see Jai et al., 1995 and Amouroux et al., 1994, respectively). For coupled CDR systems, as in this case, with complex coupled dynamics between air and product in the storage facility, this theory is commonly not applicable.

The objective of this paper is to provide more information about the spatial distribution of air- and product temperature in bulk storage facilities, for actuation and sensing. The concepts of controllability and observability are investigated by analysing the behaviour from input to state and from initial-state to output of a dynamic, spatially distributed system. The input-to-state analysis gives the relation between the control input, generated by the actuator, to the state variables over time, and over the entire spatial domain. The initial-state-to-output analysis provides the relation between the sensor output and the initial-state over time, and over the entire spatial domain. In the paper, these relationships are investigated using sensitivity analysis (SA), see e.g. Tomovic (1963) or Saltelli et al. (2000).

A local sensitivity analysis of our CDR system, using partial derivatives of the state-toinput or output-to-initial-state, led to the study of in- and output sensitivity fields. By spatially discretizing the set of partial differential equations, describing heat transfer in the bulk storage, a large set of ordinary differential equations is obtained. In such a case, typically a Direct Method (DM) sensitivity analysis (Dickinson and Gelinas, 1976) can be carried out.

The outline of the paper is as follows. Firstly, in Section 2, some background on the systems theoretical concepts of controllability and observability for CDR systems, using a state-space representation, is presented. A singular value decomposition (SVD) of the resulting controllability and observability matrices provides some further insights compared to the conventional controllability and observability analyses. However, the SVD-based controllability and observability measures, are numerical measures, influenced by the discretization step size. These concepts are illustrated by an analysis of controllability and observability, and singular values corresponding to a 1D CDR system in Section 6.3. The main contribution of the paper, however, is the construction of in- and output sensitivity fields for CDR systems. Firstly, in Section 6.4, a single-state, 1D, CDR system is used to illustrate the theory of in- and output sensitivity fields for CDR systems, followed by a detailed analysis of a 2D, coupled, CDR system in Section 6.5.

\subsection{Systems theory}

Classical systems theory can be applied to a wide range of systems. However, for some applications, concepts in systems theory are too strict, and additional information is re- 


\section{Chapter 6}

quired. For instance, applying controllability and observability theory on CDR models of temperature in a bulk storage facility only gives a very initial impression of the systems behaviour. In this section, conventional controllability and observability theory, including the singular value decomposition of the resulting controllability and observability matrices, will be applied first on a 1D boundary controlled CDR-system to demonstrate the limitations of this theory in practice.

\subsubsection{Controllability and observability for boundary controlled CDR sys- tems}

Typically, a boundary controlled CDR system is characterised by the partial differential equation:

$$
\begin{aligned}
\left(\frac{\partial \boldsymbol{X}}{\partial t}+\boldsymbol{v} \cdot \nabla \boldsymbol{X}\right) & =a \Delta \boldsymbol{X}+\boldsymbol{r}_{X} \text { in }(0, t] \times \Omega_{d} \\
\boldsymbol{X} & =\boldsymbol{u}_{\text {dirichlet }} \text { on }(0, t] \times \partial \Omega_{d 1} \\
\frac{\partial \boldsymbol{X}}{\partial n} & =\boldsymbol{u}_{\text {neumann }} \text { on }(0, t] \times \partial \Omega_{d 2}
\end{aligned}
$$

Thus, including Dirichlet Eq. (6.2) and Neumann Eq. (6.3) boundary conditions, at the corresponding boundaries $\partial \Omega_{d 1}$ and $\partial \Omega_{d 2}$, respectively. Here $\boldsymbol{X} \in \mathbb{R}^{N}$ is a state vector, $t$ represents time, $\boldsymbol{v}$ is the velocity vector, $c$ the diffusion coefficient, $\boldsymbol{r}_{X}$ a first-order reaction vector, $\boldsymbol{u}_{\text {dirichlet }}$ is the input $\boldsymbol{u}$ on boundary $\partial \Omega_{d 1}$ and $\boldsymbol{u}_{\text {neumann }}$ the flux through the boundary $\partial \Omega_{d 2}$. For the $3 \mathrm{D}$ case; $\nabla=\left[\begin{array}{lll}\frac{\partial}{\partial x} & \frac{\partial}{\partial y} & \frac{\partial}{\partial z}\end{array}\right]^{T}$ and $\Delta:=\nabla^{2}=\left[\frac{\partial^{2}}{\partial x^{2}}+\frac{\partial^{2}}{\partial y^{2}}+\frac{\partial^{2}}{\partial z^{2}}\right]$. Discretization in space results in a state vector $X \in \mathbb{R}^{n}$ containing the set of state variables $X$ for every grid point $i=1, \ldots, I$. In our example, $\boldsymbol{v}$ is constant and, thus, the equation (6.1) is approximated by a set of $n=N I$ first-order linear differential equations: Extending the set of differential equations with a set of algebraic output equations gives:

$$
\begin{aligned}
& \dot{\boldsymbol{x}}(t)=\boldsymbol{A x}(t)+\boldsymbol{B} \boldsymbol{u}(t) \\
& \boldsymbol{y}(t)=\boldsymbol{C} \boldsymbol{x}(t)+\boldsymbol{D} \boldsymbol{u}(t)
\end{aligned}
$$

Here, $\boldsymbol{x}=\left[x_{1}, x_{2}, \ldots, x_{n}\right]^{T} \in \mathbb{R}^{n}$ is the spatially discretized state vector of the system with $x(0)=x_{0}, \boldsymbol{u}=\left[u_{1}, u_{2}, \ldots, u_{m}\right]^{T} \in \mathbb{R}^{m}$ is the input vector and $y=\left[y_{1}, y_{2}, \ldots, y_{p}\right]^{T} \in \mathbb{R}^{p}$ is the output vector. Furthermore, the matrices $\boldsymbol{A}, \boldsymbol{B}, \boldsymbol{C}$ and $\boldsymbol{D}$ in the LTI system Eq. (6.4) are of appropriate dimensions. As follows, the $n \times n$ system matrix $\boldsymbol{A}$ requires special attention. If, however, $\boldsymbol{v}$ is not constant, a linearisation step is needed, most often leading to a LTV (linear time-varying) system.

The LTI system Eq. (6.4) is controllable, if, and only if, the rank of the controllability matrix:

$$
\mathcal{C}=\left[\begin{array}{lllll}
B & A B & A^{2} B & \cdots & A^{n-1} B
\end{array}\right]
$$


is equal to $n$, so of full (row) rank (Kalman, 1959). The controllability matrix multiplied with its transpose gives the $n \times n$ controllability Gramian:

$$
W_{c}=\mathcal{C C}^{T}
$$

Similarly, an LTI system is observable, if, and only if, the rank of the observability matrix:

$$
\mathcal{O}=\left[\begin{array}{c}
C \\
C A \\
C A^{2} \\
\vdots \\
C A^{n-1}
\end{array}\right]
$$

is equal to $n$, so in this case of full (column) rank (Kalman, 1959). The transpose of the observability matrix post multiplied with $\mathcal{O}$ gives the $n \times n$ observability Gramian:

$$
W_{o}=\mathcal{O}^{T} \mathcal{O}
$$

Consequently, given Eq. (6.1) with constant velocity vector $\boldsymbol{v}$, state discretization rank tests provide strict controllability and observability information on the LTI system.

\subsubsection{Singular value decomposition}

Controllability and observability theory, as presented in the previous section, gives satisfying information about the relation between the inputs and states, and outputs and states, but only in terms of true or false. As demonstrated in the following, a numerical rank test on the controllability and observability matrices will give further insight. As such, a singular value decomposition of the Gramian of $\mathcal{C}$ and $\mathcal{O}$ may give this additional information.

In general, the singular values of a rectangular matrix provide a near-singularity measure. For instance, for a non-square matrix $\boldsymbol{M}$ the decomposition provides insight in the contribution of each element in each direction, determined by the left- and right singular vectors. The singular value decomposition of an $\widetilde{m} \times \widetilde{n}$ matrix $\boldsymbol{M}$ is defined as:

$$
M=U \Sigma V^{T}
$$

Here, $\boldsymbol{U}$ is a $\widetilde{m} \times \widetilde{m}$ orthogonal matrix (containing left singular vectors), $\boldsymbol{V}$ is a $\widetilde{n} \times \widetilde{n}$ orthogonal matrix with right singular vectors and $\boldsymbol{\Sigma}$ is a $\widetilde{m} \times \widetilde{n}$ pseudo-diagonal matrix with the singular values $\sigma_{i}$ on the diagonal, which are sorted as $\sigma_{1} \geq \sigma_{2} \geq \ldots \geq \sigma_{\min (\tilde{m}, \tilde{n})}$. 


\section{Chapter 6}

The singular values are the square-roots of the eigenvalues of $\boldsymbol{M} \boldsymbol{M}^{\boldsymbol{T}}$ :

$$
\sigma_{i}=\sqrt{\lambda_{i}\left(\boldsymbol{M}^{\boldsymbol{T}}\right)}, \quad i=1, \ldots, \min (\widetilde{m}, \widetilde{n})
$$

The singular value decomposition of $\mathcal{C}$ and $\mathcal{O}$, respectively, can be used to quantify the controllable- and observable states. For example, uncontrollable states, possibly after applying a state transformation (Van Doren et al., 2013), can be found from the null space of $\mathcal{C}$, which is spanned by the $i$-th columns of $\boldsymbol{V}$ corresponding to the zero singular values $\sigma_{i}$. Similarly, unobservable states can be found from the null space of $\mathcal{O}$. Extending the tests to near-zero singular values allows the detection of states that are very difficult to control or estimate from observed input-output data.

\subsubsection{A 1D CDR system}

For further insight into the controllability and observability properties of a physical system for the heat transfer, an air temperature balance of a porous medium with convection, diffusion and reaction terms is used. In the first analysis, the system is $1 \mathrm{D}$ and has a Dirichlet boundary condition for $z=0$ and a Neumann boundary conditions for $z=L$. Hence, the complete system is defined by:

$$
\begin{aligned}
& \frac{\partial T}{\partial t}=a \frac{\partial^{2} T}{\partial z^{2}}-c \frac{\partial T}{\partial z}-r T \\
& T(t, 0)=\alpha, \quad \frac{\partial T}{\partial z}(t, L)=0
\end{aligned}
$$

Here, $T$ is the air temperature. For a specific, potato bulk storage facility (see Grubben and Keesman, 2015, Lukasse et al., 2007): $a=0.00002\left[\mathrm{~m}^{2} / \mathrm{s}\right], c=1[\mathrm{~m} / \mathrm{s}], r=1[1 / \mathrm{s}]$, $\alpha=1[\mathrm{~K}]$ and $L=1[\mathrm{~m}]$. For relatively simple partial differential equations, such as Eq. (6.11), linear infinite- dimensional system theory (Curtain and Zwart, 1995) could be used. However, for complex, coupled systems, analytical solutions become intractable. Therefore, Eq. (6.11) and in the following equations, such as: Eq. (6.11), are discretized in space using central difference methods, leading to:

$$
\begin{aligned}
\dot{T}\left(t, z_{i}\right) & =a \frac{T\left(t, z_{i-1}\right)-2 T\left(t, z_{i}\right)+T\left(t, z_{i+1}\right)}{\Delta h^{2}} \\
& -c \frac{-T\left(t, z_{i-1}\right)+T\left(t, z_{i+1}\right)}{2 \Delta h}-r T\left(t, z_{i}\right)
\end{aligned}
$$

Here, $z_{i}=i \Delta h$ is the distance from $z=0, i=0,1,2, \ldots, I-1$ with $I$ total amount of grid points and $\Delta h=\frac{L}{I-1}$ the step size with $L$ total length. A central differential method gives a more accurate solution compared to the forward- or backward difference method, due to the second order accuracy on $h$ (truncation error). Notice that $a \ll c$, which results in a large Péclet number $P e=\frac{c L}{a}$ and consequently, a large mesh Péclet number $\mathcal{P}=\frac{c \Delta h}{a}$. 
This large Péclet number results in a non-monotonous discretized state matrix $A$. In numerical calculations, this may easily lead to oscillatory behaviour, shown as follows. Rearranging the right-hand side of Eq. (6.12):

$$
\begin{aligned}
\frac{a}{\Delta h^{2}}\left[\left(\frac{\mathcal{P}}{2}+1\right)\left(T\left(t, z_{i-1}\right)-T\left(t, z_{i}\right)\right)+\right. & \\
& \left.\left(-\frac{\mathcal{P}}{2}+1\right)\left(T\left(t, z_{i+1}\right)-T\left(t, z_{i}\right)\right)-\frac{\Delta h^{2}}{a} r T\left(t, z_{i}\right)\right]
\end{aligned}
$$

A monotonous, tri-diagonal $\boldsymbol{A}$ matrix is obtained if $|\mathcal{P}|<2$. To satisfy this condition for the system Eq. (6.11), with high convection and low diffusion rates, a very small step size $\Delta h,(I=25000)$ should be used. If this small step size is used, numerical calculations of the system theory result in numerical errors. Therefore, a step size should be selected that is appropriate for the matrix calculations and results in minimal oscillatory solution. Another, but less accurate, method to avoid oscillations is to use a central-upstream differential scheme (Lynch, 2005). However, this method is not appropriate for our case, due to the repetitive multiplications of the $\boldsymbol{A}$ matrix in Eq. (6.5) and Eq. (6.7) for the controllability and observability tests.

\subsection{Controllability and observability of a 1D CDR system}

The system theory discussed in Section 6.2 is now applied to a 1D CDR system. The 1D system basically represents the porous medium domain, as de-pictured in Figure 6.1, with constant vertical flow.

\subsubsection{Controllability and observability}

Controllability and observability theory leads to a separation of the state space $\mathbb{R}^{n}$ into two spaces: the controllable/observable and the non-controllable/non-observable subspace. Commonly, these subspaces are determined numerically and, thus, the result depends on the numerical tolerance. For decreasing grid size steps, the values in the tri-diagonal system matrix $\boldsymbol{A}$ increase, which causes an increase in the dimension of the non-controllable space. For instance, in Matlab R2015b, the tolerance of the rank determination is calculated as: tolerance $=\max (\operatorname{size}(\mathcal{C}) * \operatorname{eps}(\operatorname{norm}(\mathcal{C}))$, where norm is the 2-norm of matrix $\mathcal{C}\left(\|\mathcal{C}\|_{2}\right)$, and eps specifies the distance from 1.0 to the next largest double-precision number, that is eps $=2^{(-52)} \approx 2.22 e-16$. For the $1 \mathrm{D}$ CDR system Eq. (6.11) with single-input and single output (SISO): 


\section{Chapter 6}

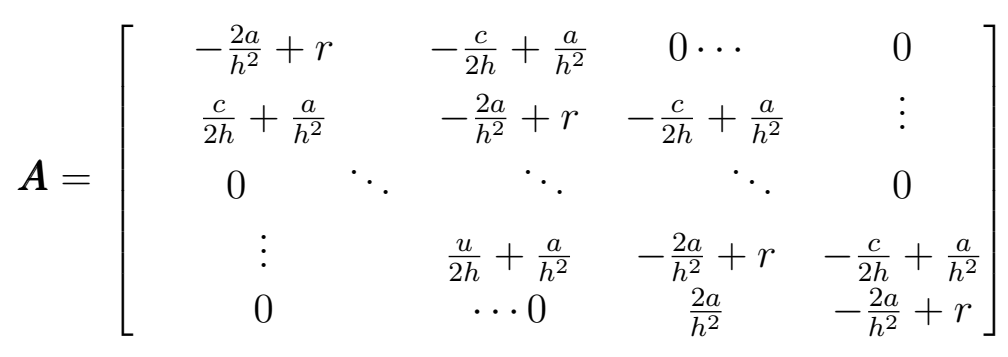

$$
\begin{aligned}
& \boldsymbol{B}=\left[\begin{array}{c}
\alpha\left(\frac{c}{2 h}+\frac{a}{h^{2}}\right) \\
0 \\
\vdots \\
0
\end{array}\right], \quad \boldsymbol{C}=\left[\begin{array}{lllll}
0 & \cdots & 1 & 0 & 0
\end{array}\right]
\end{aligned}
$$

Where $h=\Delta h$. For $a=0.00002\left[\mathrm{~m}^{2} / \mathrm{s}\right], c=1[\mathrm{~m} / \mathrm{s}], r=1[1 / \mathrm{s}], \alpha=1[\mathrm{~K}]$ and $L=1$ $[\mathrm{m}]$, the controllability and observability rank test gives full rank up to a discretization step size of $L / 12$ and $L / 13$, respectively:

$$
\begin{aligned}
\operatorname{rank}(\boldsymbol{C})= & {\left[\begin{array}{lllll}
\boldsymbol{B} & \boldsymbol{A} \boldsymbol{B} & \boldsymbol{A}^{2} \boldsymbol{B} & \cdots & \boldsymbol{A}^{11} \boldsymbol{B}
\end{array}\right]=12 } \\
\operatorname{rank}(\boldsymbol{O})=\left[\begin{array}{c}
\boldsymbol{C} \\
\boldsymbol{C A} \\
\boldsymbol{C} A^{2} \\
\vdots \\
\boldsymbol{C} \boldsymbol{A}^{12}
\end{array}\right] & =13
\end{aligned}
$$

For a smaller step size of, for instance, $L / 16 \operatorname{rank}(\boldsymbol{C})=11$ and $\operatorname{rank}(\boldsymbol{O})=10$.

\subsubsection{Singular value decomposition of $W_{c}$ and $W_{o}$}

A more detailed analysis can be performed by a singular value decomposition of the Gramians of the controllability and observability matrices. Zandvliet et al. (2008), for example, used a singular value decomposition of the Gramians in the analysis of a singlephase porous medium flow (LTI) system. Space discretization of the 1D CDR system, as in Section 6.2.3, results in a tridiagonal matrix with non-dominant diagonal and potentially oscillating behaviour, if the step size chosen is too large.With too small step size, the numerical singular value decompositions become unstable. The condition number of $\boldsymbol{W}_{\boldsymbol{c}}$ and $\boldsymbol{W}_{\boldsymbol{o}}$, respectively, will give an indication which spatial discretization step size would be appropriate.

The condition number of the rectangular matrix $\boldsymbol{M}$ is defined as the ratio of the maximum 
$\left(\sigma_{\max }\right)$ and minimum $\left(\sigma_{\min }\right)$ singular value, that is

$$
\kappa(\boldsymbol{M})=\frac{\sigma_{\max }(\boldsymbol{M})}{\sigma_{\min }(\boldsymbol{M})}
$$

A large condition number implies that matrix $\boldsymbol{M}$ is poorly conditioned, and, thus, a small condition number implies a well-conditioned matrix $\boldsymbol{M}$. From numerical analysis, it is known that if the condition number $\kappa=10^{k}$, then up to $k$ digits of accuracy can be lost (Cheney and Kincaid, 2008). It is possible that a large condition number causes the matrix $\boldsymbol{M}$ to become non-invertible due to errors in rounding-off. Hence, if large condition numbers are obtained, small changes in the system parameter can result in a non-invertible matrix. For a convection diffusion system, as in Eq. (6.11) with $a=0.00002\left[\mathrm{~m}^{2} / \mathrm{s}\right], c=1$ $[\mathrm{m} / \mathrm{s}]$ and $r=1[1 / \mathrm{s}]$, and step size of $1 / 12$, the condition numbers are:

$$
\begin{aligned}
& \kappa\left(\boldsymbol{W}_{\boldsymbol{c}}\right)=\frac{\sigma_{\max }\left(\boldsymbol{W}_{\boldsymbol{c}}\right)}{\sigma_{\min }\left(\boldsymbol{W}_{\boldsymbol{c}}\right)}=2.7 \cdot 10^{25} \\
& \kappa\left(\boldsymbol{W}_{\boldsymbol{o}}\right)=\frac{\sigma_{\max }\left(\boldsymbol{W}_{\boldsymbol{o}}\right)}{\sigma_{\min }\left(\boldsymbol{W}_{\boldsymbol{o}}\right)}=3.8 \cdot 10^{18}
\end{aligned}
$$

The condition numbers of the controllability and observability matrix are very high, and, therefore, the matrices are poorly conditioned. This poor condition is due to the large Péclet number, which results in wiggles in the discretized system. If the condition number approaches the inverse of the floating point number of the machine $4.5 \mathrm{e} 15$ (inverse eps value), precision cannot be guaranteed (Moler, 2004). Hence, from the perspective of condition number, a larger step size should be chosen, at the expense of a larger discretization error. Another option to obtain a better conditioned system is to use a forward-central discretzation method. A forward-central method for systems with large Péclet number, in general, results in a system with less wiggles. For further analysis of controllability and observability properties, we will focus on a singular value composition of $\boldsymbol{W}_{\boldsymbol{c}}$ and $\boldsymbol{W}_{\boldsymbol{o}}$, respectively. In this case: $\boldsymbol{U}=\boldsymbol{V}$, an $n \times n$ matrix.

The singular values $\left(\sigma_{i}\right)$ on the diagonal of the matrix $\Sigma$ Eq. (6.9) correspond to the $i$-th column of the left singular vector $U_{i}$. Consequently, every non-zero singular value corresponds to a set of weighting factors in the controllable or observable spatially discretized state space. The weighting factors define directions in the state space. Hence, if, for instance, $\sigma_{i}=0$, the corresponding weighting factors in the $i$-th column of $\boldsymbol{U}$ Eq. (6.9) determine the direction in state space, which is uncontrollable or unobservable. Multiplying the singular value $\sigma_{i}$ with the corresponding direction vector $\boldsymbol{U}_{i}$ gives the contribution in the controllable or observable space, of every grid point:

$$
\boldsymbol{\mu}_{i}=\sigma_{i} \boldsymbol{U}_{i}
$$

Following Van Doren et al. (2013), the sum of the singular value multiplied by the corre- 


\section{Chapter 6}

sponding direction gives the contribution of every grid point:

$$
\boldsymbol{\mu}=\sum_{i=1}^{n} \sigma_{i} \boldsymbol{U}_{i}
$$

Applying this on the controllability Eq. (6.6) and observability Eq. (6.8) Gramians of the CDR system Eq. (6.11), with $L=1$ and $h=1 / 12$ results in $\boldsymbol{\mu}_{c}$ and $\boldsymbol{\mu}_{o}$ respectively. From the controllability singular value decomposition of the controllability Grammian, it follows that the contribution $\left(\boldsymbol{\mu}_{\boldsymbol{c}}\right)$ of the first eight states are the largest and of the same order. Therefore, the first states are influenced most by the input $\alpha$. The observability singular value decomposition for a sensor on $z=0.9[\mathrm{~m}]$ show that the contribution $\left(\boldsymbol{\mu}_{\boldsymbol{o}}\right)$ of the states six to ten are the largest and of the same order. Therefore, these five states are best observable. In both cases, the states that contribute most show some wiggling behaviour. Hence, we have an initial impression of which states are controllable and observable. However, the analysis does not provide a full quantitative information of the spatial distribution of the input on the states or the output measurement on the state observability.

\subsection{Input and output sensitivities of 1D CDR sys- tems}

For spatially distributed CDR systems, classical controllability and observability analysis, even extended with a singular value decomposition, as in the previous section, may provide insufficient theoretical information of the system with boundary control. The combination of diffusion, convection and reaction terms of the physical system Eq. (6.11) with large Péclet number causes the discretized system matrix $\boldsymbol{A}$ Eq. (6.14) to have a nonmonotonous tridiagonal form. As already mentioned in Section 6.3.2, a non-monotonous matrix potentially shows oscillating behaviour.

Furthermore, a system is said to be controllable, if it is possible to transfer the system from any state to any other state in finite time. And a system is said to be observable, if it is possible to determine any (arbitrary) initial state by using only finite output data records. However, the theory does not give insight about the time afterwards, or a quantity of the spatial distribution where the system is controllable and observable. Input and output sensitivity fields provide such information. Using a input sensitivity field, the impact of the actuator on every state can be visualised, or at least interpreted. The output sensitivity field can give information about the domain that is observable, given a specific sensor location.

For the LTI state space representation, as defined in Eq. (6.4), the input and output sensitivity fields will be analysed in more detail for $m=p=1$, thus, the SISO case. All 
the dynamic relations in the system are covered by Eq. (6.4), and by taking derivatives of the state equation to input and the output to the initial state sensitivities can be calculated in each grid point. Therefore, the direct methods (DM) (Dickinson and Gelinas, 1976) are used to calculate the sensitivities, defined by

$$
\boldsymbol{S}_{x} \triangleq\left(\frac{\partial \boldsymbol{x}}{\partial u}\right), \quad \boldsymbol{S}_{y} \triangleq\left(\frac{\partial \boldsymbol{y}}{\partial x_{o}}\right)
$$

\subsubsection{Input sensitivity of 1D thermal flow in a bulk storage facility}

A direct relation between the sensitivity of the state vector $(\boldsymbol{x})$ with respect to a constant input $(u)$, and denoted as $\boldsymbol{S}_{x}$, can be derived from the state equation in Eq. (6.4) and is given by:

$$
\begin{aligned}
\frac{\partial}{\partial u}\left(\frac{d \boldsymbol{x}}{d t}\right) & =\frac{\partial}{\partial u}(\boldsymbol{A} \boldsymbol{x}+\boldsymbol{B} u), \quad u:=\text { constant } \\
\frac{d}{d t}\left(\frac{\partial \boldsymbol{x}}{\partial u}\right) & =\boldsymbol{A} \frac{\partial \boldsymbol{x}}{\partial u}+\boldsymbol{B} \\
\dot{\boldsymbol{S}}_{x} & =A S_{x}+B, \quad \boldsymbol{S}_{x}(0)=0
\end{aligned}
$$

Consequently, $\boldsymbol{S}_{x}(t)=\int_{0}^{t} e^{\boldsymbol{A}(t-s)} \boldsymbol{B} d s$. Since $\boldsymbol{A}$ is the given system matrix and $\boldsymbol{B}$ depends on the actuator location, the influence of the actuator on every place in the grid on the states in the grid can be determined.

Starting from equation (6.11), two different cases can be distinguished. Firstly, we consider the case, in which diffusion dominates, followed by the case, in which convection dominates. For the first case, in which diffusion dominates, four different diffusion rates $a=0.00002, a=0.0002, a=0.002, a=0.02\left[\mathrm{~m}^{2} / \mathrm{s}\right]$ were selected and, $c=0[\mathrm{~m} / \mathrm{s}], r=1$ $[1 / \mathrm{s}]$ and $\alpha=1\left[{ }^{\circ} \mathrm{C}\right]$. For the second case, in which convection dominates, $a=0.00002$ $\left[\mathrm{m}^{2} / \mathrm{s}\right], r=1[1 / \mathrm{s}]$ and $\alpha=1\left[{ }^{\circ} C\right]$, and four different convection rates $c=0.5, c=1.0$, $c=1.5, c=2.0[\mathrm{~m} / \mathrm{s}]$ were selected. The system has a Dirichlet boundary condition at $z=0$ and a Neumann boundary condition at the end $(z=L)$ of the profile. In Figure 6.2 for dominating diffusion (left) and for dominating convection (right) the steady state values of the sensitivity fields with a discretization step of $L / 200$ are shown.

For the steady state simulations, as shown in Figure 6.2, a simulation time of ten seconds is used. From the physical knowledge of the system to reach steady state this simulation time is long enough, due to the large convection rate $(1[\mathrm{~m} / \mathrm{s}])$. Figure 6.3 shows the change of input sensitivity over time in the first seconds. From Figure 6.3, it can be seen that the sensitivity at $z=0$ is more or less the same for every simulation time. At time $t=5[\mathrm{~s}]$, a steady state is obtained (using $a=0.00002\left[\mathrm{~m}^{2} / \mathrm{s}\right], c=1.0[\mathrm{~m} / \mathrm{s}], r=1$ $\left.[1 / \mathrm{s}], \alpha=1\left[{ }^{\circ} \mathrm{C}\right]\right)$, and sensitivity does not increases further. Hence, in this case, with $u$ 


\section{Chapter 6}
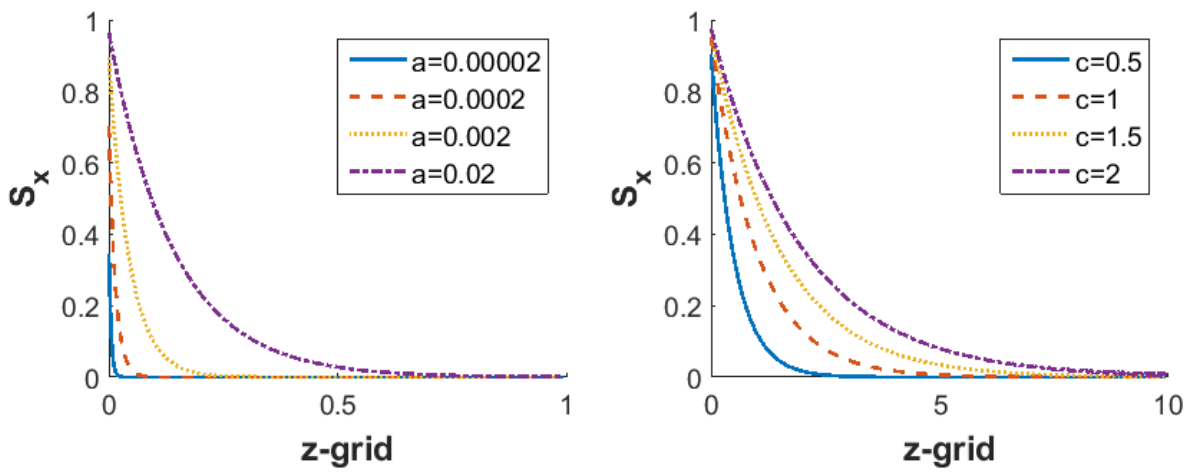

Figure 6.2: Left, 1D input sensitivity field simulated for different diffusion coefficients without convection, thus $c=0$. Right: 1D input sensitivity field simulated for different convection coefficients, including diffusion $(a=0.00002)$.

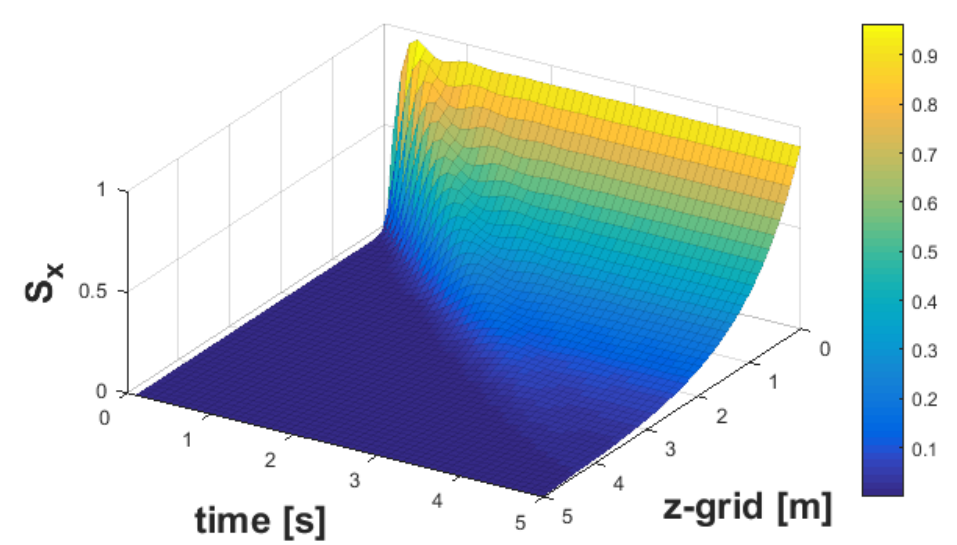

Figure 6.3: $1 \mathrm{D}$ input sensitivity field simulated for 0.1 to 5 seconds, using $a=0.00002$ $\left[\mathrm{m}^{2} / \mathrm{s}\right], c=1.0[\mathrm{~m} / \mathrm{s}], r=1[1 / \mathrm{s}], \alpha=1\left[{ }^{\circ} \mathrm{C}\right], \mathrm{L}=5[\mathrm{~m}]$ and grid size of $\Delta \mathrm{z}=\mathrm{L} / 50$.

piece-wise constant on a time interval of $10[\mathrm{~s}]$, the input sensitivity can be directly seen in the right panel of Figure 6.2. Notice that the steady state sensitivity of the actuator on the states can be checked from Eq. (6.23):

$$
\bar{S}_{x}=-A^{-1} B
$$

The sensitivity analysis of a system with only diffusion-reaction processes provides insight between the diffusion rate and the controllability of the states. For smaller diffusion rates, the effect of the input on the states fades out fast. So, there is some influence from the input to the state only at small distances from the actuator, see left panel of Figure 6.2. Varying the convection rate in a convection-diffusion-reaction equation results in comparable results, as a small convection rate results in smaller sensitivities from the input to the state, see right panel of Figure 6.2. From the results in Figure 6.2 (left panel), we conclude that a tenfold increase of the diffusion rate will lead to the same 
sensitivity at roughly three times of the original distance. Doubling the convection rate results in the same sensitivity at roughly two times of the original distance (Figure 6.2, right panel).

As seen in the left and right panels of Figure 6.2, the simulations were not conducted for the same length. In the diffusion-reaction case $\mathrm{L}=1[\mathrm{~m}]$, whilst in the convection-diffusionreaction, a length of $\mathrm{L}=10[\mathrm{~m}]$ was chosen. However, the results show that the length used in different simulations does not affect the magnitude of the steady state values of the sensitivity field.

\subsubsection{Output sensitivity of $1 \mathrm{D}$ thermal flow in bulk storage facility}

The output of Eq. (6.4) with $\boldsymbol{D}=0$ is given by:

$$
\boldsymbol{y}(t)=\boldsymbol{C} \boldsymbol{x}(t)
$$

The solution of an LTI system Eq. (6.4) with $m=p=1$ (SISO), $u(t)=0$ for $t<0$, and $D=0$ is given by:

$$
y(t)=\boldsymbol{C}\left[e^{\boldsymbol{A} t} \boldsymbol{x}(0)+\int_{0}^{t} e^{\boldsymbol{A}(t-s)} \boldsymbol{B} u(s) d s\right]
$$

The relationship between the output $y$ and the initial-state $\boldsymbol{x}(0)$ can be derived directly from equation (6.26). Taking the derivative of the output with respect to the initial-state $\left(\boldsymbol{x}(0)=\boldsymbol{x}_{0}\right)$, according to Eq. (6.20),

$$
\boldsymbol{S}_{y}=\frac{d y(t)}{d \boldsymbol{x}_{0}}=\boldsymbol{C} e^{\boldsymbol{A} t}
$$

Hence, for asymptotic stable systems the sensitivity from the output to the initial- state ranges from zero for time to infinity. In the following, instead of $\boldsymbol{S}_{y}$, the Fisher Infinite Matrix $(F I M)$ is introduced to allow a direct interpretation of the uncertainty in the estimation of the states. The FIM is given by sum of the dot product of the output sensitivity for every time step on each grid point:

$$
F I M_{S_{y}}=\int_{0}^{t_{t}} S_{y}(t)^{T} S_{y}(t) d t
$$

For the output sensitivity analysis, the diagonal of $F I M_{\boldsymbol{S}_{y}}$ is taken for each simulation time $t_{t}$. This diagonal contains information of the sensitivity of the sensor output with respect to the initial-state at every grid point. In the analysis, the same cases as in Section 6.4.1 are studied. Hence, in the first case, in which diffusion dominates the system, as described in equation (6.11), four different diffusion rates $a=0.00002, a=0.0002$, $a=0.002, a=0.02\left[\mathrm{~m}^{2} / \mathrm{s}\right]$, and $c=0[\mathrm{~m} / \mathrm{s}], r=1[1 / \mathrm{s}]$ and $\alpha=1\left[{ }^{\circ} C\right]$ are used. For 


\section{Chapter 6}

the second case, in which convection dominates the same system, $a=0.00002\left[\mathrm{~m}^{2} / \mathrm{s}\right]$, and four different convection rates $c=0.5, c=1.0, c=1.5, c=2.0[\mathrm{~m} / \mathrm{s}]$, and $r=1[1 / \mathrm{s}]$ and $\alpha=1\left[{ }^{\circ} C\right]$ are used. In the first case, a length of $L=1$ is used, and in the second case $L=4$ is used. For both cases, the sensor is located at $z=L-0.1$ [m]. The results for the output sensitivity analysis are shown in Figure 6.4. In the left panel of Figure 6.4, the diagonal of $F I M_{S_{y}}$ for the diffusion-dominant case is shown. The right panel of 6.4 shows the diagonal of $F I M_{S_{y}}$ for the convection-dominant case.
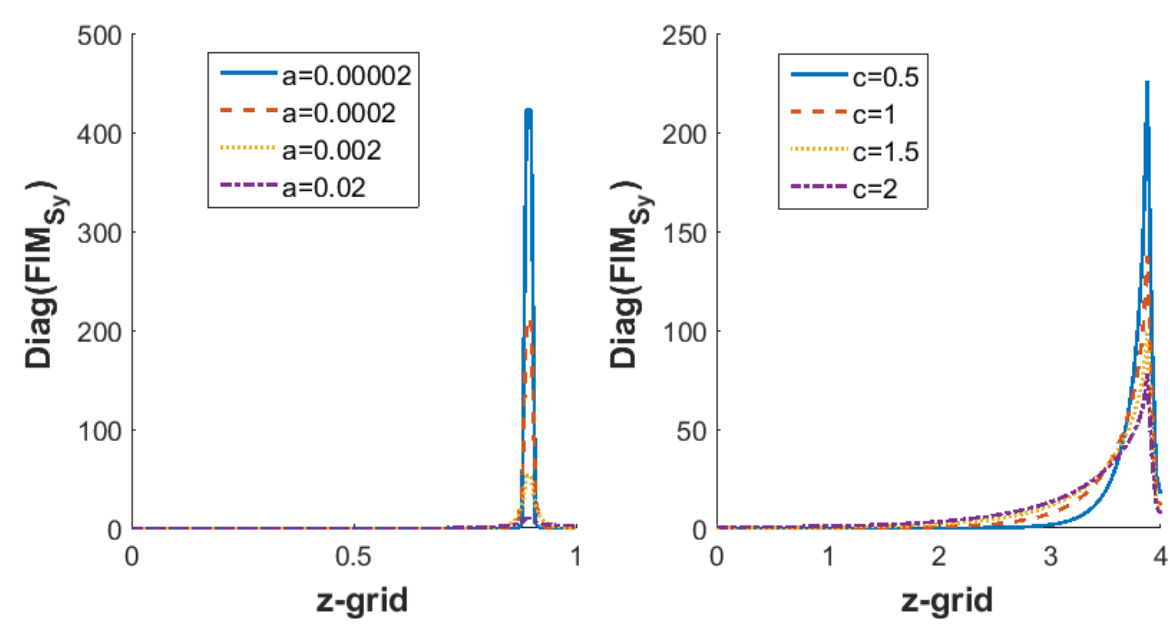

Figure 6.4: Left, 1D output sensitivity field simulated for different dominant diffusion rates. Right: 1D output sensitivity field simulated for different dominant convection rates. The sensors are placed at $z=L-0.1$.

An increase in the diffusion rate, as well as an increase in the convection rate, will give an increase of the output sensitivity over length $(L)$. The increasing output sensitivity over the whole length for increasing diffusion and convection rates results in a decreasing output sensitivity around the point the sensor is located. The sensitivity between the initial-state and the output grows in the first few seconds, but converges to zero for time to infinity. This dynamic behaviour is shown in Figure 6.5. Notice from Figure 6.5 that the sensitivity from initial-state-to-output on the interval $z \in[0,1.5]$ is very small. Hence, to obtain reliable state estimates on this interval, an accurate and sensitive sensor should be used. The sensitivity from the initial state to the output $S_{y}$ for $z=0[\mathrm{~m}]$ and $t=3$ [s] is equal to 0.1. Since, $S_{y}$ is much bigger compared to the tolerances of the numerical errors, changes in the initial state can be observed in the output.

\subsubsection{Non-linear 1D CDR sensitivity fields}

So far, a constant air velocity, $(c)$ in equation (6.11) is assumed. If the air velocity is not constant, a set of non-linear differential equations result. Hence, instead of an LTI system 


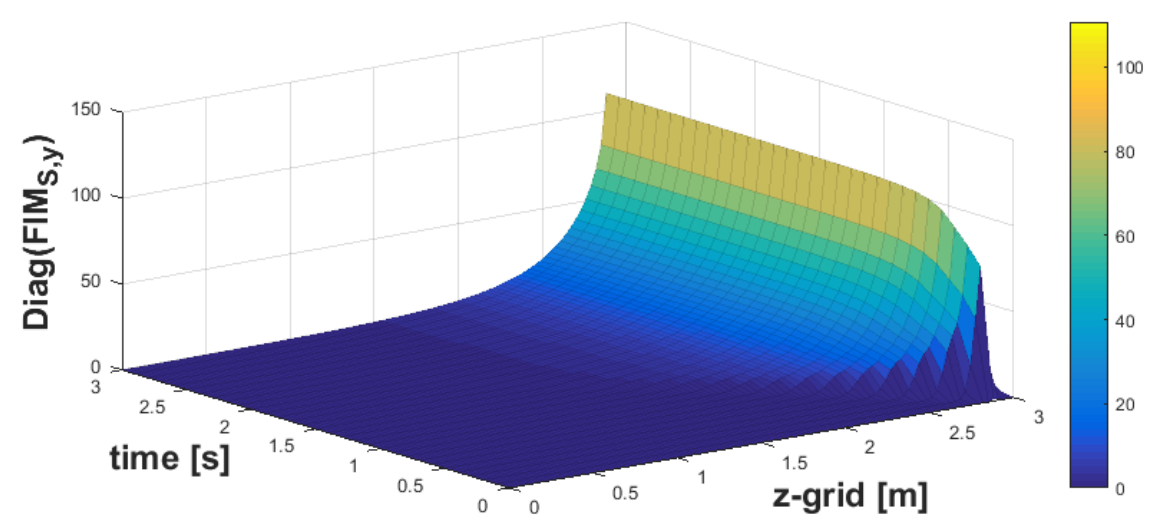

Figure 6.5: Development in time of $1 \mathrm{D}$ output sensitivity field simulated for bulk storage facility, with $a=0.00002\left[\mathrm{~m}^{2} / \mathrm{s}\right], c=0[\mathrm{~m} / \mathrm{s}], r=1[1 / \mathrm{s}], \alpha=1\left[{ }^{\circ} C\right], L=3[\mathrm{~m}]$ and $\Delta z=L / 100$.

Eq. (6.4), a non-linear state space model is obtained. The calculation of the sensitivity fields, however, can be directly extended to the non-linear case:

$$
\begin{aligned}
& \dot{\boldsymbol{x}}=f(\boldsymbol{x}, \boldsymbol{u}), \quad \boldsymbol{x}(0)=\boldsymbol{x}_{0} \\
& \boldsymbol{y}=g(\boldsymbol{x}, \boldsymbol{u})
\end{aligned}
$$

The corresponding input $\left(\boldsymbol{S}_{x u}\right)$ sensitivity equations are given by:

$$
\begin{aligned}
\dot{S}_{x u} & =\frac{\partial f}{\partial x} \boldsymbol{S}_{x u}+\frac{\partial f}{\partial u} \\
\boldsymbol{S}_{y u} & =\frac{\partial g}{\partial x} \boldsymbol{S}_{x u}+\frac{\partial g}{\partial u}
\end{aligned}
$$

Here, $\boldsymbol{S}_{x u}: \triangleq \frac{\partial x}{\partial u}$ is the input sensitivity. The sensitivities from the initial states to the output $\left(S_{y x_{0}}\right)$ are found from:

$$
\begin{aligned}
\dot{S}_{x x_{0}} & =\frac{\partial f}{\partial x} \boldsymbol{S}_{x x_{0}}+\frac{\partial f}{\partial x_{0}}, \boldsymbol{S}_{x x_{0}}(0)=1 \\
\boldsymbol{S}_{y x_{0}} & =\frac{\partial g}{\partial x} \boldsymbol{S}_{x x_{0}}+\frac{\partial g}{\partial x_{0}}
\end{aligned}
$$

Here $S_{x x_{0}}:=\frac{\partial x}{\partial x_{0}}$, and $\frac{\partial f}{\partial x_{0}}=\frac{\partial g}{\partial x_{0}}=0$. Furthermore, in both cases, we define the matrices $\boldsymbol{A}:=\frac{\partial f}{\partial x}$, and $\boldsymbol{C}:=\frac{\partial g}{\partial x}$, whilst in Eq. (6.30) and (6.31) we define $\boldsymbol{B}:=\frac{\partial f}{\partial u}$, and $\boldsymbol{D}:=$ $\frac{\partial g}{\partial u}$ 


\subsection{In- and output sensitivities of $2 \mathrm{D}$ coupled ther- mal flow in bulk storage facilities}

Coupled convection-diffusion-reaction equations typically describe the dynamics of postharvest storage processes. However, these equations are also used in a wide range of other processes that utilise the laws of conservation of heat and mass (see, for instance, Vali et al., 2009; Hsieh and Yang, 2010; Zambra et al., 2015). In the porous medium of a bulk food-storage facility, interaction between the product and the air induces the coupling between the convection-diffusion-reaction equations that describe temperature in the air and in the food product. For a more detailed analysis of the influence of the actuator and sensors on the states, a 2-D simulation will be performed. As before, temperature balances will be used, and these are defined in the spatial coordinates $x$ and $y$ on a $[0, L] \mathrm{x}[0, L]$ domain:

$$
\begin{aligned}
& \frac{\partial T_{a}}{\partial t}=a_{a x} \frac{\partial^{2} T_{a}}{\partial x^{2}}+a_{a y} \frac{\partial^{2} T_{a}}{\partial y^{2}}-c_{x} \frac{\partial T_{a}}{\partial x}-c_{y} \frac{\partial T_{a}}{\partial y}-r_{a} T_{a}+r_{a} T_{p} \\
& T_{a}(x, 0, t)=\alpha, \quad \text { for } x \in\left[0, \frac{L}{2}\right], \\
& T_{a}(x, 0, t)=0, \quad \text { for } x \in\left[\frac{L}{2}, L\right], \\
& \frac{\partial T_{a}}{\partial x}(x, L, t)=0, \\
& \frac{\partial T_{a}}{\partial y}(0, y, t)=0, \quad \frac{\partial T_{a}}{\partial y}(L, y, t)=0 \\
& \frac{\partial T_{p}}{\partial t}=a_{p x} \frac{\partial^{2} T_{p}}{\partial x^{2}}+a_{p y} \frac{\partial^{2} T_{p}}{\partial y^{2}}-r_{p} T_{p}+r_{p} T_{a} \\
& \frac{\partial T_{p}}{\partial x}(0, y, t)=0, \quad \frac{\partial T_{p}}{\partial x}(L, y, t)=0, \\
& \frac{\partial T_{p}}{\partial y}(x, 0, t)=0, \quad \frac{\partial T_{p}}{\partial y}(x, L, t)=0
\end{aligned}
$$

Here, $T_{a}$ is the air temperature, $T_{p}$ the product temperature, $a_{a x}, a_{a y}$ the diffusion coefficient of air in $x$ direction and $y$ direction respectively, $c_{x}, c_{y}$ the convection coefficient of air in $x$ direction and $y$ direction respectively, $a_{p x}, a_{p x}$ the diffusion coefficient of the product in $x$ direction and $y$ direction respectively, and $r_{a}$ and $r_{p}$ a reaction coefficient expressed as a heat transfer coefficient.

For the simulations of the system Eq. (6.34), the parameters, as in Table 6.1, are used. Notice that the system has relative fast (air-) and slow (product-) properties, which will have influence on the simulations.

For the evaluation of the input sensitivity of the 2-D system, the actuator is, as in the 1-D case, located at the bottom of the configuration at $y=0$ (see Figure 6.6). Notice that the actuator acts only on the left half. The actuator operates at a constant velocity 
Table 6.1: Paremeter values of the system as in Eq. (6.34)

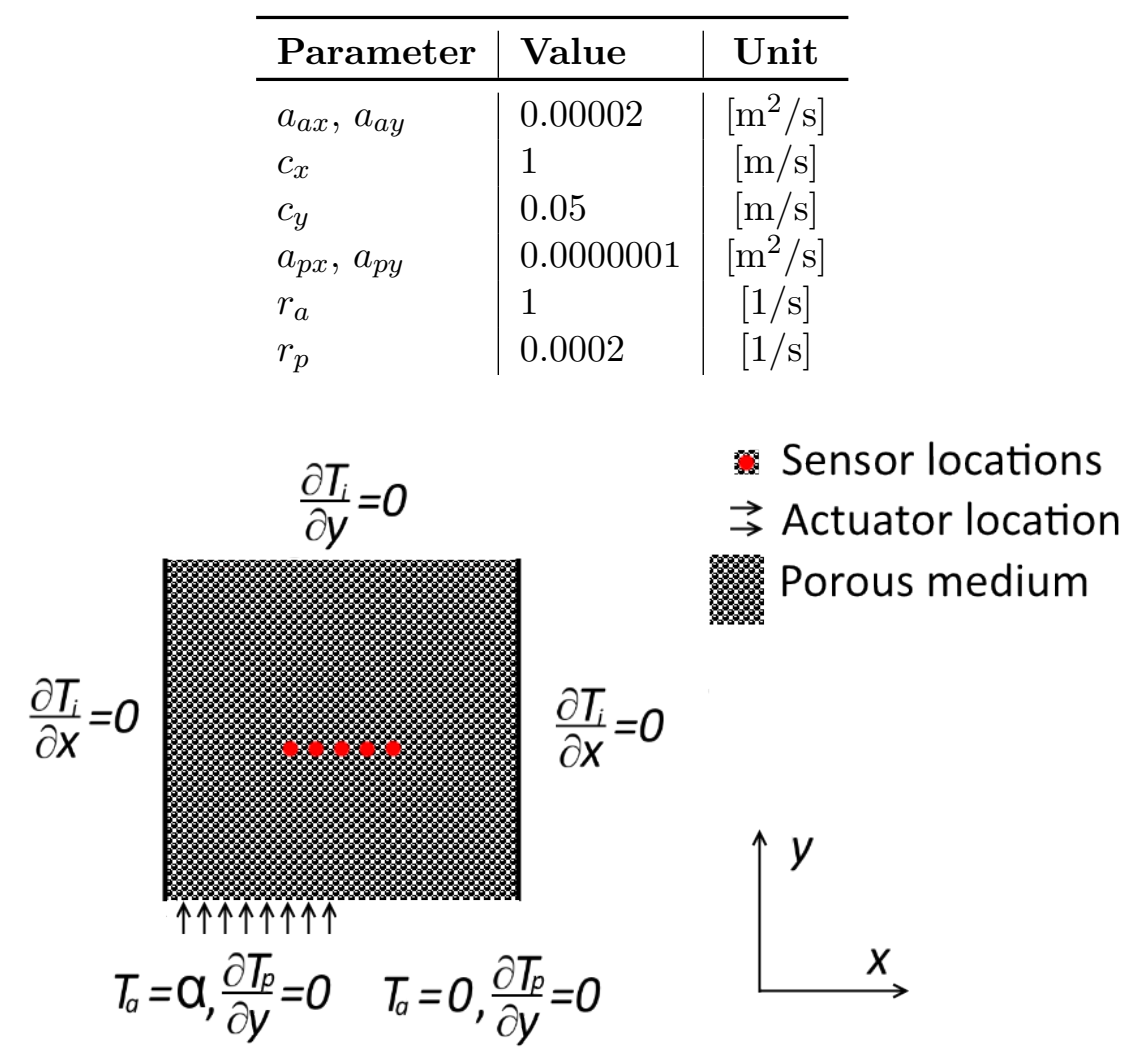

Figure 6.6: $2 \mathrm{D}$ configuration of the porous medium. Located at the bottom the inlet of the bulk system is one actuator on the left-hand side. The sensors are placed in the centre of the bulk.

and input temperature. The actuator only acts on the air domain, and by the interaction between the air and the product the temperature in the product domain is affected. Hence, a Dirichlet boundary condition is prescribed at $y=0$. At all other boundaries, a Neumann boundary condition is prescribed (Figure 6.6). A grid of 30x30 is used for the calculations. Due to the coupling between air and product, a system matrix of 1800x1800 $(30 \cdot 30 \cdot 2=1800$ states $)$ is produced. In the simulation only, the air temperature at $y=0$ can be influenced. As the sensitivities are time-dependent, different simulation times could be taken to investigate the influence of the input on the states. The steady state value of the sensitivity field is reached as time $(t)$ goes to infinity. A large simulation time gives a good approximation of steady state value, hence a simulation time of $t=400$, with steps of $0.001[\mathrm{~s}]$ is taken.

The result of the steady state sensitivity analysis of the actuator on the states is shown in Figure 6.7. As expected, the state is most sensitive at the bottom, where the actuator is located. The sensitivities show a homogeneous profile in the x-direction for $x \in\left[0, \frac{L}{2}\right]$. Despite the velocity component $d$ in horizontal direction, the sensitivity of the state for 


\section{Chapter 6}

$x \in\left[\frac{L}{2}, L\right]$ is very small. In the y-direction, an exponential decrease is obtained. Likewise
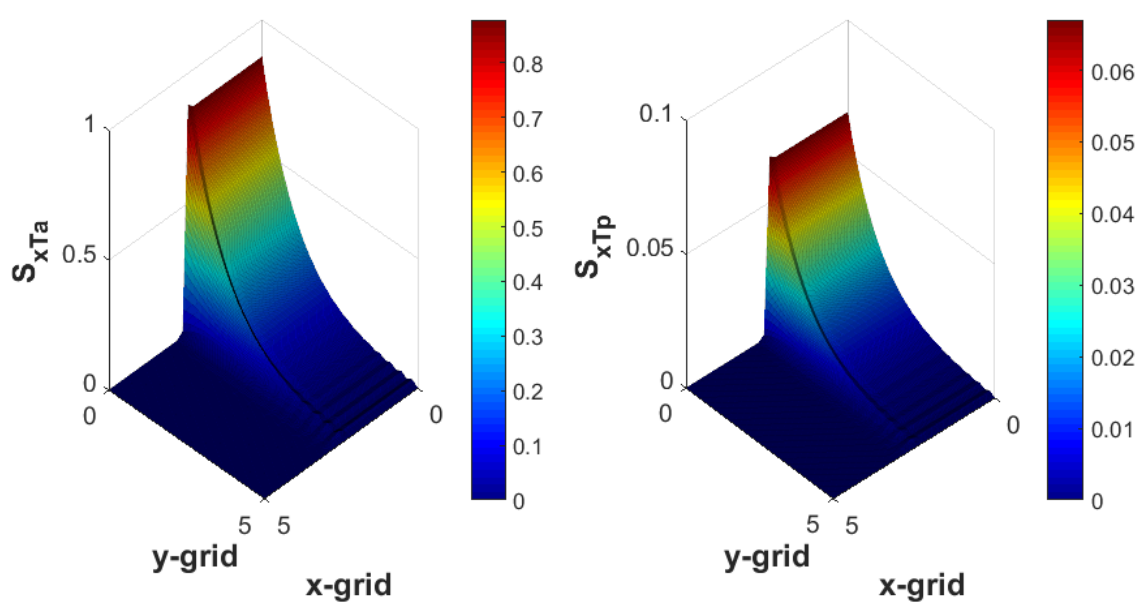

Figure 6.7: Input sensitivity field of the coupled 2D CDR-system, $t=400[\mathrm{~s}]$ and $30 x 30$ grid. Left, 2D input sensitivity field related to $T_{a}$. Right, $2 \mathrm{D}$ input sensitivity field related to $T_{p}$

as in the 1D case, the total sensitivity of the input on the states is increased for longer time periods.

For the analysis of the output, sensitivity fields initially the sensors are place in the air domain at $y=1.8$ and for $x \in\left[\frac{L}{3}, \frac{2 L}{3}\right]$, see Figure 6.6. As follows, a simulation of time of 15 seconds with steps of $0.001[\mathrm{~s}]$ and a grid of $12 \times 12$ are used. The results are shown in Figure 6.8. Notice that at the bottom $(y=0)$, the sensitivity is very small, but larger than one. Around the sensor location, the highest sensitivities are obtained. Despite the low horizontal velocity, also in horizontal direction a relatively high sensitivity is obtained.

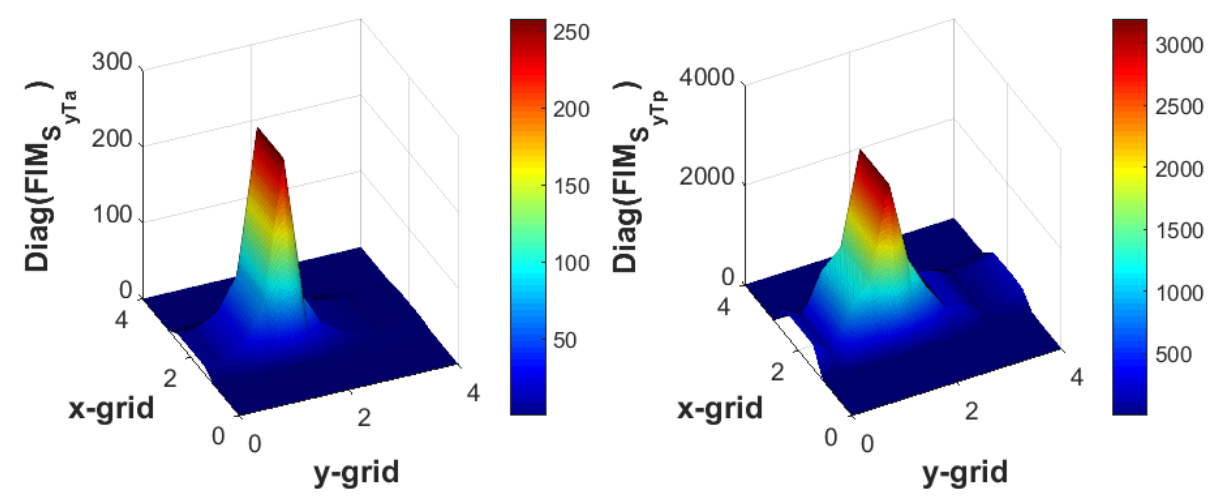

Figure 6.8: Output sensitivity field of the coupled 2D CDR-system. Left, 2D output sensitivity field related to $T_{a}$. Right, $2 \mathrm{D}$ output sensitivity field related to $T_{p}$

Figures 6.7-6.8 show results where in some areas and on a specific time instant the input or output sensitivity is close to zero and thus indicating locally uncontrollable or 
unobservable states. The results also indicate that for larger simulation time the input sensitivity and diagonal element of the FIM will increase. However, in practice, the dominant response time of the system $(\tau)$ leads. For the air domain, we would typically act or sample ever $0.1-0.2 \tau$. Thus, if, for instance, the input or output sensitivity are close to zero on a time range $[0,0.2 \tau]$, the controlled or observed system can be practically considered as uncontrollable or unobservable.

The results of this section can lead to more efficient ventilation strategies in bulk storage facilities, as the actuator and sensor locations can be re-designed by the sensitivity results. For example, the actuator location can be chosen such that the input has a stronger influence on the states in the whole domain. In the y-direction with the actuator located at $\left(\left[0, \frac{L}{2}\right], 0\right)$, small sensitivities are obtained in the top layer. To gain more influence on the states in the top layer the geometry of the storage facility, or the actuator functionality should be re-designed. In practice a better performance could be obtained, for instance, if the fan depicted in Figure 6.1 switches after a certain time period from blowing to suction.

From the results of the output sensitivity field the observable region inside the bulk, is known. From Figure 6.8, it can be seen that in case of an air temperature sensor also a relatively large sensitivity for the product temperature is obtained. Thus, for climate controlled bulk facilities, the results give supporting information on the number, the best location and the choice of the sensors. Also, for the implementation of model-based quality control in bulk storage facilities input and output sensitivity fields are of great interest for the choice of actuators and sensors and their location.

On $n D$ domains, with $n \geq 3$, SVD of the sensitivity matrices may be helpful to support the interpretation of the sensitivity fields. For more complex problems in higher dimensions we also foresee numerical issues that need to be tackled. For further understanding and application of the theory presented in the article, further research on sensitivity fields for special classes of infinite- dimensional systems is needed.

\subsection{Conclusion}

In this paper, we analysed the controllability and observability properties of spatially distributed thermal flow in bulk storage facilities. The classical system theory concepts, controllability and observability, not only provide limited, but crucial, information, but also unreliable results, due to matrix multiplications of the discretized system with fine mesh. The information from a controllable or observable analysis is insufficient because in practice, we are only interested to find out if it is possible to have some influence on a certain state, or if a certain state can be observed during a certain time period. The singular value decomposition gives additional information on which states are control- 


\section{Chapter 6}

lable/uncontrollable or observable/unobservable. However, due to the matrix computations small discretization steps result in numerical errors in the singular values.

By introducing input and output sensitivity fields, whilst using the discretized state space representation, the aforementioned problems are avoided. The sensitivity field of the input to state gives information about the influence, and thus practical controllability, of the input on a state for a specific time period. Changing the time period results in other controllable/uncontrollable states. The sensitivity field of the output to state gives information about the practical observability of the each state over a specific time period. Likewise, as for controllability, a increase or decrease of the time period results in other observable/unobservable states. In conclusion, sensitivity fields, provide, from a practical perspective, valuable information about the influence of the input-to-state and the initial-state on the output, respectively. 


\section{References}

M. Amouroux, A. El Jai, and E. Zerrik. Regional observability of distributed systems. International Journal of Systems Science, 25(2):301-313, 1994.

A. Van Brecht, S. Quanten, T. Zerihundesta, S. Van Buggenhout, and D. Berckmans. Control of the 3-D spatio-temporal distribution of air temperature. International Journal of Control, 78(2):88-99, 2005.

W. Cheney and D. Kincaid. Numerical mathematics and computing. Thomson Brooks/Cole, 2008.

M.K. Chourasia and T.K. Goswami. Three dimensional modeling on airflow, heat and mass transfer in partially impermeable enclosure containing agricultural produce during natural convective cooling. Energy Conversion and Management, 48(7):2136-2149, 2007.

R.F. Curtain and H. Zwart. An introduction to infinite dimensional linear systems theory. Springer, New york, U.S.A., 1995.

R.P. Dickinson and R.J. Gelinas. Sensitivity analysis of ordinary differential equation systems; A direct method. Journal of computational physics, 21:123-143, 1976.

D. Dochain, F. Couenne, and C. Jallut. Enthalpy based modelling and design of asymptotic observers for chemical reactors. International Journal of Control, 82(8):1389-1403, 2009.

J.F.M. van Doren, P.M.J. van den Hof, O.H. Bosgra, and J.D. Jansen. Controllability and observability in two-phase porous media flow. Computational Geosciences, 17:773-788, 2013.

B. Friedland. Control system design, An introduction to state-space methods. Dover Publications, Inc, 2005.

D.A. Garzon-Alvarado, C.H. Galeano, and J.M. Mantilla. Computational examples of reaction - convection - diffusion equations solution under the influence of fluid flow: First example. Applied Mathematical modelling, 36:5029-5045, 2012.

N.L.M. Grubben and K.J. Keesman. Modelling ventilated bulk storage of agromaterials: A review. Computers and Electronics in Agriculture, 114:285-295, 2015.

N.L.M. Grubben and K.J. Keesman. Controllability and observability of 2D thermal flow in bulk storage facilities using sensitivity fields. International Journal of Control, 91(7): 1554-1566, 2017.

P.-W. Hsieh and S.-Y. Yang. Two new upwind difference schemes for a coupled system of convection diffusion equations arising from the steady MHD duct flow problems. Journal of Computational Physics, 229(24):9216 - 9234, 2010. 


\section{Chapter 6}

A. El Jai, M.C. Simon, E. Zerrik, and A.J. Pritchard. Regional controllability of distributed parameter systems. International Journal of Control, 62(6):1351-1365, 1995.

R. Kalman. On the general theory of control systems. IRE Transactions on Automatic Control, 4(3):110-110, 1959.

H. Kwakernaak and R. Sivan. Linear optimal control systems. Wiley, 1972.

R.J.G. Lopes and R.M. Quita-Ferreira. Numerical assessment of diffusion-convectionreaction model for the catalytic abatement of phenolic wastewaters in packed-bed reactors under trickling flow conditions. Computers and Chemical Engineering, 35:2706$2715,2011$.

L.J.S. Lukasse, J.E. de Kramer-Cuppen, and A.J. van der Voort. A physical model to predict climate dynamics in ventilated bulk-storage of agricultural produce. International Journal of Refrigeration, 30(1):195-204, 2007.

D.R. Lynch. Numerical Partial Differnetial Equations for Environmetal Scientists and Engineers. Springer, 2005.

L. Mohammadi, I. Aksikas, S. Dubljevic, and J.F. Forbes. Lq-boundary control of a diffusion-convection-reaction system. International Journal of Control, 85(2):171-181, 2012 .

C. Moler. Numerical Computing with MATLAB. Society for industrial and applied mathematics, 2004.

V. Nagarajan, Y. Chen, Q. Wang, and T. Ma. Cfd modeling and simulation of sulfur trioxide decomposition in ceramic plate-fin high temperature heat exchanger and decomposer. International Journal of Heat and Mass Transfer, 80:329-343, 2015.

A. Saltelli, K. Chan, and E.M. Scott, editors. Sensitivity analysis. New York: Wiley, 2000 .

E. Storkaas and S. Skogestad. Controllability analysis of two-phase pipeline-riser systems at riser slugging conditions. Control Engineering Practice, 15:567-581, 2007.

R. Tomovic. Sensitivity analysis of dynamic systems. McGraw-Hill, 1963.

A. Vali, C.J. Simonson, R.W. Besant, and G. Mahmood. Numerical model and effectiveness correlations for a run-around heat recovery system with combined counter and cross flow exchangers. International Journal of Heat and Mass Transfer, 52(25-26): $5827-5840,2009$.

E.I. Varga, K.M. Hangos, and F. Szigeti. Controllability and observability of heat exchanger networks in the time- varying parameter case. Control Engineering Practice, 3 (10):1409-1419, 1995.

C.E. Zambra, J.E.F. Munoz, and N.O. Moraga. A 3D coupled model of turbulent forced convection and diffusion for heat and mass transfer in a bioleaching process. Interna- 
Controllability and observability of $2 \mathrm{D}$ thermal flow in bulk storage ...

tional Journal of Heat and Mass Transfer, 85(0):390 - 400, 2015.

M.J. Zandvliet, J.F.M. van Doren van, O. H. Bosgra, J.D. Jansen, and P.M.J. van den Hof. Controllability, observability and identifiability in single-phase porous media flow. Computational Geosciences, 12(4):605-622, 2008. 

CHAPter 7

General Discussion AND CONCLUSIONS 


\subsection{Introductory remarks}

This chapter reflects on the research presented in the previous five chapters in connection with the research questions and hypotheses that served as guidelines. It also includes thoughts on further research.

As Chapter 1 explained, the main objective of the research presented in this thesis was to address major gaps in the knowledge on storage climate and quality development of potatoes during bulk storage. This was accomplished by developing a spatially distributed mathematical storage model and analysing the simulation results, supported by actual data collected in a large-scale storage facility. Figure 7.1 depicts the taken multidisciplinary approach. As can be seen, obtaining the vital knowledge took place in an iterative process with five main components, namely obtaining system knowledge, conducting experiments, modelling, data integration and analysis, and control. The green activities in Figure 7.1 are included in this thesis, the (orange) control component is only used for system analysis, and takes the form of a bang-bang controller. The (red) data-driven modelling path is not addressed in this thesis, as data-driven models hardly allow any physical interpretation.

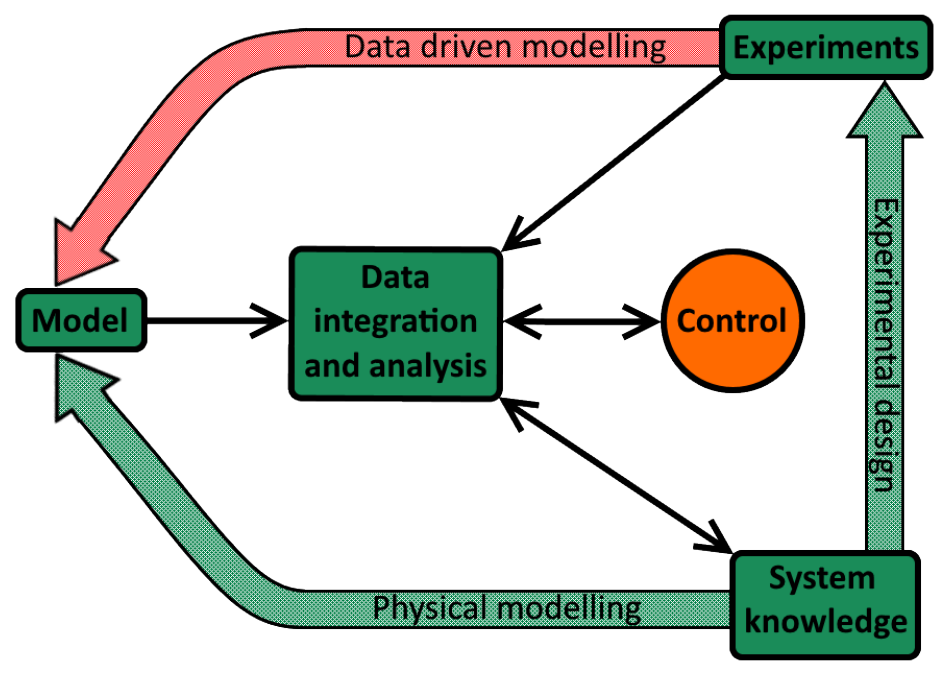

Figure 7.1: Multidisciplinary work flow to obtain more insight in the storage process. Within this thesis, the green components are addressed and used extensively. The orange component is included in the form of a bang-bang controller, and the red activity is not covered in this thesis.

Having much greater detailed insight in the development of storage climate and product quality would speed up the rate of innovation in the design of large storage facilities as 
well as in the optimisation of climate and quality control strategies. The primary reasons for the need for innovation are climate change, the continuously evolving offer of potato varieties, changing consumers demands and the resulting desire for different products, in combination with the need to reduce storage losses and energy consumption. To achieve the main objective, five research questions and three hypotheses were postulated, as set out in Chapter 1. These five questions are individually linked to Chapters 2, 3, 4, 5 and 6.

The existing system knowledge was explored in a review of the published potato storage models (Chapter 2). This knowledge was used to develop the spatially distributed climateproduct quality models based on a physical modelling approach as presented in Chapters 3 and 4 . These models were calibrated and validated with the aid of data obtained during large-scale experiments. The validated models were then used to analyse and adapt the storage process (data integration and analysis). In Chapter 4 a bang-bang controller was implemented to analyse the storage process in terms of weight loss and reducing sugar content. Chapter 5 introduced an additional quality indicator, namely the protein content, which was modelled on the basis of knowledge found in the literature and on experimental data. Next, to be able to gain practical insight (system knowledge) into the controllability and observability of the climate in a bulk storage facility, sensitivity fields were evaluated on the basis of a coupled storage temperature model (Chapter 6).

\subsection{Storage model structure and states}

Which structure is most suitable for a storage model depends on the application the model is used for. In the multidisciplinary approach pursued in this research, it had to have a spatially component and it had to be possible to adapt the basic model for different applications, however.

\subsubsection{Model structure}

Three model structures (see Chapter 2) are commonly used for potato storage modelling, namely data-based mechanistic (DBM) models, lumped parameter models, and spatially distributed parameter models. DBM models describe the inputs and outputs of a system using transfer functions. These models do not contain any a priori physical or physiological knowledge. DBM models are therefore not the best structure to obtain insight in the relationship between storage climate and product quality. By contrast, lumped parameter and spatially distributed parameter models are generally based on physical or physiological knowledge and are able to describe a spatial component in more or less detail. 
Table 7.1: Potato storage models found in the literature

\begin{tabular}{l|c|c|c}
\hline Article & Structure & Application & States \\
\hline Hertog et al. (1997) & Lumped & Simulation & $S$ \\
\hline Lukasse et al. (2007) & Lumped & Simulation & $T, X, C O_{2}$ \\
\hline Verdijck and Tijskens (2003) & 1-D , lumped & Quality control & $T, S$ \\
\hline Kondrashov (2000) & 2-D & CFD simulation & $v, T, X$ \\
\hline Chourasia and Goswami (2007) & 3-D & CFD simulation & $v, T, X$ \\
\hline
\end{tabular}

Therefore, mainly lumped and spatially distributed parameters are used to obtain systems knowledge for potato storage facilities. Using a combination of both models is also very effective (see Chapters 3 and 4). Partial differential equations (PDEs) describe the processes that are spatially and temporally dependent, such as temperature, moisture and carbon dioxide concentration. Processes that directly depend on time or temperature but also indirectly depend on the spatial distribution can be described by ordinary differential equations (ODEs). For instance, the reducing sugar content is time-dependent, and driven by the spatially distributed temperature. Although the sugar content is modelled using ODEs, a spatial component is indirectly included by the (spatially distributed) temperature dependency.

\subsubsection{Storage models}

In Chapters 3 and 4, a spatially distributed parameter model was proposed on the basis of the models listed in Table 7.1. The starting point was that a multifunctional climateproduct quality model for potato bulk storage facilities has to contain at least basic states, such as $(i)$ quality indicators of the product, (ii) climate conditions and (iii) a velocity component. Chapter 3 introduced a 2-D model, with time-varying velocity vector $(\boldsymbol{v})$, temperature of air and potato $\left(T_{a}, T_{p}\right)$, moisture content of air and potato $\left(X_{a}, X_{p}\right)$ and carbon dioxide level of the air $\left(\mathrm{CO}_{2}\right)$, for CFD simulation. Chapter 4 uses the spatially distributed model as proposed in Chapter 3 but with the reducing sugar $(R S)$ content as an additional quality indicator, and a piecewise constant velocity component. In Chapter 5 , the total protein content of the potato $(T P)$ was included as an additional quality indicator, modelled with a lumped parameter model structure.

Extending the list of quality indicators included in models, beyond moisture, reducing sugars and protein content, is of great interest. Pressure bruising, rot and dormancy state are examples of additional quality indicators that can be included. A result of pressure bruising during storage can be black spot formation after storage. The recent publications by Grudzińska and Barbaś (2017) and Gancarz (2018) contain models related to this area. For studies on rot that include models, see Lui and Kushalappa (2002) and Yellareddygari et al. (2016). Also, work that includes a model on dormancy break (Coleman, 1998) has 
been done. All these models are actually black box models, meaning they are regressionbased instead of based on physical or physiological knowledge. Hence, for instance for the pressure bruising case, the actual relative humidity or bulk height is not distinguished within the models of Grudzińska and Barbaś (2017) and Gancarz (2018). This implies that for every different situation, for example, bulk height and other model parameters have to be obtained.

\subsection{3 $\mathrm{Q}_{1}$ : What is a suitable model structure for obtaining detailed insight into the development of product quality and the interactions between product quality and ventilation strategies?}

A review of the recent literature (e.g. Grudzińska and Barbaś, 2017; Gancarz, 2018; Lui and Kushalappa, 2002; Yellareddygari et al., 2016) shows that if only a single quality indicator is studied, with the aim to find a relationship between quality and a single storage condition, regression models are often used. For a more realistic and more detailed physical modelling approach, lumped and spatially distributed models are used. See Table 7.1 and Chapter 2 for more.

For a more detailed analysis of the storage situation, including the storage facility itself, the model structure should at least include one spatial component. It is often most efficient to use CFD computations for a complete numerical analysis, including a visualisation of the development of product quality and its responses to the applied ventilation strategy. This requires the use of a spatially distributed parameter model. The distributed parameter model can be supported through the use of lumped models that rely more on the spatial distribution of other states rather than on the spatial distribution of the investigated state itself. Also for quality control applications, this combination of distributed and lumped models can be used (Verdijck and Tijskens, 2003). Hence, in a multidisciplinary approach to obtain detailed information of the storage process, a spatially distributed parameter model supported by lumped parameter models is an efficient model structure.

\subsection{Modelling a bulk storage facility}

To develop the models presented in this thesis, several domains were taken into account (Chapter 3). The potato bulk takes up the porous domain, which was represented as consisting of two phases (Chapter 2 and 3). To implement the model in a CFD application, it was not necessary to draw every individual potato in a one-phase domain for the potatoes and include a separate subdomain for the air between the potatoes. Assuming an air/potato ratio in a two-phase domain for the bulk requires fewer mesh elements in 


\section{Chapter 7}

the CFD analysis relative to having a one-phase potato domain in which the physical product is drawn (see Chapter 2).

The mathematical models were implemented in COMSOL Multiphysics. The air and product temperature, moisture states, and the carbon dioxide level in air were defined in terms of PDEs. The reducing sugar content (Chapter 4) and protein content (Chapter 5) were defined using ODEs. The velocity flow was modelled using a Reynolds-averaged Navier-Stokes (RANS) model with Comsol's algebraic yPlus model (Chapter 3). In the models presented in Chapters 4 and 6, the velocity was assumed to be piecewise constant, and in the research presented in Chapter 5, no velocity component was taken into account.

For the simulations of the RANS model the air was assumed to be incompressible. This assumption was needed to obtain a stable solution for a complete bulk storage simulation. From simulation results of only the bulk it was seen that only minor differences in the product states were seen. Using the RANS model also implies that we neglect the laminar flow during the time the fan was switched off. This assumption was made, because it is not possible to switch between flow models during a dynamic simulation. The turbulent model covered the turbulent and laminar stages better compared to the laminar flow model. The algebraic yPlus model is a turbulence model with low demands on computation power. A drawback of the model is the lack of local turbulence effects. Probably, any mismatch in the flow can be attributed to these assumptions. As in this study the flow around the hatch or through channels was not explicitly examined, and the validation results were satisfying, for now these simplifications are assumed to be valid.

\subsubsection{CFD simulations for a bulk-storage facility}

Static simulations of fluid flow generally require less computation time compared to dynamic simulations. However, a bulk storage facility requires dynamic CFD simulations because of external and internal changes in the facility. Although CFD can be relatively easily applied for dynamic simulations, implementing it for a large-scale bulk storage facility is not straightforward. This is because both fast and slow dynamics play a role in such a facility, the presence of actuators, and specification of the mesh density.

In the natural convection case, slow dynamics dominate. In the forced convective case, once the fan is switched on, the fast dynamics dominate. During the simulations, the switching between fast and slow dynamics can cause instabilities. To avoid this, events were used to reinitialise the solver at switching points. In addition to the difficulties with the switching, the dynamic interactions between the air and the potatoes also complicates the CFD simulations, as the air affects the potatoes and vice versa.

In the CFD simulations two different actuators were included, the fan and the hatches. The fan was implemented using a volume force, and hatches were modelled physically by 
using a moving mesh to move the hatches into an open, closed or intermediate position. The used moving mesh is the dynamical representation of a real hatches. As the hatches repeatedly open and close, new meshes need to be defined over time. This repeated update of new meshes can only be done a limited number of times in COMSOL 5.2a, after which numerical errors occur around the hatch. A way to simplify the modelling of a hatch is to use a moving area with manipulated physical properties, such as increasing the density or the dynamic viscosity. For dynamic simulations of a bulk storage facility, this is not efficient, however. The combination of natural convection inside the storage facility (low air velocity) and a implemented high dynamic viscosity area would lead to long computation times, as a result of bad convergence of the non-linear solvers.

An important aspect that affects the accuracy of the simulation results is the mesh density. Having a finer mesh density results in more accurate results, but results in greater computation times. As a large-scale facility has large dimensions, many more mesh elements are needed to obtain the same accuracy as for smaller facilities. Despite the large scale of a bulk storage facility $(\sim 10-100[\mathrm{~m}])$, a bulk storage facility also contains small regions $(\sim 0.01[\mathrm{~m}])$ near the hatches or in the perforated floor. To create an accurate mesh for every region, at least three mesh elements should be applied. For a bulk storage facility, this means that many small mesh elements are needed for the perforated floor. Replacing the perforated floor by an average resistance factor area (volume force) limits the number of required mesh elements, but resulted in a unrealistic pressure distribution. Thus, we implemented a performed floor in the CFD model (Chapter 3).

\subsubsection{Storage process optimisation}

To obtain representative simulation results, the models were calibrated and validated on large-scale experimental data. In Chapters 3 and 4, the models were decoupled into fast and slow dynamics to estimate the model parameters. In Chapter 3, the complete bulk storage model was decoupled into a part with flow dynamics and a part with the other climate-product quality states. Five of the six states performed within the sensor accuracy. For the carbon dioxide level $\left(\mathrm{CO}_{2}\right)$, some numerical diffusion had to be added to obtain a feasible solution. For the 1-D storage model in Chapter 4, a comparable approach and results were obtained.

Chapter 3 described how the 2-D CFD model was used for two case studies. In the first case study, the effect of using a combination of underpressure and overpressure, instead of only the conventionally applied overpressure, was analysed. In practice as well as in the simulations, it was seen that the application of only overpressure resulted in the presence of mainly vertical gradients in the bulk. To minimise these vertical gradients, a combination of underpressure and overpressure was used in a simulation. However this added a horizontal gradient in the potato bulk. After adding an extra air channel near 


\section{Chapter 7}

the roof, in the second case study the horizontal as well as the vertical gradients became smaller. Eventually, a smaller gradient in the vertical direction, a comparable average cooling rate, but a slightly lower average weight loss of the bulk resulted, relative to a situation in which only overpressure was applied in the same time period.

By changing the ventilation strategy and adapting the configuration, we were able to reduce the horizontal and vertical gradients. It may be possible to design a completely new configuration with different actuator placements or with an optimised channel configuration, through the use of CFD simulations (like we did), or by using topology optimisation (see e.g. Bruns, 2007; Dilgen et al., 2018; Zeng et al., 2018). A possible new configuration to improve air mixing for underpressure and overpressure, would place the righter (outlet) hatch beneath the fan in the pressure chamber (at the same side of the inlet hatch).

\subsection{3 $\mathrm{Q}_{2}$ : How can a potato bulk storage model be used for the (re)design and efficient operation of a storage facility so as to guarantee a uniformly high product quality?}

A model that contains the main storage climate and product states, among which at least one product quality indicator, can be used for storage system optimisation. A mathematical analysis of the states can yield some initial insights into the dynamics. A CFD application can numerically evaluate the quality development of and interaction with the climate, as well provide insights on the contribution of the storage configuration itself.

As presented in Chapter 3, if the ventilation strategy is adjusted to improve product quality, the climate distribution will change. Hence, the optimisation of product quality is an iterative process of adjusting ventilation strategy and configuration. Besides adjustments to the configuration, the addition of more actuators - such as inlets, humidification or cooling - could improve the product quality as well. By including additional quality indicators, quality development could be studied further to find the optimal way to achieve minimal storage losses on the basis of all included quality indicators at once.

\subsection{Long-term storage}

Simulations of the situation in a bulk storage facility, as detailed in Chapter 3, provide insight into the complete storage process for a relatively short period. Obtaining knowledge on the long-term development of product quality can be done with the same mathematical model. However, the results of the 2-D CFD simulations described in Chapter 3 showed that there are mainly vertical gradients in the bulk in a conventional bulk storage facility (Figure 3.10). This implies that the configuration of a conventional storage facility has a 
homogenizing effect in the horizontal direction. And to obtain knowledge on the product quality throughout a complete year, the influence of the configuration is less important, which means that a 1-D model with a piecewise constant velocity flow can be considered. This reduction of the model was based on the results of the numerical analysis. More formal model reduction methods, most often with loss of physical insight, are also available as described by, e.g., Benner et al. (2005), Wattamwar et al. (2009) and Hoffmann and Leugering, 2014. For model reduction, while conserving as much as possible physical insight, Padé reduction and singular perturbation decomposition methods can be used (see, e.g., Keesman et al., 2003; Van Mourik, 2008).

While in storage, the potatoes should remain in the dormant state. To that end, they are cooled down, but this results in cold-induced sweetening, as well as in dehydration. The applied climate control strategy should strive for minimal sugar formation in addition to minimal weight loss. We therefore added the reducing sugar content to the 1-D model, as presented in Chapter 4. From the review in Chapter 2, it appeared that coupling multiple quality indicators to a spatially distributed storage climate model has not been attempted before yet. Hence, this model forms a good basis for speeding up the acquisition of knowledge on the development of potato quality and how it interacts with the storage climate.

\subsubsection{Modelling potato quality}

The calibrated 2-D and 1-D models presented in Chapters 3 and 4 gave parameter estimates within the same range. The parameter sensitivity analysis showed differences for especially the product temperature and product moisture content. Changing parameters in the CFD model showed a sensitive evaporation parameter $\left(K_{\text {evap }}\right)$. Changing parameters in the 1-D quality model revealed a sensitive respiration parameter (Resp). Both evaporation and respiration depend on potato variety, growing season and especially skin set (Lukasse et al., 2007; Pinhero and Yada, 2016; Heltoft et al., 2016), and seem to have a dominant influence on the model states.

The sugar concentration was modelled based on the model presented by Hertog et al. (1997). While the model followed the same trends as the measurements, it did not follow every fluctuation seen in the measurements (see Chapter 4). Despite the fact that the sugar behaviour in the model is reasonable, from the data it can be seen that the temperature influence on the reducing sugar development proceeds slowly. This implies the possible presence of a time lag between the temperature and sugar development. This lag was confirmed by using a cross-correlation analysis on the temperature-sugar data of both the calibration and validation set used in Chapter 4; see Figure 7.2.

The cross-correlation plot (see Figure 7.2) shows no correlation for sucrose with temperature at lag $=0$. For both data sets, a positive correlation is seen at a lag of around -10 


\section{Chapter 7}
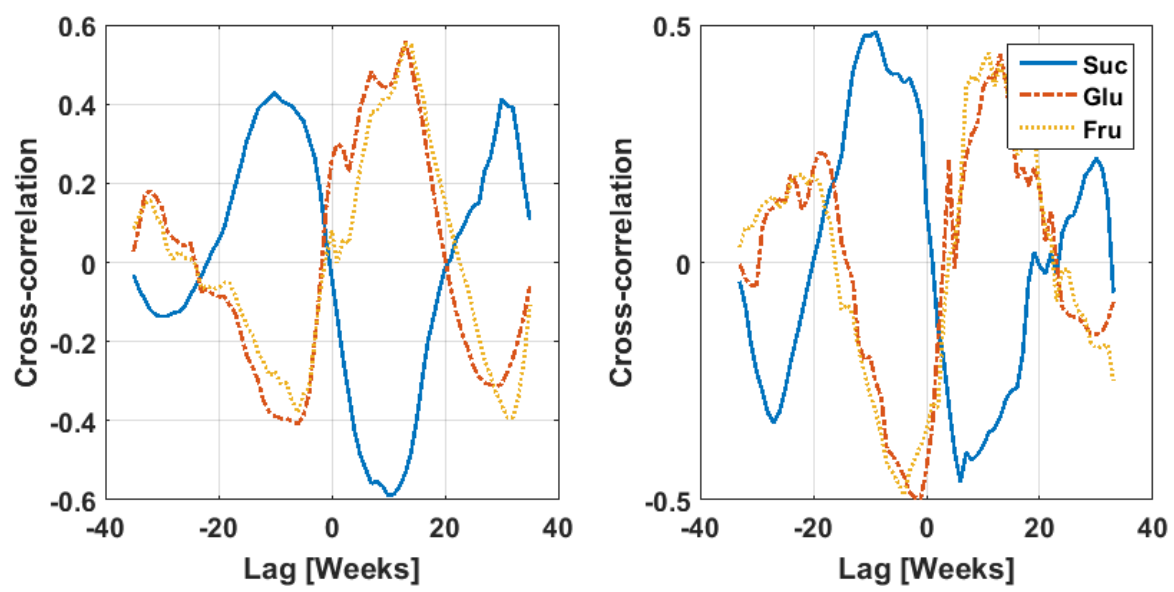

Figure 7.2: Cross-correlation plot between the temperature and the sugar (sucrose, glucose and fructose) concentration. Left panel: Ramos data of calibration set. Right panel: Ramos data of the validation set.

weeks. For the calibration data set (left panel in 7.2), the glucose and fructose show a negative correlations for a lag of -6 weeks. For the validation data set (right panel in Figure 7.2), negative correlations for lags of -2 and -4 weeks are seen for glucose and fructose, respectively. This indicates that there is some delay between the temperature differences and the formation of sugars. Cross-correlations for positive lags do not allow a physical (causal) interpretation and are thus excluded from further discussion. The model of Chapter 4 did not take these lags into account. Consequently, this model error was compensated for by the parameter estimates.

\subsubsection{Storage strategy optimisation}

The climate-product quality model presented in Chapter 4 was used to obtain knowledge on the effects of the storage strategy. An important step in the storage process is the cooling period in which the product cools down to the long-term storage temperature. In this period, most weight is lost from the potatoes. The case study we described in Chapter 4 showed that a shorter cooling period resulted in less weight loss, but an increase in sugar formation.

In addition to the work presented in Chapter 4 (using a 5-day cooling period and inlet air humidity of $80 \%$ ), we carried out three simulations for 230 storage days. Case (1) concerned a simulation of 230 storage days with a conventional overpressure regime. Case (2) also used 230 storage days but a combination of overpressure and underpressure. Case (3) also simulated 230 storage days and a combination of overpressure and underpressure but with an inlet air humidity of $98 \%$ instead of the $80 \%$ used in the other two cases.

In the first two cases (see blue dashed and red dash-dotted line in Figure 7.3), the aver- 

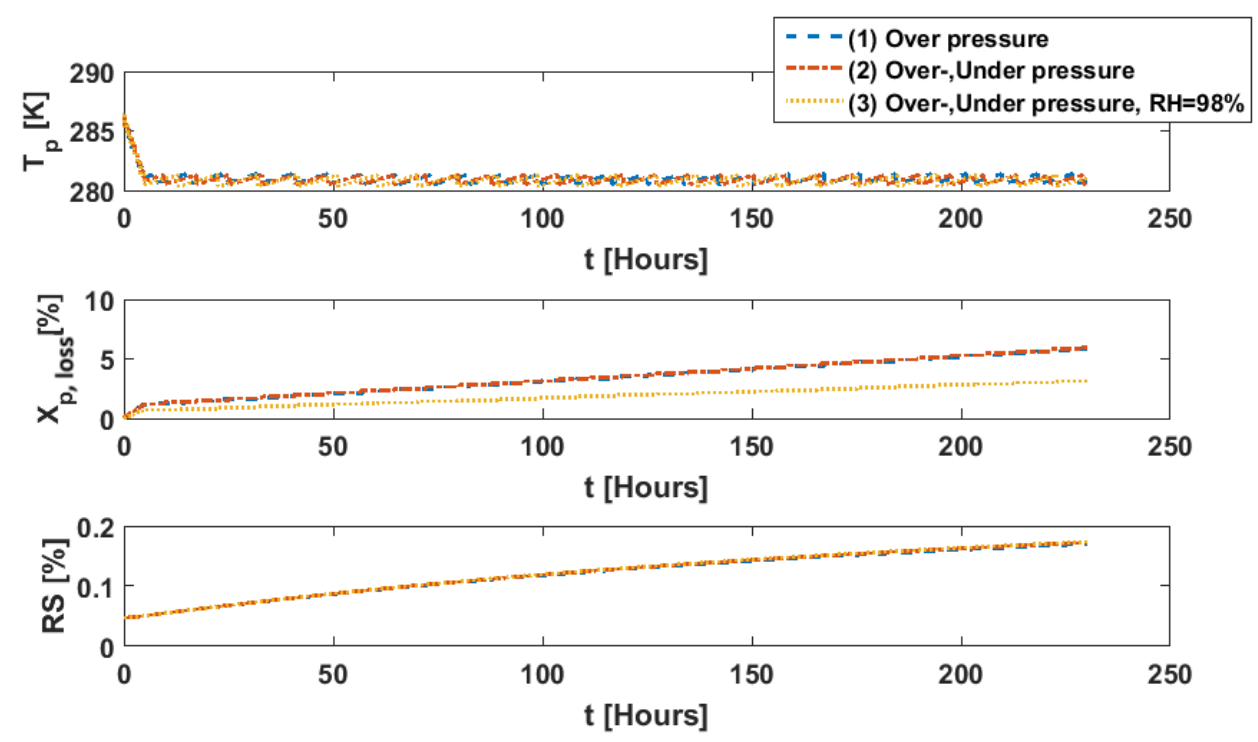

Figure 7.3: Three case simulations for 230 storage days and 5 days of cooling. Case (1) has conventional overpressure ventilation and an inlet air humidity of $80 \%$. Case (2) combines overpressure and underpressure ventilation and also uses an inlet air humidity of $80 \%$. Case (3) uses overpressure and underpressure ventilation and an inlet air humidity of $98 \%$.

age weight loss $\left(X_{p, l o s s}[\%]\right)$ was comparable. However, as Figure 7.4 makes clear, with conventional overpressure ventilation, the lower part of the bulk (height=0-1.3 $[\mathrm{m}]$ ) experienced significantly more weight loss than occurred with the combination of overpressure and underpressure. In practice, this lower weight loss in the bottom section obtained with a combination of overpressure and underpressure may lead to a reduction in pressure flattening defects (Castleberry, 2013). The simulation, of case 3, shows that the storage strategy could even be improved further, in terms of reduction of weight loss, by humidification of the air that entered the bulk to $98 \%$ (yellow dotted line in Figure 7.3 and 7.4).

\subsection{3 $\mathrm{Q}_{3}$ : How can a climate-product quality model be used to obtain system knowledge for a complete potato storage season?}

Observing the storage process during a longer time period allowed us to gain insight into the slower dynamics, but it automatically also means that the computation time for the simulations increases. Therefore, to limit computation times model reduction/simplification methods should be applied. Within the context of this research, and assuming a conventional storage configuration as depicted in Figure 1.1, it was justified to reduce the model from 2-D to 1-D (Chapter 3).

Using a validated 1-D climate-product quality model is an efficient way to obtain system knowledge in a systematic way. It can generate results for different inputs, such as input 

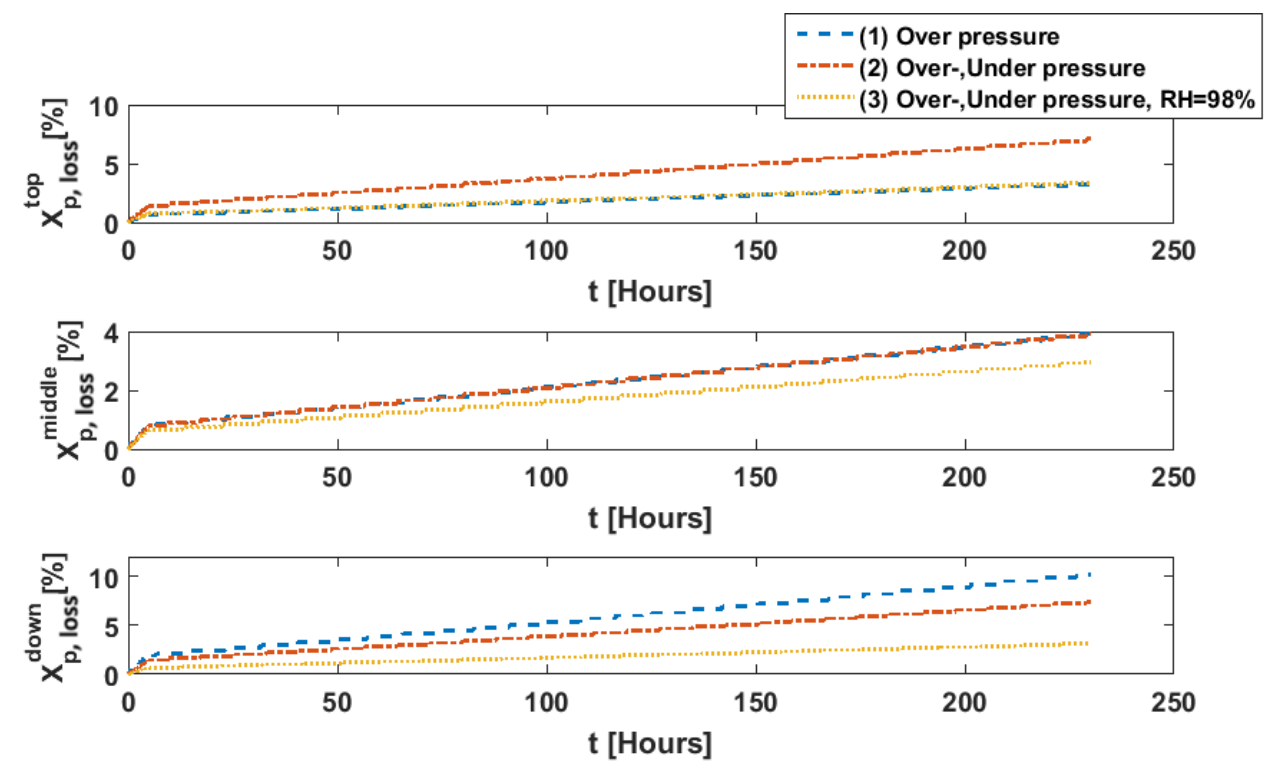

Figure 7.4: Weight loss $\left(X_{p, l o s s}\right)$ at three levels in the bulk; i.e. down 1-1.3 [m], middle 1.3$2.6[\mathrm{~m}]$, top 2.6-4 [m], for three case simulations for 230 storage days, and 5 days of cooling. Case (1) a conventional overpressure ventilation and an inlet air humidity of $80 \%$. Case (2) over- and underpressure ventilation and an inlet air humidity of $80 \%$. Case (3) over- and underpressure ventilation and an inlet air humidity of $98 \%$.

temperature or input moisture content, about $\sim 1000$ times faster than real-time experiments can accomplish. The more quality aspects are included in the model, the more knowledge can be obtained and eventually, the simulations will be able to support the optimisation of the storage strategy. However, it should be kept in mind that a 1-D model can only be applied to obtain valid results if the configuration shows only gradients in the vertical direction.

\subsection{Frying-potato protein content}

As described in Chapter 5, the protein content during storage can either increase, stay constant or decrease. The total protein turnover consists of the sum of the total protein synthesis and degradation. The three main soluble protein fractions in potato juice are patatin, protease inhibitors and other (high-molecular-weight) proteins. As potato protein has been gaining interest due to its high nutritional quality, there is also more interest in how to obtain potatoes with high protein levels at the end of a storage season. Chapter 5 proposed a mathematical model that describes the protein development of potatoes during storage. 


\subsubsection{Modelling protein content}

The protein model contains three states, the total protein content $(T P)$, the protease inhibitors $(P I)$ and the patatin content $(P)$. For the total protein content and protease inhibitors, the rate of change was determined as the sum of synthesis and degradation. For patatin, only degradation was assumed, as no patatin can be produced after the growing season (see Chapter 5). The protein content depends on the potato variety as well as on the storage temperature (Brasil et al., 1993). On the basis of this knowledge, a model was proposed using Michaelis-Menten protein kinetics in combination with the (temperature-dependent) Arrhenius equation.

The calibrated model shows a reasonable fit with the measured protein content for both varieties. However, the temperature-dependent parameters could not be uniquely estimated as a result of low (signal) excitation of the temperature and/or the weak temperature dependency. The low dependency was confirmed by the cross-correlations at lag 0 for both potato varieties; see Figure 7.5.


Figure 7.5: Cross-correlation plot between the temperature and protein (total protein $(T P)$, patatin $(P a t)$ and protease inhibitor $(P I)$ ) contraction. Left panel: Miss Malina variety. Right panel: Agria variety

Similar to what is seen with the temperature-sugar relationship, a negative lag was also revealed for the highest temperature-protein correlations, for both potato varieties, as is visible in Figure 7.5. For the Miss Malina variety, a correlation of about 0.3 was obtained for -9 weeks for all three protein groups (left panel in Figure 7.5). For the Agria variety, a correlation of, respectively, 0.3 for the total protein and patatin content and of 0.5 for the protease inhibitors occurred for a lag of about -7 weeks (right panel in Figure 7.5). 


\section{Chapter 7}

\subsection{2 $\mathrm{Q}_{4}$ : How can storage strategies influence the protein content?}

Chapter 5 presented a model for obtaining knowledge on the protein turnover, with the objective of fine-tuning the storage strategy to influence the protein content. We found a dependence on storage temperature in the literature, and observed different protein developments for the two varieties in our study, that is Miss Malina and Agria.

The model followed the trends visible in the measurements, but showed only a very small temperature contribution to protein turnover. From the cross-correlation analysis, it became clear that there is a lag in the correlation between temperature and protein turnover. This lag was not taken into account in the model, which caused the parameter estimates to compensate for the lag, probably resulting in an insensitivity for temperature. Hence, no statement can be made on the relationship between storage strategy and protein content on the basis of the model at this point. However, with dedicated experiments and a protein model that contains lags, this should be possible.

\subsection{Bulk storage actuator and sensor location}

In general all bulk storage faculties are equipped with an actuator and one or more sensors, to control and monitor the storage climate. The CFD simulation results (Chapter 3) showed that large vertical gradients occur with the conventionally used strategy of applying only an overpressure. In case study 1 described in Chapter 3, the fan (actuator) was used to create a combination of overpressure and underpressure to minimise these gradients. The results provided a first impression of the influence of the actuator on temperature gradients. Providing input-to-state (temperature at every spatial coordinate) information by using a CFD simulation is valuable, because it allows visualising the influence of the actuator on a state at every spatial coordinate. However, using CFD simulation to provide this kind of information costs more computational effort compared with the classical systems theory approaches, such as controllability analysis providing this if applicable to our case.

To provide more insight on effects of the actuator and sensor locations in the bulk storage system, a classical systems theory approach was applied on the basis of PDEs describing only the temperature in the air and potato in the bulk. From classical system theory analysis of the resulting convection-diffusion-reaction (CDR) system, it was found that $(i)$ the CDR system was too complex for an in-depth controllability and observability analysis and (ii) the controllability and observability concepts are too limited for a bulk storage facility. These concepts indicate only whether the complete set of states (at each spatial coordinate in this case) are controllable or observable. In addition, after discretizing the CDR sytem, a singular value decomposition (SVD) of the controllability and observability Gramian matrices was performed. The results of the SVD analysis indicated which 
state (at which spatial coordinate) is controllable/uncontrollable or which state is observable/unobservable. However, because of matrix multiplications of the discretised system, with a fine mesh, the analysis becomes unreliable. These problems can be overcome by calculating the input-to-state and initial state-to-output relationships using a sensitivity analysis, to obtain practical results.

The practical results of the sensitivity field of the input-to-state and initial state-tooutput relationships were obtained by coupling the CDR equations of air- and product temperature. It also would be interesting to couple the moisture content to investigate to what extend these states can be controlled and observed. In that case, in particular, a scenario with only a temperature sensor would be of interest. The proposed concept of sensitivity fields could also be applied to other industrial applications with actuators and/or sensors, and be described by CDR equations as, for instance, gas analysis, porous media flows or industrial reactors (see e.g. Shyla et al., 2014; Van Doren et al., 2013; Ramirez-Castelan et al., 2016).

\subsection{1 $\mathrm{Q}_{5}$ : Given a bulk storage model, how can knowledge for actuator and sensor location be obtained?}

The fact that only overpressure is used in conventional storage storage facilities, makes the system uncontrollable and unobservable using the classical systems theory concepts of controllability and observability. Additional information on which state (at which spatial coordinate) is uncontrollable or unobservable can be provided using a SVD analysis. However, matrix multiplication issues cause this analysis to become unreliable.

More practical knowledge on the influence of actuators and sensors can be obtained in the first place by using CFD simulations. However, in view of the required computational effort, the use of a sensitivity field, as proposed in Chapter 6, can provide this practical knowledge. The sensitivity field of the input-to-state gives information about the influence of the input on a state for a specific time period. The sensitivity field of the output-tostate provides information on the observability of each state over a specific time period. For both analyses, it holds that for different simulation times, the actuator influence on the system and the practically observable states can differ. Thus, choosing appropriate switching and sampling intervals is crucial and can be facilitated by a sensitivity field analysis.

\subsection{General conclusions}

The hypotheses which were analysed in this research project, as addressed in Chapters 3 and 4 were the following: 


\section{Chapter 7}

$\mathbf{H}_{1}$ Combining underpressure and overpressure instead of the conventional application of only overpressure results in faster homogenisation of the bulk.

$\mathbf{H}_{2}$ A 1-D model is an appropriate approximation of a conventional real full-scale bulk storage facility.

$\mathbf{H}_{3}$ Slow cooling is more beneficial for quality indicators related to moisture and sugar content than rapid cooling.

On the basis of our findings, hypothesis $\mathbf{H}_{2}$ is not rejected, while hypotheses $\mathbf{H}_{1}$ and $\mathbf{H}_{3}$ are not accepted. From the CFD simulations of the conventional storage facility, with a cellar and perforated floor, it was seen that the configuration shows mainly vertical gradients. Therefore, hypothesis $\mathbf{H}_{2}$ can be accepted for configurations that shows mainly vertical gradients. With regard to hypothesis $\mathbf{H}_{1}$ holds that the conventional bulk storage facilities are designed for overpressure. When applying underpressure, the configuration first needs to undergo some changes to make the combination of underpressure and overpressure work. For hypothesis $\mathbf{H}_{3}$, it was seen that fast cooling has some beneficial effects on the weight loss (decrease), at the expense of the development of (increased) sugar levels. For the Ramos variety the reducing sugar concentration was kept within acceptable bounds for processing industry. For other varieties and growing conditions, no conclusions can be stated. Eventually, the rate of the positive or negative bonus on the considered quality indicator is leading on which strategy is best.

\subsubsection{Scientific and social contribution}

The main scientific contribution of this study is the provided analyses of the development of and the interaction between product quality (temperature, moisture and reducing sugar level), climate and actuators in bulk-storage facilities, taking a multidisciplinary approach. A spatially distributed climate-product quality model was proposed, calibrated and validated on unique data sets obtained from different large-scale potato bulk-storage facilities. Additionally, a potato protein model was proposed. This work may spark new developments in the bulk storage of not only potatoes but of agro-materials in general.

The main social contribution can be best formulated in the social impact of the findings during this study. Limiting the storage losses will lead to better nutritious food sources, with a lower environmental impact. Growing a product with all the energy and nutrients it costs results in valuable products. Thereafter inappropriately ventilating the valuable part of the harvested product during storage, due to a lack on knowledge of the development of the product, is very inefficient. This work provides knowledge for efficient ventilation strategies that limit storage losses. 


\subsection{Outlook}

The findings from this research help to understand and optimise bulk storage processes better. Following the multidisciplinary approach, the investigation and optimisation of storage facilities is an iterative process. Several items were not yet included in this research, and need additional research to become useful.

The first item relate to extending the climate-product quality model:

- Calibration of the model should take place on multiple years and on several potato varieties, to obtain a range of parameter values that depend on the number of years and the potato variety.

- Adding additional quality parameters should provide more insight in the storage process. Two interesting quality indicators to include are pressure bruising and dormancy state of the potato, for example.

- Integration of the growing season could provide additional valuable information for the storage model. If a model describing the growing process and the product quality at the end of the growing season could be developed, the initial storage quality would be known.

- Expansion of the model to include other agricultural products. The basic model should also hold, for instance, to onions and wheat, as only the model parameters differ.

Other areas to explore in future research:

- Extending the CFD model, for other configurations and sets of actuators, like humidifiers and cooling units should be possible.

- Zooming in on a specific potato could also be done by CFD simulations. In that way, respiration and evaporation rates could be described in more detail and used in the two-phase model.

- Exploration of the lag between temperature on the one hand and sugar and protein turnover on the other hand, through dedicated experiments.

- Using the model for predictive quality control to anticipate on and make use of near-future weather conditions (or financial aspects) instead of relying only on bangbang climate control, as proposed by Keesman et al. (2003), Verdijck (2003) or Van Mourik et al. (2010).

- Using the model for quality development predictions, to predict the best processing moment for each facility individually. Consequently, a more efficient (logistic) 


\section{Chapter 7}

processing planning can be made in advance by the industry, or it can support the farmers selling moment. 


\section{References}

P. Benner, V. Mehrmann, and D.C. Sorensen, editors. Dimension reduction of large-scale systems. Springer, 2005.

P.J. Brasil, A.B. César, and H.P. Marcio. Effects of different storage temperatures on protein quantities of potato tubers. Revista Brasileira de Fisiologia Vegetal, 5(2):167$170,1993$.

T.E. Bruns. Topology optimization of convection-dominated, steady-state heat transfer problems. International journal of heat and mass transfer, 50:2859-2873, 2007.

H.C. Castleberry. Development of methods to estimate or reduce pressure flattening of potatoes during storage. PhD thesis, Colorado State University, 2013.

M.K. Chourasia and T.K. Goswami. Three dimensional modeling on airflow, heat and mass transfer in partially impermeable enclosure containing agricultural produce during natural convective cooling. Energy Conversion and Management, 48(7):2136-2149, 2007.

W.K. Coleman. Carbon dioxide, oxygen and ethylene effects on potato tuber dormancy release and sprouth growth. Annals of Botany, 82:21-27, 1998.

C.B. Dilgen, S.B. Dilgen, D.R. Fuhrman, and O. SIgmund. Topology optimization of turbulent flows. Computer Methods in Applied Mechanics and Engineering, 331:363393, 2018.

J.F.M. van Doren, P.M.J. van den Hof, O.H. Bosgra, and J.D. Jansen. Controllability and observability in two-phase porous media flow. Computational Geosciences, 17:773-788, 2013.

M. Gancarz. At harvest prediction of the susceptibility of potato varieties to blackspot after impact over long-term storage. Postharvest Biology and Technology, 142:93-98, 2018.

M. Grudzińska and P. Barbaś. Natural losses in tuber weight during storage as a predictor of susceptibility to post-wounding blackspot in advanced potato breeding materials. Journal of the science of food and agriculture, 97:3841-3846, 2017.

P. Heltoft, A.-B. Wold, and E.L. Molteberg. Effect of ventilation strategy on storage quality indicators of processing potato with different maturity levels at harvest. Postharvest Biology and Technology, 117:21-29, 2016.

M.L.A.T.M. Hertog, L.M.M. Tijskens, and P.S. Hak. The effects of temperature and senescence on the accumulation of reducing sugars during storage of potato (Solanum tuberosum L.) tubers: A mathematical model. Postharvest Biology and Technology, 10 (1):67-79, 1997. 


\section{Chapter 7}

K.H. Hoffmann and G. Leugering, editors. Trends in PDE constrained optimization. Birkhauser, 2014.

K.J. Keesman, D. Peters, and L.J.S. Lukasse. Optimal climate control of a storage facility using local weather forecasts. Crontol engineering practice, 11:505-516, 2003.

V.I. Kondrashov. Mathematical simulation of the coupled heat and moisture exchange in storehouses of agricultural production. Heat and Mass Transfer, 36:381-385, 2000.

L.H. Lui and A.C. Kushalappa. Response surface models to predict potato tuber infection by fusarium sambucinum from duration of wetness and temperature, and dry rot lesion expansion from storage time and temperature. International Journal of Food Microbiology, 76:19-25, 2002.

L.J.S. Lukasse, J.E. de Kramer-Cuppen, and A.J. van der Voort. A physical model to predict climate dynamics in ventilated bulk-storage of agricultural produce. International Journal of Refrigeration, 30(1):195-204, 2007.

S. van Mourik. Model and control of systems with flow. PhD thesis, University of Twente, 2008.

S. van Mourik, H. Zwart, and K.J. Keesman. Switching input controller for a food storage room. Control engineering practice, 18:507-514, 2010.

R.G. Pinhero and R.Y. Yada. Advances in potato chemistry and technology. Academic Press, 2016.

C.E. Ramirez-Castelan, J. Moguel-Castanneda, H. Puebla, and E. Hernandez-Martinez. A study of temperature sensor location based on fractal analysis fro cascade control schemes in turbulent reactors. Chemical engineering Science, 141:195-204, 2016.

M.V. Shyla, K.B. Naidu, and G. Vansanth Kumar. Fixing sensor position using computational fluid dynamic analysis for trace detection of toxic gases. Indian Journal of science and technology, 7(12):1987-1998, 2014.

G.J.C. Verdijck. Product quality control. PhD thesis, University of Eindhoven, 2003.

G.J.C. Verdijck and L.M.M. Tijskens. Quality control in the storage of potatoes for industrial processing. Acta Horticulturae, 599:479-487, 2003.

S. Wattamwar, S. Weiland, and T. Backx. Identification of low order models for large scale systems. IFAC Proceedings, 42(11):464-469, 2009.

S.K.R. Yellareddygari, J.S. Pache, and R.J. Taylor. Beta regresion model for predicting the development of pink rot in potato tubers during storage. The american phytopahological society, 100(6):1118-1124, 2016.

S. Zeng, B. Kanargi, and P.S. Lee. Experimental and numerical investigation of a mini channel forced air heat sink designed by topology optimization. International journal of heat and mass transfer, 121:663-679, 2018. 


\section{ACKNOWLEDGEMENTS}

This PhD thesis covers the work done in the past 4.4 years, and I would like to thank all people who contributed in this process.

This PhD research evolved from my Master's thesis, and was initiated by Karel and Omnivent Techniek B.V. I would like to thank Karel and Luuk for the faith they had in me, enabling me to embark on this research. I am grateful to Karel for his patience, his help and his positive outlook. I thank Luuk for the space and financial support he provided.

I would also like to thank Marjolein for her support during these past years. Her encouragement, empathy, and patience were a great resource. I also would like to thank my family, in particular Koos and Marlies, for their sympathy.

Of course, I am very grateful to my friends as well. I apologise to the ones I spent less time with during this period of dedicated research, in particular my paranymphs and friends Stef and Teun.

I also greatly appreciated the contribution of everyone else who assisted with this research. In particular, I must mention Susan, who was a great source of help regarding the experimental work in the labs. Luc, I want to thank you for your contribution and enthusiasm. I thank all the colleagues and interns at Omnivent Techniek B.V. for their cooperation and support during the field experiments. I also would like to thank the frying potato processing industry for their assistance with the data collection. 



\section{Curriculum Vitae}

Nik Lodevicus Marinus Grubben was born on 7 April 1989. He grew up on an arable farm in Dronten, the Nederlands. After completing his secondary education (VWO) at the Almere College Kampen in 2007, he started his Bachelor in Mechanical Engineering at the Delft University of Technology (TUD). In 2014, he received his Master's degree in Control Engineering from the TUD. His Master's research was conducted in cooperation with the TUD, Wageningen University and Omnivent Techniek B.V., and in March 2014 became the starting point for the research described in this PhD thesis. Since 2016, he has been in a partnership with his parents concerning the operation of an arable farm $(\sim$ 80 hectare) in Dronten. 



\section{OVERVIEW OF COMPLETED TRAINING ACTIVITIES}

The training and education activities listed below took place under the auspices of the graduate school VLAG (a community of research within the Biobased, Biomolecular, Food and Nutrition Sciences in the Netherlands).

\section{Discipline-specific activities}

- EAPR conference, EAPR, 2014, 2016 and 2017

- Dynamic simulation for sustainable potato storage. EAPR conference poster presentation, 2014

- Modelling and control of potatoes in storage facilities. EAPR post harvest section meeting oral presentation, 2016

- Modelling of potato quality in storage facilities. EAPR conference oral presentation, 2017

- CFD of multiphase flow, OSPT, 2015

- Computational Fluid Dynamics 1 \& 2, JMBC, 2016 and 2017

- 37th Benelux Meeting on Systems and Control, DISC 2018

- Dynamic simulation of ventilated potatoes in large-scale bulk storage facilities. BM conference presentation, 2018

\section{General courses}

- Working in a growing organisation, MoreProfit, 2015

- Spraying license, Bureau Erkenningen, 2014-2017

- Scientific writing, Wageningen in'to Languages, 2016

- Efficient writing strategies, Wageningen in'to Languages, 2017

\section{Optionals}

- Preparation of research proposal, WUR/Omnivent, 2014

- Potato demonstration day, NAO and WUR, 2014 and 2016 
- PhD/cluster meeting, WUR/BCT, 2014-2018

- Parameter estimation and model structure identification, WUR, 2016

- Potato Europe, DLG Benelux, 2017

- Workshop potato storage, Omnivent, 2017

- Study group potato storage, Omnivent, 2017 and 2018 


\section{FUNDING}

This research was performed in the cooperation framework of Omnivent Techniek B.V. and the Wageningen University and Research centre. The funding was provided by Omnivent Techniek B.V., an international specialist in the storage of foods like potatoes, onions, carrots and other fruits and vegetables. This research project will provide Omnivent Techniek B.V. with more information and knowledge on how storage and control strategies influence potato quality and storage losses.

Cover design by: Author and Ivo Solinger

Scientific edited by: Angelina Souren

Printed by: Digiforce \| ProefschriftMaken 